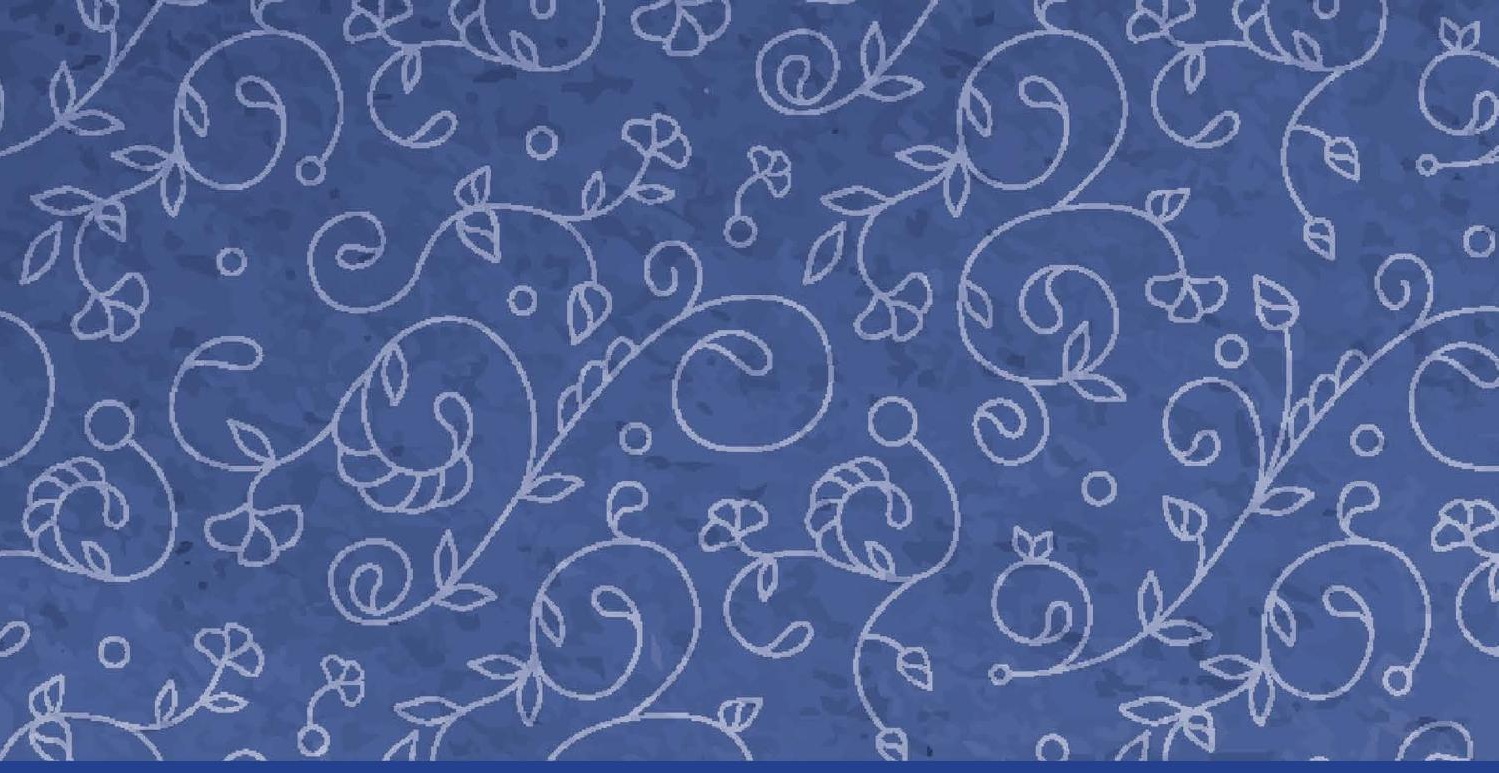

\title{
INTERNATIONAL AID AND \\ DEMOCRACY PROMOTION
}

LIBERALIZATION AT THE MARGINS

Bann Seng Tan

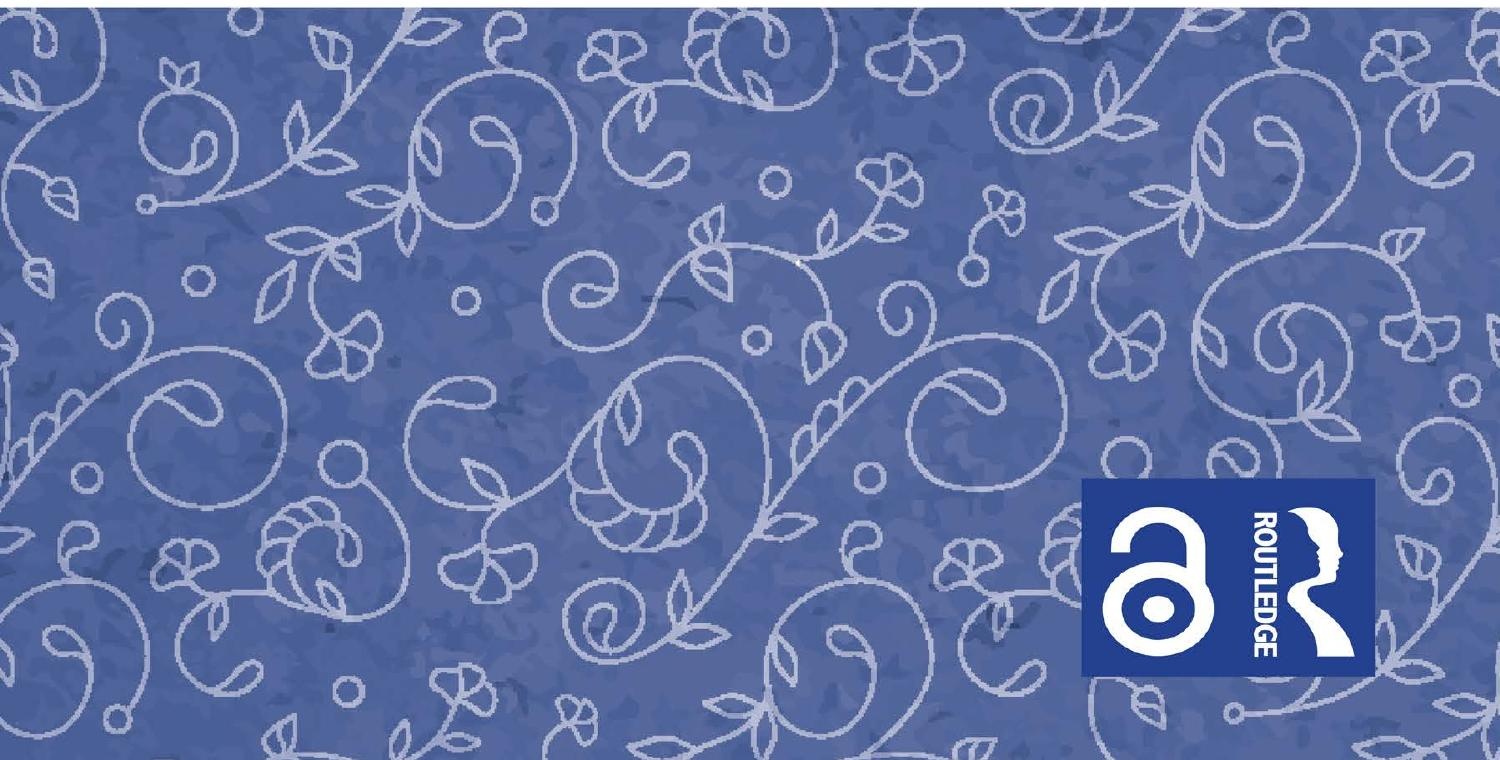


"International Aid and Democracy Promotion is the all-too-rare example of thoughtful theorizing and testing that is crafted into a powerful, politically meaningful, plausible program for improving political liberalization. Bann Seng Tan has contributed significantly to the theory of foreign aid; to rigorous empirical tests of his theoreticallydeveloped hypotheses; to nuanced regional and case study analyses that nail down what can work and what cannot work in inducing greater political accountability; and he has done so in a way that opens the path to actual improvement in the well-being of people around the world. International Aid and Democracy Promotion does what the best social science should and can do. It is a must-read for anyone who wants to understand how to promote better governance or, for that matter, better social science."

- Bruce Bueno de Mesquita, Julius Silver Professor of Politics at New York University, USA

"This is a must-read book for scholars and students of democracy promotion. Bann Seng Tan employs both quantitative and qualitative evidence to test and further develop a political economy model that incorporates geopolitical salience, domestic politics, and the bargaining power of the governments that receive foreign assistance-not just those providing it. The book explains the success and failure of democracy promotion efforts in specific cases, but also suggests how donors can deploy such assistance more effectively."

— Michael J. Tierney, George and Mary Hylton Professor of Government and Director of the William \& Mary Global Research Institute, USA

"This book offers a refreshing perspective on the international dimension of democratization and delineates the conditions under which democratic aid can, in fact, be effective. Using selectorate theory and informed by strategic leveraging and bargaining processes among donors and recipients, the author combines originally compiled big data analysis with careful case studies from Africa and Asia (as well as wide range of recipient countries such as Myanmar, Fiji, and Egypt). He meticulously demonstrates the importance of the incentives of both the donors and the recipients in this 'game of democratic aid'. This book will be of great value not only to the foreign aid community but also to politicians and policy makers, who, in this world of persistent democratic backsliding, do not lose hope and aim to navigate effectively so as to "nudge' the autocrats in the right direction."

\section{- Mine Eder, Professor of Political Science and International Relations at Boğaziçi University, Turkey}

"This book ties theory and the application of aid in the promotion of democratization to selected country case studies. The topic is both interesting and timely for testing a number of hypotheses in the literature including how such aid favours incumbent regimes and the inability of donors to stay focussed on original goals over time. It is also thoughtful in its reflections on older questions like the linkage between aid and development on the one hand and democratization on the other. This book is a welcome addition to the studies on political development in general and the circumstances surrounding the onset and consolidation of democracy."

- Narayanan Ganesan, Professor of Southeast Asian Politics at Hiroshima Peace Institute at Hiroshima City University, Japan 
$\because$ Taylor \& Francis

Taylor \& Francis Group

http://taylorandfrancis.com 


\section{International Aid and Democracy Promotion}

International Aid and Democracy Promotion investigates the link between foreign aid and the promotion of democracy, using theory, statistical tests, and illustrative case studies.

This book challenges the field of development to recognize that democracy promotion is unlike other development goals. With a goal like economic development, the interests of the recipient and the donor coincide; whereas, with democratization, authoritarian recipients have strong reasons to oppose what donors seek. The different motivations of donors and recipients must be considered if democracy aid is to be effective. The author examines how donors exercise their leverage over aid recipients, and, more importantly, why, using selectorate theory to understand the incentives of both aid donors and recipients.

International Aid and Democracy Promotion will be of great interest to academics and students of development and democratization, as well as policymakers with authority over foreign aid allocation.

Bann Seng Tan is Assistant Professor of Political Science and International Relations at Ashoka University, India. 


\section{Democratization Studies}

\section{(Formerly Democratization Studies, Frank Cass)}

Democratization Studies combines theoretical and comparative studies with detailed analyses of issues central to democratic progress and its performance, all over the world.

The books in this series aim to encourage debate on the many aspects of democratization that are of interest to policy-makers, administrators and journalists, aid and development personnel, as well as to all those involved in education.

The Legitimacy of Citizen-led Deliberative Democracy

The G1000 in Belgium

Didier Caluwaerts and Min Reuchamps

Democracy Assistance Bypassing Governments in Recipient Countries

Supporting the "Next Generation"

Paulina Pospieszna

Transatlantic Democracy Assistance

Promoting Different Models of Democracy

Jan Hornat

Innovations, Reinvented Politics and Representative Democracy

Edited by Agnès Alexandre-Collier, Alexandra Goujon and Guillaume Gourgues

Nationalism, Referendums and Democracy

Voting on Ethnic Issues and Independence

2nd edition

Edited by Matt Qvortrup

\section{International Aid and Democracy Promotion}

Liberalization at the Margins

Bann Seng Tan

For more information about this series, please visit: www.routledge.com/ Democratization-Studies/book-series/DS 


\title{
International Aid and Democracy Promotion \\ Liberalization at the Margins
}

\author{
Bann Seng Tan
}


First published 2021

by Routledge

2 Park Square, Milton Park, Abingdon, Oxon OX14 4RN

and by Routledge

52 Vanderbilt Avenue, New York, NY 10017

Routledge is an imprint of the Taylor \& Francis Group, an informa business

(C) 2021 Bann Seng Tan

The right of Bann Seng Tan to be identified as author of this work has been asserted by him in accordance with sections 77 and 78 of the Copyright, Designs and Patents Act 1988.

The Open Access version of this book, available at www.taylorfrancis.com, has been made available under a Creative Commons Attribution-Non Commercial-No Derivatives 4.0 license.

Trademark notice: Product or corporate names may be trademarks or registered trademarks, and are used only for identification and explanation without intent to infringe.

British Library Cataloguing-in-Publication Data

A catalogue record for this book is available from the British Library

Library of Congress Cataloging-in-Publication Data

A catalog record for this book has been requested

ISBN: 978-0-367-50585-1 (hbk)

ISBN: 978-1-003-05043-8 (ebk)

Typeset in Times New Roman

by Apex CoVantage, LLC 
To Unice Soh 
$\because$ Taylor \& Francis

Taylor \& Francis Group

http://taylorandfrancis.com 


\section{Brief table of contents}

List of figures $\quad$ xiv

List of tables $\quad \mathrm{xV}$

Preface xvi

Acknowledgments xvii

1 Looking for democracy in all the wrong places 1

2 The big picture 26

3 The components of salience 49

4 The regional picture $\quad 68$

5 Myanmar and donor switching 93

$\begin{array}{llr}6 & \text { Egypt and Fiji } & 122\end{array}$

7 No golden age, no silver bullet 149

$\begin{array}{lr}\text { Index } & 172\end{array}$ 
$\because$ Taylor \& Francis

Taylor \& Francis Group

http://taylorandfrancis.com 


\section{Detailed table of contents}

List of figures xiv

List of tables $\quad \mathrm{xV}$

Preface xvi

Acknowledgments xvii

$1 \quad$ Looking for democracy in all the wrong places 1

Introduction 1

The reaction of Western donors 3

The first step towards resolution 4

The politics of democracy aid 7

Giving directly to civil society 10

Aid fungibility and recipient survival 12

Bargaining between donors and recipients 15

Caveats 18

The rest of the way 20

2 The big picture

Introduction 26

Data 27

Key variables 29

Theoretical expectations 38

Results 43

Conclusion 45

3 The components of salience

Introduction 49

Data, variables, and method 51

Key variables 51

Theoretical expectations 57

Results 61

Conclusion 65 
xii Detailed table of contents

4 The regional picture

Introduction 68

The African context 70

The Asian context 74

Data and methods 81

Key variables 82

Theoretical expectations 83

Results 84

Conclusion 88

$5 \quad$ Myanmar and donor switching

Introduction 93

What is in a name? 96

Salience of Myanmar 97

Burmese praetorian politics and its concomitant foreign policy 101

A series of political change 104

The impact of external actors 106

The reactions of external actors to Burmese reforms 110

Alternative accounts of the Burmese reforms 111

On democratization 112

On sanctions 113

The price of political change 115

Conclusion 117

$6 \quad$ Egypt and Fiji

Introduction 122

Theoretical expectations 123

Salience of the recipients 124

Case study of Egypt's aid relations 129

The nature of the US-Egypt relations during Mubarak's reign 129

The donor pressure that failed 131

The aid conditionality that worked 135

Case study of Fiji's aid relations 137

The nature of Fijian politics 137

The international reaction to the 2006 coup 138

The Fijian response and Chinese Aid 141

Conclusion 144 
7 No golden age, no silver bullet

Introduction 149

What is to be done? 150

What we now know 150

For the modal policymaker 151

The autocrats' response 153

Research overlaps and future research 156

Other types of conditionalities 157

Democracy diffusion, leverage and linkages 158

Securitization of external democracy promotion 159

The tradeoffs we make 160

Feckless liberal democracies 160

Resurgent authoritarianism 161

No golden age 163

No silver bullet 165

Index 


\section{Figures}

4.1 Average Polity Scores of the Countries in the Respective Regions (1973-2006) 


\section{Tables}

2.1 Measures of Recipient Salience 35

2.2 Summary Statistics for Key Independent and Control Variables 38

2.3 The Effect of Recipients' Status on Regime Change for Primary and Secondary Recipients 40

2.4 The Effect of Recipients' Status on Regime Change for All Recipients 41

2.5 The Aid Dynamic on Stable Recipients 42

2.6 The Aid Dynamic on Stable Recipients during the Cold War 45

3.1 Four Measures of the Recipient Status with Different Emphasis $\quad 56$

3.2 Summary Statistics for the Main Independent Variables 57

3.3 The Effect of Individual Components of Salience on the Subsequent Regime Change in Aid Recipients 59

3.4 Comparing the Effects of Four Measures of Recipient Salience $\quad 60$

3.5 A Critical Test of Economic and Strategic Salience 61

3.6 The Effect of Economic and Strategic Salience, Controlling for

4.1 Summary Statistics for Key Variables in Africa and Asia 83

4.2 The Effect of Recipients' Status on Regime Change for Global and Regional Recipients $\quad 85$

4.3 The Effects of Recipients' Status on Regime Change for African
Recipients

4.4 The Effects of Recipients' Status on Regime Change across Salience Thresholds 87

7.1 List of Primary and Secondary Recipients 153

7.2 List of Secondary Recipient-Years 154 


\section{Preface}

Many years ago, I was teaching at Queens College, City University New York. I invited Bruce Bueno de Mesquita to give a guest lecture in one of my classes. I expected him to reject the invitation but was pleasantly surprised that he accepted. It turned out he had personal ties to and fond memories of Queens College.

I asked about his research and was surprised at his interest in foreign aid. The topic was far removed from my dissertation focus on democratic peace. As a $\mathrm{PhD}$ candidate, I was on the lookout for new research interests. Intrigued, I started to pay attention to the politics of foreign aid. I was fascinated by the complexity of the politics behind development, even though the absolute values of foreign aid relative to national budgets are trivial. I learned an important lesson from Bruce that in some political situations, the signal that is important is the fact there was an agreement rather than the absolute amount that was agreed upon. In aid-for-policy deals, the absolute monetary value of the foreign aid is typically small. However, the fact that both the donor and recipient must agree in order for the deal to exist is significant in itself.

The core argument was fleshed out in the two years of my visiting professorship at William and Mary. There I had a chance to observe and learn from AidData, an up-and-coming organization that is specialized in empirical data on foreign aid.

The book, however, took over five years to write. There were two periods when circumstances facilitated productivity. The first was from 2016-2017 or the years spent living in Boğaziçi University. It was also the period when Turkey accelerated its turn to authoritarianism. The second period was the first four months of 2020 at Ashoka University. It was also the period of the COVID-19 pandemic and the inept responses by those in authority.

It will be nice to live during a period with less drama. My expectation, however, is that the world will turn authoritarian as people give in to their fears. This book is my small attempt to push in the other direction. 


\section{Acknowledgments}

Open Access for this book is generously supported by the Ashoka University.

The manuscript benefited from the advice, mentorship, and friendship of Bruce Bueno de Mesquita.

I thank the following scholars for their comments on different drafts of what became separate chapters in the book. In no particular order, they include Peter Liberman, Tsveta Petrova, Kerim Can Kavakli, Chanintira Na Thalang, Yong Soo Eun, Yue Hou, Michael Tierney, Olga Onuch, Konstantinos Travlos, Tolga Sinmazdemir, Mine Eder, and Reşat Bayer.

Emily Ross and Meredith Norwich gave valuable professional advice as well.

The following students provided research and editorial assistance. From Boğaziçi University, they include Ahmet Utku Akbiyik, Ayshe Savut, Pınar Erçetin, Mehmet Hakkı Uysal, and Oytun Tükenmez. From Ashoka University, they include Chhani Bungsut, Payoja Ahluwalia, Atishay Khanna, and Sourav Dahal.

Since I wrote the acknowledgment under time pressure (thanks to COVID-19), I may have inadvertently forgotten some names. I ask for their forgiveness.

Any errors that remain are my sole responsibility. 
$\because$ Taylor \& Francis

Taylor \& Francis Group

http://taylorandfrancis.com 


\section{Looking for democracy in all the wrong places}

\section{Introduction}

When Egypt's President Mohamed Morsi was ousted in a military coup in 2013, the United States refused to cut aid to Egypt. By contrast, when Fiji's Prime Minister Laisenia Qarase was overthrown in a military coup in 2006, the United States was quick to rescind aid, citing concerns over Fijian democracy. Both countries were aid recipients who suffered setbacks in democracy, yet donors were noticeably more willing to assert their leverage on one but not on the other. ${ }^{1}$ Within the aid dynamic, what accounts for the willingness of aid donors to exert pressure only on some recipients? If we can systemically differentiate between the "Egypts" and "Fijis" in the world of foreign aid, we can identify those that are susceptible to donor pressure. What is more, we can then use this information to nudge authoritarian aid recipients towards democracy. This book articulates a strategy to do just that.

At first glance, the need for an analysis of the role of foreign aid in democracy promotion may not be obvious. If we treat aid-giving between states as an exercise in inequality, we may assume the donors have leverage. After all, the donors have a precious resource - foreign aid - that recipients desire. Donors can simply attach political conditions, such as the holding of multiparty elections, to the delivery of aid. Authoritarian recipients who refuse to shape up and democratize will be defunded. Yet the empirical record suggests otherwise (Bush 2015a; Carothers 2015). According to Diamond (2015), instead of the gradual spread of democracy, we are heading towards a democratic recession.

Five systemic trends help to explain why the state of democracy aid has been in the doldrums. By democracy aid, I mean international assistance with the specific goal of fostering and advancing democratization (this shorthand is from Carothers 2015: 59). First, there has been a global loss of democratic momentum. The end of the Cold War ushered an expectation, best articulated by Fukuyama's End of History (Fukuyama 1992), that every country would eventually become democratic. The steady expansion of democratic states appeared to have peaked in 2006 (Diamond 2015). Since then, we witnessed the rise of electoral authoritarian regimes (Schedler 2013), democratic backsliding in many prominent countries including Turkey and the Philippines, and the failure of the United States 


\section{Looking for democracy}

to promote democracy and stability in Afghanistan and Iraq. In the current international context, expecting the further spread of democracies seems unrealistic. Since democracy aid "gains credibility by association" (Carothers 2015: 67), the loss of democratic momentum hurt the credibility of democracy aid.

Authoritarian regimes are getting smarter at nullifying the impact of democracy aid. A traditional avenue of democracy aid is to fund non-governmental groups in the recipient country. This creates a civil society that can in turn facilitate a democratic transition. Such a bottom-up approach to democracy promotion could work if such groups are left alone to conduct their activities. Authoritarian regimes understand the Achilles heel of this type of democracy aid and act accordingly. They can co-opt such groups into the regime. The regimes can pass laws blocking the foreign funding of such groups or outright ban the existence of such groups. They can increase state surveillance of such groups and use criminal elements to intimidate the staff of non-governmental organizations. Faced with systemic harassment, non-government groups become understandably defensive and do not threaten their authoritarian hosts (Bush 2015a).

The rise of non-liberal aid donors has increased the options available for the aspirant dictator. The end of the Cold War helped democracy promotion by the West by removing the Soviet Union as a potential patron for the would-be dictator. Now, the rise of authoritarian bulwarks (Russia and China) and oil-based donors (Iran, Venezuela, Saudi Arabia) gives countries under Western pressure an alternative source of funding. Of those alternatives, China has attracted the most attention since its economic strength means it has the spending power to compete with Western donors should it choose to. The recent setup of the Asian Infrastructure Investment Bank, where many countries joined against the objections of the United States, is a testament to the extent of China's economic influence (New York Times 2015).

It does not help that the West is itself less committed to democracy promotion than before (Carothers 2015: 70-71). The heyday of democracy promotion was during the 1990s (Levitsky and Way 2005: 22), when democracy promotion was a national security priority in both the Bill Clinton and George W. Bush administrations. Since then, the West acquired new priorities such as counterterrorism. As far as the West is concerned, political stability in useful nondemocratic regimes aligned with the West is more important than democracy promotion in those same regimes (Carothers 2015: 71).

Lastly, the idea of democracy is itself under challenge. Skepticism about the normative value of democracy stems from two sources. The first is from the policy failures of liberal democracy in recent times (Diamond 2015: 152-153). Exemplar democracies such as the United States developed a polarized society. The United States struggles to deliver economic opportunities for its citizens after the financial crisis of 2008. Likewise, with European democracies, the Greek financial crises and Brexit has created uncertainty over the long-term viability of the European Union. The European Union is dealing with the fallout of an integration process that emphasizes political union instead of a proper fiscal union. In both America and Europe, there has been a rise in xenophobia, anti-free 
trade sentiments, anti-system parties, and anti-establishment politicians. The economic malaise of Western democracies compares unfavorably with the economic performance of prominent authoritarian regimes such as China and Singapore. As Fukuyama (2015: 13-14) observes:

Or to put it slightly differently, the development of modern states has not kept pace with the development of democratic institutions, leading to unbalanced situations in which new (and sometimes even well-established) democracies have not been able to keep up with their citizens' demand for high quality government services. This has led, in turn, to the delegitimation of democracy as such. Conversely, the fact that authoritarian states like China and Singapore have been able to provide such services has increased their prestige relative to that of democracy in many parts of the world.

All five trends work against democracy promotion. ${ }^{2}$ The question is, what can we do about it?

\section{The reaction of Western donors}

Western donors appear to have reacted in three ways. They gave up democracy promotion altogether, they chose the easy targets, and they narrowed the scope of democracy promotion.

Part of the problem is that donors have other policy priorities in addition to democracy promotion. Consider the question posed by Carothers (2015: 72): ${ }^{3}$

How can Western governments insert an effective prodemocracy element into their dealings with democratically deficient but strategically useful governments without sacrificing a broader cooperative relationship with them?

Carothers represents the orthodox American view on international democracy promotion and by extension, the Western view towards democracy promotion. Securing a useful ally and promoting democracy are two different goals. By seeking both, the West, as it were, want to have their cake and to eat it too. The problem emerges when political realities force Western donors to choose between the two objectives. Rather than promoting democracy, Western donors favor allies who are anti-democratic - think Egypt under Hosni Mubarak over democracies who are anti-Western - think Egypt under Mohamed Morsi (Bueno de Mesquita and Smith 2009a). This becomes a Faustian bargain when sponsored autocratic allies collapse, leaving donors to face the inevitable democratic backlash. Ratner (2009) observed, for example, that when the United States supported the prior autocratic regime and the client subsequently democratized anyway, the foreign policy of the regime post-transition is more likely to be aligned against the United States. This helps to explain the political fallout from the Arab Spring. The Arab dictators who received support from the United States were overthrown only to be replaced by regimes that were more 


\section{Looking for democracy}

democratic compared with their predecessors but also more anti-American in their orientation.

The second reaction by donors is to play it safe. Donors can select countries that are already liberalizing, such as Malawi (Emmanuel 2013) or Mali (Carothers 2015: 67) and allocate aid to them. This approach allows donors to claim political credit for a transition that is already underway. There are understandable reasons for this. At the organizational level, aid agencies and non-governmental groups need cases of policy success to justify their funding. The broader issue with this approach is that it is opposite of what democracy aid is meant in principle to achieve. Instead of using aid to induce democratization, aid now follows political change.

A third reaction by donors is to limit the ambit of democracy promotion to quick fixes. Western donors tend to use democracy aid to hold multiparty elections instead of promoting the deeper political reforms that could entrench liberal democracy (Crawford 2001).

The issue is the uneven political playing field between the incumbent party and the opposition parties in authoritarian recipients. Incumbent parties endowed with the aid resource could develop in one of three quasi-democratic directions. The authoritarian incumbent could retain power through repeated elections (Dietrich and Wright 2015: 23). It could develop into electoral authoritarianism (Schedler 2013), or a type of authoritarian regime where elections are held in such a way as to guarantee the victory of the incumbent. Finally, it could simply end the multiparty system and revert back to authoritarianism (what Dietrich and Wright 2015 described as multipartyism failure).

The reaction of donors to secure allies instead of democracies, to pick only the safe bets, and to settle for lesser objectives suggests donors do not know quite how to use democracy aid effectively. This lack of a coherent strategy explains why the outcomes are lopsided. The few cases of aid-induced liberalization pale in comparison with the longer list of recipients where democracy is in retreat. For every case of limited success, such as Malawi (Emmanuel 2013), Mali (Resnick 2013), or Fiji (BBC 2014), an honest assessment has to recognize such failures as China (Neier 1997), Pakistan and Russia (McFaul 2004: 158), Iraq (Diamond 2004), Ethiopia (Guevara 2007) and more recently Egypt (Brownlee 2012), where donors are reluctant to use aid as leverage to push for political liberalization.

To be clear, my objective is not to indict Western efforts to promote democracy. Rather, the aim is to recognize the real constraints imposed on democracy promotion nowadays, such as they are, and find a way to work around them.

\section{The first step towards resolution}

I argue that donors are looking for democracy in the wrong place. Countries such as Egypt, whose democratization would provide the greatest value to the donors, are least likely to do so but, others like Fiji, whose overall value to donors are smaller, are more susceptible to pressure to liberalize their governance. This is 
expected to be true because recipients with value to donors can offer alternative policy concessions as a way to mitigate Western pressure to democratize.

To elaborate, I take the lower priority that Western donors themselves accord to democracy promotion as a theoretical starting point. Within political science literature, the selectorate theory (Bueno de Mesquita et al. 2003) helps us understand the aid allocation priorities of Western donors. The selectorate theory focuses on the incentives of political leaders to seek political survival and how that in turn affects the policies that the state adopts. All leaders, regardless of regime type, need the political support of some important segments of society. The selectorate is comprised of those supporters who have some say in leadership selection. The winning coalition is that subset of the selectorate whose political support is crucial for the leader to retain office. The combinations of these two support groups can be used to derive different regime types. Democracies have a large selectorate and large winning coalition while autocracies have a large selectorate but small winning coalitions. Leaders offer supporters governmental policies consisting of a mix of public and private goods. Public goods have the key characteristic of non-rivalry in consumption, which means the value of goods on offer does not decrease as the number of consumers increases. The value of private goods, by contrast, decreases as the number of consumers increases. Since public goods have non-rivalry in consumption, it is more useful for democratic leaders who have large winning coalitions. For autocratic leaders, it is more efficient to win support from a small winning coalition by offering policies emphasizing private goods (think of corruption, nepotism, and cronyism). The imperative of political survival thus explains the domestic policy proclivities of states.

In a series of articles, Bueno de Mesquita and Smith (2009a, 2009b, 2016) applied the logic of political survival to the domain of foreign aid. They argued that foreign aid is primarily a vehicle for leaders from donor countries to purchase policy concessions from leaders in aid-receiving countries. By getting their domestic constituents the policies they want, democratic leaders of the donor states are directly enhancing the prospects of their own political survival. Three implications follow from the selectorate argument.

In the selectorate understanding of aid, the actual developmental needs of the people in aid-receiving countries is not the primary motivation of the leadership in donor countries. Thus, Bueno de Mesquita and Smith (2009a) argue we should not be surprised that aid frequently fails to achieve its development outcomes. Furthermore, they note that since the aid is meant to purchase policy concessions, donors continue to send aid even after repeated development failures. Even systemic aid diversion or official corruption in aid recipients will not cut the flow of aid, so long as the policy concessions that donors desire are met.

The policy concessions that donors desire to be implemented are frequently unpopular with the populace in aid recipients. To understand why, it is instructive to draw a parallel of the typical bribery scenario between a citizen and the local officeholder. The citizen gives a bribe to induce the officeholder to reach a decision that would not otherwise favor them. After all, if the officeholder was originally going to rule in the citizen's favor, what is the incentive of the citizen to 


\section{Looking for democracy}

offer a bribe in the first place? Similarly, in the foreign aid context, the donor has an incentive to offer aid only because the policy concession desired is politically painful for the would-be recipient to implement. Otherwise, the donor would not have felt a need to offer the aid as an inducement. For example, the US offers aid to Pakistan in exchange for military cooperation in its fight against the Taliban (Ibrahim 2009). As one would imagine, cooperation with the United States against an organization that is domestically popular with the Pakistan people is costly for the Pakistan government. Conversely, if the state in question, say Britain, is voluntarily participating in the international coalition against the Taliban, the US has no compulsion to offer Britain aid as an inducement.

Since the concession requested is unpopular, the leadership of the aid-receiving country has to compensate its key supporters - the winning coalition - with the resources drawn from the foreign aid itself. This means the value of the aid needed to induce cooperation is a function of the size of the winning coalition of the recipient's leadership (Bueno de Mesquita and Smith 2009a). Democratic leaders have larger winning coalitions than autocratic leaders. This explains why, conditional on aid receipt, democratic aid recipients tend to receive more aid than their autocratic counterparts.

It gets worse. The selectorate theory treats foreign aid as an external resource that flows into the recipient's economy. This is a bonus income that the recipient government does not have to derive from the taxation of its own people. The extra income has greater utility when spread over a small winning coalition. Thus, the selectorate theory concludes that foreign aid tends to tilt the aid recipient's regime towards autocracy over time (Bueno de Mesquita and Smith 2009b).

The selectorate theory is perceptive in the cases where recipients have manifest strategic and commercial concessions to offer donors in exchange for aid. For example, Egypt under Mubarak is an important regional ally of the United States. The United States must consider the geostrategic ramifications when considering the exertion of donor pressure on Egypt under Al-Sisi. However, what about the prospective aid recipients that lack the attributes to be attractive to donors? Those cases are the focus of this research.

There are two possibilities for recipients lacking commercial or security value to a donor. Thus far, only one of these possibilities has been thoroughly investigated. It may be that recipients lacking the desired attributes simply get no aid. That is undoubtedly true for some. However, donors might prioritize secondary objectives such as democratization in making aid-giving decisions (Bermeo 2016). In that case, there will be a subset of recipients who lack the desired attributes, but who are prepared to liberalize in exchange for aid.

I examine the effectiveness of donor pressure on aid recipients to encourage political liberalization. By political liberalization, I mean the governance reforms that increase accountability of the incumbent regime to its own citizens. Now, in order to investigate the conditions under which liberalization as a negotiated outcome is possible, I focus on the respective incentive structures of donors and recipients. Consistent with the selectorate view, I accept that recipients who can offer security or economic concessions that are of primary interest to prospective 
donors at an acceptable cost in aid should be successful in attracting offers of foreign aid. These recipients are in effect, parlaying their attractiveness as leverage to resist donor pressure to liberalize. Recipients who lack such value have less leverage to resist donor pressure and hence are more likely to liberalize as the price for getting aid. It is in these residual cases, where the donors have no clear strategic or commercial interests, that democracy promotion with aid might be effective. In investigating these cases, I broaden the selectorate perspective from an emphasis on recipients with manifest value to a larger spectrum of recipient categories. In doing so, I account for the general selectorate finding that foreign aid does not promote democracy, and I create a theoretical possibility for aid to be effective for a subset of cases.

\section{The politics of democracy aid}

I start by demarcating the phenomenon of interest. The internal politics of a given country accounts for the majority of the democratization outcomes we do observe. This is why democratization is typically studied as a domestically driven process (Remmer 1995). Given its internally driven nature, it is true that foreign countries have limited direct influence, short of military intervention, over regime transitions. This recognition, however, should not be conflated with a study of the external means, without the use of force, available to promote democratization. Just because much of democratization lies outside the purvey of the West does not mean that Western donors cannot be strategic with the tools they do have.

What kind of tools does the West have? The scholarship on the international dimensions of democracy promotion (Levitsky and Way 2005; Bush 2015a; Petrova 2014) has a specific set in mind. Levitsky and Way (2005), in a study of Western leverage and linkage, listed the following means:

External democratizing pressures, in the form of diffusion, diplomatic or military pressure, multilateral political conditionality, democracy assistance programs, and the activities of transnational human rights and democracy networks.

(Levitsky and Way 2005: 21)

Levitsky and Way sought to understand how these means affect the potential for democratization in different regions of the world. Their list is, of course, not comprehensive since it excludes bilateral foreign aid. Theirs is a broad inquiry, whereas I am conducting a targeted examination of a specific type of external pressure, financial inducements in the form of foreign aid, to persuade authoritarian recipients to liberalize.

The list of means by Levitsky and Way is also characterized by a focus on direct means of external democracy promotion. This excludes indirect means of democracy promotion through the building up of the economic underpinnings of democracy. Consider Modernization theory and its claim that democracy is the natural mode of governance for modern societies and developed economies 


\section{Looking for democracy}

(Lipset 1960). Economies in the underdeveloped world lack the investment level needed to achieve Rostow's stage of "take-off growth" because their domestic savings are low. Foreign aid from the developed world fills this gap between investment and savings in these recipients (Chenery and Strout 1966). The idea is to use aid to help recipients breach the income threshold necessary to sustain democracy (Epstein et al. 2006; Przeworski et al. 2000; Knack 2004). Even if high levels of income by itself may not lead to democratization, the hope is that the economic dividend from democracy may discourage a return to authoritarianism (Burnell 2005: 363). In the famous figure by Przeworski et al. (1996), countries that cross the economic threshold of US\$ 6000 per capita tend to stay democratic once they become democracies. Whereas countries below that threshold tend to lapse back into autocracy even if they were democratic. Such indirect means of democracy promotion is set in the long run and is not what the scholarship usually mean when they refer to external democracy promotion (see Burnell 2005: 362-363 for a similar view).

The second demarcation concerns the type of aid. I distinguish between democracy aid and foreign aid in general. The former is aid given for the purpose of encouraging political reforms in a democratic direction (Carothers 2015: 59) while the latter is meant to support economic development. ${ }^{4}$ Foreign aid, in general, is also a type of non-tax revenue. A government that can raise its revenue without relying on the taxation of the people has also less incentive to be accountable to its citizens. If the regime does not need to tax its people as much due to an independent source of revenue from foreign aid, why should that regime be responsive to the demands of the people for representative government? This is why scholars have argued that foreign aid in general does not promote democracy in aid recipients (Djankov et al. 2008; Morrison 2009; Bueno de Mesquita and Smith 2009b).

This negative correlation between aid and democracy promotion, it is crucial to note, is derived from a focus on foreign aid in general. Dietrich and Wright (2015: 232) notes that "the aid-curse literature focuses on economic, not democracy, assistance". A negative relationship between foreign aid in general and democracy does not preclude a different effect for democracy aid. Indeed, other scholars have parsed the effects of democracy aid to draw a different conclusion (Dietrich and Wright 2015; Bermeo 2016). Likewise, I explore the conditions under which democracy aid can be effective.

A key mechanism by which democracy aid works is through political conditionality where the donor demands political reforms as a condition for giving aid (Burnell 1994; Crawford 1997). Crawford notes that the concept of political conditionality is broad. It includes both funding for aid projects to improve human rights and democratic governance and economic sanctions for human rights violations and democratic backsliding (Crawford1997: 69-70). The emphasis of Crawford (1997) is on punishment (the sanctions) whereas the focus of this book is on positive inducements (the funding). ${ }^{5}$ As examples of positive inducements, consider the Millennium Challenge Corporation of the United States and the European Neighborhood Policy of the European Union. Both explicitly tie aid 
to political reforms towards good governance. For the political conditionality to work, recipients have to believe that the threat to withhold or withdraw aid to be real. This is why the credibility of such threats has been a focus on the scholarship.

It turned out that the credibility of threats to withhold aid has fluctuated over time. During the Cold War, recipients who received aid from the West knew they could switch allegiance to the Soviet camp instead (Dunning 2004). The Western donors were correspondingly reluctant to exert too much pressure on those same recipients for fear of them switching sides. By doing so, the West has prioritized the ideological struggle against communism over the promotion of democracy (Lancaster 2007). With the collapse of the Soviet Union, both considerations have dissipated. The West is now free to assert pressure without a fear of losing influence. It follows that the threat to withhold aid became credible in the post-Cold War environment. Thus, political conditionality that was treated as rhetorical during the Cold War became substantive in the post-Cold War era (Dunning 2004; Brown 2005; Bearce and Tirone 2010; Bermeo 2016; Marinov and Goemans 2014).

That is the standard view of political conditionality. There are however two reasons to question whether the Cold War represents a clean break in the efficacy of political conditionality. First, the emphasis on democracy promotion as an aid objective is itself a relatively new phenomenon. Chronologically, it became prominent only after the Cold War (Crawford 1997: 69; Brown 2005: 181; Baylies 1995: 321). This makes it harder to assess the credibility of threats to withhold aid during the Cold War. Second, there may be options available to aid recipients after the Cold War even with the collapse of the Soviet Union. The majority of Western donors belong to a donor club within the Organization of Economic Cooperation and Development (OECD) known as the Development Assistance Committee or the DAC. ${ }^{6}$ Members of the DAC are traditional in the sense that they share a preference, if only mildly expressed, for democracy promotion. By contrast, the newer, non-traditional donors are not only outside the DAC, they have little interest in democracy promotion (Bermeo 2011: 2023). By non-traditional donors, Bermeo (2011: 2022) has in mind the oil-based authoritarian regimes, as well as Venezuela (back when the oil price was high) and China. Of those, China, by virtue of its economic size and authoritarian nature, has attracted the bulk of critical attention. The implication of a donor with the potential to serve as an alternative supply of aid has been explored from the selectorate perspective (Bueno de Mesquita and Smith 2016). They argued that during the Cold War, the presence of the Soviet Union as an alternative donor caused the United States to both pay more in aid and receive less concession in return (Bueno de Mesquita and Smith 2016). While this has implications for a potential competitive donor environment in the post-Cold War era, it is important to note their domain is on security concessions and not on liberalization of the recipient - the focus in this work. I discuss some implications of donor competition in Chapter 5 .

It is unrealistic to expect non-traditional aid donors to drop their hostility to democracy promotion in the near future. Therefore, we should recognize that the presence of competitive donors is a variable that lies largely outside the direct 
influence of the Western donors. It is more practical to focus on adaptations that are within the capabilities of Western donors - that is, to search for an aid allocation strategy that takes the harsher international context into account.

\section{Giving directly to civil society}

A tradition of research on the modality of aid giving emerged out of this search for a practical strategy. Instead of the donor government giving aid to the recipient government, an alternative is to give aid directly to the non-state actors working in the recipient country (Easterly 2007; Dietrich 2013; Bush 2015a; Ottaway and Carothers 2012). In Dietrich's account, the list of non-state actors includes "international and local NGOs, international organizations, public private partnerships" (Dietrich 2016: 9), private companies, and research institutes. Her list of non-state actors is expansive ${ }^{7}$ because her concern is whether the recipient government is the implementing partner. There are substantive reasons why donors may prefer not to use the recipient government as the implementing partner. The recipient government may be corrupt, and donors want to avoid aid capture. The recipient government may lack absorptive capacity, and donors want to avoid aid wastage. To use the market-based logic established in Dietrich (2016), donors are deliberately bypassing the recipient government and outsourcing aid implementation to third parties, in this case, non-state actors. Although the general concern of this research tradition on aid modality is on economic development, there are implications for democracy promotion as well. If the recipient government is authoritarian, giving aid to local NGOs in the recipient's civil society holds special appeal. It widens the space for civil society, potentially leveling the playing field between the incumbent regime and its opposition political parties (Dietrich and Wright 2015). Thus donor-to-civil society aid, as opposed to donor-to-government aid, could potentially promote democratic consolidation.

Having said that, even the advocates of this aid modality acknowledge several pitfalls with the approach. Bypassing the government means that the donors are missing an opportunity to build up the institutional capacity of the recipient state. The lack of investment in the long run is likely to result in a recipient with low absorptive capacity (Dietrich 2013: 708, 2016). It subverts the standard development goal of building the recipient up to the point where they wean themselves off foreign aid. Furthermore, bypassing the recipient government violates one of the current principles in international aid policymaking, namely country-ownership (Dietrich and Wright 2015). The recipient government can hardly be expected to be enthusiastic about an aid modality in which they were deliberately barred from managing! Both drawbacks (no capacity-building and no country-ownership) suggest such aid modality may not be sustainable in the long run.

Those are drawbacks from the economic-development side. There are also problems from the political economy side. In a study of the effort of donors to promote democracy in Sub-Saharan Africa, Dietrich and Wright (2015) were careful to distinguish between economic aid and democracy aid as well as between democratic transition and democratic consolidation. They found that donors were 
effective in promoting democratic transitions with economic aid. However, they also found that donors were less successful with democratic consolidation using democracy aid. The holding of multiparty elections (democratic transitions) does not lead to incumbent turnover (democratic consolidation). Instead it is more likely to be accompanied with electoral misconduct, entrenchment of the incumbent party, and the failure of the multiparty system.

The second political problem is the likely authoritarian reaction. When the Cold War ended, authoritarian regimes worried about their future viability. Those days are long gone. The current batch of authoritarian regimes are more confident, aggressive, and proactive. We are now in an era of "resurgent authoritarianism" (Cooley 2015; Diamond et al. 2016). Cooley (2015: 50) characterizes these regimes as thus:

Perhaps most disturbingly, authoritarians have pursued these tactics and coun-
terpractices because they are proving effective: The activities of NGOs can be
successfully restricted; regional organizations can be repurposed to support
the political agendas of authoritarian member states; and international invest-
ment and assistance can be procured from new donors without accompany-
ing political conditions. Success breeds imitation, and more authoritarian
regimes (plus some backsliding democracies) across Eurasia, Latin America,
the Middle East, and Africa are beginning to emulate these practices.

As an example, when a local non-governmental group receives funding from foreign donors, it is vulnerable to the charge (however contrived) of treason from its autocratic government. Furthermore, laws to restrict the political space of non-governmental groups or NGOs have a contagion effect (Bush 2015b). Authoritarian regimes are learning from each other to suppress potential avenues of democratic regime change. NGOs working in hostile environments found it necessary to adapt to new political realities. In fact, Sara Bush found that NGOs seeking normal organizational goals of survival and funding could only undertake projects that do not challenge the authority of their incumbent authoritarian governments (Bush 2015a). To use her expression, this represents the taming of democracy promotion.

I have discussed four problems with this particular aid modality of donor to civil-society aid. Collectively, they highlight the difficulties of democracy promotion from without - against the wishes of authoritarian incumbents. Yet this is not a counsel of despair. I argue we have not seriously considered the alternative route of democracy promotion with the consent of those same incumbents. There is empirical precedence for this alternative. Recall Dietrich and Wright's (2015) study of donors' efforts to promote democracy with aid in Sub-Saharan Africa? Despite justified skepticism on democratic consolidations in Africa, they conclude that "the primary channel through which democracy promotion occurs is [through] government-led political reform" (Dietrich and Wright 2015: 232).

Just because there is empirical precedence does not mean a grand bargain between donors and authoritarian incumbents is easy. For one, donors have to 
be convinced that the aid is actually applied to the sectors they desire. This is the issue of aid fungibility.

\section{Aid fungibility and recipient survival}

The use of aid for democracy promotion faces a potential pitfall. If donors simply transfer resources with no oversight and control on how the aid is spent, such aid may merely replace other aspects of the recipients' budget. Aid meant for training election monitors could end up training the regime's secret police instead! Thus the extent to which aid can be redirected from its intended purposes by the recipient if it so wishes, also known as aid fungibility (Hagen 2006: 267) matters.

Within Political Science, the concept of fungibility has been prominently applied to studies of the impact of oil revenue on the state's regime type. The wellknown "resource-curse" resolves around observations that oil-rich economies tend to be autocratic and regimes that are dependent on oil revenue tend to turn authoritarian (Ross 2001). The resource curse is pertinent because its framework has been applied to the world of foreign aid. Consider the selectorate perspective, it treats aid as a type of non-labor-based income that displaces labor-based income in the recipient's budget (Bueno de Mesquita and Smith 2009b). An independent source of revenue strengthens the hand of the authoritarian incumbent. It allows the leader to substitute for the loss for revenue the regime would derive from taxing its own people. It means the regime has less to lose even if it does not heed the wishes of its own people (Morrison 2009). Thus, leadership turnover is decreased. Notice that in this setup, the selectorate theory treats foreign aid as another type of non-tax revenue that is fungible just as is the case with oil revenue. The equivalence extends to political consequences as well. Just like oil revenue, aid income promotes and props authoritarian regimes (Bueno de Mesquita and Smith 2009b; Morrison 2009).

The idea that the effects of foreign aid and of oil are equivalent was orthodox view since the 1990s. This is challenged by later scholarship (Bermeo 2011, 2016; Dietrich and Wright 2015; Tan 2016). Sarah Bermeo is a prominent voice in this regard. She argues that the effects of oil revenue should be parsed separately from the effects of aid. This is because the latter involves a third party the donor - who could attach condition on the aid such that the aid could be more or crucially less fungible (Bermeo 2016). Since the preference of donors changes depending on the prevailing geostrategic climate, the effects of aid on democratization should vary over time while the effects of oil on democratization do not. She found evidence that during the Cold War, both aid and oil revenue inhibit democratic change. However, after the Cold War, aid facilitates democratic change while oil revenue retains its democracy-inhibiting effects (Bermeo 2016). Since donor preference for democratization in the recipient depends on their valuation of the strategic importance of the recipient, she also found that democratization is less likely to follow aid when the recipient in question is strategically important. Here, I adopt a similar perspective but differ from Bermeo 
(2016) in that she links importance to prior aid receipts, whereas I explicitly measure the likelihood that a prospective recipient has the internal characteristics that make it commercially or strategically valuable to the donor. Thus, the tests conducted in this book, while based on a similar theoretical argument, rely on a more nuanced approach to recipient importance as explained in subsequent chapters.

The scholarly literature also considered another way to conceptualize aid fungibility. Instead of treating aid income as a replacement for other parts of the recipients' budget, one can think of the aid income as a supplement to the recipients' budget. In this alternative, the aid income allows the recipients to acquire additional capabilities or buy off key constituents that were not possible before. The regime that received aid could purchase political support (Bueno de Mesquita and Smith 2009a) or improve their coercive capabilities (Djankov et al. 2008; Lai and Morey 2006). This increased capacity for both patronage and repression can retard democratization and promote autocratization.

The standard view is that foreign aid has a negative relationship with democracy when aid supplements the recipients' budget. Later works challenged this view arguing that the relationship is itself conditional on the recipient's regime type (Kono and Montinola 2009; Wright 2009; Licht 2010). The common core of these studies is that they are informed by the selectorate theory (Bueno de Mesquita et al. 2003). As such, the central concern in these works is the political survival of the incumbent leadership and how foreign aid plays into it.

Kono and Montinola (2009) argue that the extent to which aid translates into income that is actually useful for political survival depends on the regime's stockpiling capacity. Autocrats can stockpile aid more effectively than democrats. As a result, sustained aid increases the longevity of autocratic recipients more than it does for democratic recipients in the long run. Since the stockpile of aid is used by regimes to insulate against negative shocks in the future, each subsequent disbursement of aid is more valuable to the democratic recipient because democratic leaders have fewer alternative resources to fall back on. Therefore, in the short run, the marginal effect of aid is to support the survival of a democratic recipient.

Licht (2010) observes that autocracies, unlike democracies, lack institutionalized means to turnover leaders. This affects the loyalty of the winning coalition to the leader and through it, political survival over time. When a new democrat is elected into office, the loyalty of the large winning coalition is assured and strongest at the beginning of the leader's tenure. This is sometimes described in American politics as the honeymoon phase of democratic politics. Foreign aid during this honeymoon period helps the incumbent to claim political credit for it. Over time, the political benefit for that aid is limited. This is because i) the private benefit of the aid is diluted when it is spread out over a large winning coalition and because ii) domestic challengers could credibly promise to perform as well as the incumbents (Licht 2010: 68). By contrast, when a new autocrat comes into power after an irregular event, such as after a coup, he is at his weakest at the beginning of his leadership tenure. This is because the loyalty of the small winning coalition 
is not assured and has to be bought with the private benefits the leader provides. At this initial period of vulnerability, aid destabilizes the regime as domestic challengers can promise a greater share of the aid as a reward for defecting from the new incumbent leadership (Licht 2010: 67). As the incumbent secures the loyalty of his wining coalition over time, the additional resources granted by the aid increases the odds the autocratic regime will survive. Thus, Licht (2010) argues the impact of aid varies both over time and across the regime type of the recipient.

Wright (2009) focuses on the authoritarian leader's calculations. One key concern for authoritarian incumbents is their own political survival after regime change. Authoritarian leaders typically oppose political liberalization precisely because they have no realistic prospect of winning a free and fair election. Wright's insight is to treat this as a function of the relative size of the authoritarian leaders' winning coalition. Authoritarian leaders who depend on a relatively small winning coalition should have a smaller chance of retaining power after elections compared to their counterparts who rely on a relatively larger winning coalition. Thus, authoritarian leaders who are reasonably confident that they can be elected are willing to consider democratization as a survival strategy. This type of leader - authoritarian but with a relatively large winning coalition - should be more amendable to liberalization with aid.

While there are nuances in the mechanisms utilized, the time horizon of analysis (Kono and Montinola 2009), institutionalization of the support base (Licht 2010), and the prospects of survival post-liberalization (Wright 2009), it is clear that donor pressure is generally more effective with democratic targets than autocratic targets. If so, the policy implications are pessimistic since it is precisely autocratic recipients that Western donors are the most interested in democratizing. In the face of this, one could be forgiven for concluding, as Licht (2010: 81) did, that as far as democracy promotion is concerned, "aid may be an inappropriate policy tool". The main dependent variable in these studies is regime failure, and that is analytically distinct from democratization. Using aid to induce the collapse of a dictator, only to have him replaced with another dictator, would hardly be considered an improvement for those committed to democracy promotion.

To analyze the extent of aid fungibility, we have to determine which aspect of the recipients' budgets is being replaced. As Hagen (2006) notes, this is not a simple question. Empirical studies of aid fungibility showed that its extent varies by space and across time (Hagen 2006: 279). For example, Feyzioglu et al. (1998) study of aid fungibility examines only concessionary loans and has a limited cross-national scope. Case studies also show mixed results regarding aid fungibility (Pack and Pack 1990, 1993). In a path-breaking study, Bermeo (2016) argues the extent of aid fungibility varies depending on donors' needs, over time, and across recipients. Aid, she asserts, need not necessarily impede democratization. Hagen (2006) argues that the extent of aid fungibility depends on the strategic interaction between donors and recipients. A non-strategic approach to studying aid fungibility is, therefore, inadequate as both donors and recipients adapt their policies in reaction to each other (Hagen 2006: 279). 


\section{Bargaining between donors and recipients}

What have we learned thus far? Several themes have been highlighted in the literature. We learned that the effectiveness of democracy aid is partly dependent on the credibility of political conditionality and the extent of aid fungibility. While the presence of competing donors is outside the control of Western donors, the choice of whom to give democracy aid lies within donors' discretion. If we want aid to induce liberalization, we have to take the incentives of the incumbent governments in authoritarian recipients into account. This entails - as unpalatable as it may sound - direct negotiations with those same governments. Theoretically, this method of democracy promotion with the cooperation of the recipient's incumbent government dovetails most closely with the selectorate perspective (Bueno de Mesquita and Smith 2009a, 2016). Just like the selectorate theory, I treat aid giving as a transaction whereby the donor purchases a desired policy concession from the recipient.

I start with the donors' calculus. We know from Fleck and Kilby (2006) that most donors seek four objectives with foreign aid: i) geostrategic concerns, ii) commercial concerns, iii) economic development, and iv) democracy-promotion. The selectorate theory (Bueno de Mesquita and Smith 2009a) contends that donors have a hierarchy among these objectives. Geostrategic and commercial concerns are generally posited to be more important than development and democracy promotion for donors. This is not a radical premise. In a detailed account of the history of aid, Lancaster (2007) noted that the United States and European donors subordinated their foreign aid to the objective of fighting communism during the Cold War. Likewise, the Soviet Union favored its allies in its aid allocation. Post2001, the new imperative for US aid is to combat terrorism (Cooley 2015). This is why Western donors generally push for democracy but not so hard as to threaten their other geostrategic and commercial priorities.

Let's parse out the implication of donors' commitment to democracy. The rhetoric of Western donors suggests that they seek the democratization of aid recipients or, alternatively, further democratic consolidation in recipients that are already democratic. The rhetoric notwithstanding, in practice the evidence suggests otherwise (Bueno de Mesquita and Smith 2009a; Lancaster 2007; Cooley 2015). Their actions suggest they merely seek governance reforms that are in the general direction of democracy. This may entail democratization since an authoritarian regime that is systemically liberalizing eventually becomes a democracy. However, democratization is not a necessary condition for the receipt of aid as far as the donors are concerned.

Since this nuance is significant, consider the following highlights from the literature that emphasize the limited nature of donors' demands. We have already learned from Dietrich and Wright (2015) that donors may use aid to induce liberalization but will settle for political reforms "that do not necessarily threaten incumbents" (Dietrich and Wright 2015: 232). That is, democratic consolidation is optional for donors. Likewise, Young (1999) in a study of the implementation of aid conditionality by four Western donors (including the US and the EU) in the 
1990s noted a consistent pattern whereby the donors do not push for full democratization. He observed:

Semi-democracy is probably sufficient to deflect international system pressures for more complete political opening, particularly if macro-political economic management earns external approbation.

(Young 1999: 35)

This trend of settling for less is not confined to foreign aid. In the related field of imposed democracy or democratization by an occupying force, Bueno de Mesquita and Downs (2006) argue that democratic occupiers seek policy concessions that are best delivered by target states with small rather than large winning coalitions. As a result, they argue democratic occupiers seek only the trappings of democratic reforms instead of real democratization. They observed:

To summarize, the lower the democracy score at the outset, the more likely that a democratic intervener will raise it modestly and symbolically relative to comparable states that do not experience intervention; the higher the degree of democracy before an intervention, the more likely that the intervener will unravel substantively important aspects of democracy, leaving symbolic trappings but no more than that.

(emphasis added, Bueno de Mesquita and Downs 2006: 642)

For many, this pursuit of limited reforms is not normatively ideal. I agree. However, while I concur that full democratization is a worthwhile goal in itself, it does not mean that we should not study the pursuit of lesser goals such as political liberalization. We do not need to make the perfect the enemy of the good.

If democracy promotion is a lesser priority for most donors, the willingness of the donors to tolerate democratic transgressions by recipients is dependent on the attractiveness of the alternative policy concessions that recipients might offer. If the concessions offered are valuable, such as access to strategic minerals (oil), support in counterterrorism, or access to a previously closed market, I expect donors to reciprocate with foreign aid. When a recipient lacks the capacity to offer such concessions, donors can choose to give no aid or grant aid on the basis of some other secondary preferences, such as political reforms in the recipient.

I turn now to the considerations of potential aid recipients. Just like the selectorate theory, my theory assumes leaders seek to enhance their prospects of political survival. The issue is how the incumbent leader views an offer of aid for political reforms. Simply put, democratization hurts! Political reforms that increase the accountability of a regime to its people entail multiple risks for the autocratic recipient. Such reforms may reduce the ability of the regime to extract rents from its populace. It reduces the income from which the incumbent can use to finance clientelism. Worse, political reforms such as the holding of multiparty elections may lead the country on a path of accidental democratization. In losing the office, the former autocratic incumbent could lose their assets, freedom and even their 
life. Given that democratic reforms are costly, what can the autocratic recipient who desires aid do if it does not like the political conditions that are attached to a given aid package?

There are three possibilities. The recipient could search for alternative donors who will grant aid without requiring democratization. This possibility has been explored from the selectorate perspective (Bueno de Mesquita and Smith 2016) where the focus is on the impact of donor competition on aid-for-policy deals. The second possibility is for the recipient to make a credible counteroffer to exchange some degree of policy compliance with the donor in exchange for aid. In this situation, the donor, consistent with its hierarchy of objectives, is likely to accept a façade of reform.

The third possibility arises when the recipient lacks the ability to offer valuable alternative concessions for the desired aid. Because the recipient cannot offer alternative concessions, it is left with democratization as the only concession of value. Since democracy promotion is a low priority for Western donors, why might they accept this offer? I return to the selectorate perspective, for it gives us a useful way to approach this question: What is in it for the donor? From the selectorate perspective, the concession on offer must be more valuable than what the donors could have had by direct provision from the donors' governments themselves (Bueno de Mesquita and Smith 2009a: 320). ${ }^{8}$ In the context of democracy promotion, donors could have chosen to impose democracy by force instead (Russett 2005; Bueno de Mesquita and Downs 2006). The literature on imposed democracy is unequivocal on this. Compared to peaceful alternatives, the imposition of democracy by force is costly, failure-prone, and politically unsustainable (Russett 2005: 406; Bueno de Mesquita and Downs 2006: 647). Hence, this third possibility allows donors to indulge in their secondary preferences. In the situation where the potential aid recipient does not have alternative strategic and commercial concessions to offer, I conclude that the offer of political liberalization by authoritarian recipients fits the bill.

Conditional on an aid-for-policy deal being struck, two outcomes from the bargaining process are plausible depending on the salience of the recipient to the donors. One group of recipients, Secondary recipients, lack the strategic and commercial attributes that donors value. ${ }^{9}$ They do not have much to offer besides liberalization. Precisely because secondary recipients have little of value to exchange for aid, donors can afford to indulge in their second-order preference for political reforms. Therefore, we expect the following:

H1: Aid to Secondary recipients who are pressured to reform politically increases the odds of liberalization.

The other group of recipients, Primary recipients, possess the strategic and commercial attributes that donors value. They can offer alternative policy concessions instead of liberalization as a basis of a counteroffer for aid. It follows that Primary recipients have more bargaining leverage than Secondary recipients against donors seeking political reforms. Precisely what primary recipients choose to do 
with their extra leverage is up to their internal dynamics, which I do not address directly. ${ }^{10}$ Primary recipients might react to donor pressure by moving in a more autocratic direction. Alternatively, they might be already satisfied with their current regime setup and see no need to change that just because they are under donor pressure. Since I do not model the internal dynamics of primary recipients, the more conservative approach is a focus on the likelihood of subsequent liberalization only.

H2: Aid to Primary recipients accompanied by pressure to reform politically should not increase the odds of subsequent liberalization.

When the posited aid dynamic is applied to both recipient groups together, we should observe a systemic difference in their respective likelihoods of subsequent liberalization.

H3: Conditional on being pushed to reform, there should be a significant, positive difference in the likelihood of political reform when comparing Secondary recipients and Primary recipients.

Collectively, I describe this theory as liberalization at the margins.

\section{Caveats}

As with any theory, there will be caveats. Here, I deal with six of them.

First, both Carothers $(1997,2004)$ and Burnell $(2005)$ made a case that a proper strategy of external democracy promotion should also include a theory of democratization. This implies that the West should hold off on democracy promotion until a consensus on the best way to democratize emerges. ${ }^{11}$ I suggest we do not need to do that. Empirically, the literature highlights that the donors are more interested in political liberalization than in democratization or democratic consolidation (Bueno de Mesquita and Smith 2009a; Lancaster 2007; Cooley 2015; Dietrich and Wright 2015; Young 1999; Bueno de Mesquita and Downs 2006). While a theory of democratization might supplement my theory of liberalization at the margins, it is not a necessary part of my theory.

Since donors are mostly interested in political liberalization, the proper "targets" for donor pressure, as it were, should be potential aid recipients who are currently authoritarian. Empirically, this means we are focusing on regimes that are not democratic (Polity score under +6 ) rather than borderline democracies (Polity score above +6). A full empirical account will be covered in the next chapter. Theoretically, there is another reason to focus on authoritarian regimes. My theory argues that aid recipients that do not like the political reforms donors prefer have a strong incentive to make counteroffers. Between democratic and authoritarian aid recipients, the former group has less reason to oppose political reforms and is less likely to resist donor pressure. While the study of democratic consolidation in democratic recipients is possible, it is also theoretically uninteresting because 
there is no policy impediment to speak of! Studying the reactions of autocratic aid recipients is a different matter since autocrats have good reasons to oppose political reforms that donors seek.

This relates to the third caveat on the import of democracy aid projects and donor pressure. Aid projects that have governance reforms as an objective are distinct from other types of general development projects (a catchall category) in the reaction they are likely to inspire in aid recipients. With development aid, the interest of donors and recipients coincide, the recipients have little reason to make counteroffers since they seek economic development too. The case for democracy aid is different since only one side desires them. While donors wish to induce political reforms, aid recipients (provided they are authoritarian) seek to evade them due to the political pain reforms entail. Given the political costs, the fact that authoritarian aid recipients accepted the aid implies the application of donor pressure on the recipient. While it is ideal to get direct evidence of such pressure, we have to acknowledge the incentive for both parties to mislead. Donors want to avoid the political embarrassment from a failed attempt to persuade with aid. Recipients want to avoid the political humiliation of being seen to reform just for money. Such incentives are not unique to the aid bargaining process (see Stone 2002) and are similar to those encountered in studies of corruption. In studies about corruption, the verification of official corruption is difficult since the personnel involved have good reason to hide their involvement for fear of subsequent prosecution. Instead of measuring corruption directly, one workaround is to measure the perception of corruption instead (see Corruption Perception Index). ${ }^{12}$ Here, instead of focusing on aid conditionality per se, I observe what can reasonably be inferred as evidence of donor pressure. Although donors may push for political reform in some circumstances in which it is not expected to occur (that is, in the case of primary recipients), when donors push for political reform with secondary aid targets they have a reasonable expectation that if aid is taken, reform will follow. Otherwise, the potential recipient could have walked away from the aid-for-reform deal.

If the theory is borne out, then reverse causality as a plausible alternative explanation will be addressed in subsequent empirical analysis. Aid agencies may, for perfectly legitimate reasons, allocate aid to recipients where democratization is feasible. The Millennium Challenge Corporation, for example, has an explicit policy of focusing on "threshold" countries or poor countries that have demonstrated "sufficient capacity, resources or political will to focus on policy reform" (USAID 2013; Bader and Faust 2014: 583-584). The concern is that aid agencies under considerable policy constraints (Carothers 2015) might be tempted to allocate aid to recipients that were already democratizing (Nielson and Nielson 2010), suggesting reverse causality in which the prior expectation of political liberalization is used to identify aid recipients. Empirical studies that address this concern have been inconclusive. Nielson and Nielson (2010) found evidence of selection bias in aid allocation towards states that are already partially democratic. However, Scott and Steele (2011) found that United States aid increases subsequent democratization after controlling for prior democratization. To address 
reverse causation, I leverage the information donors have about the stability of the recipient's governance structure at the time aid is allocated. The claim that aid induces liberalization, rather than the claim that liberalization induces aid, is stronger when donors have not observed political liberalization in the recipient prior to giving aid. The claim for reverse causality, in contrast, is stronger in those cases in which the recipient's governance structure has liberalized prior to the aid allocation decision.

Finally, the international context also affects the bargaining leverage of recipients. As Bueno de Mesquita and Smith (2016) report, during the Cold War - when there was competitive aid-bidding - we observe both in theory and empirically that donors pay more to get less from recipients. This suggests that we should be less likely to observe political reform among Secondary recipients under donor pressure during the Cold War years. The aid dynamic my theory focuses on should have less impact during the Cold War when aid recipients are able to play one donor bloc against another.

\section{The rest of the way}

In summary, this book is about the efficacy of democracy aid in inducing regime change. Under what conditions might such external aid be useful for the promotion of democracy? In even asking this question, the astute reader might challenge its implicit premise. To be clear, I recognize that the spread of political reform is out of favor in the current international environment.

Be that as it may. This book takes all of the factors that generally hurt democracy promotion as a given. To be blunt, and this is worth emphasis - I recognize the odds are bad. I am interested in how, given a poor initial hand, the cards that democrats do have might be played in such a way as to advance the course of democracy promotion.

Instead of despair, I argue the strategic incentives of leadership in both aid donors and recipients have to be accounted for. Donors are not that interested in democracy promotion. Authoritarian recipients will seek to deflect donor pressure to liberalize where they can. Putting the two together, I argue some recipients, which I call the Primary recipients, should be able to get away with no reforms so long as they have something else to offer that donors value. I suggest that another group of recipients - which I label the Secondary recipients - should be willing to offer and implement political liberalization as the price for the receipt of aid. The reason why these recipients are willing is to do so is not because the dictator woke up and magically decided to become a democrat. Rather it is because the dictator has no other strategic or commercial assets to counteroffer for the aid they need. Likewise, the reason why the donors end up promoting political liberalization is not due to their altruistic preference for democracy, it is because the recipient in question has no other strategic or commercial concessions of value to extract. This strategy of liberalization at the margins is not a comprehensive one. It may not lead to full democratization nor democratic consolidation. It will not resolve the serious challenges that liberal democracy faces. Nevertheless, it is a step in the right direction. 
The layout of the book is as follows. In Chapter 2, I will conduct the main empirical analysis using aggregated data of aid commitments and regime type on a global pool of aid recipients. In Chapter 3, the data is disaggregated into their strategic and commercial subcomponents. We want to understand which of the attribute sets, strategic or commercial, is generally valued by donors. This information helps policymakers allocate aid when facing recipients who may possess only some of the sought-after attributes. Chapter 4 looks at regional variation. I focus on Africa and Asia, as both regions have democracy scores that are below the global average. The different regional dynamic, explained in that chapter, leads us to suspect that Africa, rather than Asia, should be the more conducive environment for democracy promotion. Chapter 5 focuses on the aid relationship between Myanmar and its two donors, the US and China. The attempt by Myanmar to switch between the US and China can backfire on the military junta and lead, in turn, to limited political liberalization. Chapter 6 focus on the aid dynamics for a pair of recipients, Egypt and Fiji. The former is a typical Primary recipient while the latter is conventionally perceived as a Secondary recipient (even though it has some salience). I find that the recipient with more leverage, Egypt, was able to stave off political liberalization during Mubarak's reign while the recipient with less leverage, Fiji, held multiparty elections in 2014. Finally, Chapter 7 summarizes the evidence and discusses the policy implications.

\section{Notes}

1 While the examples highlighted are related to the literature on the international reactions to coups (Shannon et al. 2015), my focus is on the broader aid relationship between donors and recipients.

2 The arguments advanced on this book speak primarily to the first four trends: loss of democratic momentum, authoritarian resurgence, authoritarian patrons, and weaker commitment to democracy promotion. It is agnostic on the normative appeal of democracy against non-democratic alternatives. Put in another way, this is an exercise in empirical, not normative theory.

3 Thomas Carothers is the vice president for studies at the Carnegie Endowment for International Peace. He has been described as the "world's leading authority of democracy promotion" by Robert Kagan (in Carothers 2004).

4 The alternative interpretation from the selectorate theory is that the foreign aid, regardless of its declared intent (development or democracy promotion), is practically used to purchase policy concessions that benefit the donors instead. As mentioned previously, this view explains aid to recipients with much to offer to donors but not those recipients with little of value to offer to donors.

5 Crawford's research question is "whether aid sanctions" work (Crawford 1997: 70), whereas I am interested in how aid can be used to promote democracy. I do consider the threats to withhold aid (which should not be conflated with economic sanctions) shortly.

6 I include Japan, Australia, New Zealand and South Korea into the category of Western donor. South Korea did not formally join the DAC until 2010.

7 As will be made clear shortly, my focus compared to Dietrich (2016) is on bilateral government-to-government aid.

8 The analysis of Bueno de Mesquita and Smith 2009a is on security concessions. The political calculus is between buying a security concession (for example, paying a 


\section{Looking for democracy}

recipient to suppress terrorism) and donor doing the work itself (for example, sending its own troops to suppress terrorism). In translating that framework to my situation, the calculus is between (A) the donor paying a recipient to liberalize and (B) the alternative of liberalizing the regime through a military intervention by the donor. The question is now, which option is cheaper: (A) or (B)? Option A does not have to be absolutely better, it merely has to be relatively better than option $\mathrm{B}$ to be considered as a viable policy option.

9 For ease of narration, I use the noun secondary recipients as a concept and italicize it as Secondary recipient when using it as a variable. I do likewise for primary recipients.

10 To illustrate this point, I use metrics from the Polity 4 project (Marshall and Jaggers 2014), a standard dataset used in many studies on regime type. I will elaborate on metrics in the following chapter. Under Polity 4, regimes whose Polity score ranges from -6 to -10 are considered autocracies. A score of -10 is the lowest possible score and represents a regime with maximum autocracy. Now imagine two authoritarian aid recipients, one with a score of -6 and another with a score of -10 . After the receipt of foreign aid, the leadership of the regime with a score of -6 has the resources to reduce its autocracy even further (towards -10). This is not the case for the regime with the score of -10 since by definition the regime is already at the lowest possible number. My theory does not emphasize the different shades of authoritarianism. My focus is more on the democracy-authoritarian divide. The aim is to nudge those on the authoritarian side towards the democracy side with aid.

11 I will bracket aside the issue whether a full theory of democratization is needed to act, and concentrate on the actual revealed preferences of donors.

12 A description of the Corruption Perception Index, managed by the NGO Transparency International, is available here: http://cpi.transparency.org/cpi2012/.

\section{Bibliography}

Bader, J., and J. Faust. 2014. "Foreign Aid, Democratization, and Autocratic Survival." International Studies Review 16: 575-595.

Baylies, C. 1995. "Political Conditionality' and Democratisation." Review of African Political Economy 22: 321-337.

BBC. 2014. "Australia Ends Sanctions on Fiji After Democratic Elections." British Broadcasting Corporation. www.bbc.com/news/world-australia-29844291.

Bearce, David H., and Daniel C. Tirone. 2010. "Foreign Aid Effectiveness and the Strategic Goals of Donor Governments." Journal of Politics 72: 837-851.

Bermeo, Sarah Blodgett. 2011. "Foreign Aid and Regime Change: A Role for Donor Intent." World Development 39: 2021-2031.

Bermeo, Sarah Blodgett. 2016. "Aid Is Not Oil: Donor Utility, Heterogeneous Aid, and the Aid-Democratization Relationship." International Organization 70: 1-32.

Brown, Stephan. 2005. "Foreign Aid and Democracy Promotion: Lessons from Africa." The European Journal of Development Research 17: 179-198.

Brownlee, Jason. 2012. Democracy Prevention: The Politics of the US-Egyptian Alliance. Cambridge: Cambridge University Press.

Bueno de Mesquita, Bruce, and George W. Downs. 2006. "Intervention and Democracy." International Organization 60: 627-649.

Bueno de Mesquita, Bruce, and Alastair Smith. 2007. "Foreign Aid and Policy Concessions." Journal of Conflict Resolution 51: 251-284.

Bueno de Mesquita, Bruce, and Alastair Smith. 2009a. "A Political Economy of Aid." International Organization 63: 309-340. 
Bueno de Mesquita, Bruce, and Alastair Smith. 2009b. "Political Survival and Endogenous Institution Change." Comparative Political Studies 42: 167-197.

Bueno de Mesquita, Bruce, and Alastair Smith. 2016. "Competition and Collaboration in Aid-for-Policy Deals.” International Studies Quarterly. doi:10.1093/isq/sqw011.

Bueno de Mesquita, Bruce, Alastair Smith, Randolph M. Siverson, and James D. Morrow. 2003. The Logic of Political Survival. Cambridge, MA: MIT Press.

Burnell, Peter. 1994. "Good Government and Democratization: A Sideways Look at Aid and Political Conditionality." Democratization 1: 485-503.

Burnell, Peter. 2005. "Political Strategies of external support for democratization." Foreign Policy Analysis 1: 361-384.

Bush, Sara. 2015a. The Taming of Democracy Assistance: Why Democracy Promotion Does Not Confront Dictators. Cambridge: Cambridge University Press.

Bush, Sara. 2015b. "Democracy Promotion Is Failing. Here's Why." The Monkey Cage on WashingtonPost.com, November 9.

Carothers, Thomas. 1997. "Democracy Assistance: The Question of Strategy." Democratization 4: 109-132.

Carothers, Thomas. 2004. Critical Mission: Essays on Democracy Promotion. Washington, DC: CEIP.

Carothers, Thomas. 2015. "Democracy Aid at 25: Time to Choose." Journal of Democracy 26: 59-73.

Chenery, Hollis B., and Alan M. Strout. 1966. "Foreign Assistance and Economic Development." American Economic Review 56: 679-733.

Cooley, Alexander. 2015. "Countering Democratic Norms." Journal of Democracy 26: 49-63.

Crawford, Gordon. 1997. "Foreign Aid and Political Conditionality: Issue of Effectiveness and Consistency." Democratization 4: 69-108.

Crawford, Gordon. 2001. Foreign Aid and Political Reform: A Comparative Analysis of Democracy Assistance and Political Conditionality. New York: Palgrave Macmillan.

Diamond, Larry. 2004. "What Went Wrong in Iraq." Foreign Affairs 83: 34-56.

Diamond, Larry. 2015. "Facing Up to Democratic Recession." Journal of Democracy 26: $141-155$.

Diamond, Larry, Marc F. Plattner, and C. Walker. 2016. Authoritarianism Goes Global. Baltimore: John Hopkins University Press.

Dietrich, Simone. 2013. "Bypass or Engage? Explaining Donor Delivery Tactics in Foreign Aid Allocation.” International Studies Quarterly 57: 698-712.

Dietrich, Simone. 2016. "Donor Political Economies and the Pursuit of Aid Effectiveness." International Organization 70: 65-102.

Dietrich, Simone, and J. Wright. 2015. "Foreign Aid Allocation Tactics and Democratic Change in Africa." The Journal of Politics 77: 216-234.

Djankov, S., J. G. Montavlo, and M. Reynal-Querol. 2008. “The Curse of Aid.” Journal of Economic Growth 13: 169-194.

Dunning, Thad. 2004. "Conditioning the Effects of Aid: Cold War Politics, Donor Credibility, and Democracy in Africa." International Organization 58: 409-423.

Easterly, William. 2007. The White Man's Burden: Why the West's Efforts to Aid the Rest Have Done So Much Ill and So Little Good. Reprint edition. New York: Penguin Books.

Emmanuel, Nikolas G. 2013. "Democratization in Malawi: Responding to International and Domestic Pressures." African and Asian Studies 12: 415-434.

Epstein, L. David, Robert Bates, Jack Goldstone, Ida Kristensen, and Sharyn O'Hallora. 2006. "Democratic Transitions." American Journal of Political Science 50: 551-569. 


\section{Looking for democracy}

Feyzioglu, Tarhan, Vinaya Swaroop, and Min Zhu. 1998. "A Panel Data Analysis of the Fungibility of Foreign Aid." World Bank Economic Review 12: 29-58.

Fleck, Robert K., and Christopher Kilby. 2006. "How Do Political Changes Influence US Bilateral Aid Allocations? Evidence from Panel Data." Review of Development Economics 10: 210-223.

Fukuyama, Francis. 1992. The End of History and the Last Man. New York: The Free Press.

Fukuyama, Francis. 2012. "The Patterns of History." Journal of Democracy 23: 14-26.

Fukuyama, Francis. 2015. "Why Is Democracy Performing so Poorly." Journal of Democracy 26: $11-20$.

Guevara, M. W. 2007. “Allegiance Rewarded: Ethiopia Reaps U.S. Aid by Enlisting in War on Terror and Hiring Influential Lobbyists.”@MiscBarbieri2012, author=K. Barbieri and O. Keshk, title $=$ Correlates of War Project Trade Data Set Codebook, Version 3.0., year $=2012$, note $=$ http://correlatesofwar.org. Accessed 27 January 2015.

Hagen, Rune Jansen. 2006. "Buying Influence: Aid Fungibility in a Strategic Perspective." Review of Development Economics 10: 267-284.

Ibrahim, Azeem. 2009. "Belfer Center Discussion paper \#2009-06." Chap. US Aid to Pakistan-US Taxpayers Have Funded Pakistani Corruption. Harvard Kennedy Scho: Belfer Center for Science and International Affairs.

Knack, Stephen. 2004. "Does Foreign Aid Promote Democracy." International Studies Quarterly 48: 251-266.

Kono, Daniel Yuich, and Gabriella R. Montinola. 2009. "Does Foreign Aid Support Autocrats, Democrats, or Both." Journal of Politics 71: 1-15.

Lai, Brian, and Daniel Morey. 2006. "Impact of Regime Type on the Influence of U.S. Foreign Ai." Foreign Policy Analysis 2: 385-404.

Lancaster, Carol. 2007. Foreign Aid: Diplomacy, Development, Domestic Politics. Chicago: University of Chicago Press.

Levitsky, Steven, and Lucian Way. 2005. "International Linkage and Democratization." Journal of Democracy 16: 20-34.

Levitsky, Steven, and Lucian Way. 2010. Competitive Authoritarianism Hybrid Regimes after the Cold War. Cambridge: Cambridge University Press.

Licht, Amanda A. 2010. "Coming into Money: The Impact of Foreign Aid on Leader Survival." Journal of Conflict Resolution 54: 58-87.

Lipset, Seymour Martin. 1960. Political man: The Social Bases of Politics. Garden City, New York: Anchor Books.

Marinov, N., and H. Goemans. 2014. "Coups and Democracy." British Journal of Political Science 44: 799-825.

Marshall, Monty G., and Keith Jaggers. 2014. Polity IV Project: Political Regime Characteristics and Transitions, 1800-2013. The Polity IV Dataset.

McFaul, M. 2004. "Democracy Promotion as a World Value." The Washington Quarterly 28: $147-163$.

Morrison, Kevin. 2009. "Oil, Non-Tax Revenue, and the Redistributional Foundations of Regime Stability." International Organization 63: 107-138.

Neier, A. 1996-97. “The New Double Standard.” Foreign Policy 105: 91-102.

Nielsen, Richard, and Daniel L. Nielson. 2010. "Triage for Democracy: Selection Effects in Governance Aid." Annual Meeting of the Political Science Association, Washington, DC.

NYT. 2015. "China Creates a World Bank of Its Own, and the U.S. Balks." New York Times. 
Ottaway, Marina, and Thomas Carothers. 2012. Funding Virtue: Civil Society Aid and Democracy Promotion. Washington, DC: Brookings Institution Press.

Pack, Howard, and Janet Rothenberg Pack. 1990. "Is Foreign Aid Fungible? The Case of Indonesia." The Economic Journal 100: 188-194.

Pack, Howard, and Janet Rothenberg Pack. 1993. "Foreign Aid and the Question of Fungibility." The Review of Economics and Statistics 75: 258-265.

Petrova, T. 2014. From Solidarity to Geopolitics. Cambridge: Cambridge University Press.

Przeworski, Adam, Michael E. Alvarez, Jose Antonio Cheibub, and Fernando Limongi. 1996. "What Makes Democracies Endure?” Journal of Democracy 7: 39-55.

Przeworski, Adam, Michael E. Alvarez, Jose Antonio Cheibub, and Fernando Limongi. 2000. Democracy and Development: Political Institutions and Well-Being in the World, 1950-1990. New York: Cambridge University Press.

Ratner, Ely. 2009. "Reaping What You Sow: Democratic Transitions and Foreign Policy Realignment." Journal of Conflict Resolution 53: 390-418.

Remmer, K. 1995. "New Theoretical Perspectives on Democratization." Comparative Politics 28: 103-122.

Resnick, D. 2013. "Democratic Trajectories in Africa: Unravelling the Impact of Foreign Aid." Foreign Aid in Africa: Tracing Channels of Influence on Democratic Transitions and Consolidation, edited by Danielle Resnick and Nicolas van de Walle. Oxford: Oxford University Press.

Ross, Michael L. 2001. “Does Oil Hinder Democracy?” World Politics 53: 325-361.

Russett, Bruce. 2005. "Bushwhacking the Democratic Peace." International Studies Perspectives, 395-408.

Schedler, Andreas. 2013. The Politics of Uncertainty: Sustaining and Subverting Electoral Authoritarianism. Oxford: Oxford University Press.

Scott, James M., and Carie A. Steele. 2011. "Sponsoring Democracy: The United States and Democracy Aid to the Developing World, 1988-2001." International Studies Quarterly 55: 47-69.

Shannon, Megan, Clayton Thyne, Sarah Hayden, and Amanda Dugan. 2015. "The International Community's Reaction to Coups.” Foreign Policy Analysis 11: 363-376.

Stone, Randall W. 2002. Lending Credibility: The International Monetary Fund and the Post-Communist Transition. Princeton: Princeton University Press.

Tan, Bann Seng. 2016. "Aid and Democracy Promotion in Asia." Asian Journal of Comparative Politics 1: 152-170.

USAID. 2013. “"The MCC Effect.“ Issue Brief.” Millennium Challenge Corporation.

Wright, Joseph. 2009. "How Foreign Aid Can Foster Democratization in Authoritarian Regimes." American Journal of Political Science 53: 552-571.

Wright, Joesph, and M. Winters. 2010. "The Politics of Effective Foreign Aid." Annual Review of Political Science, 61-80.

Young, Crawford. 1999. "State, Conflict, and Democracy in Africa." Chap. The Third Wave of Democratization in Africa: Ambiguities and Contradictions, edited by Richard Joseph, 15-38. Boulder, CO, London: Lynne Rienner. 


\section{The big picture}

\section{Introduction}

To nudge authoritarian recipients towards democracy, we should anticipate the likely reaction of recipients when faced with donor pressure. Authoritarian regimes that desire the aid naturally seek to avoid the political costs concomitant with political reforms. Instead of democratization, they might offer alternative policy concessions that donors value in exchange for the aid. The reason why the counteroffers work is that the donors themselves do not always prioritize democracy promotion. Frequently, they value strategic and economic concessions that recipients can provide more. ${ }^{1}$

It is in this context that I argue those interested in democracy promotion should distinguish between aid recipients who have the wherewithal to resist donor pressure from those who do not. The bad news is that those who have the means to provide other concessions that donors also value should be largely immune to donor pressure to liberalize. I call this group the Primary recipients. ${ }^{2}$ The good news is that there should also be a group of recipients who lack the means to make counteroffers and therefore should be more likely to liberalize with democracy aid. I call this group the Secondary recipients. When comparing the effects of donor pressure with aid on these two groups, we should find that Secondary recipients are the group that is systemically more likely to liberalize.

The main goal of this chapter is to test the theoretical claims on the pertinent pools of recipients consisting of a pool of Primary aid recipients, a pool of Secondary aid recipients, and a global pool.

Two challenges to inference lie with the influence of the Cold War and the potential for reverse causality. The first challenge is whether the theoretical claims hold during the Cold War when the geostrategic value of recipients may be especially valued. The second challenge is whether it could be the case that aid follows liberalization instead. Both will be addressed after presenting the main analyses. A secondary goal of the chapter is to identify the empirical characteristics of both recipient groups. These will help us identify the recipients that donors should be focusing on. Only then can we discuss the policy implications in a subsequent chapter (Chapter 7).

Toward these ends, I start by describing the data and explaining the unit of analysis. This will allow me to operationalize the key variables and present summary 
statistics. Next, I will explain the empirical patterns we should expect to observe if the hypotheses hold true. I follow up by presenting the main analyses and the auxiliary findings. Finally, I conclude our findings and motivate the next chapter.

\section{Data}

The argument presented in Chapter 1 relies on two main types of data: foreign aid and the regime characteristics of recipients.

For regime characteristics, I rely on the Polity Project housed by the Center for Systemic Peace. The Polity data series was originally used to measure authority but has since been used to classify the regime type of states. The version used in this book is Polity IV (Marshall and Jaggers 2014) as the Polity V is still in development. Although Polity has been criticized (Munck and Verkuilen 2002), even the critics acknowledge it is widely used and accepted in academic circles. Polity IV codes the institutional authority characteristics for each state in the international system annually, from the 1800 s to the present. Each state receives a numeric score that sums its autocracy traits within a range from -10 to 0 . Likewise, each state also receives a numeric score that sums its democracy traits within a range from 0 to +10 . A common approach to capture the overall regime character of a given state is to sum both the democracy and autocracy traits. This creates a 21-point scale ranging from most autocratic $(-10)$ to most democratic $(+10)$. This Polity score is the foundation used to determine subsequent measures of regime change. The convention among Polity IV users is to classify a regime as a democracy in the year in which it has a Polity score of +6 or above. The same regime would be classified as an autocracy in the year in which it has a Polity score of -6 or below. Regimes with scores in the intermediate range, between +6 and -6 , are mixed regimes in the sense they have both democratic and autocratic characteristics.

A feature of Polity IV is that it considers only countries with a population of 500,000 or above. This classification excludes small islands, such as Niue, who may also receive foreign aid. We want to consider the implication of the exclusion of these microstates. Since microstates are more likely to be politically insignificant, their exclusion reduces the population of Secondary recipients from which to test my hypotheses. This has the effect of increasing the demands on my existing pool of Secondary recipients, thus it increases the rigor of the test.

For data on foreign aid, I draw upon research by the organization known as AidData, currently based in the College of William and Mary. ${ }^{3}$ Its most prominent project is its collection of information on development finance, also called, confusingly enough, "AidData". I use version 2.1 of the dataset described in Tierney et al. (2011), as that is the version that was publicly released at the time of data construction. The dataset, AidData codes at the individual aid project level. This means a given aid recipient can receive multiple aid projects from different donors in a given year. For example, an aid recipient Haiti in the year 2000 may receive five aid projects from France and ten aid projects from the United States. However, for the outcome we are studying, regime change is a long-term process that 
is not granular beyond the country-year level. For example, under Polity IV, Haiti can have at most one regime change for the year $2000 .{ }^{4}$ It is necessary to convert the data structure in AidData into a country-year data format so as to facilitate subsequent dataset merges. Thus, I aggregate individual aid projects that a recipient receives in a given year to the recipient-year level.

While aggregating to the recipient-year level, we also want to preserve information about individual aid projects that are useful for subsequent analysis. In particular, we want to distinguish between aid projects that are associated with democracy promotion from those that are not. This information can be extracted from the declared intent by the donors in the main sector of the recipient that the given aid project is intended to foster. For example, an aid project to build a hospital would be recorded with the purpose of the project and a corresponding numeric code. In this example, the purpose could be building health infrastructure with the associated numeric code of 12230 . This is the concept underlying the widely used OECD Credit Reporting System (CRS). ${ }^{5}$ Here, I use a version of the purpose code in the original OECD CRS that has been modified by AidData 2.1 (Tierney et al. 2011) to be more granular. The granularity is meant to help AidData distinguish among different types of aid. Applied to this situation, the key distinction is whether the aid is meant for democracy promotion or democracy aid. For this purpose, I classify an aid project to be for democracy promotion if its purpose code falls within the category of government and civil society (with AidData 2.1 purpose codes 15000 to 15200). This classification dovetails with the literature (Carothers 2015) and accounts for the majority of cases. I deviate slightly from previous literature by also including projects that support nongovernmental and governmental organizations (codes 92000 to 92030) but exclude those projects with generic budget support (codes 15110). The former category of aid is included because funding non-governmental organizations (NGOs) is a way to promote democracy by supporting civil society (see Bush 2015). The latter category is excluded because unconditional budget support from the donor to the recipient is highly fungible. From the selectorate perspective (Bueno de Mesquita and Smith 2009b), the resource serves to entrench autocratic regimes and retards democracy. Only a small number of cases were affected by this change. Finally, I sum all democracy aid projects to a given recipient by the recipient-year. I do likewise for other categories of non-democracy-related aid as described in latter chapters. ${ }^{6}$ In this manner, dyadic information on democracy aid is preserved when individual aid projects are aggregated into the recipientyear level of analysis.

We could use either aid commitments or aid disbursements to build the dataset. The former is a promise from the donor while the latter represents concrete payments made by the donor. The coverage of aid disbursements is always less than that for the aid commitments. In fact, much of the values for aid disbursement are missing in AidData 2.1. ${ }^{7}$ Thus, the availability of data dictates the use of aid commitments to use to infer the developmental objectives of donors.

Combining both types of data results in a dataset with aid commitments from donors and regime characteristics from recipients. Each observation is a 
recipient-year that includes aggregated information on the relationship between recipients and donors as well as the regime characteristics of the recipient five years after the aid is committed. The dataset contains time series cross-sectional data from 1973 to 2006 with a total of 2091 observations with complete data. ${ }^{8}$

\section{Key variables}

Our main dependent variable is political liberalization. It is measured as a change in the recipient's Polity IV score five years after the donor's decision to commit aid. An increase in this variable denotes political liberalization while a decrease reflects a political change towards less governmental accountability. As I explain in Chapter 1, donors prioritize strategic and commercial concessions over political reform and do not mind settling, when necessary, for political liberalization instead of full democratization.

I also focus on governments with a Polity score that is less than 6 at the time of the aid commitment; that is, the recipient does not meet the standard notion of what it means to be a democratic government at the time of an aid commitment. There are two reasons for this focus. Empirically, donors tend to direct democracy aid to authoritarian recipients instead of democratic recipients. Bueno de Mesquita and Smith (2009a) found that rich democratic donors tend to give aid primarily (but not exclusively) to recipients who are both poor and autocratic. Theoretically, it is authoritarian regimes that have the strongest political incentives to resist liberalization since it puts their hold on power in jeopardy. Potential aid recipients who are democracies, by contrast, have little reason to be subject to the political reforms that donors seek and are thus less theoretically interesting to study.

As nonviolent regime change is generally a long-term process, I do not expect a recipient's Polity score to vary by much in the short run. That is why I focus on an assessment of regime type five years after aid commitment. To determine the extent of regime change, I subtract the recipient's Polity score at the time of the donor's commitment to the aid project from its Polity score five years later. This generates the measure Regimechange5. The use of this variable involves right censoring for observations after the year 2006 because 2011 is the last year for which data on subsequent regime change is recorded. I also assess regime change three years after an aid commitment, Regimechange3, for the purpose of facilitating robustness checks. While I found the aid dynamic to be weaker using Regimechange3, using it did not otherwise substantially alter the conclusion. This is expected since the time frame of observation - three years - is shorter and we know regime change is a slow process. Although both dependent variables are analyzed in the replication files, I emphasize in this chapter mainly the results using the five-year time frame.

My main independent variables are recipient status, donor pressure, and the interaction between them. To operationalize the recipient's status, I start by identifying the type of value recipients could provide to donors. A recipient may provide strategic and/or commercial value to donors. I use indices to separately capture 
information on the various aspects of strategic and commercial value. Composite indices will then be used to estimate the overall salience that a given recipient provides to donors.

I estimate strategic value as a composite index of i) the geographical distance between the donor and recipient, ii) the population size of the recipient, and iii) the affinity in the preferences between the donor and recipient.

Donors tend to prioritize recipients in their immediate neighborhood when allocating aid. For example, the European Union prioritizes recipients in Eastern Europe after the end of the Cold War. Similarly, the bulk of Japanese Official Development Aid is directed to Asia (Soesastro 2004: 9). To capture information on the geographic distance between donors and recipients, I treat the capital as the political center of a country and use data on the distance in kilometers between the capitals of the given donor and recipient in the Geodist dataset (Mayer and Zignago 2011). Since the raw measure is skewed and we want to compare across variables, I standardize the distance measure to generate a variable, Distance, that has a standard deviation of 1 and a mean of 0 . Standardizing the measure also allows me to use it as a building block for the construction of subsequent indices. The theory argues that donors tend to give aid to recipients that are nearby. Therefore, I multiply the standardized variable by -1 so that geographic proximity can be captured in the upper end of the distribution. I impose a cutoff at the upper $25 \%$ of the distribution of Distance to denote the geographically proximate recipients. Thus, I generate a binary variable, Distpol75, that has a value of 1 if the recipient in question falls within the upper $25 \%$ of the distribution of Distance and a value of 0 otherwise. To facilitate robustness checks, I also generate two additional variables with different cutoff points. I generate the binary variable, Distpol90, that has a value of 1 if the recipient in question falls within the upper $10 \%$ of the distribution of Distance and a value of 0 otherwise. Likewise, I use the same procedure to generate the variable, Distpol50, using the upper $50 \%$ of the distribution as the cutoff for this variable.

The astute reader will notice that the operationalization of the other subcomponents of salience adopts a similar general format. This is deliberate. The goal is to generate multiple standardized measures of different aspects of recipient value and use them as building blocks to construct an overall measure of recipient salience.

All other things being equal, recipients with large populations are more strategically valuable to donors. For the recipient's population size, I use population data from Penn World Tables version 8.0 (Feenstra et al. 2013). Since we want to compare across variables and the raw population measure is skewed, I standardize the raw data to generate a variable, Population, with a standard deviation of 1 and a mean of 0 . As is the case with geographic distance, I also use cutoffs on the distribution of Population to denote recipients with significant population and hence (strategically) valuable to donors. In this way, I generate the binary variable, $\operatorname{Pop} 75$, to have a value of 1 if the recipient in question falls within the upper $25 \%$ of the distribution of Population and a value of 0 otherwise. To facilitate robustness checks, I generate additional variables using different cutoff points. 
I generate the variable, Pop50, using the upper $50 \%$ of the distribution of Population as the cutoff point. It has a value of 1 if the recipient in question lies above that cutoff point and it has a value of zero otherwise. The same procedure is applied to generate the variable, Pop90, using the upper $10 \%$ of Population as the cutoff point.

The third sub-component of strategic value lies in the shared preferences between recipients and donors, also known as the affinity between states. From the donors' point of view, recipients that share a similar worldview are more likely prospects for diplomatic or even military alliances, compared to recipients who do not. This creates an incentive for donors to allocate aid to like-minded recipients. Since the preferences of states are arguably innate and not directly observable, proxies to infer their presence have to be developed. One popular proxy is to use states' alliance portfolios (Bueno de Mesquita 1981). In an alliance, at least one state commits to the security of another. As such, an alliance between two states is a strong signal that the interests of both states coincide, thereby implying shared preferences between them. The problem with the use of military alliances as a proxy is that they constitute overdetermined relationships. It is difficult to infer the true preferences of state $\mathrm{A}$ if it also needs the military protection of state $\mathrm{B}$ that a military alliance automatically signifies (Gartzke 2000). For example, during the Cold War, West Germany needed the military protection from the Soviet Union that an alliance with the United States provided. As such, Germany had a strong incentive to align diplomatically with the United States. It was only when Germany did not need the United States, when the Soviet Union collapsed, that a unified Germany was free to indulge in its true preferences. ${ }^{9}$ For this reason, signals of preferences that are detached from the core security interests of states are preferred (Gartzke 2000). From this perspective, the roll call votes of the United Nations General Assembly are suitable precisely because they constitute a weak signal of security interests and as such allow the true preferences of states to be revealed (Gartzke et al. 1999). States change their voting patterns more frequently than they change allies.

Empirically, there is more variation in voting patterns than in alliance portfolios. Such variance is significant. It helps us parse out the important recipients from the insignificant ones. For these theoretical and empirical reasons, the data on United Nation General Assembly votes (Gartzke et al. 1999) is adopted to infer the preferences of states.

Under the Affinity of Nations dataset (in Gartzke et al. 1999), the "S" Affinity score captures the similarity in dyadic voting patterns in UN General Assembly roll call votes. This score ranges from -1 to +1 . At the minimum score of -1 , it indicates a scenario where two voting states, in this case between a donor and a recipient, are issuing opposite votes in the UN General Assembly. At the maximum score of +1 , it indicates a scenario where both the donor and recipient are voting in tandem. Since we want to compare across variables, I standardize the Affinity score to generate a variable, Reward, ${ }^{10}$ with a standard deviation of 1 and a mean of 0 . As is the case with the operationalization of previous subcomponents, I impose different cutoff points along the distribution of Reward to denote 
recipients who vote alongside their donors. I generate the binary variable, UN75, that has a value of 1 if the recipient in question falls within the upper $25 \%$ of the distribution of Reward and a value of 0 otherwise. To facilitate robustness checks, I generate the variable, UN50, by using the upper $50 \%$ of the distribution of Reward as the cutoff point. Likewise, the variable, UN90, is generated using the upper $10 \%$ of the distribution of Reward as the cutoff point.

The conception adopted thus far assumes donors prefer to allocate aid to recipients who vote the same way as the donors. Aid in this conception is a reward for sharing similar preferences. An alternative assumption is that donors give aid to recipients who can be persuaded to vote alongside the donors. Aid in this alternative conception is a bribe to change votes. In this alternative conception, the relationship between aid allocation and affinity is not linear. Why is this the case? Since each state has one vote in the UN General Assembly, a prospective donor has to balance the amount of aid needed to persuade a given recipient to switch its vote against alternative prospects. Donors could spend aid on recipients whose preferences coincide with the donor, represented by the case when the "S" Affinity score is +1 , but why should they? Such recipients were going to vote for the donors' position in any case! Alternatively, donors could spend aid on recipients with strong preferences against them, represented by the case when the "S" Affinity score is -1 . It would be against their interest to do so, as cheaper alternatives are available for that given amount of aid. It is in the middle scenario of recipients with moderate preferences, represented by the case when the " $\mathrm{S}$ " Affinity score is 0 , where it is not too expensive for donors to use aid to bribe recipients to change their votes. Thus, in this alternative conception, donors are more interested in recipients with moderate affinity than in recipients with a strong affinity with or against the donors. To capture this tendency empirically, I square the basic " $\mathrm{S}$ " Affinity score and subtract 1 from the result. As before, I standardize the variable such that it has a standard deviation of 1 and a mean of 0 . I name this resultant variable, Bribe. ${ }^{11}$ A score of 1 in Bribe indicates recipients with moderate preferences (and thus susceptible to bribery with aid); a score of 0 on this variable indicates recipients with strong preferences, either for or against the donors (and where the donors are reluctant to invest aid on these recipients). Following the same principles established for the previous subcomponents, I impose cutoff points along Bribe to identify recipients whose voting patterns are of interest to donors. I generate the variable, $U N 3$ _ 75 , to have a value of 1 if the recipient in question falls within the upper $25 \%$ of the distribution of Bribe and a value of 0 otherwise. ${ }^{12}$ To facilitate robustness checks, I also generate additional variables, UN3_75 and UN3_90, using the upper 50\% and the upper $10 \%$ of the distribution of Bribe, respectively, as the cutoff points. The analyses using the alternative measure of affinity are recorded in the replication files. They show that the use of either conceptualization does not substantively alter the results.

Armed with measures of the three main subcomponents, we can now assess the strategic salience of recipients. A recipient is strategically valuable if it is proximate to the donor or it has a large population or if its UN voting pattern mirrors that of its donors. This measure, Strategic Value, has a value of 1 if any of the 
foregoing conditions hold true and a value of 0 if none of the foregoing is true. This variable is generated using the $75 \%$ threshold. Our use of different cutoff points to generate alternative thresholds of salience is now starting to bear fruit. They allow us to generate the alternative measures, Strategic Value50 and Strategic Value 90 . They are created using the $50 \%$ and $90 \%$ thresholds respectively.

I turn now to measures of the commercial value where I apply a similar operationalization framework. ${ }^{13}$ I estimate the commercial value of a recipient as a composite index of i) the significance of the recipient to the donor's total imports, ii) the significance of the recipient to the donor's total exports, and iii) the size of recipient's economy.

Recipients may be economically valuable to donors as a source of imports and/or as a destination for exports. To start, I use bilateral trade data, between a given donor and a given recipient from the International Trade dataset (Barbieri and Keshk 2012). We want to know how much the donor values the imports and exports from a recipient in a given year.

I express the recipient's significance to the donor as a source of imports as a ratio of the recipient's exports to the donor over the donor's total imports for each dyad-year. Using ratios has the additional benefit of removing the currency unit, which was in current US dollars. Since we want to compare across variables, I standardize the ratio so that it has a standard deviation of 1 and a mean of 0 . This variable is called Importshare. Values at the higher end of this standardized ratio represent recipients who are important sources of imports from the donors' perspective. As is the case with previous operationalization, I impose different cutoff points to denote such recipients who are important sources of imports. I generate the binary variable, Importsig75, which has a value of 1 if the recipient in question falls within the upper $25 \%$ of the distribution of Importshare and with a value of 0 otherwise. To facilitate robustness checks, I also generate the variable, Importsig 50 , by using the upper $50 \%$ of the distribution of Importshare as the cutoff point. Likewise, I generate the variable, Importsig90, by using the upper $10 \%$ of the distribution of Importshare as the cutoff point.

Likewise, I express the recipient's significance to the donor as a destination for exports as a ratio of the recipient's imports from the donor over the donor's total exports for each dyad-year. As before, we standardize this ratio to facilitate comparisons across variables. This generates the variable, Exportshare, with a standard deviation of 1 and a mean of 0 .

Values at the higher end of Exportshare represent recipients who are important destinations of exports from the donors' perspective. As before, cutoff points along this distribution are used to denote significant recipients. I generate the variable, Exportsig75, that has a value of 1 if the recipient in question falls within the upper $25 \%$ of the distribution of Exportshare and with a value of 0 otherwise. I also generate the alternative measures, Exportsig50 and Exportsig90, using the $50 \%$ and the $90 \%$ cutoff points respectively as the threshold.

Under the gravity model of trade, countries tend to trade more with large economies (as well as nearby economies). Applied to this situation, donors are more likely to trade with recipients with larger economies. As a consequence, donors 
have a greater economic incentive to allocate aid to such recipients. For the economic size, I use the recipient's Gross Domestic Product or GDP, measured in millions of US dollars using 2005 as the base year, ${ }^{14}$ from the Penn World Tables version 8.0 (Feenstra et al. 2013). Since GDP figures are skewed and we wish to compare across variables, I standardized the recipient's GDP figures to create the variable, GDP, such that it has a standard deviation of 1 and a mean of 0 . I generate the variable, $G d p 75$, that has a value of 1 if the recipient in question falls within the upper $25 \%$ of the distribution of GDP and a value of 0 otherwise. To facilitate robustness checks, I also generate the alternative measures, Gdp50 and Gdp90, using the $50 \%$ and the $90 \%$ cutoff points respectively as the threshold.

Now that the subcomponents are complete, we can address the overall measure of economic salience. A recipient is commercially valuable if it is a significant source of imports, a destination for exports, or if it has a large economy. This measure, Economic Value, has a value of 1 if any of the foregoing conditions hold true and a value of 0 otherwise. This variable is generated using the $75 \%$ threshold. Since we have already created alternative cutoff points using the $50 \%$ and $90 \%$ thresholds, we can utilize those, respectively, to generate alternative measures of commercial importance, Economic Value50 and Economic Value 90. These can then be used for robustness checks.

The theory considers recipients to have more leverage in aid negotiations if they have strategic and commercial attributes considered attractive by donors. This stance treats the recipients' value as an aggregation of the recipient's strategic and commercial attributes but is otherwise agnostic on the exact combination of the attributes that determine salience. A straightforward interpretation, therefore, is to require both sets of commercial and strategic attributes to be present for a recipient to be considered salient. To sidestep the possibility that a given aid recipient can be important to some donors but not others within the same year, the aggregation principle focuses on the cases where the given recipient is considered by all its donors for that given year to be either important or not important as the case may be. Such a move allows the theory to maintain its emphasis on the comparative leverage of two distinct groups of recipients - a group with clear-cut salience and a group without.

A country is a Primary recipient if it has both strategic and commercial value to all its donors for a given year. Primary recipients have a value of 1 for Strategic Value and Economic Value. Moreover, that condition holds true for all donors that committed aid to that specific recipient in that given year. A country is a Secondary recipient if it lacks strategic and commercial value to all its donors for a given year. Secondary recipients have a value of 0 for Strategic Value and Economic Value. Furthermore, that condition must hold true for all donors that committed aid to that specific recipient in that given year. These specifications are very demanding; as such, they help most clearly to differentiate between Primary and Secondary aid recipients. To help the reader understand how the different measures of recipient salience relate to each other, I summarize the key concepts and their associated variables in Table 2.1.

The next main independent variable is a measure of donor pressure. The theory asserts that donors use foreign aid to pursue various objectives by attaching 
Table 2.1 Measures of Recipient Salience

\begin{tabular}{ll}
\hline Strategic Value & Commercial Value \\
\hline Distance & Source of imports \\
(Distpol75) & (Importsig75) \\
Population & Destination for exports \\
$($ Pop 75) & (Exportsig75) \\
Affinity & Recipient's GDP \\
$($ UN75) & (Gdp75) \\
Strategic Value $=1$ if any of the above & Economic Value $=1$ if any of the conditions \\
$\quad$ conditions is true & above is true \\
Recipient status: & \\
If both strategically and commercial valuable: Primary recipient \\
If neither strategically nor commercial valuable: Secondary recipient \\
\hline
\end{tabular}

Variable names in italics

conditions in a political quid pro quo. To assess this, we need to know the objectives donors pursue with foreign aid. The OECD Credit Reporting System identifies the main sector of the recipient's economy that the project is designed to assist and uses this to give a purpose code to each individual aid project. I use the modified version of purpose codes provided by AidData 2.1 (Tierney et al. 2011). I use these codes to separate democracy aid from other types of aid using the criteria described in the preceding section. ${ }^{15}$

Donors could, of course, pursue a variety of other goals beside democracy promotion with aid. Aid projects with democracy promotion as the goal are different from aid projects with other objectives such as economic development. When a donor offers aid to build, say, a power plant, the recipient has no incentive to oppose the aid - it seeks the same economic development too! If the donor had sought democracy promotion and offered aid for the holding of multiparty elections, an authoritarian recipient who wants to stay in power has strong incentives to seek a way to obstruct such goals. Therefore, democracy aid is distinctive because it reflects a circumstance in which donors seek and are willing to pay for political reforms that autocratic recipients naturally prefer not to undertake. Since recipients could have chosen to reject the aid aimed at inducing them to make costly reforms, the fact that they accepted the aid is a strong signal that they are open to the donor's pressure.

We have three plausible candidate variables to proxy donor pressure. They are the summed monetary value of the aid, the total number of democratic aid projects, and the receipt of democracy aid. ${ }^{16}$ The summed monetary value of democracy aid can be misleading given the possibility of aid diversion. Consider as an example, the observation by Moyo (2010) in a critical study of aid to Africa:

A World Bank study found that as much as 85 percent of aid flows were used for purposes other than that for which they were initially intended, very often diverted to unproductive, if not grotesque ventures. 
In such circumstances, large sums of democracy aid need not necessarily indicate a sustained effort by donors to apply pressure to recipients.

Furthermore, to understand the distinction between the proxy candidates, consider the following emphasis in the selectorate theory:

Aid-for-policy deals must be acceptable to each leader! Recipient leaders must prefer (at least weakly) the additional rewards they can give their coalition rather than receiving no aid and making no concessions. The donor leaders must value the policy concessions they obtain for their coalition more highly than the direct rewards they could have provided their supporters had they not spent resources on aid.

(Bueno de Mesquita and Smith 2009a: 320)

Since both the donor and the recipient must agree for a deal to be struck, the utility of the aid and policy concession purchased will be calibrated to meet the needs of both parties. This renders the first two proxy candidates problematic because the required number in terms of monetary value or the total aid projects needed to induce political reform is a function of their utility for the aid compared to their utility for the required concession. These utilities necessarily vary from recipient to recipient. For example, a given monetary amount (in democracy aid) that may be enough to persuade an autocratic Fiji to liberalize might not be enough to persuade an autocratic Egypt to reform. Likewise, for a given amount of donor pressure, Egypt may end up with a greater total number of democracy-aid projects than Fiji simply because of its size. As Bueno de Mesquita and Smith (2009a) have shown, there is no reason to expect these utilities are linear in the amount of money (or by extension, in the number of projects).

In light of these issues, the signal that is meaningful is the decision by the recipient to accept aid conditioned on political reforms and not the absolute totals per recipient-year. To capture this concept of donor pressure, I generate the proxy variable, Democratic Push, that has a value of 1 if the recipient in question has accepted any aid project with democracy promotion as its stated goal from any donor for that year, and a value of 0 otherwise.

Our third main independent variable is an interaction term. The theory argues that the effect of foreign aid on subsequent liberalization is conditional on the salience of the recipients to donors. Such a construct calls for the use of interaction effects (Brambor et al. 2006). To capture the interaction of donor pressure on Primary recipients, I multiply donor pressure with recipient status to generate the interaction term, Democratic Push $\times$ Primary. I do likewise for Secondary recipients to generate the interaction term, Democratic Push $\times$ Secondary.

Regarding control variables, I follow the injunctions of Ray (2003) and Achen (2002) that more is not necessarily better. Achen argues that it is difficult to meaningfully interpret the results of a statistical model when more than three control variables are involved. He calls this rule of thumb the "rule of three" (Achen 2002). Ray (2003), for his part, argues that control variables should have a plausible causal relationship that is backed by the pertinent theory with both the independent and dependent variables to be included in a multivariate model. Both 
authors warn against the inclusion of control variables merely for the sake of improving the overall fit of the statistical model (Ray 2003; Achen 2002). Since I am interested in the key relationships between democracy aid, donor pressure, and the subsequent political liberalization in the recipient country, the control variables I use are meant to account for alternative explanations for both aid allocation and regime change. They are the development levels of the recipient and the Cold War context. They are selected with a view to the substantive interpretation of the results while avoiding the omitted variable bias.

The economic development level of each recipient is a pertinent control variable for three reasons. First, countries with a low level of development tend to be more likely to receive aid, all else being equal. Second, countries with high levels of development tend to be democratic. Third, although the relationship between economic development and democratization is contested, there is some evidence to suggest a correlation. For example, Przeworski et al. (2000) found that countries that democratize after they cross the US\$ 6,000 GDP per capita threshold tend to stay democratic. By contrast, they also found that countries that fail to breach that threshold tend to turn authoritarian even if they manage to democratize. For these reasons, I measure the recipient's economic development with GDP per capita data from the Penn World Tables version 8.0 (Feenstra et al. 2013). That data is denominated in millions of US dollars using 2005 as the base year. I take its natural logarithm to create the variable GDP per capita. This variable has only 2091 observations because there are missing values for Yemen from the years 1973 to 1988 in the original Penn World Tables 8.0 data. $^{17}$

To reflect the international context, I generate a dummy variable, Cold War, that has a value of 1 if the year of aid commitment is before 1991, the year that the Soviet Union collapsed, and a value of 0 otherwise. I use this variable in two ways. I use it as a control variable and also as a filter to separate the data into the Cold War and post-Cold War subsets. When we use the Cold War as a filter, we seek to understand how the Cold War affects the effectiveness of donor pressure. To capture the interactive effects of this period, I examine the regression coefficients on each relevant variable for the Cold War (Cold War=1) and the post-Cold War (Cold War $=0$ ) period.

A final concern is the possibility of reverse causality, an issue that was discussed in Chapter 1. To recap, we want to be sure it is foreign aid that is responsible for inducing political reforms in aid recipients. To increase our confidence that this is indeed the case, we want to rule out the alternative possibility that the aid is given systemically to recipients that were already liberalizing and/or democratizing (a case of aid following reforms). To allow us to do this, we focus on the set of recipients that have not previously already shown themselves to be liberalizing politically. Why focus on this set? Since this set of countries has not been reforming prior to the commitment of aid, donors could not have conceivably known in advance to emphasize this set in their aid allocation. If we find subsequent political reform in this set of recipients, we can be reasonably confident that reverse causality is not a primary explanation for subsequent political reform. To identify the set of prospective aid recipients who did not reform their political system prior to the commitment of aid, I construct two variables, Liberalize and Democratize. 
Table 2.2 Summary Statistics for Key Independent and Control Variables

\begin{tabular}{lllllc}
\hline Variable & Observations & Mean & $\begin{array}{l}\text { Standard } \\
\text { Deviation }\end{array}$ & Minimum & Maximum \\
\hline Strategic Importance & 2104 & 0.504 & 0.500 & 0 & 1 \\
$\begin{array}{l}\text { Commercial } \\
\quad \text { Importance }\end{array}$ & 2104 & 0.348 & 0.477 & 0 & 1 \\
$\begin{array}{l}\text { Primary (recipient) } \\
\text { Secondary (recipient) }\end{array}$ & 2104 & 0.168 & 0.374 & 0 & 1 \\
$\begin{array}{l}\text { Democratic Push } \\
\text { Cold War }\end{array}$ & 2104 & 0.564 & 0.496 & 0 & 1 \\
$\begin{array}{l}\text { GDP per capita } \\
\quad \text { logged, recipient) }\end{array}$ & 2104 & 0.632 & 0.482 & 0 & 1 \\
$\quad$ Regime Change (Five & 2104 & 0.558 & 0.497 & 0 & 1 \\
$\quad$ years after aid) & & 7.522 & 0.892 & 5.031 & 10.222 \\
\hline
\end{tabular}

I follow Polity IV's (Marshall and Jaggers 2014) procedure to generate a variable, Liberalize, that has a value of 1 if at the time of the aid commitment the Polity score of the recipient has improved towards democracy (became more positive or less negative) by at least 3 Polity points over the previous three years. When this condition is not met, then Liberalize takes a value of 0 , identifying the subset of cases in which reverse causality is unlikely to be a credible explanation if we observe subsequent political liberalization. To capture information on a more demanding indicator intended to root out the threat of reverse causality, I follow Polity IV's (Marshall and Jaggers 2014) procedure to generate an alternative variable, Democratize. Democratize has a value of 1 if at the time of the aid commitment, the recipient's Polity score has increased by at least 3 points over the previous three years and the regime transition in question either crosses the 0 point on the Polity Democracy-Autocracy scale or it has shifted from a partial democracy $(0<$ Polity $<7)$ to full democracy (Polity $>6)$. If this condition is not met, then Democratize takes a value of 0 . When Democratize $=1$, we are dealing with recipients with a prior history of political liberalization. When Democratize $=0$, we are dealing with recipients with a history of political stability.

To give readers a sense of the key variables, Table 2.2 provides summary statistics.

\section{Theoretical expectations}

Using time-series cross-sectional data, the extent of the recipient's subsequent political liberalization is modeled as a function of donor pressure, the recipient's salience, and the interaction between donor pressure with the recipients' salience, with the development levels of the recipients and the Cold War context as control variables. To determine if the use of the fixed effects model or the random effects model is more appropriate, I use a Hausman test. The null hypothesis in the Hausman test is that the difference in the coefficients from the two models is not systemic. The Hausman test shows that the null hypothesis can be rejected 
and that the difference between the models is systemic. This result supports the use of fixed effects. Furthermore, Clark and Linzer (2015) suggest that the use of fixed effects is more appropriate when interactive effects are involved, as it is in my case. Therefore, I include country fixed effects in my models to control for the domestic political conditions that are idiosyncratic to specific recipients and which may induce political liberalization in those same recipients.

Before going over the specific empirical expectations, we want to clarify the aim of the analyses. The goal is to ascertain the extent to which the recipient's status, combined with donors' pressure for political liberalization, contributes to the recipient's subsequent reforms as part of a non-violent effort at democracy promotion. For that specific purpose, a comprehensive account of regime change is not necessary. Statistically, my goal is not to maximize the R-squared. Rather, it is to assess the marginal effect of the recipient status on the subsequent liberalization in the recipient, conditional on the exertion of donor pressure for democracy promotion. Are the marginal effects statistically significant (after considering the interaction effects)? Furthermore, are the marginal effects in the theoretically anticipated directions (positive for Secondary recipients and agnostic for Primary recipients)? Those are the questions that are pertinent to the analysis that follows.

Since the distinction between these two research objectives is nuanced (and a common source of confusion) I hope the reader will indulge me as I offer an analogy from studies of cigarette smoking and lung cancer. If the research question is whether smoking causes lung cancer, what is important is not the overall fit of the statistical model for predicting lung cancer, but whether the coefficient for the smoking variable is statistically significant (and substantively meaningful). Since lung cancer has many other causes besides smoking, it is possible to find a strong relationship between smoking and subsequent lung cancer in a statistical model where the predicted overall rate of lung cancer is low. Likewise, it is possible for democracy aid (with donor pressure and recipient status) to have a statistically significant impact on the subsequent liberalization of recipients even where the overall expectation for political change is low.

This distinction has policy-relevant implications. After all, many of the drivers of regime change are domestic in nature and from a policy viewpoint fall outside the direct influence of donors. Yet, if the hypotheses are borne out, then donors can use the information generated here to improve the odds that their aid, properly targeted, encourages political reform.

To refresh our memory, the claim is that the effectiveness of using aid to promote liberalization is conditional on the status of the recipient. Donor pressure is effective at inducing liberalization when the recipient in question has a secondary status. This reflects the lack of leverage by such recipients. Donor pressure is agnostic or statistically insignificant at inducing political change when the recipient in question has a primary status. This reflects the abundance of leverage such recipients possess. Such a theoretical setup is a type of conditional statement with the structure, "the effect of X on Y is conditional upon Z". The interpretation of marginal effects in conditional statements requires careful attention to interaction terms (Brambor et al. 2006). The marginal effect of the status of recipients as secondary on political liberalization, conditional on the exertion of donor pressure 
using aid, is empirically captured by the sum of the coefficients for Secondary and Democratic Push $\times$ Secondary. If that sum of coefficients is positive and statistically significant, we will conclude support for $\mathrm{H} 1$ or the claim that donor pressure is effective on Secondary recipients.

For Primary recipients, the marginal effect of recipient status on political liberalization, conditional on donor pressure, follows a similar structure. Empirically, it is captured by the sum of coefficients for Primary and Democratic Push $\times$ Primary. Since the claim in $\mathrm{H} 2$ is that donor pressure under such conditions should not be effective, we should observe the sum of coefficients to be either i) negative and statistically significant or ii) not statistically significant. If either situation holds, we conclude support for H2. The results of these analyses are reported in Table 2.3.

A feature of conditional statements is that two causal stories can be told from the same empirical model (Brambor et al. 2006: 72, footnote 9). In notational terms, the marginal effect of $\mathrm{X}$ on $\mathrm{Y}$ modified by $\mathrm{Z}$ is symmetric to the marginal effect of $\mathrm{Z}$ on $\mathrm{Y}$ modified by $X$. In this case, we can focus on either the marginal effect of donor pressure on liberalization modified by recipient status; or alternatively we can focus on the marginal effect of recipient status on liberalization modified by donor pressure.

The principle is to use the theory (and its concomitant policy implications) to decide which causal story to emphasize. The discussion in Chapter 1 makes the

Table 2.3 The Effect of Recipients' Status on Regime Change for Primary and Secondary Recipients

\begin{tabular}{llc}
\hline $\begin{array}{l}\text { Fixed Effects } \\
\text { TSCS }\end{array}$ & $\begin{array}{l}\text { Model 1 } \\
\text { Primary } \\
\text { Recipients only }\end{array}$ & $\begin{array}{l}\text { Model 2 } \\
\text { Secondary } \\
\text { Recipients only }\end{array}$ \\
\hline $\begin{array}{l}\text { Primary } \\
\text { (recipient) }\end{array}$ & -0.708 & $\mathrm{NA}$ \\
Secondary & $(0.549)$ & 0.142 \\
$\quad$ recipient) & NA & $(0.376)$ \\
Democratic Push & $1.153^{* *}$ & $0.745^{*}$ \\
& $(0.226)$ & $(0.307)$ \\
Interaction term & -0.797 & 0.543 \\
(Democratic Push & $(0.535)$ & $(0.376)$ \\
$\quad \times$ Primary/ & & \\
$\quad$ Secondary) & $0.752^{* *}$ & $0.701^{* *}$ \\
GDP per capita & $(0.270)$ & $(0.267)$ \\
$\quad$ logged, recipient) & 0.102 & 0.093 \\
Cold War & $(0.211)$ & $(0.211)$ \\
& $-4.489^{*}$ & $-4.304^{*}$ \\
constant & $(2.022)$ & $(2.029)$ \\
& 2091 & 2091 \\
N & 0.021 & 0.021 \\
Within R-Squared & 0.000 & 0.000 \\
Prob>F & & \\
\hline
\end{tabular}

** Significant at .01 level, two-tailed

* Significant at .05 level, two-tailed

() standard errors 
case that democracy promotion using foreign aid is performing poorly. This is in part because they do not know who to properly target when applying donor pressure. My theoretical claim is that donors should select candidates based on their leverage. That leverage is in turn captured by the candidate's status as a Primary or a Secondary recipient. Thus, the causal story here is on the marginal effect of recipient status (Primary or Secondary) on liberalization modified by the exertion of donor pressure using foreign aid.

This distinction between recipient types has policy relevance. Many of the drivers of regime change are domestic in nature and, from a policy viewpoint, fall outside the direct influence of donors. Conditional on donors choosing to exert international pressure for democracy promotion, a legitimate concern is over the effective use of their limited capital. Should they target every aid recipient, those with great value to donors, or those with little value to donors? I argue they should focus on the secondary recipients. If my hypotheses are borne out, then donors can use the information generated here to improve the odds that their effort, properly targeted, encourages political reform.

The analysis reported in Table 2.4 asks whether the difference between being a Secondary recipient that is subjected to donor pressure to liberalize and being a

Table 2.4 The Effect of Recipients' Status on Regime Change for All Recipients

\begin{tabular}{lc}
\hline Fixed Effects & Model 3 \\
TSCS & Universal Pool \\
\hline Primary & -0.810 \\
(recipient) & $(0.583)$ \\
Secondary & 0.181 \\
$\quad$ (recipient) & $(0.414)$ \\
Democratic Push & $0.862^{*}$ \\
& $(0.380)$ \\
Interaction term & -0.541 \\
(Democratic Push $\times$ Primary) & $(0.619)$ \\
Interaction term & 0.440 \\
(Democratic Push $\times$ Secondary) & $(0.437)$ \\
GDP per capita (logged, recipient) & $0.824^{* *}$ \\
& $(0.273)$ \\
Cold War & 0.097 \\
& $(0.211)$ \\
constant & $-5.109 *$ \\
& $(2.081)$ \\
N & 2091 \\
Within R-Squared & 0.023 \\
Prob>F & 0.000 \\
Joint Test & 0.003 \\
&
\end{tabular}

** Significant at .01 level, two-tailed

* Significant at .05 level, two-tailed

() standard errors 
Primary recipient that is subjected to the same democratic pressure is significant. To be clear, the first group consists of the sum of the coefficients of Secondary and Democratic Push $\times$ Secondary. The second group consists of the sum of the coefficients of Primary and Democratic Push $\times$ Primary. We care about the difference between these two groups. If the resultant F-test shows the difference is statistically significant and the substantive effects are in the theoretically anticipated directions - positive and statistically significant when recipients are Secondary and are pushed by one or more donors to liberalize - I conclude support for H3.

I examine the risk of reverse causality in Table 2.5 by taking into account the prior information that donors have about the stability of each recipient's regime. In it, I test for two measures of prior regime change, when Liberalize $=0$ (Model 4) and when Democratize $=0$ (Model 5). For each model, we use the F-test to determine if the marginal effects of Secondary recipients under donor pressure are equivalent to the marginal effects of Primary recipients under the same donor pressure. We will be confident in $\mathrm{H} 3$ if, for both models, the Primary and Secondary recipients are reacting to aid under donor pressure in systemically different ways.

The international environment affects the ease with which recipients can play one donor bloc against another. As the selectorate perspective (Bueno de Mesquita

Table 2.5 The Aid Dynamic on Stable Recipients

\begin{tabular}{lcc}
\hline Fixed Effects & $\begin{array}{l}\text { Model } 4 \\
\text { Non-liberalizing } \\
\text { recipients }\end{array}$ & $\begin{array}{l}\text { Model 5 } \\
\text { Non-democratizing } \\
\text { recipients }\end{array}$ \\
\hline Primary & -0.705 & -0.837 \\
$\quad$ (recipient) & $(0.596)$ & $(0.591)$ \\
Secondary & 0.139 & 0.132 \\
$\quad$ (recipient) & $(0.415)$ & $(0.412)$ \\
Democratic Push & $0.999^{* *}$ & $0.973^{*}$ \\
Interaction term & $(0.383)$ & $(0.380)$ \\
(Democratic Push $\times$ Primary) & -0.834 & -0.627 \\
Interaction term & $(0.634)$ & $(0.627)$ \\
(Democratic Push $\times$ Secondary) & 0.310 & 0.310 \\
GDP per capita & $(0.442)$ & $(0.438)$ \\
$\quad$ logged, recipient) & $0.705^{*}$ & $0.714^{*}$ \\
Cold War & $(0.279)$ & $(0.276)$ \\
& 0.219 & 0.206 \\
constant & $(0.216)$ & $(0.212)$ \\
N & $-4.351^{*}$ & $-4.374^{*}$ \\
Within R-Squared & $(2.132)$ & $(2.106)$ \\
Prob>F & 1952 & 2005 \\
Joint Test & 0.022 & 0.022 \\
\hline
\end{tabular}

** Significant at .01 level, two-tailed

* Significant at .05 level, two-tailed

() standard errors 
and Smith 2016) notes, during periods of donor competition, such as during the Cold War, we should expect donors to pay more to get less from recipients. Applied to democracy aid, it suggests we are less likely to observe political liberalization in Secondary recipients under donor pressure during the Cold War. Empirically, it means the aid dynamic should be statistically insignificant regardless of the specific measure of prior reform during the Cold War. To investigate this, I conduct a reanalysis of Table 2.5 in which I account for both the threat of reverse causality and the effect of the Cold War context simultaneously. The results are reported in Table 2.6. As before, the focus is on previously stable recipients identified using the measure Liberalize $=0$ (Model 6) or Democratize $=0$ (Model 7).

\section{Results}

The first model, Model 1 in Table 2.3, focuses on Primary recipients. It shows that five years after aid, the Primary status of the recipient in the absence of donor pressure to liberalize is associated with an insignificant decrease in the Polity score, with a coefficient of -0.708 . Among non-primary recipients - that is, the group consisting of Secondary and non-primary recipients together - democratic push by donors, in the form of aid conditionality linked to democracy promotion, is associated with a statistically significant increase in liberalization of 1.153 Polity points. The interaction term for the two effects is insignificant. Of the three independent variables, only the effect of democratic pressure is statistically significant $(\mathrm{p}=0.000)$. The sum of Primary and Democratic Push $\times$ Primary is negative and statistically significant $(\mathrm{p}=0.013)$, as discussed in more detail later. Of the two control variables, only the economic development of the recipient is statistically significant $(\mathrm{p}=0.005)$. It increases subsequent regime change by 0.752 Polity points.

Model 2 examines the situation for Secondary recipients. It shows that five years after aid, the Secondary status of the recipient in the absence of donor pressure to liberalize is associated with an insignificant increase in the Polity score, with a coefficient of 0.142 . Among non-secondary recipients - that is, the group consisting of Primary and non-secondary recipients together - democratic push by donors is associated with a statistically significant increase in liberalization of 0.745 Polity points. The interaction term for the two effects is insignificant.

The sum of the coefficients of Secondary and Democratic Push $\times$ Secondary reflects the effect of a lesser status (as Secondary recipients) on subsequent regime change for those under reform pressure. It increases the Polity score of Secondary recipients by 0.684 points. The probability that this marginal effect is due to chance is $0.030(\mathrm{~F}(1,1989)=4.72)$. This supports $\mathrm{H} 1$ or the claim that donor pressure is more effective on Secondary recipients.

To assess the marginal effect of Primary recipients on subsequent regime change under donor pressure, we focus on the sum of the coefficients of Primary and Democratic Push $\times$ Primary. It decreases their Polity score by 1.505 points. The probability that this marginal effect is by chance is $0.013(\mathrm{~F}(1,1989)=6.18)$. This supports $\mathrm{H} 2$, or the claim that aid and donor pressure is not effective at liberalizing 
Primary recipients. Turning to the control variables, the economic development of the recipient and the Cold War context increase subsequent regime change by 0.701 Polity points $(\mathrm{p}=0.009)$ and by 0.093 Polity points $(\mathrm{p}=0.659)$ respectively.

Whereas Table 2.3 applies the aid dynamic to separate pools of recipients, Table 2.4 applies it to the universal pool of recipients. It shows that the effect of asserting donor pressure, Democratic Push, among non-secondary and nonprimary recipients is 0.862 . That is, Democratic Push is associated with liberalization among those recipients. When the recipient is Primary and is subjected to donor pressure to reform, its subsequent Polity score decreases by 1.351 points. This outcome is statistically significant (probability of 0.029 ; F $(1,1987)=4.79$ ). The ineffectual nature of donor efforts supports H2. By contrast, when the recipient is Secondary and is subjected to the same donor pressure to reform, its subsequent Polity score increases by 0.622 points. The probability that this result is due to chance is $0.052(\mathrm{~F}(1,1987)=3.78)$. This indicates donors are more successful with Secondary recipients, supporting H1.

We also want to examine if the marginal effects for Secondary recipients are statistically significant and substantively meaningful from the marginal effects for their primary counterparts. The F-test shows that the odds of the two marginal effects are equivalent, with the difference accounted by chance alone, are 0.003 $(\mathrm{F}(1,1987)=8.88)$. The recipient groups are systemically reacting to aid under donor pressure in ways anticipated by $\mathrm{H} 3$.

Do donors give that aid to induce liberalization (the objective) or to reward recipients that were already liberalizing (a check for spurious explanation)? Table 2.5 addresses this concern. By focusing on the cases where the recipient has not been undergoing prior regime change when Liberalize $=0$ (Model 4) or when Democratize $=0$ (Model 5), we have eliminated reverse causation as an alternative explanation for the results. The joint test in Model 4 verifies if the marginal effects for Secondary recipients is different from the marginal effects for Primary recipients in a statistically significant manner. The F-test shows that the odds of them being equivalent, with the difference due to chance, are $0.004(\mathrm{~F}(1,1848)=8.37)$. Using the alternative measure Democratize in Model 5 yields similar results. The joint test in Model 5 checks if the marginal effects of the two recipient groups on the aid dynamic are significantly different from each other. The F-test of the odds of them being equivalent, with the difference due to chance, has a probability of $0.005(F(1,1901)=7.85)$. Both tests reported in Table 2.5 demonstrate that reverse causality is not likely to be the alternative explanation for the findings in support of the theory (as reported in Tables 2.3 and 2.4).

The extant literature (Bueno de Mesquita and Smith 2016; Bermeo 2016) highlights the impact of the Cold War. In the face of donor competition, we expect recipients to be more resilient against donor pressure across the board. Table 2.6 reports the result controlling for both the Cold War and for the threat of reverse causality simultaneously. It does this by identifying the recipients that were politically stable (using either Liberalize $=0$ or Democratize $=0$ ) during the Cold War. The joint test in Model 6 focuses on recipients that were not previously liberalizing (using Liberalize=0). It examines if the marginal effects for Secondary 
Table 2.6 The Aid Dynamic on Stable Recipients during the Cold War

\begin{tabular}{lcc}
\hline Fixed Effects & $\begin{array}{l}\text { Model 6 } \\
\text { Non-liberalizing } \\
\text { recipients }\end{array}$ & $\begin{array}{l}\text { Model } 7 \\
\text { Non-democratizing } \\
\text { recipients }\end{array}$ \\
\hline Primary & -0.676 & -0.737 \\
$\quad$ (recipient) & $(0.880)$ & $(0.882)$ \\
Secondary & 0.318 & 0.284 \\
$\quad$ (recipient) & $(0.520)$ & $(0.520)$ \\
Democratic Push & $1.672^{* *}$ & $1.621^{* *}$ \\
& $(0.513)$ & $(0.511)$ \\
Interaction term & -0.162 & 0.082 \\
(Democratic Push $\times$ Primary) & $(0.862)$ & $(0.855)$ \\
Interaction term & 0.245 & 0.288 \\
(Democratic Push $\times$ Secondary) & $(0.606)$ & $(0.604)$ \\
GDP per capita & $2.257^{* *}$ & $2.306^{* *}$ \\
$\quad$ logged, recipient) & $(0.636)$ & $(0.636)$ \\
constant & $-15.700^{* *}$ & $-16.036^{* *}$ \\
N & $(4.771)$ & $(4.778)$ \\
Within R-Squared & 1110 & 1127 \\
Prob>F & 0.060 & 0.060 \\
Joint Test & 0.000 & 0.000 \\
\hline
\end{tabular}

** Significant at .01 level, two-tailed

* Significant at .05 level, two-tailed

() standard errors

recipients and the marginal effects for Primary recipients are different from each other in a statistically significant manner. The F-test of the odds that the two marginal effects are effectively equivalent, with the difference due to chance, has a probability of $0.301(\mathrm{~F}(1,1018)=1.63)$. The joint test in Model 7 conducts a similar query, in this case on the recipients that were not previously democratizing (using Democratize $=0$ ). The F-test of the odds that the marginal effects of the two recipient groups are effectively equivalent, with the difference due to chance, has a probability of $0.262(\mathrm{~F}(1,1035)=1.26)$. Both sets of results are statistically insignificant but are theoretically anticipated. The Cold War does make a difference.

\section{Conclusion}

The analyses thus far suggest the existence of two types of recipients. One group that I term the primary recipients - has the attributes that give them leverage to bargain with donors. Another group -- that I term the secondary recipients lacks those attributes and thus has less to bargain with. The theory posits the aid dynamic, in the form of donor pressure in conjunction with foreign aid, should have a different impact on these two groups. The results, especially in Tables 2.3 and 2.4, show that the same aid dynamic that fails to persuade Primary recipients 
to liberalize is more successful with Secondary recipients. This finding, that aid can nudge some but not all towards political liberalization, stands up when reverse causality is taken into account. The Cold War context did affect the bargaining leverage of recipients, but we should also remember the Cold War is over.

The tests thus far were done on a global pool of aid recipients; we also want to explore the components of salience in themselves. After all, some recipients may be strong in some specific attributes but weak in others. Are some sets of attributes more important than others? The next chapter investigates this question.

\section{Notes}

1 Consider, for example, the "America First!" mantra evoked by the Trump administration when justifying their foreign policy worldview. As of $1 / 3 / 17$, they wanted to cut funding to US foreign aid unless a clear case can be built that it benefits the US more.

2 For the ease of narration, I use the noun primary recipients as a concept and italicize it as Primary recipient when using it as a variable. I do likewise for secondary recipients. All the variables in this chapter are formatted in the same manner.

3 The AidData website is available here: http://aiddata.org/ (last accessed 11/2/17).

4 Polity IV does have variables that record the date of regime change. However, the validity and precision of such data are contested. By contrast, the use of country-year is established. The validity of the established measures in Polity IV has been compared with other prominent datasets in Collier and Adcock (1999). Here, I adopt a more conservative approach using country-year as the level of analysis.

5 The OECD Credit Reporting System (CRS) is available at www.oecd.org/dac/stats/ idsonline.htm (last accessed 11/12/14).

6 This information is captured by the variable goal in the dataset. In this chapter, I do not focus on non-democracy aid. I return to those other categories in a subsequent chapter and will operationalize the goal variable in greater detail.

7 The codebook for AidData 2.0 explicitly warned that the values of aid commitments and aid disbursement do not tally even within the same project. Consider:

In the case of CRS information, many disbursement records cannot at present be reliably linked to commitment records for the same project. . . . But at present, records that only include disbursements are excluded from the AidData dataset. This means that disbursement sums for OECD members do not reflect the values reported by the donor.

(AidData User's Guide, Version 2.0, page 12, released 17/11/2011)

To the best of my knowledge, AidData does not upload the codebook for 2.0 any more at http://aiddata.org/aiddata-research-releases (last accessed 10/3/17). Scholars who wish to verify the AidData 2.0 codebook can email me at my institutional email for my copy of the codebook. Furthermore, AidData no longer codes for aid disbursements and concentrates only on aid commitments in AidData 3.0 (AidData 3.0 Codebook, page 20, http://aiddata.org/aiddata-research-releases, last accessed 10/3/17). This reinforces the decision to use aid commitments.

8 The lower limit of 1973 is inherited from AidData 2.1 while the upper limit of 2006 is inherited from the "S" Affinity scores. A further limiting factor is 13 missing values in the recipient's GDP that is inherited from Penn World Tables version 8.0.

9 For example, in the diplomatic buildup to the 2nd Gulf War, Germany did not support the US decision to invade Iraq. 
10 The name of the variable is meant to denote the concept of affinity as a reward for recipients who vote the same way as donors. The shortened name is necessary to conserve space in subsequent tables in Chapter 3.

11 The name of the variable is meant to denote the concept of affinity as a bribe to persuade recipients to vote the same way as donors. The shortened name is necessary to conserve space in subsequent tables in Chapter 3.

12 The name of this variable is deliberate. Previous operations to square and subtract 1 from the raw "S" Affinity score took up the second name slot. That is why I start with "UN3" for this particular variable.

13 The logic behind the construction of both commercial and strategic values is the same. The goal is to build a composite index of each recipient's overall value to the donor. This construction echoes the logic behind the construction of the winning coalition in the selectorate theory (Bueno de Mesquita et al. 2003: 134-135).

14 Penn World Tables has multiple variables for estimating national products. I use in this case the "rgdpe" variable.

15 In brief, democracy aid is aid where the main sector of focus is "government and civil society". Such projects have purpose codes between 15000 to 15200 .

16 Receipt of democracy aid in this case does not refer to the physical receipt of the funds (which would be classified as aid disbursements), it means the recipient has nominally accepted aid projects with democracy promotion as its stated goals. As will be clarified shortly, I am less interested in summed monetary values (whether in aid commitments or aid disbursements) than in the fact the recipient chose to accept the aid.

17 The same values are also missing in the Penn World Tables 9.0.

\section{Bibliography}

Achen, Christopher. 2002. "Toward a New Political Methodology: Microfoundations and ART." Annual Review of Political Science 5: 423-450.

Barbieri, Katherine, and Omar Keshk. 2012. "Correlates of War Project Trade Data Set Codebook, Version 3.0." Correlates of War Project Trade Data Set Codebook, Version 3.0. http://correlatesofwar.org

Bermeo, Sarah Blodgett. 2016. "Aid Is Not Oil: Donor Utility, Heterogeneous Aid, and the Aid-Democratization Relationship.” International Organization 70: 1-32.

Brambor, Thomas, William Roberts Clark, and Matt Golder. 2006. "Understanding Interaction Models: Improving Empirical Analyses.” Political Analysis 14 (Winter): 63-82.

Bueno de Mesquita, Bruce. 1981. The War Trap. New Haven: Yale University Press.

Bueno de Mesquita, Bruce, Alastair Smith, Randolph M. Siverson, and James D. Morrow. 2003. The Logic of Political Survival. Cambridge, MA: MIT Press.

Bueno de Mesquita, Bruce, and Alastair Smith. 2009a. "A Political Economy of Aid." International Organization 63: 309-340.

Bueno de Mesquita, Bruce, and Alastair Smith. 2009b. "Political Survival and Endogenous Institution Change." Comparative Political Studies 42: 167-197.

Bueno de Mesquita, Bruce, and Alastair Smith. 2016. "Competition and Collaboration in Aid-for-Policy Deals.” International Studies Quarterly. doi:10.1093/isq/sqw011.

Bush, Sara. 2015. The Taming of Democracy Assistance: Why Democracy Promotion Does Not Confront Dictators. Cambridge: Cambridge University Press.

Carothers, Thomas. 2015. "Democracy Aid at 25: Time to Choose." Journal of Democracy 26: 59-73.

Clark, T. S., and D. A. Linzer. 2015. "Should I Use Fixed or Random Effects?" Political Science Research and Methods 3: 399-408. 
Collier, David, and Robert Adcock. 1999. "Democracy and Dichotomies: A Pragmatic Approach to Choices About Concepts." Annual Review of Political Science, 537-565.

Feenstra, R. C., R. Inklaar, and M. P. Timmer. 2013. "The Next Generation of the Penn World Table." Groningen Growth and Development Centre. www.ggdc.net/pwt/.

Gartzke, E. 2000. "Preferences and the Democratic Peace." International Studies Quarterly 44: 191-212.

Gartzke, E., D. Jo, and R. Tucker. 1999. “The Similarity of UN Policy Positions, 1946-96, Version 1.17." The Similarity of UN Policy Positions, 1946-96, Version 1.17. www. vanderbilt.edu/rtucker/data/affinity/un/similar.

Marshall, Monty G., and Keith Jaggers. 2014. Polity IV Project: Political Regime Characteristics and Transitions, 1800-2013. The Polity IV dataset. www.systemicpeace.org/ inscrdata.html.

Mayer, T., and S. Zignago. 2011. "Working Papers 2011-25." Chap. Notes on CEPII's Distances Measures: The GeoDist Database. CEPII research center. www.cepii.fr/ anglaisgraph/bdd/distances.htm.

Moyo, D. 2010. Dead Aid: Why Aid Makes Things Worse and How There Is Another Way for Africa. London: Penguin Books.

Munck, Gerardo L., and Jay Verkuilen. 2002. "Conceptualizing and Measuring Democracy: Evaluating Alternative Indices.” Comparative Political Studies 35: 5-34.

Przeworski, Adam, Michael E. Alvarez, Jose Antonio Cheibub, and Fernando Limongi. 2000. Democracy and Development: Political Institutions and Well-Being in the World, 1950-1990. New York: Cambridge University Press.

Ray, J. L. 2003. "Explaining Conflict and War: What Should Be Controlled for?" Conflict Management and Peace Science 20: 21-31.

Soesastro, Hadi. 2004. "Sustaining East Asia's Economic Dynamism: How Aid Worked." CSIS Working Paper. www.csis.or.id/papers/wpe084.

Tierney, M. J., D. L. Nielson, D. G. Hawkins, J. T. Roberts, M. G. Findley, R. M. Powers, B. Parks, S. E. Wilson, and R. L. Hicks. 2011. "More Dollars than Sense: Refining Our Knowledge of Development Finance Using Aid data." World Development 39: 1891-1906. 


\section{The components of salience}

\section{Introduction}

Since recipients are not equally endowed, their leverage in bargaining vis-à-vis donors must necessarily vary. Policymakers should make use of this fact to nudge authoritarian regimes towards democracy. The theory asserts that recipients who possess the strategic and commercial attributes that donors desire should be more resistant to donor pressure and less likely to liberalize. Conversely, recipients who lack those valuable attributes should be more vulnerable to donor pressure and hence more likely to liberalize. For narrative convenience, I term those in the first group, primary recipients and those in the second group, secondary recipients.

Previous chapters presented empirical evidence that the difference in outcomes for Primary and Secondary recipients are systemic at both the global and regional levels. While this is reassuring from the perspective of theory-testing, from the perspective of policymaking, more pragmatic concerns can yet be raised.

By way of an analogy, consider a hypothetical realist-style theory that seeks to explain alliance dynamics. This hypothetical theory could argue that countries with a strong military provide more value to the military alliance. Consequently, such countries have more leverage within the alliance. A policymaker might seek to determine which specific military assets - the army, navy, or the air force - yield the most leverage for the country who possesses them. Likewise, the policymaker might want to know which force structure - that is, the combination of air, naval, and land units that generate the most leverage for a given country within a military alliance.

Likewise, a policymaker invested in democracy promotion may observe that aid recipients they deal with do not fit within the ideal types of primary and secondary recipients. Recipients may not only be valuable or valueless to donors; they may have partial salience too. For example, if a given recipient provides donors with economic benefits but lacks strategic value, is it a suitable target for democracy promotion? Likewise, we could flip the attribute set of the recipient and ask if a recipient that is in a strategic location but otherwise lacks economic value is a suitable target for democracy promotion. At a more granular level, if a given recipient has only one specific attribute - say it is a vital source of a rare mineral from which donors import - does that grant the recipient more leverage 
vis-à-vis donor, compared to another recipient with a different attribute, such as a recipient in the donor's neighborhood?

In the main, these are not theoretical questions. Rather, they originate from the policy realities that decision makers work with. I have in mind the typical section head of a foreign ministry with a limited budget for democracy promotion. Such policymakers do not choose a suitable recipient-target among a buffet of options drawn throughout the world. Rather, they are faced with a recipient with a specific combination of attributes and must make a choice whether to apply donor pressure given the likely pushback from the authoritarian aid recipient.

In this context, the implications for theory building are limited. The theory asserts that recipients with both commercial and strategic attributes that donors value have bargaining power. The goal was to identify the recipients that lack both sets of attributes as the group that is susceptible to donor pressure and hence likely to liberalize. The theory is otherwise agnostic over the exact composition of those attributes. I could find that a specific attribute or a particular attribute set generates salience. Conversely, I could also find no one specific attribute or particular attribute set generates salience. Neither group of findings by themselves constitutes a falsification of the theory. This is because the emphasis of the theory is on the effects of the recipient's salience on aid dynamics (and how that affects the subsequent liberalization) and not on the determinants of such salience.

Therefore, the goal of this chapter is to investigate the relative importance of those attributes, either individually or in attribute sets, in inoculating the recipient against donor pressure. This, in turn, helps us to estimate the likelihood that the recipient under pressure will undergo the subsequent reforms. Policy-wise, the objective is to help the policymakers allocate aid where donors have the leverage given the specific attributes of the recipient.

Given the exploratory nature of this investigation, the structure of this chapter is different from preceding chapters. It is organized around four empirical questions. The first explores whether any of the six components of recipient salience yield disproportionate leverage for the recipient. Upon finding that only one of the components is statistically significant, I focus my inquiry on composite indices. The second question compares four aggregation rules used to determine recipient salience. I find the default aggregation rule to be more useful. The third question asks whether economic or strategic determinants of salience yield more leverage for the recipient. The statistical significance of the economic attribute set invites further research. I investigate whether the significance of the attribute sets varies over the Cold War. Thus, the approach is iterative, each attempt to answer a question opens up new questions and additional ways to explore the data. Empirically, the aim is to explore both i) the determinants of salience that allow some recipients to be classified as important (Primary) or not (Secondary) and ii) the different ways of aggregating the components of recipient status.

The rest of the chapter is as follows. I start with an overview of the data. Since I am using data from previous chapters, the emphasis will be on the new variables 
introduced in this chapter. This is followed by an elaboration on the theoretical expectations given the new variables. I then present the results and discuss them. I summarize my findings and discuss the policy implications at the end.

\section{Data, variables, and method}

The theory links the commitment of democracy aid to the subsequent political liberalization by aid recipients. The data on regime characteristics of recipients are drawn from Polity IV (Marshall and Jaggers 2014) and the data on aid commitments is drawn from AidData (Tierney et al. 2011). The building of the dataset follows the procedures described previously in Chapter $2 .{ }^{1}$ The resultant dataset contains time-series cross-sectional data on aid commitments by donors, recipients' regime characteristics, and the salience relationships between donors and recipients from the years 1973 to 2006 with a total of 2091 observations. The unit of analysis is the recipient-year.

There is one change in the version of the dataset used for this chapter. Since Polity IV only accords one regime score to a country per year, known as Polity2 in the Polity dataset, and a given aid recipient can receive multiple aid projects per year, it is necessary to convert the data into a country-year format. Before data conversion, I generated variables (explained in Chapter 2) to capture information on the relationships between recipients and donors. I kept those variables after the data conversion. In this way, dyadic information on the importance of the recipients to donors is preserved when the dataset is converted into a monadic format. In prior chapters, this step was used to preserve information on the salience of recipients to donors using composite indices. In this chapter, I include information on the six component indicators that were subsequently used to construct the composite indices. These additions allow me to conduct a disaggregated analysis of the components of salience.

\section{Key variables}

The dependent variable, represented by the variable, regimechange5, captures the extent of liberalization in the recipient five years after the commitment of aid. The control variables are meant to account for factors that might affect both aid allocation and the subsequent regime change. The first control variable is the development level of the recipient, measured as the natural logarithm of the GDP per capita of the recipients, and represented by the variable, GDP per capita. As explained in the previous chapter, this particular data has missing values. To facilitate subsequent analysis in this chapter, I constrain the number of observations for the key variables to 2091.

The second control variable is the international context. It captures the notion that recipients have more options during the Cold War. It is represented by the binary variable, Cold War. It has a value of 1 if the year of aid commitment is before 1991 and a value of 0 otherwise. 
I have three main types of independent variables: the status of the recipients (Primary or Secondary recipients), the application of donor pressure, and the interactions between them.

On donor pressure, I make use of the fact that democracy aid is different from other types of developmental objectives as it entails political costs for an authoritarian recipient. Since authoritarian recipients could have walked away from the aid deal, their acceptance of democracy aid implies the exertion of donor pressure. To capture this, I generate the variable, Democratic Push, that has a value of 1 if the recipient in question has accepted any democracy aid project for that year and a value of 0 otherwise.

One of the two research foci of this chapter is to understand the determinants of recipient salience. In previous chapters, I used composite indices to aggregate the strategic and commercial value that recipients provide to donors. The strategic value of the recipient is derived from i) its geographic proximity to the donors, ii) its population size, and iii) its affinity or its propensity to share preferences with the donors. The economic value of the recipient is derived from its value to donors as i) a source of imports, ii) a destination for exports, and iii) from the size of its economy.

The operationalization for the six components is almost identical (and described in detail in Chapter 2). For each component, I used the appropriate variable from the relevant dataset to capture the salience relationship. I standardized that variable so as to facilitate comparison across indicators. At this stage of data construction, the variables are continuous. I impose cutoff points along the standardized variable to denote recipients of significant importance. The default threshold used is set at $75 \%$ of the standardized distribution. Recipient-years that fall within that upper $25 \%$ of that standardized distribution are considered significant. The remaining recipient-years that constitute the other $75 \%$ of standardized distribution are considered nonsignificant. I also use different cutoffs so that different thresholds of salience can be generated for the purposes of robustness checks. ${ }^{2} \mathrm{By}$ this stage of data construction, the variables are binary. They have a value of 1 if they meet the threshold for salience and a value of 0 otherwise. In this manner, I generated a series of binary indicator variables for each of the six components.

Specifically, I use the procedure to generate variables, Distpol50, Distpol75, and Distpol90, to capture geographic proximity and I generate variables, Pop50, Pop 75, and Po90, to capture the population size of recipients. Likewise, I generate variables, UN50, UN75, and UN90, to capture state affinity. On the commercial value side, I use the same procedure to generate variables, Importsig50, Importsig75, and Importsig90, to capture the importance of the recipient as a source of imports. I do the same for exports, generating the variables, Exportsig50, Exportsig75, and Exportsig90. Finally, I apply the procedure to generate variables, $G d p 50, G d p 75$, and $G d p 90$, to capture the recipient's economic size.

These variables are binary in nature because my theoretical concern in prior chapters is to demarcate recipients with high salience from the recipients with low salience. We want to use these variables to help us compare between different composite indices. 
Moreover, we want to investigate further here. Instead of focusing on the demarcation between Primary and Secondary recipients, we can drill down to components of salience themselves. Are some components more significant for salience than others? If so, what can policymakers do about it? To answer such questions, I draw upon the standardized variables - that are used as the building blocks for the binary indicators - because these standardized variables are continuous in nature.

Thus, to capture recipient proximity, I use the Distance variable, which is the standardized distance subcomponent used to construct the variables, Distpol50, Distpol75, and Distpol90. Likewise, to capture the influence of the recipient's population size, I use the standardized population subcomponent, Population. The situation for state affinity is slightly more complex because there are two possible interpretations of how foreign aid interacts with state preferences. ${ }^{3}$ Donors could allocate aid as a reward to recipients for voting similarly with them in the United Nations General Assembly. This is the default conception that is used in analysis thus far. Alternatively, donors could use aid as a bribe to persuade moderate recipients to change their preferences to vote alongside the donors at the UN General Assembly. To capture the notion of aid as a reward, I use the Reward variable, which is the default standardized affinity subcomponent. To capture the alternative notion of aid as a bribe, I use the Bribe variable, which is an alternative standardized affinity subcomponent.

On the commercial side, I use the GDP variable to capture the economic size of the recipient. To capture the value of the recipient as a trading partner, I use the Importshare variable, which represents the standardized trade ratios for imports from recipients, and I use the Exportshare variable, which represents the standardized trade ratios for exports to the recipients.

The theory argues the effect of donor pressure is different depending on whether it is applied to Secondary recipients or on Primary recipients. The structure of the argument calls for interaction effects. Therefore, the pertinent interaction terms have to be generated.

To capture the interaction effect for geographic proximity, I multiply donor pressure with proximity to generate the interaction term, Democratic Push $\times$ Distance. To capture the interaction effect for population size, I multiply donor pressure with the recipient's population size to generate the interaction term, Democratic Push $\times$ Population. To capture the interaction effect with aid as a reward, I multiply donor pressure with the default concept of state affinity to generate the interaction term, Democratic Push $\times$ Reward. To capture the interaction effect with aid as a bribe, I multiply donor pressure with the alternative affinity concept of state affinity to generate the interaction term, Democratic Push $\times$ Bribe.

I do likewise for commercial components. To capture the interaction effect for economic size, I multiply donor pressure with the recipient's economic size to generate the interaction term, Democratic Push $\times G D P$. To capture the interaction effect with imports, I multiply donor pressure with the trade ratios for imports to generate the interaction term, Democratic Push $\times$ Importshare. To capture the 
interaction effect with exports, I multiply donor pressure with the trade ratios for exports to generate the interaction term, Democratic Push $\times$ Exportshare.

The second research focus of the chapter is over the different aggregation rules for the composite index. The question is how the default composite index stacks up against the alternatives. To begin, I use the same aggregation rules discussed in Chapter 2 to determine the strategic value (Strategic Value) and commercial value (Commercial Value). The core of my argument emphasizes the salience of a recipient to the donor as a function of the recipient's strategic and commercial attributes. A straightforward interpretation is to treat a country with both sets of attributes as a recipient that is likely to be valued by the donor. Therefore, the default aggregation rule is that a country is a Primary recipient if it has both strategic value (Strategic Value $=1$ ) and commercial value (Commercial Value $=1$ ) to all its donors for a given year. A country is a Secondary recipient if it lacks strategic value (Strategic Value $=0$ ) and commercial value (Commercial Value $=0$ ) to all its donors for a given year.

We can relax the assumption that the recipient needs both sets of attributes to be deemed important by donors. It may be the case that a given country needs only to score high enough on either set of attributes in order to persuade a donor to make an aid offer. For example, Pakistan is important to the US as an arena for counterterrorism operations. The US decision to give aid to Pakistan is driven primarily by its security considerations rather than by its economic considerations. By contrast, Mexico is the third largest trading partner to the US. US aid to Mexico is correspondingly driven primarily by economic considerations rather than by security considerations. Both aid recipients, Pakistan and Mexico need only to be valued in one domain (economic or security) in order to persuade the US of its salience. To capture this notion, I create a dummy variable, EitherPrimary, that has a value of 1 if the recipient has either commercial or strategic value (either Strategic Value $=1$ and/or Commercial Value $=1$ ) and a value of 0 otherwise (both Strategic Value $=0$ and Commercial Value $=0$ ).

We can go further - it might even be the case that recipients only need a specific attribute set, strategic or commercial, to be valuable to donors. There is historical precedence for this. It has been argued, for example, in aid scholarship that the Cold War hindered the effective use of aid for democracy promotion (Bueno de Mesquita and Smith 2016; Bermeo 2016; Dunning 2004). Authoritarian recipients who dislike the political conditionality of Western aid could turn to the Soviet Union for aid. In such an international context, clients in strategic locations (Egypt with its Suez Canal), or with key military bases (Vietnam's Cam Ranh Bay, an important deepwater bay) would have more leverage. One interpretation of the impact of the Cold War, therefore, is that the strategic attributes of recipients are especially valued during that period.

That said, it is possible to argue that commercial attributes were also valued by donors during the Cold War. Take for example, the argument of George Kennan, an American statesman who is widely credited as the intellectual founder of the Containment Policy adopted by the United States during the Cold War. In his famous Long Telegram (Kennan 1947), ${ }^{4}$ Kennan argued that the Soviet Union that 
is captured by communist ideology is fundamentally hostile but its threat can be managed since the balance of forces favors the West in the long run. Specifically, Kennan (1947) asserts:

It is entirely possible for the United States to influence by its actions the internal developments, both within Russia and throughout the international Communist movement, by which Russian policy is largely determined. . . It is rather a question of the degree to which the United States can create among the peoples of the world generally the impression of a country which knows what it wants, which is coping successfully with the problem of its internal life and with the responsibilities of a World Power, and which has a spiritual vitality capable of holding its own among the major ideological currents of the time. To the extent that such an impression can be created and maintained, the aims of Russian Communism must appear sterile and quixotic, the hopes and enthusiasm of Moscow's supporters must wane, and added strain must be imposed on the Kremlin's foreign policies. For the palsied decrepitude of the capitalist world is the keystone of Communist philosophy.

(emphasis added)

Kennan's basic idea is to reinforce the Western strengths in the economic and social sphere and let the communist system collapse from its own contradictions. There is a distinctive non-military orientation to his grand strategy. For him, the Cold War is primarily an ideological struggle. In this contest, it is not just the geostrategic value of the recipient that appeals to Western donors. The recipient's potential and ability to demonstrate success in navigating the challenges of modernity, or as Kennan phrases it, "coping successfully with the problem of its internal life" is also important. One way to demonstrate success is through economic development. Recipients that developed using the Western model, and are integrated into the Western capitalist system, importing and exporting to the global market, are useful to the West. They showcase the ideological superiority of the Western development model. During the Cold War, they were ways of demonstrating ideological superiority through economic performance.

To capture the notion that a recipient can be valuable for its commercial attributes only, I create a dummy variable, the Economically Valuable recipient, that has a value of 1 if the recipient has commercial value (Economic Value $=1)$ and a value of 0 (Economic Value $=0)$ otherwise. To capture the notion a recipient can be valuable for its strategic attributes only, I create a dummy variable, the Strategically Valuable recipient, that has a value of 1 if the recipient has strategic value (Strategic Value $=1)$ and a value of $0($ Strategic Value $=0)$ otherwise.

If we think of the master data as different combinations of strategic value (Strategic Value) and commercial value (Economic Value), we get a classic two-bytwo table represented by Table 3.1. The table shows how each of four rules of aggregation - reflecting their respective conception of recipient salience - has a different permutation of strategic and commercial value. The default measure 
(Primary and Secondary recipients) is different from the other three measures in that it emphasizes only two of the four cells of information in Table 3.1. By contrast, the other three aggregation rules utilize all four cells of information in Table 3.1. This is intentional. The theory claims that recipients who are deemed important by donors have more leverage and those deemed unimportant have less leverage. For that purpose, we want an operationalization that sets a high bar to be considered as important. This is why I require the presence of both sets of attributes to be considered as a Primary recipient. The theory is otherwise agnostic on the exact composition of the salience (although we will explore this issue in this chapter).

As before, interaction terms are necessary. Thus, I multiply donor pressure with primary recipients to generate the interaction term, Democratic Push $\times$ Primary. I do likewise for Secondary recipients generating the interaction term, Democratic Push $\times$ Secondary. To capture the interaction effects for the second measure, I multiply donor pressure by recipients with any of the two attributes sets to generate the interaction term, Democratic Push $\times$ Eitherprimary. To capture the interaction effects for the third measure emphasizing economics, I multiply donor pressure with recipients with high commercial value to generate the interaction term, Democratic Push $\times$ Economically Valuable. To capture the interaction effects for the fourth measure emphasizing geostrategy, I multiply donor pressure

Table 3.1 Four Measures of the Recipient Status with Different Emphasis

Measure 1 (both economic and strategic value)

\begin{tabular}{|c|c|c|c|}
\hline & & \multicolumn{2}{|l|}{ Economic Value } \\
\hline & & Yes & No \\
\hline Strategic Value & $\begin{array}{l}\text { Yes } \\
\text { No }\end{array}$ & Primary recipient $=1$ & Secondary recipient $=1$ \\
\hline Measure 2 (eith & onom & $\begin{array}{l}\text { strategic value) } \\
\text { Economic Value } \\
\text { Yes }\end{array}$ & No \\
\hline Strategic Value & $\begin{array}{l}\text { Yes } \\
\text { No }\end{array}$ & $\begin{array}{l}\text { EitherPrimary }=1 \\
\text { EitherPrimary }=1\end{array}$ & $\begin{array}{l}\text { EitherPrimary }=1 \\
\text { EitherPrimary }=0\end{array}$ \\
\hline Measure 3 (only & nomic & $\begin{array}{l}\text { ue) } \\
\text { Economic Value } \\
\text { Yes }\end{array}$ & No \\
\hline Strategic Value & $\begin{array}{l}\text { Yes } \\
\text { No }\end{array}$ & $\begin{array}{l}\text { Economically Valuable }=1 \\
\text { Economically Valuable }=1\end{array}$ & $\begin{array}{l}\text { Economically Valuable }=0 \\
\text { Economically Valuable }=0\end{array}$ \\
\hline Measure 4 (only & tegic & $\begin{array}{l}\text { e) } \\
\text { Economic Value } \\
\text { Yes }\end{array}$ & No \\
\hline Strategic Value & $\begin{array}{l}\text { Yes } \\
\text { No }\end{array}$ & $\begin{array}{l}\text { Strategically Valuable }=1 \\
\text { Strategically Valuable }=0\end{array}$ & $\begin{array}{l}\text { Strategically Valuable }=1 \\
\text { Strategically Valuable }=0\end{array}$ \\
\hline
\end{tabular}


Table 3.2 Summary Statistics for the Main Independent Variables

\begin{tabular}{|c|c|c|c|c|c|}
\hline Variable & Observations & Mean & $\begin{array}{l}\text { Standard } \\
\text { Deviation }\end{array}$ & Minimum & Maximum \\
\hline $\begin{array}{l}\text { Primary } \\
\text { (recipient) }\end{array}$ & 2091 & 0.163 & 0.369 & 0 & 1 \\
\hline $\begin{array}{l}\text { Secondary } \\
\text { (recipient) }\end{array}$ & 2091 & 0.568 & 0.496 & 0 & 1 \\
\hline $\begin{array}{l}\text { Either Primary } \\
\text { (recipient) }\end{array}$ & 2091 & 0.596 & 0.491 & 0 & 1 \\
\hline $\begin{array}{l}\text { Economically } \\
\text { Valuable } \\
\text { (recipient) }\end{array}$ & 2091 & 0.344 & 0.475 & 0 & 1 \\
\hline $\begin{array}{l}\text { Strategically } \\
\text { Valuable } \\
\text { (recipient) }\end{array}$ & 2091 & 0.501 & 0.500 & 0 & 1 \\
\hline GDP (recipient) & 2091 & -0.102 & 0.787 & -0.268 & 13.425 \\
\hline $\begin{array}{l}\text { Importshare } \\
\text { (recipient) }\end{array}$ & 2091 & 0.011 & 0.891 & -0.251 & 15.216 \\
\hline $\begin{array}{l}\text { Exportshare } \\
\text { (recipient) }\end{array}$ & 2091 & 0.024 & 1.030 & -0.284 & 22.288 \\
\hline $\begin{array}{l}\text { Distance } \\
\quad \text { (proximity) }\end{array}$ & 2091 & 0.004 & 1.000 & -3.372 & 2.074 \\
\hline $\begin{array}{l}\text { Population } \\
\text { (recipient) }\end{array}$ & 2091 & -0.135 & 0.707 & -0.307 & 6.549 \\
\hline Reward (affinity) & 2091 & -0.120 & 0.984 & -4.002 & 2.320 \\
\hline Bribe (affinity) & 2091 & 0.152 & 0.892 & -5.188 & 1.180 \\
\hline
\end{tabular}

with recipients with strategic value to generate the interaction term, Democratic Push $\times$ Strategically Valuable.

A summary of the parameters for the key independent variables is presented in Table 3.2. The seven subcomponent variables were standardized before the conversion of the data from a dyadic to a monadic format. After conversion, the values of those variables will, of course, vary.

\section{Theoretical expectations}

Although the theory is agnostic on the exact composition of salience, we can nevertheless outline some theoretical expectations to guide the interpretation of results that follow.

The basic idea is to model the recipient's subsequent political liberalization as a function of the recipient's status (Primary and Secondary), the exertion of donor pressure, and their respective interaction terms. I also use the development levels of the recipients and the Cold War context as control variables in such models. As is the case with previous chapters, I use country fixed effects in my models to control for the domestic political conditions that are idiosyncratic to specific recipients and which may induce political liberalization in those same recipients. 
Our first aim is to understand the determinants of recipient salience. To assess the influence of the subcomponents of salience, I run the basic model replacing recipient status with those six subcomponents and their respective interaction terms as the key independent variables. We want to know if the marginal effects for any of the six subcomponents have statistically significant relationships with the subsequent liberalization in the recipient. If none of the six components of salience has a statistically significant impact on the subsequent liberalization but the default aggregation rule does, then we can be confident that we are on the right track. If some of the subcomponents of salience turn out to be significant, we want to consider their practical policy implications. It is important to stress that the theory itself does not take a stand on the direction, whether positive or negative, of that relationship for subcomponents. Rather, the overall theoretical claim is that the default aggregation rule captures the components of salience reasonably well.

To account for the two ways to interpret the strategic use of foreign aid, I run the model twice. In the first model (Model 8 in Table 3.3), I use the variable, Reward, which captures the default notion of aid as a reward to recipients who happen to vote in the direction that donors prefer. In the second model (Model 9 in Table 3.3), I use the variable, Bribe, which captures the alternative notion of using aid as a bribe to persuade recipients to vote in the direction that donors prefer. Here, we want to know whether the relationship of interests is a consequence of our conception of affinity. If the results for the two models are similar, the use of different conceptions of state affinity is not driving the outcomes.

Our second aim is to explore how the alternative indices of salience stack up against the default index (Primary and Secondary recipients). The theory argues that the effect of donor pressure is different depending on the status of the recipient, that is, whether the recipient is Secondary or Primary. Empirically, we should observe that the marginal effect of aid on liberalization for Secondary recipients is significant, statistically speaking, from their Primary counterparts. We have evidence from Chapter 2 (Model 3 in Table 2.4) that this is true under the default index. The issue is how the alternative indices stack up against the default. The empirical expectations tested in Table 3.4 have to take into account the fact that the three alternative indices - Eitherprimary, Economically Valuable, and Strategically Valuable - are constructed as continuous measures of salience. For these alternative indices, the test is whether the marginal effect of aid on liberalization on recipients filtered using these same alternative indices is statistically significant. If the marginal effects are all found not to be statistically significant, we gain confidence in our default index since it is able to filter between recipients in a manner that the alternative indices were not able to.

If any of the alternative indices generate a marginal effect that is statistically significant, follow-up analyses are warranted. In Table 3.5, we test the strategic and economic attribute sets together in a combined pool of recipients. This allows us to ask three questions. We want to know if the marginal effect of aid on the subsequent liberalization in recipients filtered on economic importance is statistically significant. Likewise, we do the same test for recipients filtered on strategic importance. Finally, we can compare the marginal effects for both groups of 
Table 3.3 The Effect of Individual Components of Salience on the Subsequent Regime Change in Aid Recipients

\begin{tabular}{|c|c|c|}
\hline TSCS; Fixed Effect & $\begin{array}{l}\text { Model 8: Affinity } \\
\text { as Reward }\end{array}$ & $\begin{array}{l}\text { Model 9: Affinity } \\
\text { as Bribe }\end{array}$ \\
\hline (Recipient) Proximity & $\begin{array}{l}-0.138 \\
(0.193)\end{array}$ & $\begin{array}{l}-0.094 \\
(0.175)\end{array}$ \\
\hline (Recipient) Population & $\begin{array}{l}3.761 \\
(3.264)\end{array}$ & $\begin{array}{c}3.793 \\
(3.253)\end{array}$ \\
\hline (Recipient) Affinity & $\begin{array}{c}0.228 \\
(0.171)\end{array}$ & $\begin{array}{l}-0.208 \\
(0.165)\end{array}$ \\
\hline GDP (logged, recipient) & $\begin{array}{c}2.227 \\
(1.574)\end{array}$ & $\begin{array}{c}2.299 \\
(1.574)\end{array}$ \\
\hline Import (from Recipient) & $\begin{array}{l}-0.079 \\
(0.319)\end{array}$ & $\begin{array}{l}-0.113 \\
(0.316)\end{array}$ \\
\hline Export (from Recipient) & $\begin{array}{c}0.124 \\
(0.235)\end{array}$ & $\begin{array}{c}0.100 \\
(0.235)\end{array}$ \\
\hline Democratic Push & $\begin{array}{c}0.549^{*} \\
(0.259)\end{array}$ & $\begin{array}{c}0.596^{*} \\
(0.261)\end{array}$ \\
\hline Proximity $\times$ Democratic Push & $\begin{array}{l}-0.257 \\
(0.196)\end{array}$ & $\begin{array}{l}-0.369^{*} \\
(0.187)\end{array}$ \\
\hline Population $\times$ Democratic Push & $\begin{array}{c}0.765 \\
(0.968)\end{array}$ & $\begin{array}{c}0.767 \\
(0.968)\end{array}$ \\
\hline Affinity $\times$ Democratic Push & $\begin{array}{l}-0.396^{*} \\
(0.199)\end{array}$ & $\begin{array}{c}0.077 \\
(0.204)\end{array}$ \\
\hline GDP $\times$ Democratic Push & $\begin{array}{l}-2.959 \\
(1.522)\end{array}$ & $\begin{array}{l}-3.056^{*} \\
(1.523)\end{array}$ \\
\hline Import $\times$ Democratic Push & $\begin{array}{c}0.450 \\
(0.392)\end{array}$ & $\begin{array}{c}0.512 \\
(0.390)\end{array}$ \\
\hline Export $\times$ Democratic Push & $\begin{array}{l}-0.280 \\
(0.294)\end{array}$ & $\begin{array}{l}-0.240 \\
(0.295)\end{array}$ \\
\hline GDP per capita (logged, recipient) & $\begin{array}{c}0.595^{*} \\
(0.273)\end{array}$ & $\begin{array}{c}0.571^{*} \\
(0.273)\end{array}$ \\
\hline Cold War & $\begin{array}{c}0.128 \\
(0.232)\end{array}$ & $\begin{array}{c}0.182 \\
(0.231)\end{array}$ \\
\hline Constant & $\begin{array}{l}-2.466 \\
(2.063)\end{array}$ & $\begin{array}{l}-2.314 \\
(2.062)\end{array}$ \\
\hline $\mathrm{N}$ & 2091 & 2091 \\
\hline Within R-squared & 0.031 & 0.030 \\
\hline Prob $>F$ & 0.000 & 0.000 \\
\hline
\end{tabular}

** Significant at .01 level, two-tailed

* Significant at .05 level, two-tailed

() standard errors

recipients against each other and ask if the difference between them is statistically significant. If none of the three tests yields statistically significant results, we can be confident that neither attribute set alone is responsible for the heavy lifting behind recipient salience.

If either the economic or the strategic attribute set turns out to have a statistically significant effect on the subsequent liberalization, a follow-up query is to 
Table 3.4 Comparing the Effects of Four Measures of Recipient Salience

\begin{tabular}{|c|c|c|c|c|}
\hline TSCS; Fixed Effect & $\begin{array}{l}\text { Model 10: } \\
\text { Default measure }\end{array}$ & $\begin{array}{l}\text { Model 11: } \\
\text { Either Economic } \\
\text { or Strategic }\end{array}$ & $\begin{array}{l}\text { Model 12: } \\
\text { Strategically } \\
\text { Valuable }\end{array}$ & $\begin{array}{l}\text { Model 13: } \\
\text { Economically } \\
\text { Valuable }\end{array}$ \\
\hline $\begin{array}{l}\text { Primary } \\
\text { (recipient) }\end{array}$ & $\begin{array}{l}-0.810 \\
(0.583)\end{array}$ & & & \\
\hline $\begin{array}{l}\text { Secondary } \\
\quad \text { (recipient) }\end{array}$ & $\begin{array}{c}0.181 \\
(0.414)\end{array}$ & & & \\
\hline $\begin{array}{l}\text { Either Primary } \\
\text { (recipient) }\end{array}$ & & $\begin{array}{c}0.477 \\
(0.336)\end{array}$ & & \\
\hline $\begin{array}{l}\text { Economically Valuable } \\
\text { (recipient) }\end{array}$ & & & & $\begin{array}{c}0.767^{*} \\
(0.379)\end{array}$ \\
\hline $\begin{array}{l}\text { Strategically Valuable } \\
\text { (recipient) }\end{array}$ & & & $\begin{array}{l}1.007 * * \\
(0.327)\end{array}$ & \\
\hline Democratic Push & $\begin{array}{l}0.862 * \\
(0.380)\end{array}$ & $\begin{array}{l}1.415^{* *} \\
(0.299)\end{array}$ & $\begin{array}{l}1.411 * * \\
(0.273)\end{array}$ & $\begin{array}{l}1.206^{* *} \\
(0.248)\end{array}$ \\
\hline $\begin{array}{l}\text { Democratic Push } \times \\
\text { Primary }\end{array}$ & $\begin{array}{r}-0.541 \\
(.619)\end{array}$ & & & \\
\hline $\begin{array}{l}\text { Democratic Push } \times \\
\text { Secondary }\end{array}$ & $\begin{array}{c}0.440 \\
(0.437)\end{array}$ & & & \\
\hline $\begin{array}{l}\text { Democratic Push } \times \\
\text { Either Primary }\end{array}$ & & $\begin{array}{l}-0.625 \\
(0.373)\end{array}$ & & \\
\hline $\begin{array}{l}\text { Democratic Push } \times \\
\text { Economically Valuable }\end{array}$ & & & & $\begin{array}{l}-0.534 \\
(0.395)\end{array}$ \\
\hline $\begin{array}{l}\text { Democratic Push } \times \\
\text { Strategically Valuable }\end{array}$ & & & $\begin{array}{l}-0.737^{*} \\
(0.366)\end{array}$ & \\
\hline $\begin{array}{l}\text { GDP per capita* (logged, } \\
\text { recipient) }\end{array}$ & $\begin{array}{l}0.824 * * \\
(0.273)\end{array}$ & $\begin{array}{c}0.622 * \\
(0.264)\end{array}$ & $\begin{array}{l}0.632^{*} \\
(0.264)\end{array}$ & $\begin{array}{l}0.828^{* *} \\
(0.270)\end{array}$ \\
\hline Cold War & $\begin{array}{c}0.097 \\
(0.211)\end{array}$ & $\begin{array}{c}0.090 \\
(0.211)\end{array}$ & $\begin{array}{c}0.128 \\
(0.211)\end{array}$ & $\begin{array}{c}0.141 \\
(0.211)\end{array}$ \\
\hline constant & $\begin{array}{l}-5.109 * \\
(2.081)\end{array}$ & $\begin{array}{l}-3.909 \\
(1.994)\end{array}$ & $\begin{array}{l}-4.217^{*} \\
(1.993)\end{array}$ & $\begin{array}{l}-4.934^{*} \\
(2.019)\end{array}$ \\
\hline $\mathrm{N}$ & 2091 & 2091 & 2091 & 2091 \\
\hline Within R-Squared & 0.023 & 0.020 & 0.023 & 0.025 \\
\hline Prob $>F$ & 0.000 & 0.000 & 0.000 & 0.000 \\
\hline F-Test & 0.003 & 0.557 & 0.285 & 0.000 \\
\hline
\end{tabular}

** Significant at .01 level, two-tailed

* Significant at .05 level, two-tailed

() standard errors

ask if this is due to the impact of the Cold War. I ran the regression model for recipients using each attribute set twice, once during the Cold War and once after it. This is reported in Models 15 to 18 in Table 3.6. What we are assessing is the statistical significance of the marginal effects for each attribute set for each period. If one attribute set, either economic or strategic, is consistently statistically significant during the Cold War and the period after it, we will have reason to focus on that particular attribute set as the driver of recipient salience. Conversely, if both attribute sets are not statistically significant for all time periods, we can be sure 
Table 3.5 A Critical Test of Economic and Strategic Salience

\begin{tabular}{lc}
\hline TSCS & $\begin{array}{c}\text { Model 14 } \\
\text { Critical Test }\end{array}$ \\
Fixed Effects & $0.955^{* *}$ \\
\hline Strategically Valuable & $(0.337)$ \\
$\quad$ (recipient) & $-0.939^{*}$ \\
Economically Valuable & $(0.387)$ \\
$\quad$ (recipient) & $1.453^{* *}$ \\
Democratic Push & $(0.283)$ \\
& -0.684 \\
Democratic Push $\times$ & $(0.385)$ \\
$\quad$ Strategically Valuable & -0.293 \\
Democratic Push $\times$ & $(0.416)$ \\
Economically Valuable & $0.845^{* *}$ \\
GDP per capita & $(0.270)$ \\
(logged, recipient) & 0.177 \\
Cold War & $(0.211)$ \\
& $-5.501^{* *}$ \\
constant & $(2.026)$ \\
& 2091 \\
N & 0.029 \\
Within R-Squared & 0.000 \\
Prob>F & 0.001 \\
Joint Test & \\
** Significant at .01 level, two-tailed \\
* Significant at .05 level, two-tailed \\
() standard errors
\end{tabular}

neither attribute set alone captures the notion of recipient salience. This, in turn, increases our confidence in the default aggregation rule. Our default aggregation rule, as the reader will recall, requires a recipient to possess both economic and strategic value to be considered important by the donors (a Primary recipient).

Overall, if the various disaggregated measure of recipient salience does not yield strong results in their favor, we have fewer reasons to believe these alternatives to be superior to our default measure of salience (Primary and Secondary). This is especially true given that we have subjected our default measure to a battery of tests in Chapter 2. The implicit empirical claim advanced in this chapter, therefore, is that the default measure fares relatively well against its alternatives.

\section{Results}

We want to understand the impact of individual subcomponents of salience. Table 3.3 presents the regression results using two variants for state affinity. For the model that treats aid as a reward for state affinity (Model 8 of Table 3.3), we observe that donor pressure on recipients to liberalize, or, Democratic Push, by itself increases the subsequent Polity score of recipients by 0.549 points. The probability that this result is by chance is 0.034 . The other relationship that is 
Table 3.6 The Effect of Economic and Strategic Salience, Controlling for the Cold War

\begin{tabular}{|c|c|c|c|c|}
\hline $\begin{array}{l}\text { TSCS } \\
\text { Fixed Effects }\end{array}$ & $\begin{array}{l}\text { Model } 15 \\
\text { Cold War }\end{array}$ & $\begin{array}{l}\text { Model } 16 \\
\text { Cold War }\end{array}$ & $\begin{array}{l}\text { Model } 17 \\
\text { Post-Cold War }\end{array}$ & $\begin{array}{l}\text { Model } 18 \\
\text { Post-Cold War }\end{array}$ \\
\hline $\begin{array}{l}\text { Strategically Valuable } \\
\text { (recipient) }\end{array}$ & & $\begin{array}{c}0.602 \\
(0.406)\end{array}$ & & $\begin{array}{l}2.269 * * \\
(0.674)\end{array}$ \\
\hline $\begin{array}{l}\text { Economically Valuable } \\
\text { (recipient) }\end{array}$ & $\begin{array}{l}-0.873 \\
(0.474)\end{array}$ & & $\begin{array}{c}0.565 \\
(0.845)\end{array}$ & \\
\hline Democratic Push & $\begin{array}{l}1.591 * * \\
(0.318)\end{array}$ & $\begin{array}{l}2.159 * * \\
(0.351)\end{array}$ & $\begin{array}{c}0.348 \\
(0.419)\end{array}$ & $\begin{array}{c}0.631 \\
(0.492)\end{array}$ \\
\hline $\begin{array}{l}\text { Democratic Push } \times \\
\text { Strategically Valuable }\end{array}$ & & $\begin{array}{l}-0.898 \\
(0.508)\end{array}$ & & $\begin{array}{l}-1.773^{*} \\
(0.695)\end{array}$ \\
\hline $\begin{array}{l}\text { Democratic Push } \times \\
\text { Economically Valuable }\end{array}$ & $\begin{array}{c}0.390 \\
(0.539)\end{array}$ & & $\begin{array}{l}-2.226^{* *} \\
(0.840)\end{array}$ & \\
\hline $\begin{array}{l}\text { GDP per capita } \\
\text { (logged, recipient) }\end{array}$ & $\begin{array}{l}2.309^{* *} \\
(0.625)\end{array}$ & $\begin{array}{l}2.343^{* *} \\
(0.624)\end{array}$ & $\begin{array}{c}0.174 \\
(0.363)\end{array}$ & $\begin{array}{l}-0.127 \\
(0.358)\end{array}$ \\
\hline constant & $\begin{array}{l}-15.656^{* *} \\
(4.667)\end{array}$ & $\begin{array}{l}-16.556^{* *} \\
(4.683)\end{array}$ & $\begin{array}{c}0.219 \\
(2.710)\end{array}$ & $\begin{array}{l}1.516 \\
(2.690)\end{array}$ \\
\hline $\mathrm{N}$ & 1161 & 1161 & 930 & 930 \\
\hline Within R-Squared & 0.057 & 0.057 & 0.020 & 0.016 \\
\hline Prob $>F$ & 0.000 & 0.000 & 0.002 & 0.010 \\
\hline Joint Test & 0.366 & 0.496 & 0.000 & 0.077 \\
\hline
\end{tabular}

** Significant at .01 level, two-tailed

* Significant at .05 level, two-tailed

() standard errors

statistically significant by itself is the control variable for development, GDP per capita. Economic development alone increases the subsequent Polity score of recipients by 0.595 points with a probability of 0.029 . Our primary concern, however, is the statistical significance of the marginal effects using specific subcomponents of salience. Empirically, this is captured by the F-test of the sum of the coefficient for the specific subcomponent along with the coefficient for its interaction with donor pressure. Thus, for the subcomponent of geographic proximity (Distance), Model 8 shows that the effect of aid on liberalization in recipients filtered by proximity is negative. It decreases the subsequent Polity score of recipients by 0.395 points. This outcome is statistically significant (probability of $0.015 ; \mathrm{F}(1,1979)=5.95)$. None of the other five subcomponents of salience - emphasizing recipients' population, affinity, GDP, the share of imports and exports - in Model 8 has statistically significant marginal effects of note.

We see a similar picture when I rerun the model treating aid as a bribe to induce state affinity (Model 9 of Table 3.3). It reports that donor pressure by itself increases the subsequent Polity score of recipients by 0.595 points with a probability of 0.023 . The influence of economic development increases the subsequent Polity score of recipients by 0.571 points. That relationship is also statistically significant, with a probability of 0.036 . As before, we want to focus on the statistical significance of the marginal effects using specific subcomponents of salience. Out of the six subcomponents, Model 9 reveals that only geographic proximity has a 
statistically significant result with a probability of $0.001(\mathrm{~F}(1,1979)=10.25)$. The effect of aid on liberalization in recipients filtered by proximity is to decrease the subsequent Polity score by 0.463 points.

Both models 8 and 9 of Table 3.3 reveal a similar pattern of results. This suggests the use of different conceptions of state affinity (Reward and Bribe) is not affecting the outcome. For both models, it turns out that the only subcomponent of salience that has a statistically significant marginal effect on the subsequent liberalization in recipients is geographical proximity.

Recipients that are geographically further away from donors are more likely to liberalize to a greater extent compared to recipients that are proximate to donors. One interpretation, consistent with the logic presented in Chapter 1, is to recognize that donors simply do not accord a high priority to democracy promotion. Since donors are more conscious about security in their immediate neighborhood, it follows that donors are more willing to indulge in democracy promotion with distant recipients, where the security imperative is weaker.

We should also consider the policy implications of geographic proximity. Unlike the other five subcomponents, proximity is not policy amendable. A policymaker might manipulate the trade relations between a given donor and its recipient in the direction of democracy promotion. For example, the imports from a given recipient can be decreased. This reduces the economic value of the recipient and increases the likelihood the donor will value democratization in the recipient as a lesser objective. By contrast, the distance between a given donor and a recipient is practically immutable. At most the policymakers are encouraged to select recipients that are distant from the neighborhood of the donor. Thus, even if geographic proximity is empirically significant, substantively, this subcomponent has limited policy applications.

The results of the disaggregated analysis of salience reveal that only one out of the six subcomponents of salience is statistically significant. Furthermore, that component, geographic proximity, is generally not policy amendable. Our conclusion, therefore, is that the default index (Primary and Secondary) which aggregates across six components of salience fares well compared to their disaggregated counterparts.

Our next task is to assess how the default index stacks up against the alternatives. Each of the four models (Models 10 to 13) in Table 3.4 captures the aid dynamic using a different index for overall salience. Model 10 presents the results using the default index (Primary and Secondary). It reports that the marginal effects of aid are negative for Primary recipients but positive for Secondary recipients. ${ }^{5}$ Since there are two recipient groups, we want to know if they are statistically indistinguishable from each other. The F-test shows that the odds of them being equivalent (with the difference due to chance) are $0.003(\mathrm{~F}(1,1987)=8.88)$. We can infer from this result that the default index is systemically differentiating between the two recipients in theoretically anticipated ways. Furthermore, the F-test demonstrates that this systemic difference is statistically significant.

As an alternative, it might be the case that donors merely want some concessions from recipients and are not particularly fussy on the nature of those concessions. 
In that case, recipients need only possess either economic or strategic value or both to be deemed valuable (EitherPrimary). Model 11 presents the results using this composite index. As before, the focus is on the statistical significance of the marginal effects. The sum of coefficients of EitherPrimary and Democratic Push $\times$ EitherPrimary reflects the effects of aid on the subsequent regime change in recipients filtered by EitherPrimary is negative. It decreases the Polity score of such recipients by 0.148 points. The result is, however, not statistically significant, with a probability of $0.557(\mathrm{~F}(1,1989)=0.35)$. This means this alternative composite index (EitherPrimary) is not capturing the aid dynamic posited by the theory. This specific filter is not able to differentiate between recipients with salience and those without. This suggests it is not the possession of either attribute set that donors value but rather the possession of both attributes that grant the recipients bargaining leverage.

We can also explore the effects of individual attribute sets. Model 12 focuses on the strategic importance of recipients. It shows that the marginal effect of aid on the subsequent regime change in recipients filtered by strategic importance (Strategically Valuable) is positive. It seems to increase the Polity score of strategically important recipients by 0.270 points. The probability of this outcome occurring due to chance is $0.285(\mathrm{~F}(1,1989)=1.14)$. Since this is not statistically significant, we can be reasonably confident that the possession of strategic importance by itself is not the key determinant of recipient salience. This, in turn, suggests that our default aggregation rule compared with this alternative is more useful for capturing the aid dynamic posited by the theory.

Model 13 concentrates on the economic importance of recipients. It shows that the marginal effect of aid on the subsequent regime change in recipients filtered by economic importance (Economically Valuable) is negative. It decreases the Polity score of economically important recipients by 1.301 points. This result has a probability of $0.000(\mathrm{~F}(1,1989)=13.58)$. Of the three alternatives indices that were tested thus far, this index is the only one that was statistically significant. Before we conclude that economic importance is the primary determinant of recipient salience, further inquiry is warranted.

Now that we know that the economic attribute set by itself is deemed important by donors, the next issue is to explore how this economic filter performs in a bigger pool comprising of both economically and strategically valuable recipients. Table 3.5 addresses this. In Model 14, both attribute sets are tested against each other. In this combined pool, the marginal effect of aid on liberalization in recipients filtered by strategic value (Strategically Valuable) is positive. However, the outcome has a probability of only $0.224(\mathrm{~F}(1,1987)=1.48)$. By contrast, the result for the economic counterparts is negative and statistically significant. The marginal effect of aid on recipients filtered by economic value decreases their Polity score by 1.232 points. The probability that the outcome is due to chance is $0.001(\mathrm{~F}(1,1987)=11.97)$. The final query is to test if the marginal effects on the two recipient groups identified using economic and strategic filters are statistically equivalent. The F-test shows that the odds of the two sets of marginal effects being equivalent, with the difference due to chance, are $0.001(\mathrm{~F}(1,1987)$ 
$=11.40$ ). This set of results reveals that economic importance plays a large role in the donors' evaluation of recipients even in a combined pool of recipients filtered by both the economic and the strategic attribute sets.

Before we conclude that economic importance is the only consideration of donors in their assessment of recipient salience, it is worth asking if this is an artifact of the Cold War. Table 3.6 addresses this concern. Model 15 focuses on the effects of the economic attribute set during the Cold War. It reports the marginal effect of aid on the subsequent regime change in recipients filtered by economic value (Economically Valuable $)$ is negative. This outcome has a probability of $0.366(\mathrm{~F}(1,1071)=0.82)$. The economic value of recipients does not seem to matter much to donors during the Cold War. Model 16 focuses on the effects of the strategic attribute set during the Cold War. The marginal effect of aid on the subsequent regime change in recipients filtered by strategic value (Strategically Valuable) is also negative. It is also not statistically significant, with a probability of $0.496(\mathrm{~F}(1,1071)=0.46)$. Both Models 15 and 16 test for the effects of the attribute sets during the Cold War. In doing so, we get a sense of donors' priorities during that period. Contrary to expectations from the extant literature (Kennan 1947; Bueno de Mesquita and Smith 2016; Bermeo 2016; Dunning 2004), neither attribute set is particularly significant in the calculus of donors when it comes to democracy promotion.

Models 17 and 18 examine the period after the Cold War. Model 17 shows that the marginal effect of aid on the subsequent regime change in recipients filtered by economic value (Economically Valuable) is negative. It decreases the Polity score of economically valuable recipients by 1.661 points. Unlike the models during the Cold War, the probability that this outcome is due to chance is 0.000 $(\mathrm{F}(1,847)=14.04)$. This statistically significant result allows for two inferences. Donors rank the economic attributes of recipients highly when assessing the salience of recipients. Additionally, it suggests that the economic value of recipients is dampening the effectiveness of donor pressure in the post-Cold War era. The situation for the strategic attribute set is covered by Model 18. It shows that the marginal effect of aid on the subsequent regime change in recipients filtered by strategic value (Strategically Valuable) is positive. However, that outcome is not statistically significant with a probability of $0.077(\mathrm{~F}(1,847)=3.14)$.

With the results presented in Table 3.6, we now have a nuanced overview of the influence of the two attribute sets. Neither the strategic nor economic attributes had a statistically significant marginal effect during the Cold War. This is contrary to expectations from the extant literature, which emphasized the impact of the Cold War on aid effectiveness. After the Cold War, only the economic attribute set has a marginal effect that is statistically significant. Possession of economic value, it seems, depresses the subsequent liberalization in aid recipients. It is worth stressing that its impact is only confined to the post-Cold War period.

\section{Conclusion}

This chapter conducted four investigations into both the subcomponents of salience and the different ways salience can be aggregated. It found that only one of 
the six subcomponents of salience, proximity, is significant for the outcome of interest - subsequent liberalization in the recipient. Proximity is however, immutable. The lack of policy relevance implies an aggregation rule that sums across the subcomponents of salience is more useful. Our default aggregation rule is to require a recipient to possess both strategic and economic value to be considered important by donors. Since there are several plausible ways to aggregate salience, the question becomes which particular aggregation rule is more useful. The results reveal that two of the alternative indices, one that emphasizes strategic value and one that allows for either attribute sets to be important, fail to differentiate between recipients in ways required by the theory.

The index emphasizing economic attributes (Economically Valuable) performs better when compared to the index emphasizing strategic attributes (Strategically Valuable). The policy implications here are straightforward. Given a choice between two recipients to nudge towards democracy, one with economic leverage and the other with strategic leverage, the latter is more likely to yield results.

I also examine how the index that emphasizes economic attributes stacks up against the default aggregation rule. The index (Economically Valuable) is able to differentiate in a statistically significant manner between recipients when tested in a pool of recipients i) filtered by both strategic and economic value, as well as when ii) filtered by economic value alone. However, when we also control for the Cold War, we find that the economic attribute set does not generate additional information during the Cold War. That is, the marginal effect of aid on recipients filtered by economic importance is not statistically significant during the Cold War.

Which index is better? It is helpful to refer back to the theory. We know from Chapter 1 that the Cold War is an especially challenging environment for the posited aid dynamic. This is because the superpower competition over patrons increased the leverage of would-be recipients. This, in turn, reduces the effectiveness of donor pressure for democracy. From the evidence in Chapter 2, we find as theoretically expected, that the aid-posited dynamic does not apply when controlling for both the Cold War and reverse causality. ${ }^{6}$ This means the default index has a reason, a theoretical explanation to account for the absence of statistical significance for its associated marginal effects during the Cold War.

By contrast, the index emphasizing economic value (Economically Valuable) lacks a theoretical justification for the absence of statistical significance for its associated marginal effects during the Cold War. If economics is indeed the primary driver of recipient salience, this should hold true both during the Cold War and the period after it. The evidence presented in this chapter does not support this expectation. The index, Economically Valuable, does not have a consistent pattern of statistical significance for both time periods. Rather, its impact on recipient salience seems to be driven mostly by the post-Cold War period.

We have a situation where both indices have a null finding for the Cold War. However, the default index has a theoretical justification for this outcome whereas the index emphasizing economics does not. For this reason, even as I acknowledge the Economically Valuable index yields useful information, I conclude the default index stands up reasonably well against its alternatives. 
The tests thus far were done on a global pool of aid recipients. The results confirm that the demarcation of recipients into Primary and Secondary groups helps us anticipate their susceptibility to donor pressure. In the next chapter, we move down a level of analysis to consider the regional dynamics. Are some regions more conducive to democracy promotion, and if so, why might that be? The next chapter undertakes this task.

\section{Notes}

1 Since the dataset is largely the same, I abbreviate the operationalization of variables that was done in prior chapters and elaborate in full for the new variables introduced in this chapter.

2 This is analogous to using cutoff points to denote students who score a letter grade of A. The thresholds can be varied to set different standards of academic rigor.

3 This was discussed in detail in Chapter 2.

4 Full text can also be found at this website: www.historyguide.org/europe/kennan.html (last accessed 6/6/17).

5 This model is the same as that used for Model 3 in Table 2.4 (Chapter 2). The different marginal effects are discussed in greater detail there.

6 See Table 2.6 in Chapter 2.

\section{Bibliography}

Allison, Graham. 1969. "Conceptual Models and the Cuban Missile Crisis." The American Political Science Review 34: 689-718.

Bermeo, Sarah Blodgett. 2016. "Aid Is Not Oil: Donor Utility, Heterogeneous Aid, and the Aid-Democratization Relationship." International Organization 70: 1-32.

Bueno de Mesquita, Bruce, and Alastair Smith. 2016. "Competition and Collaboration in Aid-for-Policy Deals.” International Studies Quarterly. doi:10.1093/isq/sqw011.

Dunning, Thad. 2004. "Conditioning the Effects of Aid: Cold War Politics, Donor Credibility, and Democracy in Africa." International Organization 58: 409-423.

Kennan, George. 1947. "The Sources of Soviet Conduct." Foreign Affairs 25: 566-582.

Marshall, Monty G., and Keith Jaggers. 2014. "Polity IV Project: Political Regime Characteristics and Transitions, 1800-2013." The Polity IV dataset. www.systemicpeace.org/ inscrdata.html.

Tierney, M. J., D. L. Nielson, D. G. Hawkins, J. T. Roberts, M. G. Findley, R. M. Powers, B. Parks, S. E. Wilson, and R. L. Hicks. 2011. "More Dollars than Sense: Refining Our Knowledge of Development Finance Using Aid data." World Development 39: 1891-1906. 


\section{The regional picture}

\section{Introduction}

Not all recipients are equal. Some are blessed with the attributes that donors value, while others are not as fortunate. Those who do have, are in a position to rebuff the donors, while those who do not, are not. The difference between the two bargaining positions presents a precious opportunity for those interested in democracy promotion. In essence, I argue we should focus on the authoritarian aid recipients that are susceptible to donors' offers and stop wasting resources on those that are not.

In the previous two chapters, I demonstrated empirical support for the argument with statistical tests on the global pool of aid recipients - the big picture if you will. To what extent is the strategy of liberalization at the margins viable when scaled down to the regional level? I will focus on the African and Asian region and suggest that Africa, rather than Asia, is the more conducive environment with which to apply the theory. ${ }^{1}$

Why focus on Africa and Asia? From the perspective of the potential for democracy, both regions have room for improvement. Using the regime type indicators from Polity IV, Figure 4.1 visualizes the Polity score of the average country from 1973 to 2006 (the time frame of inquiry). It shows that the average country in Asia, represented by the grey unbroken line, and the average country in Africa, represented by the grey dotted line is usually below their global counterparts, represented by the black straight line. Since the population in Africa and Asia collectively accounts for 78\% of the global total in 2014 (OECD 2016a), we have good reasons to focus on these regions.

From the perspective of aid effectiveness, it is puzzling that both regions experienced divergent developmental outcomes despite a long history of aid receipt. Historically, the major proportion of Official Development Assistance (ODA) from the DAC donors has been allocated to Africa and Asia (OECD 2016a). From 1970 to 2014, the average Asian recipient receives around US\$ 53,785 million in aid annually (OECD 2016b). For the same period, the average African recipient receives around US\$ 54,193 million in aid annually (OECD 2016c). At first glance, those values look similar, but they are not when we also consider their respective population size. Going by the OECD figures for the year 2014, Asia has 


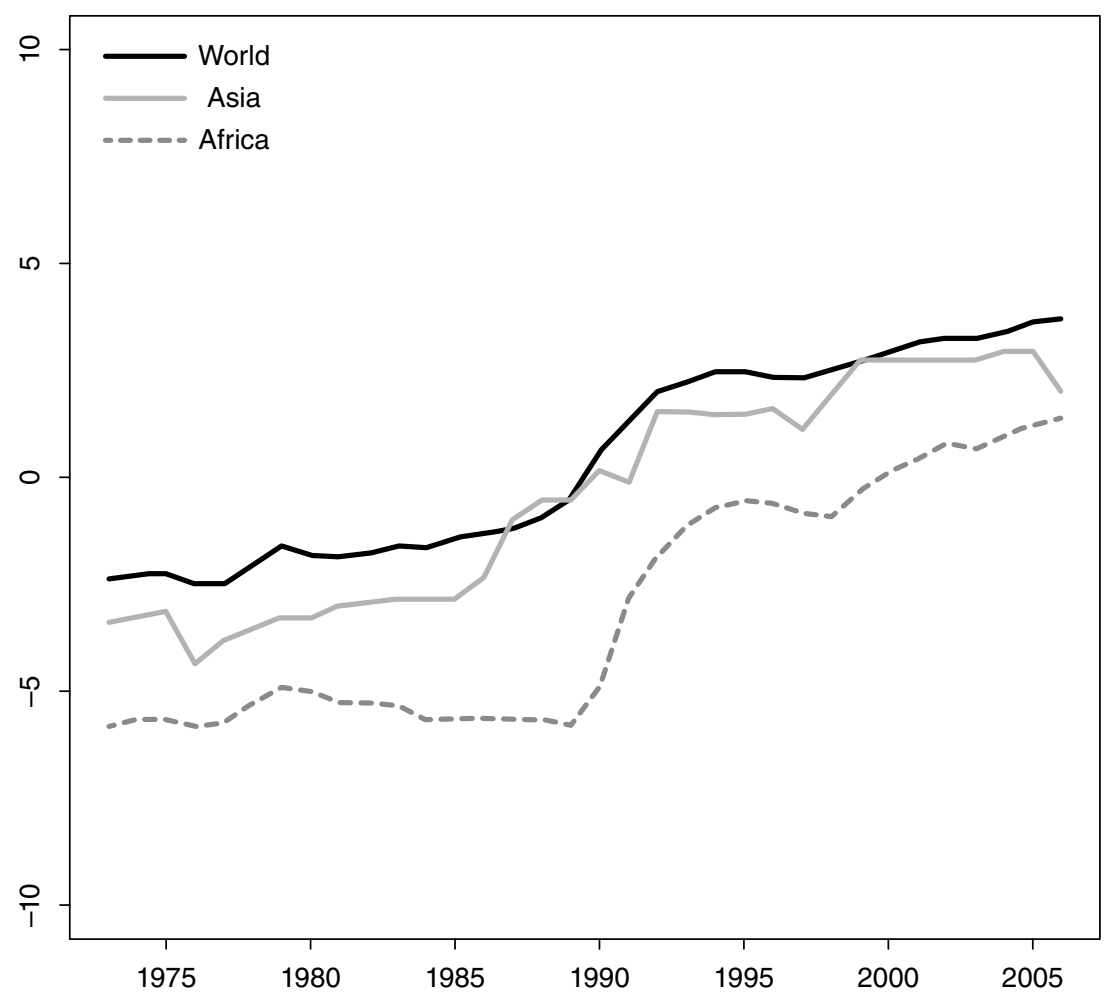

Figure 4.1 Average Polity Scores of the Countries in the Respective Regions (1973-2006)

a population of 3,993 million while Africa has 1,155 million out of a total world's population of 5,931 million (OECD 2016a). To put into perspective, countries in Africa, a region with approximately $11 \%$ of the world's population, are receiving more aid than countries in Asia, with around $67 \%$ of the world population (OECD 2016a)!

The posited theory focuses on the leverage recipients have. Recipients in a region with successful economic development should have more leverage compared to recipients in a region with development failures. This is the motivating idea underlying the regional comparisons.

The chapter is organized as follows. I start with an overview of the literature on foreign aid and political liberalization in both regions, starting with Africa followed by Asia. I use the regional contexts to derive hypotheses that are then subject to statistical tests. I outline the data and methods, identify the key variables and set the theoretical expectations. I present the results, draw conclusions and discuss policy implications. 


\section{The African context}

Despite receiving a disproportionate share of ODA aid, Africa remains underdeveloped. In Moyo's critique of aid to Africa, she observes that:

More than US\$ 2 trillion of foreign aid has been transferred from rich countries to poor countries over the last fifty years - Africa the biggest recipient by far. Yet regardless of the motivation for aid giving - economic, political or moral - aid has failed to deliver the promise of sustainable growth and poverty reduction.

(Moyo 2010: 28)

Moyo (2010) goes further. She argues that in terms of poverty, life expectancy, literacy rates, health indicators, and, crucially, in economic growth rates, Africa, especially sub-Saharan Africa is regressing while the rest of the world is progressing (Moyo 2010: 5-6, 28, 46-47).

Is the lack of development in Africa particular to Africa or is it a problem with aid in general? Thus, the failure of aid in Africa fed into a larger debate over the effectiveness of aid for development. The effectiveness of aid is a recurring issue in the literature on aid with three broad schools of thought (Edwards 2014). The first group treats foreign aid itself as the problem (Moyo 2010; Easterly 2014). In its view, the implementation of aid is not only ineffective; it encourages aid dependency and corruption. Instead of aid to Africa, Moyo (2010) prefers trading with the West and foreign investment from China. Likewise, Easterly (2014) argues the technocratic attitude adopted by aid experts has done more harm than good for the global poor (many of which are in Africa). He prefers instead a political approach that respects the rights of the poor (implying an end to support for African dictators).

The second group focuses on the amount of aid as the main cause of its ineffectiveness (Sachs 2005; Stiglitz 2002). This group argues that the aid given to the less developed countries, many of which are in Africa, is too little to achieve the economies of scale that is required for positive development outcomes. As a case in point, all donors signed up to the UN Millennium Development Goals. That accord requires signatories to set aside 0.07 percent of their national GDP to foreign aid (United Nations 2006). With the exception of the Scandinavian countries, most donors failed to meet that goal. For this group, the problem lies not with the aid per se but rather in the stinginess of the donors. It is the absence of political will in donors that causes aid failures.

The third group adopts a more agnostic position on aid effectiveness at the macro-level (Collier 2007; Banerjee and Duflo 2011). Instead, they prefer a targeted, sector-by-sector, even micro-level examination of the outcomes of aid intervention. Applying to African development, they would have noted the series of thematic initiatives adopted by Western donors. There was the focus on largescale infrastructure projects in the 1960s, on agriculture and rural development in the 1970s, on structural adjustment in the 1980s, on good governance in the 
1990s, and on glamor aid in the 2000s (Moyo 2010: 14-28). Instead of looking for silver bullets with the aggregate aid, this group argues for a focus on specific programs and the context under which they might or might not be effective (Edwards 2014). In its view, the problematic record of aggregate aid does not by itself foreclose the possibility that more targeted programs might be successful.

This search for an appropriate context for effective aid has a particular history. By the end of the 1980s, the failure of Africa to develop, given that other regions such as Asia were successful, demanded an explanation. The initial answer focused on the neoliberal economic policies that successful recipients adopted. Such policies emphasized reducing the state, liberalizing the domestic economy, and integrating into the global economy. Major multilateral financial institutions, such as the World Bank and the International Monetary Fund (IMF) adopted a set of fiscal and monetary policy prescriptions that prospective loan recipients have to qualify for assistance. The mindset that animated this set of policy prescriptions came to be known as the Washington Consensus. Consequently, bilateral donors attached economic reforms to aid packages that prospective recipients have to implement in order to qualify for aid. This is known as economic conditionality.

The effectiveness of the Washington Consensus and economic conditionality is tangential here. ${ }^{2}$ What is pertinent is that the failure of Africa to develop in the early 1990s prompted yet another search for an explanation. It is in this context that the arguments of Burnside and Dollar (1997) and Dollar and Pritchett (1998) become prominent. Burnside and Dollar (1997) argued aid could work in a good policy environment but was ineffective in a bad one. Countries with good policy environments have sound fiscal, monetary, and trade policies (Moyo 2010: 40). They can successfully maintain such policies due to good governance. "Good governance was a euphemism for strong and credible institutions, transparent rule of law, and economies free of rampant corruption"(Moyo 2010: 22). Such governance in practice is associated with democracies. Donors latch on to these and related findings (Burnside and Dollar 2000, 2004). ${ }^{3}$ They demanded governancerelated reforms in exchange for the aid (Dietrich and Wright 2015: 216; Moyo 2010: 22; Haynes 2001: 146). This type of aid conditionality focused on political and governance reforms came to be known as political conditionality (Brown 2013: 194). Thus, the emphasis on good governance through political conditionality became, in effect, a way of promoting democracy in Africa (and elsewhere).

At first glance, the application of the good governance conditionality to Africa is unusual. After all, the track record of democracy in Africa is poor. After decolonization in the 1950s and the 1960s, many of the newly independent African states adopted democratic institutions left by their colonial masters. This state of affairs did not last. By 1989, the majority of African states lost their democratic status, becoming various forms of authoritarian government (Brown 2013). The reason for this record stems from both domestic and international factors.

Domestically, the typical African state has multiple structural impediments to the survival of democracies. These include i) serious ethnic and religious cleavages in society, ii) long periods of dictatorial rule prior to democratization, iii) 
weak and fragmented civil societies, iv) close ties between the state and its military, v) low levels of accountability, which lead to the de-legitimatization of the government (Haynes 2001: 139).

Internationally, the Cold War favored the survival of authoritarian regimes. The colonial powers in Africa, typically France and Britain, were more interested in maintaining ties with the former colonies than in promoting democracy (Brown 2005: 181). The Cold War context meant that the superpowers were willing to fund their respective African client states regardless of the nature of the client's regime. One egregious example was Mobutu Sese Seko of Zaire, also known as the Democratic Republic of Congo today. He is alleged to have stolen US\$ 5 billion from his country and yet continued to receive foreign aid. He deflected donor pressure to democratize by allowing multipartyism and yet remained in power until 1997 (Brown 2005: 184)!

Yet when we consider the international changes since the 1990s, the donors do have some grounds for optimism. There are four factors that have changed. First, there was the end of the Cold War. With it went the imperative of strategic competition with the now-defunct Soviet Union. This allowed democracy promotion to rise to the top of the aid agenda of donors, even when we allow for intra-donor differences in the tactical emphasis (Carothers 2009). This remarkable consensus among the Western donors (Dietrich and Wright 2015: 216) reduced the ability of African authoritarian recipients to shop around within the Western camp for a better deal.

The end of the Cold War also removed the Soviet Union as the source of aid. Western donors need no longer hold back on political conditionality for fear of losing African client states to the Soviet camp. This meant African recipients could no longer play one donor bloc against the other. Concomitantly, the threats of Western donors to withhold aid if good governance-related reforms were not forthcoming increased in credibility (Dunning 2004). Together the consensus over democracy promotion and the loss of the Soviet alternative increased the effectiveness of political conditionality and the prospects for democracy promotion (Dunning 2004; Brown 2013).

The second factor is the economic malaise in Africa. Africa suffered from "endemic economic weakness" (Haynes 2001: 145). It was this economic vulnerability that led donors to attempt economic conditionality and then resort to political conditionality. Hayes observed that:

Driven by the understanding that one of the prime causes for Africa's economic weakness and political instability was the lack of democratic governments, external pressure was also applied to authoritarian regimes - vulnerable to such external pressure because of their countries economic weakness - to allow meaningful democratization.

(emphasis added, Haynes 2001: 146)

This is further magnified when many of the African recipients depend on aid to finance their public expenditure (Moyo 2010: 42, 65-67). There is a sense that 
economic vulnerability - however unfortunate it is for African sovereignty - is in itself an opportunity for democracy promotion in Africa.

Third, economic malaise reduced the leverage of African recipients. It meant the typical African recipient provides little by way of economic value to Western donors outside of the Cold War context. Crawford, in a qualitative study of political conditionality using the tool of aid sanctions, observes that:

[T] he regional analysis of the 29 country cases displayed the overwhelming extent to which aid sanctions have been taken in sub-Saharan Africa, where Northern government have little to lose (sic).

(emphasis added, Crawford 1997: 101)

Western donors took a concerted effort to promote a democratic transition in cases like Malawi precisely because Malawi has little else to offer (Brown 2013). The low economic value of African recipients creates a space for democracy promotion.

The fourth factor is the empirical pattern of democratization. Huntington (1991) argued it operates in waves. Just as a rising tide lifts all boats, Western donors could legitimately expect their limited influence over aid to be more effective on top of a "democracy wave" than in the absence of one. The Third Wave of democratization, which started in Europe (Portugal in 1974), did not emphasize Africa (Huntington 1991). Yet, in the two decades after the end of the Cold War, many different types of authoritarian regimes in Africa experienced democratic transitions. Kenya (Brown 2013) and Malawi (Emmanuel 2013) were two examples of African regimes where Western donors were influential in ensuring a democratic transition. In fact, Dietrich and Wright (2015: 216) noted that from "1989 to 2008, roughly half of all democratic transitions in the world occurred in sub-Saharan Africa". The Third Wave, it would seem, reached Africa.

To be sure, the scholarship is generally critical of the quality of African transitions (Haynes 2001; Brown 2005, 2013; Dietrich and Wright 2015). They took pains to distinguish between democratic transitions and democratic consolidation. Likewise, they distinguished between multipartyism and incumbent-leadershipturnover. It helps to briefly define these four terms without delving into the associated debates over their definitions. A democratic transition is the process by which an authoritarian regime becomes a democratic one. This usually involves the holding of elections with the feature of multipartyism, a condition wherein, as the name suggests, multiple parties in addition to the ruling incumbent party are allowed to participate. Whereas the existence of multipartyism denotes the end of the one-party state, it need not also indicate democratic consolidation. Democratic consolidation is a long-term process by which democracy becomes the mode of governance accepted as legitimate by the key actors. One key signal of acceptance occurs when the incumbent party accepts an electoral loss and peacefully transfers power to the opposition party, also known as incumbent-leadershipturnover. In an evocative phrase, democracy is consolidated when it becomes the only game in town (Przeworski et al. 2000). The critique, therefore, is that 
political conditionality in Africa promoted democratic transitions without democratic consolidations in the form of multipartyism without incumbent-leadershipturnover (Haynes 2001; Brown 2005, 2013; Dietrich and Wright 2015).

Yet, there are doubts if donors genuinely seek democratic consolidation. Brown (2005) argued that donors should aim for democratic consolidation, if only because it is necessary to prevent democratic backsliding after democratic transitions. Yet, he observed that in practice:

Nowhere in Africa have donors aggressively pursued a program of political conditionality to further consolidation.

(Brown 2005: 191)

Brown's observation highlights an important distinction. The general critique focuses on democratic consolidation while the emphasis of this book is on political liberalization. The absence of the former does not preclude the possibility of the latter. ${ }^{4}$

The review thus far highlighted the considerable variation in both the independent and dependent variables. On side of the independent variable (donor pressure), Western Donors used to neglect democracy promotion during the Cold War. They have emphasized political conditionality after its end (Dietrich and Wright 2015: 216). On side of the dependent variable (political liberalization), many African aid recipients, despite a history of authoritarianism (Haynes 2001: 139), experience a wave of democratic transitions after the Cold War, even if that did not necessarily translate into democratic consolidation.

Hence, despite all the structural impediments against African democracy, the (temporarily) permissive international environment, economic vulnerability, and enough variation in the outcome of interest render Africa a suitable region for further inquiry. For these reasons, one would expect the aid dynamic posited in Chapter 1 to apply to Africa. Specifically, the hypotheses are:

H4: Aid to African Secondary recipients who are pressured to reform politically increases the odds of liberalization.

H5: Aid to African Primary recipients accompanied by pressure to reform politically should not increase the odds of subsequent liberalization.

H6: Conditional on being pushed to reform, there should be a significant, positive difference in the likelihood of political reform when comparing Secondary recipients and Primary recipients in Africa.

\section{The Asian context}

By contrast, the regional context for Asia is different. For one, Asia is more prosperous. In the light of Asia's economic ascendancy, it may surprise some to note that from 1970 to 2014, Asia is always the second largest recipient of ODA funding (OECD 2016a). Even in the current period, OECD reports that Asia accounts for $34 \%$ of all ODA aid from the DAC donors from 2010-2014 (OECD 2016b). 
Furthermore, in terms of domestic factors, the typical Asian state faces four structural impediments to democratic survival (Haynes 2001: 83-84). These include i) the nature of agrarian class relations, ${ }^{5}$ ii) the close relationship between the state and the army, iii) a lack of governmental accountability justified by political culture, and iv) a legacy of authoritarian development. Two of them need some elaboration. The claim that certain political cultures may not be suitable for democracy is not new. The Asian twist is to attribute to either Confucianism or "Asian values" (Teehankee 2007). The ensuing Asian values debate in the 1990s changed the minds of neither donors nor Asian recipients (McCawley 1998: 43). The fourth impediment is more significant. Asian authoritarian regimes and elites such as Singapore's Lee Kuan Yew, Malaysia's Mahathir Mohamad, Indonesia's Suharto, and the Thai military and bureaucratic elite share a common rhetoric. Asian authoritarian regimes tend to justify domestic repression by arguing that a strong state is necessary to promote economic development (Kurlantzick 2014: 4). Given the importance of economic performance for regime legitimacy, we should also consider briefly the Asian developmental experience.

Asia has had an impressive track record of economic growth in the last 60 years. The explanation for this record is itself a major debate in developmental economics (World Bank 1993; Chang 2006). In the conventional view, there are two developmental paths for developing countries, import substitution industrialization or ISI and export-oriented industrialization or EOI. The objective of ISI is to get the domestic industrial base to produce the goods that would otherwise have to be imported. The objective of EOI is to get the domestic industrial base to produce goods that are meant for export. Unlike regions that opted for an ISI strategy, Asia opted for an EOI strategy. Asian states that exemplified this willingness to integrate into and compete in the global economy include Hong Kong, South Korea, Singapore, and Taiwan, popularly known as the Asian Tigers. Their developmental success was attributed to the "adoption and implementation of domestic policies that promote efficient use of resources and encourage private sector initiative" (James et al. 1989: 4). Under this perspective, foreign aid played its traditional role, it supplemented private capital inflows until such time that export-oriented industrialization becomes self-sustaining.

There is some disagreement with this conventional view. The developmental path Asian states took did not fit the model presumed by the Washington Consensus. Under the Washington Consensus, the role of the state is to provide a regulatory framework and to correct market imperfections. This minimalist approach for the state is meant to allow the private sector free reign. In a free market with perfect competition, some firms will fail. The state does not intervene since it favors no one firm in particular.

Yet the Asian developmental experience is different (World Bank 1993; Aoki et al. 1998). Asian states play an active role in resource allocation. They pick selected industries to invest in and deliberately favor some firms over others. The chosen firms such the Zaibatsu in Japan or the Chaebol in South Korea are, in effect national champions, able to draw from the state's resource base. Foreign aid in this alternative view has a larger role than supplementing capital inflows. 
For the Asian states deemed the bulwarks of anti-communism, South Korea and Taiwan, aid from the US was crucial in their economic development (Woo-Cumings 1998: 334-335).

Of course, our concern here is not on the role of aid in economic development per se but rather in democracy promotion. During the Cold War, democracy promotion was simply not an emphasis for Western donors (Kurlantzick 2014: 19). Significant donors, the United States and Japan, have "long regarded democracy as dangerous to [their] strategic interests as it might allow communists or socialists to achieve power via the ballot box" (Haynes 2001: 84). When we add to this donor reticence with the aforementioned structural impediments to democracy in Asia, it is not surprising that most Asian countries by the end of the Cold War were not democratic.

By around the 1990s, circumstances started to tilt in favor of democracy promotion. In terms of security ties, Asian states lost the anti-communist rationale they used as an excuse to maintain authoritarianism (Kurlantzick 2014: 4). The US was in a position to let its authoritarian Asian allies collapse. Notably, in 1986, the US refused to support Ferdinand Marcos, thus allowing the Philippines to begin its democratic transition (Kurlantzick 2014: 19). Despite this, all the Asian states that built their security ties with the US during the Cold War maintained them even after its end.

In terms of economic ties, the Asian Financial Crises (1997-8) weakened the appeal of the Asian developmental model. The champions of "Asian values" found themselves on the political defensive (Teehankee 2007). Since Asian economic development also facilitated the rise of a middle class in many Asian states (Kurlantzick 2014: 5-6), their dissatisfaction with the fallout of the financial crisis led to demands for political change. Notably, in 1998, it led to the fall of the Suharto regime and democratic transition in Indonesia. Since Japan and the United States were key trading and investment partners of many Asian states in the 1990s, both enjoyed considerable leverage. ${ }^{6}$ Collectively, these security and economic ties gave the Western donors, especially Japan and the US, a temporary boost in their influence.

It was, in this context of increased influence in the 1990s, under which the donors started to emphasize good governance. Asian recipients were skeptical about the donors' motives. First, many Asian recipients who form the core of what the World Bank came to call the "Asian Economic Miracle" (World Bank 1993) have faster growth rates than the Western donors. Donors could argue that more deserving recipients with greater needs can be found instead of Asian recipients. Second, it is redundant to give Asian recipients aid for good governance since they already have pro-growth policies. Together, these lead to a view that "Asia no longer needs foreign aid" (McCawley 1998: 42; Soesastro 2004: 5). Asian recipients saw such arguments as an excuse to reduce the total volume of aid to the region (McCawley 1998: 44).

To be sure, donors did not present a united front on democracy promotion. The top two bilateral donors to Asia from 1970 to 2014 were Japan and the US (OECD 2016b). Japan was less enthusiastic about the good governance agenda 
(McCawley 1998: 42). It provided substantial aid to Myanmar when it was under military rule and under Western sanctions (Steinberg 1990). The preeminent donor, however, was the United States. Under the Clinton administration, democracy promotion became a foreign policy priority. Even if this commitment was somewhat rhetorical in other regions, in Asia, especially in Southeast Asia, the US was sincere (Kurlantzick 2014). Kurlantzick noted the US took concrete steps.

The White House and Congress offered significant public criticism of authoritarian leaders in the region, such as Malaysia's Mahathir Mohamad, boosted aid for democracy promotion programs in the region, imposed sanctions on countries like Myanmar and Indonesia that had committed severe human right abuses, and conditioned further aid to countries like Cambodia and Vietnam on improvements in the climate of rights and political freedoms. Overall, between the early 1990s and 2000, US government spending on democracy promotion grew from around $\$ 100$ million to over $\$ 700$ million annually (Kurlantzick 2014:19).

When the Third Wave of Democracy reached Asia in the 1990s, countries such as the Philippines, Thailand, Singapore, Malaysia, and, eventually, Indonesia (Kurlantzick 2014: 22) underwent reforms in a democratic direction. ${ }^{7}$ To a limited extent, pressure from Western donors helped create an international milieu that was more conducive to democracy promotion in that period.

This benign milieu did not last. The September 2001 attacks on the United States pushed counterterrorism to the forefront of the Western donors' policy agenda. Authoritarian regimes that could provide military and logistical help in counterterrorism campaigns could expect to get away with non-democratization. In a telling example, the US was noticeably reluctant to criticize the Thai military coup in 2006 (Tan 2016). Thailand provides important logistic support to the American military, including support for the US campaigns in Afghanistan (Chanlett-Avery 2009: 5). Under the Bush administration, the United States did suspend some aid but was careful not to cut its military ties to Thailand (Chanlett-Avery 2009). It did not suspend the Cobra Gold program, the largest multilateral military exercise the has in Asia (Kurlantzick 2014: 20). The US did not revoke Thailand's status as a major non-NATO ally (Asian Times 2009). The status matters because it qualifies Thailand for military aid from the US. As a matter of fact, the US ambassador in Bangkok met with the 2006 coup leaders to reassure them that the coup would not affect the US-Thai relations unduly (Kurlantzick 2014: 20).

The United States under the Obama administration conducted a shift of the US diplomatic and military assets to Asia as part of its "Asian Pivot". A conventional realist interpretation is that this is an attempt to build a coalition with Asian countries in an effort to contain China or, at minimum, limit Chinese influence. Geostrategic competition between China and the US provided opportunities for Asian recipients to play one donor bloc against another (Tan 2016). The situation of Myanmar, discussed in a subsequent chapter, illustrates the complexity of donor-recipient bargaining.

The problems with democracy promotion in Asia go beyond the mere donor reticence. They stem from the fact that Asia is the home ground of an authoritarian 
major power, China. The perception of China's economic success cast a long shadow on democracy in Asia as Fukuyama observes:

In many respects, the legitimacy and appeal of democracy in East Asia will depend not on how democratic countries in the region stack up on some global scale, but on how they are seen in relation to the region's dominant authoritarian country, China. Like Singapore before it, China represents a huge challenge because it has been so economically successful; the temptation to copy parts of the China model are strong both in the region and beyond.

(Fukuyama 2012: 17)

In an assessment of the Chinese influence on the world order, Nathan (2015) argues that China's foreign policy goals are essentially defensive because its leadership is primarily focused on domestic security. Since democracy threatens its internal political order, China seeks to render international order "regime-type neutral" (Nathan 2015: 157). By that term, Nathan does not mean China seeks to roll back democracy and replace it with authoritarian regimes. He means that China wants to reduce what it perceives as the pro-democracy bias in the international order.

Even with this defensive goal, Nathan argues China is nevertheless affecting the world order in six ways. First, China seeks to shift the discourse in various international organizations away from an emphasis on democracy. Within the UN, China champions the principle of state sovereignty, and allows the UN interventions only with the host states' consent (Nathan 2015: 166-167). In the UN Human Rights Council (UNHRC), China advocates procedural measures to insulate itself and like-minded authoritarian states from serious international scrutiny on their human rights record (Nathan 2015: 165-166). In foreign aid, China gives aid and loans without conditionality, especially without political conditionality. It refuses to participate in the reporting norms of the Development Assistance Committee (DAC). By setting up the new and Chinese-dominated Asian Infrastructure Investment Bank (AIIB), it provides alternative sources of funding to would-be recipients. This undermines the effectiveness of aid conditionality by Western donors and by extension, the overall aid regime of the DAC (Nathan 2015: 167).

Second, China funds various state-run media and public diplomacy initiatives to promote a positive image of China. For example, there are more than 500 Confucius institutes promoting Chinese culture and philosophy in foreign universities (Nathan 2015: 160). Some of those located in Western universities, including the United States and Canada, have been censored for violating academic freedom (Chronicle of Higher Education 2014). Berridge (2015: 198) distinguishes between "white propaganda" where the state is openly acknowledged as the source of information and "black propaganda" where the state hides its authorship. Public diplomacy, Berridge (2015: 200) argues, is white propaganda at best. The distinguishing features of Chinese propaganda are an emphasis on legitimizing alternatives to democracy without portraying the Chinese model as universally applicable (Nathan 2015: 161). 
Third, authoritarian regimes learn from each other, and China is a center for best practices in authoritarian repression. China trains foreign bureaucrats, especially from Africa. The Chinese legal infrastructure that is useful for repression, such as using the letter of the law to censor Internet criticism, is imitated by aspiring autocracies (Nathan 2015: 162-163).

Fourth, China supports authoritarian states for strategic reasons. These include material support for North Korea, Cambodia, Burma, Pakistan, Nepal, and states that constitute the Shanghai Cooperation Organization, namely Kazakhstan, Kyrgyzstan, Russia, Tajikistan, and Uzbekistan (Nathan 2015: 165). In so doing, China gives those recipients leverage to bargain with the West.

Fifth, China also suppresses pro-democracy movements in Hong Kong and Macau and exerts international pressure on Taiwan (Nathan 2015: 163). Although these can seem to be localized issues, the demands for democracy in an otherwise Sinic region puncture the myth that Asians do not want democracy (BBC 2019).

The last reason is the most important one. China is seen as a rare example of a successful authoritarian state (Nathan 2015: 158). By modernizing with an authoritarian regime, the economic success of China challenges the idea that democracy is the only viable developmental path to modernity. Worse, this developmental experience does not seem to be sui generis. In fact, Fukuyama observes a regional developmental dynamic; he asserts:

First and most important, almost all the recent examples of successful authoritarian modernization cluster in East Asia rather than other parts of the world. Hong Kong under British rule, Japan, Singapore, South Korea, Taiwan, Thailand, and of course China itself all developed rapidly in the second half of the twentieth century (in Japan's case, the process started a century earlier) under the stewardship of authoritarian governments that were only weakly constrained by democratic accountability.

(Fukuyama 2012: 16)

Yet, Fukuyama (2012) argues the Asian developmental model is not easily transferable elsewhere. The Asian countries have a strong state with a genuine developmental focus. Elsewhere, the more likely scenario obtains when authoritarian elites capture the state for the purpose of rent-seeking (Fukuyama 2012: 16). That inconvenient truth, however, does not stop authoritarian regimes elsewhere from using the Chinese model as the justification for not democratizing.

What makes the Chinese authoritarian development model especially alluring is the fact that the policy performance of Western liberal democracies in recent years has been poor. A lot of it stems from within the United States. Writing in 2015, Diamond notes:

Perhaps the most worrisome dimension of the democratic recession has been the decline of democratic efficacy, energy, and self-confidence in the West, including the United States. There is a growing sense, both domestically and 
internationally, that democracy in the United States has not been functioning effectively enough to address the major challenges of governance.

(Diamond 2015: 152)

Since then, American governmental dysfunction has contributed to the election victory of Donald Trump in 2016. Likewise, the dissatisfaction of the masses in liberal democracies has fueled a wave of populist backlash against the establishment and the political status quo (BBC 2017). As a consequence, it is simply much harder to persuade the would-be Asian authoritarian regime to liberalize when alluring alternatives are convenient and when liberal democracies themselves are underperforming.

Asia is a more challenging environment for democracy promotion. As the discussion on the influence of China suggests, Asian secondary recipients may be able to rely on China patronage as a means of leverage against the West that is perceived to be declining.

The typical Asian recipient is also wealthier. According to data from the World Bank, the average developing country in East Asia and the Pacific has a GNI per capita income of $\$ 6,121$ in current 2014 US dollars. By contrast, the average developing country in the Low and Middle-Income Countries category - the group most likely to qualify for aid receipt - has a GNI per capita income of only $\$ 4,226$ in current 2014 US dollars. ${ }^{8}$ By virtue of being $45 \%$ richer than the typical developing country, the average Asian aid recipient has more wherewithal to draw upon when resisting donor pressure (Tan 2016: 153).

For these reasons, I do not expect the theory presented in Chapter 1 to apply directly to Asian aid recipients. That is, I do not expect Asian Secondary recipients to be significantly more likely to liberalize after donor pressure. This is a firstorder effect of the theory. It does not prevent the possibility that a second-order implication of the theory might still apply. By a first-order effect, I mean the direct impact of the aid with donor pressure on the two recipient groups. Second-order effects are the indirect implications of the theory, focusing on the effect across different salience thresholds. ${ }^{9}$ Let's unpack this point.

The theory posits that recipients who are salient to donors have bargaining leverage with which to resist pressure for political reforms. We cannot, however, directly observe such leverage. This is because researchers typically do not have access to the transcripts of the deliberations of decision makers in meetings on aid allocation. The theory uses a theoretical construct - the recipient salience - to approximate the leverage a recipient has in aid negotiations. Recipient salience is thus a proxy concept for leverage. I use different cut points on a sliding scale of recipient salience as an example of the Hempelian bridge principle (Hempel 1966: 72-73) to demarcate when a given recipient has leverage. At some point at the upper end of salience, the recipient becomes important enough to bargain for aid without liberalization that donors in turn accept. Conversely, at some point at the lower end of salience, the recipient is inconsequential enough that donors insist on political liberalization as a condition for aid that the recipient in turn accepts. We observe discontinuities in aid bargaining behavior as the pertinent thresholds in salience are crossed. 
We should also take into account the regional context. A country that is judged by donors as a primary recipient in an African context may not be seen as such in an Asian context, especially since Asian recipients are on average noticeably wealthier. Although we cannot directly observe the precise salience considerations of donors, we can infer from the theory that there should be a significant difference in subsequent liberalization when different thresholds of salience are tested relative to each other. This is a second-order effect of the theory (Tan 2016: 157).

H7: Aid to Asian recipients accompanied by pressure to reform politically, is more likely to result in political liberalization as we shift from less constraining to more constraining indicators of the recipient's salience for donors.

\section{Data and methods}

The theory is about the extent of political liberalization in aid recipients after pressure from donors. To test for regional implications of the theory, I use data on donors' aid commitments and the recipients' regime characteristics. ${ }^{10}$

For indicators of regime type, I use Polity IV (Marshall and Jaggers 2014). It codes the institutional characteristics of states on a 21-point scale that ranges from most autocratic $(-10)$ to most democratic $(+10)$. I follow the convention among Polity IV users by defining a regime as a democracy in the year where it has a Polity score of +6 and above. The focus of donors is on authoritarian aid recipients, which are states with a Polity score below +6 .

For data on aid projects, I use AidData (Tierney et al. 2011). AidData codes at the individual project level. I aggregate information on the donors' intentions for individual aid projects up to the recipient-year level.

The observations are recipient-years. The global dataset contains time series cross-sectional data from 1973 to 2006 with 2091 observations. Of that global pool, 220 observations involve Asian recipients and 1270 observations involve African recipients.

The primary concern with the coding of regions was to ensure there is enough variation to conduct the subsequent statistical analysis. Africa is defined here as states in continental Africa. This definition includes countries in Sub-Saharan Africa, countries north of the sub-Sahara, as well as the outlying island states such as Madagascar. These are countries with the Correlates of War country codes between 400 and 629, including Egypt (country code 651).

By Asia, I am interested in the developing states that are subject to DAC and non-DAC influence. The variable Asia is defined as states in East Asia (country codes 710 to 750 ) and in Southeast Asia (country codes 800 to 850 ). This denotes that part of Asia where Chinese influence is purported to be greatest (Nathan 2015). Although China is seen as an economic powerhouse now, historically it was an aid recipient. It might be the case that China is such an important country that its very inclusion in the list of recipients is distorting the donors' calculus of salience in Asia. To examine Asian recipients without China, I generate the 
variable, Sinic World. This is defined as East and Southeast Asia without China (country code 710). The Sinic World has only 192 recipient-years since China accounts for 28 of the observations. Including two conceptions of Asia (Asia and

Sinic World) reassures us that the anticipated relationship across salience thresholds is not idiosyncratic to the composition of Asia.

\section{Key variables}

The dependent variable, Regimechange 5, measures the extent of political liberalization in the recipient after the exertion of donor pressure. We have two main independent variables. The first, Democratic Push, is a proxy for donor pressure.

The second, recipient status, captures information on the salience of recipients. The salience of a recipient is a composite index derived from its economic and/ or commercial value to donors. A given country has salience and is considered a Primary recipient if it has both strategic and commercial value to all its donors for a given year. Primary recipients have a value of 1 for Strategic Importance and Commercial Importance and that condition holds true for all donors that committed aid to that specific recipient in that given year. Conversely, a country lacks salience and is considered as a Secondary recipient if it lacks strategic and commercial value to all its donors for a given year. Secondary recipients have a value of 0 for Strategic Importance and Commercial Importance and that condition holds true for all donors that committed aid to that specific recipient in that given year.

The default threshold to establish the salience of a recipient is set at the upper $75 \%$ of the standardized distribution. ${ }^{11}$ We can raise the criteria by setting the threshold at $90 \%$, which allows us to generate the variable, Primary 90 , and its corresponding counterpart, Secondary 90 . Raising the criteria means fewer recipients will be considered as "primary" and more recipients will qualify as "secondary". Conversely, we can lower the criteria for primacy by setting the threshold at $50 \%$, allowing us to generate the variable, Primary 50 , and its corresponding counterpart, Secondary50. Lowering the criteria has the effect of making it easier for a given recipient to be considered as a primary recipient but renders it harder to be a secondary recipient; hence fewer countries will qualify as secondary recipients under this criterion. The construction of recipient salience using different thresholds will prove useful for the Asia region where we expect shifts in the likelihood of political liberalization to correspond to the shifts in the salience thresholds. That way, policymakers can anticipate how their aid might still promote democracy even in the more challenging environment of Asia.

The theory argues that the effectiveness of donor pressure using aid to nudge recipients towards democracy is conditional on the salience of the recipient. To capture the interaction of donor pressure on primary recipients, I multiply donor pressure with primary recipients to generate the interaction term, Democratic Push $\times$ Primary. I do likewise for secondary recipients to generate the interaction term, Democratic Push $\times$ Secondary. I repeat the same procedure for the alternative measures of recipient salience, and this allows me to generate the following 
Table 4.1 Summary Statistics for Key Variables in Africa and Asia

\begin{tabular}{llrllll}
\hline Variable & Region & Observations & Mean & $\begin{array}{l}\text { Standard } \\
\text { Deviation }\end{array}$ & Minimum & Maximum \\
& & & & & \\
& & & & & \\
\hline Strategic Importance & Africa & 1270 & 0.408 & 0.492 & 0 & 1 \\
& Asia & 220 & 0.636 & 0.482 & 0 & 1 \\
Commercial & Africa & 1270 & 0.198 & 0.398 & 0 & 1 \\
Importance & Asia & 220 & 0.745 & 0.437 & 0 & 1 \\
Primary (recipient) & Africa & 1270 & 0.054 & 0.227 & 0 & 1 \\
& Asia & 220 & 0.491 & 0.501 & 0 & 1 \\
Secondary & Africa & 1270 & 0.686 & 0.464 & 0 & 1 \\
(recipient) & Asia & 220 & 0.345 & 0.477 & 0 & 1 \\
Democratic Push & Africa & 1270 & 0.674 & 0.469 & 0 & 1 \\
& Asia & 220 & 0.582 & 0.494 & 0 & 1 \\
Cold War & Africa & 1270 & 0.569 & 0.495 & 0 & 1 \\
& Asia & 220 & 0.636 & 0.482 & 0 & 1 \\
GDP per capita & Africa & 1270 & 7.138 & 0.738 & 5.031 & 9.574 \\
(logged, recipient) & Asia & 220 & 8.024 & 0.869 & 6.571 & 10.052 \\
Regime Change & Africa & 1270 & 1.588 & 3.982 & -12 & 15 \\
(5 years after aid) & Asia & 220 & 1.591 & 3.788 & -8 & 16 \\
\hline
\end{tabular}

interaction terms, Democratic Push $\times$ Primary 90 and Democratic Push $\times$ Secondary 90 for $90 \%$ threshold and Democratic Push $\times$ Primary 50 and Democratic Push $\times$ Secondary 50 for $50 \%$ threshold.

Control variables provide alternative accounts of aid allocation and regime change. The variable, Cold War, captures information on the ease with which recipients can switch donor blocs. Likewise, I use the natural logarithm of the recipient's development per capita to create GDP per capita as a control variable.

To give the reader a sense of the distribution of the key variables for African and Asian recipients, Table 4.1 with the summary statistics is presented.

\section{Theoretical expectations}

I use a time series cross-sectional dataset to explore the relationship between donor pressure and political liberalization for global, African, and Asian recipients.

In all three sets of recipients, I include country-fixed effects to control for the domestic political conditions that are idiosyncratic to specific recipients and which may induce political liberalization in those same recipients. I also include the economic development of the recipients and the Cold War context into the regression models as control variables.

For global and African recipients, we expect the marginal effects of recipient status on subsequent liberalization to be statistically significant in a positive direction for Secondary recipients. By contrast, we do not expect the same marginal effect to be statistically significant for Primary recipients. Furthermore, the difference between the two sets of marginal effects should be statistically significant. 
Asia is more challenging for democracy promotion. Since, as previously mentioned, we do not have access to the deliberation of policymakers to determine with exact precision the threshold of salience below which donors will insist on political liberalization in exchange for aid, we focus on the second-order effect inferred from the theory. The idea is that as the criteria for being a secondary recipient become more demanding (as is true for Secondary50 compared to Secondary90), the expectation of liberalization increases.

To examine this second-order effect, the extent of the recipient's subsequent political liberalization is modeled as a function of donor pressure, two different thresholds for determining Primary recipients and likewise for Secondary recipients (for a total of four), the interaction terms between donor pressure and their respective measures of recipient salience, with the development levels of the recipients and the Cold War context as control variables.

Since we are using interaction terms (Brambor et al. 2006), the focus is on the sum of coefficients for the Secondary recipients and their respective interaction terms. For recipients identified by using the " 50 " threshold, we are looking at the sum of Secondary50 and Democratic Push $\times$ Secondary50. Likewise, for recipients identified by using the "90" threshold, we focus on the sum of Secondary90 and Democratic Push $\times$ Secondary 90 .

If the resultant F-test of the difference in the sum of coefficients across the two thresholds is statistically significant and positive when the "90" thresholds are subtracted from the " 50 " thresholds, it means that our measures of recipient salience, however imprecise, are capturing the theoretically expected effects of recipient salience on subsequent liberalization. The more clearly a state is a secondary recipient, the more liberalization we observe. That helps policymakers identify the best candidates for liberalization in the Asian context.

\section{Results}

Our first model, Model 19 in Table 4.2, tests the aid dynamic on the global pool of recipients. It shows that Secondary recipients at the global level are more likely to liberalize after the application of donor pressure. Their primary counterparts however are less likely to liberalize after the application of donor pressure. The F-test that the marginal effects for the two recipient groups are equivalent, with the difference between them due to chance, is 0.003 (F $(1,1987)=8.88)$. Since the result of this model is essentially a replication of Model 3 in Table 2.4 from Chapter 2, its purpose is to be the baseline for comparisons with the regional dynamics to follow.

Model 20 in Table 4.2 shows the results for African recipients. It shows that the effect of a primary status combined with donor pressure using aid is negative. It decreases the subsequent Polity score by 1.599 points. This effect is however not statistically significant (probability of 0.086 ; F $(1,1219)=2.96$ ). By contrast, the same effect for Secondary recipients in Africa is positive, it increases the subsequent Polity score by 0.781 points. The probability that this result is due to chance is $0.043(\mathrm{~F}(1,1219)=3.78)$. Comparing the marginal effects on the two African 
Table 4.2 The Effect of Recipients' Status on Regime Change for Global and Regional Recipients

\begin{tabular}{lccc}
\hline $\begin{array}{l}\text { TSCS, Fixed Effects. Primary } \\
\text { and Secondary Recipients }\end{array}$ & $\begin{array}{l}\text { Model 19: } \\
\text { Global }\end{array}$ & $\begin{array}{l}\text { Model 20: } \\
\text { Africa }\end{array}$ & $\begin{array}{l}\text { Model 21: } \\
\text { Asia }\end{array}$ \\
\hline Primary (recipient) & -0.810 & 0.567 & 0.905 \\
& $(0.583)$ & $(1.372)$ & $(1.535)$ \\
Secondary (recipient) & 0.181 & 0.442 & -0.326 \\
& $(0.414)$ & $(0.516)$ & $(1.039)$ \\
Democratic Push & $0.862^{*}$ & $1.223^{*}$ & -1.520 \\
& $(0.380)$ & $(0.483)$ & $(1.163)$ \\
Interaction term & -0.541 & -2.166 & $2.596^{*}$ \\
(Democratic Push $\times$ & $(.619)$ & $(1.310)$ & $(1.288)$ \\
$\quad$ Primary) & & & \\
Interaction term & 0.440 & 0.339 & 0.602 \\
(Democratic Push $\times$ & $(0.437)$ & $(0.547)$ & $(1.285)$ \\
$\quad$ Secondary) & & & $3.278^{* *}$ \\
GDP per capita* (logged, & $0.824 * *$ & 0.587 & $(1.030)$ \\
$\quad$ recipient) & $(0.273)$ & $(0.331)$ & -0.137 \\
Cold War & 0.097 & -0.071 & $(0.793)$ \\
& $(0.211)$ & $(0.254)$ & $-25.002^{* *}$ \\
constant & $-5.109 *$ & -3.777 & $(8.633)$ \\
& $(2.081)$ & $(2.397)$ & 220 \\
N & 2091 & 1270 & 0.155 \\
Within R-Squared & 0.023 & 0.035 & 0.000 \\
Prob>F & 0.000 & 0.000 & 0.068 \\
Joint Test & 0.003 & 0.016 & \\
** Significant at .01 level, two-tailed & & & \\
* Significant at .05 level, two-tailed & & & \\
() standard errors & & & \\
& & &
\end{tabular}

recipient groups shows that the odds of them being equivalent, with the difference due to chance, are $0.016(\mathrm{~F}(1,1219)=5.83)$. This supports $\mathrm{H6}$, or the claim that in Africa, Secondary and Primary recipients are reacting to donor pressure in systemically different ways.

Exactly how the two African recipient groups react is investigated in follow-up analyses in Table 4.3. Model 22 focuses on African Primary recipients. We found that the status of African recipients as primary is negatively correlated with subsequent liberalization after the application of donor pressure. The status variable reduces the subsequent Polity score by 1.660 points. The chance that this association is random has a probability of $0.069(\mathrm{~F}(1,1221)=3.30)$. The fact that the effect is not statistically significant supports $\mathrm{H} 5$, or the claim that donor pressure on African Primary recipients is ineffective.

Model 23 in Table 4.3 focuses on African Secondary recipients. Here, the status of African recipients as Secondary increases their subsequent Polity score by 0.873 points, after the application of donor pressure. This outcome is statistically significant, with a probability of $0.023(\mathrm{~F}(1,1221)=5.20)$. This supports the 
Table 4.3 The Effects of Recipients' Status on Regime Change for African Recipients

\begin{tabular}{lcc}
\hline TSCS & $\begin{array}{l}\text { Model 22 } \\
\text { Primary } \\
\text { Recipients }\end{array}$ & $\begin{array}{l}\text { Model 23 } \\
\text { Secondary } \\
\text { Recipients Only }\end{array}$ \\
\hline Primary (recipient) & 0.741 & NA \\
Secondary (recipient) & $(1.352)$ & 0.175 \\
NA & $1.467^{* *}$ & $(0.499)$ \\
Democratic Push & $(0.268)$ & $0.881^{*}$ \\
Interaction Term & $-2.401^{*}$ & $(0.451)$ \\
(Democratic Push $\times$ & $(1.243)$ & 0.698 \\
$\quad$ Primary/Secondary) & 0.482 & $(0.516)$ \\
GDP Per Capita & $(0.327)$ & 0.447 \\
$\quad$ logged, recipient) & -0.058 & $(0.320)$ \\
Cold War & $(0.254)$ & -0.023 \\
Constant & $-2.746^{*}$ & $(0.253)$ \\
N & $(2.312)$ & -2.618 \\
Within R-Squared & 1270 & $(2.315)$ \\
Prob>F & 0.032 & 1270 \\
Joint Test & 0.000 & 0.032 \\
\hline
\end{tabular}

** Significant at .01 level, two-tailed

* Significant at .05 level, two-tailed

() standard errors

claim that donor pressure on African Secondary recipients is effective at inducing political liberalization. I conclude support for $\mathrm{H} 4$.

Additional robustness checks show that the Cold War context matters and that the posited aid dynamic still applies even when controlling for reverse causality. Collectively, these results for African recipients confirm our theoretical expectations that the aid dynamic should apply to Africa. In Africa, Secondary recipients are susceptible to donor pressure to liberalize politically; Primary recipients, by contrast, are not.

The literature on development and democracy in Asia cautions us to expect Asia to be different. This is indeed what we find when we return to Table 4.2; only this time, our focus is on Model 21 for Asian recipients. Aid with donor pressure on Asian Primary recipients is associated with an increase in subsequent liberalization by 3.501 Polity points. However, that association is not significant with a probability of $0.066(F(1,202)=3.43)$. The same effect on Asian Secondary recipients is associated with an increase in the subsequent liberalization by 0.275 Polity points. This effect is also not significant with a probability of $0.821(\mathrm{~F}(1,202)=0.05)$. Comparing the marginal effects on the two Asian recipient groups shows that the odds of them being equivalent are $0.068(\mathrm{~F}(1,202)=3.37)$. This means chance 
Table 4.4 The Effects of Recipients' Status on Regime Change across Salience Thresholds

\begin{tabular}{llc}
\hline TSCS & Model 24 & Model 25 \\
Fixed Effects & Asia & Sinic World \\
\hline Secondary90 Recipient & -0.454 & -0.850 \\
& $(0.919)$ & $(0.986)$ \\
Interaction term & $-2.416^{*}$ & -2.239 \\
(Democratic Push*Secondary90) & $(1.206)$ & $(1.278)$ \\
Secondary50 Recipient & 2.039 & 2.497 \\
& $(1.740)$ & $(1.846)$ \\
Interaction term & -1.422 & -1.963 \\
(Democratic Push*Secondary50) & $(1.979)$ & $(2.102)$ \\
Primary90 Recipient & $2.986^{*}$ & 1.383 \\
& $(1.322)$ & $(1.848)$ \\
Interaction term & $-3.790^{* *}$ & -1.832 \\
(Democratic Push*Primary90) & $(1.372)$ & $(2.273)$ \\
Primary50 Recipient & -1.501 & -1.294 \\
& $(1.215)$ & $(1.321)$ \\
Interaction term & -0.467 & -0.781 \\
(Democratic Push*Primary50) & $(1.701)$ & $(1.808)$ \\
Democratic Push & 2.486 & 2.564 \\
& $(1.845)$ & $(1.956)$ \\
GDP per capita & $3.760^{* *}$ & $4.614^{* *}$ \\
(logged, recipient) & $(1.079)$ & $(1.298)$ \\
Cold War & -0.322 & -0.307 \\
& $(0.784)$ & $(0.913)$ \\
Constant & $-27.794 * *$ & -34.334 \\
& $(8.889)$ & $(10.718)$ \\
N & 220 & 192 \\
Within R-Squared & 0.208 & 0.242 \\
Prob>F & 0.000 & 0.000 \\
Joint Test & 0.029 & 0.032 \\
\hline
\end{tabular}

** Significant at .01 level, two-tailed

* Significant at .05 level, two-tailed

() standard errors

alone could have accounted for the difference between them. The fact that all three findings are statistically insignificant is revealing. It suggests, as theoretically expected, that the Asian context is so challenging that the first-order effects of the theory are not active.

The absence of support for the first-order effects does not necessarily imply second-order effects are not possible in Asia, a task that Table 4.4 investigates. The discussion will be on Secondary recipients since that is the recipient group that the theory posits is vulnerable to donor pressure. Model 24 focuses on Asia, a region that includes East and Southeast Asia. The marginal effect of recipient status (using Secondary90) on liberalization modified by the exertion of donor pressure using foreign aid, is associated with a decrease in the Polity score by 2.869 points. 
By contrast, the marginal effect of recipient status (using Secondary50) on liberalization modified by the same exertion of donor pressure using foreign aid, is associated with an increase in the Polity score by 0.617 points. Is the difference in subsequent regime change across the thresholds statistically significant? The F-test to determine whether the effects on the two Asian recipient groups are truly distinct has a probability of $0.029(\mathrm{~F}(1,198)=4.85)$. This shows that as we move from the lax criterion (Secondary90) to a more restrictive criterion (Secondary50), the effectiveness of donor pressure for political reform increases. This lends support to $\mathrm{H} 7$.

Model 25 of Table 4.4 focuses on the Sinic World, a region that excludes China. By removing China as an aid recipient, we remove its potential to distort donors' assessment of salience in Asia. As before, the focus is on Secondary recipients. It shows that the marginal effect of recipient status (using Secondary90) on liberalization modified by the exertion of donor pressure using foreign aid, is associated with a decrease in the Polity score by 3.090 points. By contrast, the same marginal effect on recipients identified using the Secondary50 is associated with an increase in their subsequent Polity score by 0.534 points. The F-test to determine whether the effects on the two Asian recipient groups are truly distinct has a probability of 0.032 (F $(1,171)=4.66)$. Even in the Sinic World, donor pressure for political reform is more effective as we move from the lax criterion (Secondary90) to a more restrictive criterion (Secondary50). This change in effectiveness across salience thresholds supports $\mathrm{H} 7$.

\section{Conclusion}

The theory claims that the effectiveness of donor pressure in nudging recipients towards democracy is dependent on the salience of the recipients. Recipients that are in a position to make attractive counteroffers should be more resilient against donor pressure. Whereas recipients that lack such attributes should be more susceptible to donor pressure. This chapter applies the posited aid dynamic to two regions, Africa and Asia, that account for the majority share of official development aid.

The African region is characterized by persistent developmental needs, inflows of aid, and poor developmental outcomes (Moyo 2010). The region does not have its own developmental model that can provide ideological defense against the Western pressure. The economic malaise of the African recipients translates into political vulnerability. Furthermore, the spate of democratic transitions in SubSaharan Africa from 1989 to 2008 provide the necessary variation in the outcome of interest to suggest the region is conducive for application of the theory.

By contrast, Asia region is relatively prosperous with its own developmental experience. Almost all cases of recent successful authoritarian modernization stories are from Asia (Fukuyama 2012: 16). What is worse from the perspective of democracy promotion, Asia is the home region of an authoritarian China with the potential, if not the political will, to act as a hegemon (Nathan 2015). 
Collectively, this experience grants Asian recipients an ideological alternative with which to rebuff donor pressure from the West to reform. Furthermore, the average Asian recipients are notably wealthier compared to their counterparts in the rest of the world (Tan 2016). For this reason, I argue Asia is a difficult terrain for democracy promotion. While the first-order effects for Asia may not show up, second-order effects may still apply.

The empirical findings support the application of the aid dynamic into the African context well. Unlike their primary counterparts, African Secondary recipients are more likely to liberalize with democracy aid. The differences in marginal effects for the two African recipient groups are statistically significant. This dynamic holds for Africa even when we account for reverse causality. The Asian context is markedly different. As expected, the first-order effects are not supported. To approximate the donors' estimation of salience, I compare across different thresholds of salience for Asian recipients as a Hempelian bridge principle (Hempel 1966). The results show that as we move from lax to more rigorous criteria for Asian Secondary recipients, donor pressure becomes more effective. These provide partial support for the theory.

These results show that Africa is more conducive for democracy promotion but Asia is the more challenging environment. At this moment in history when the concept of democracy is challenged by ideological alternatives such as political meritocracy (Bell 2015), a neighborhood of small democracies around an authoritarian hegemon may be the best that we can realistically hope to achieve in Asia. Policymakers invested in democracy promotion should take note.

We have been gradually moving down the level of analysis from the global to the regional. In the next two chapters, we will apply the theory to specific cases where donors did apply pressure to recipients. We want to understand how effective such nudges are, given concrete politics and by using case studies.

\section{Notes}

1 Parts of this research on Asia builds upon my previous work (Tan 2016). The current version is a modified analysis that builds on and, I believe, improves on my earlier paper on the subject.

2 For an overview of the mindset of that time with an emphasis on globalization, see Bhagwati 2004. Bhagwati has spoken out against unfettered capital flows and is thus not an uncritical cheerleader of globalization.

3 The concern here is on the policy influence of the argument of Burnside and Dollar rather than on the follow-up research on it.

4 The premise of the theory is that we can still test for the possibility of political liberalization in a harsh international environment. This should hold true even if there is a democratic recession after 2006 (Diamond 2015).

5 South Korea and Taiwan undertook land reforms early in the 1950s and subsequently democratized while Philippines and Thailand did not. Both would still experience problems with a regional elite (problem of bossism in Philippines and rural urban tensions in Thailand). 
6 Both Japan and the United states were especially dominant in Southeast Asia (Kurlantzick 2014: 19).

7 A substantial proportion of the Third Wave literature on democratization tends to use the Freedom House Index which measures the civil and political liberties states and classifies them into three categories: free, partly free, and not free.

8 Figures for East Asia and the Pacific and for Low and Middle Income countries are derived from the World Bank at http://data.worldbank.org/region/EAP and http://data. worldbank.org/income-level/LMY respectively (last accessed 6/11/15).

9 It may help to think of an analogy of the difference between speed and acceleration. The latter is derived from measures of the former.

10 Since the dataset \& variables used here are the same as before, I am abbreviating the discussion on the operationalization here and refer the reader to Chapter 2. All the caveats on the data in Chapter 2 apply to this chapter. I will elaborate further when discussing the new variables.

11 The procedure by which I generate the thresholds from the components of strategic and economic value is described in full in Chapter 2.

\section{Bibliography}

Aoki, Murdock, and Okuno-Fujiwara. 1998. "The Role of Government in East Asian Economic Development: Comparative Institutional Analysis." Chap. Beyond the East Asian Miracle: Introducing the Market-Enhancing View, edited by Masahiko Aoki, Hyung-Ki Kim and Masahiro Okuno-Fujiwara, 1-38. Oxford: Clarendon Press.

Asian Times. 2009. "When Allies Drift Apart." 14 February.

Banerjee, A., and E. Duflo. 2011. Poor Economics: A Radical Rethinking of The Way to Fight Global Poverty. New York: Public Affairs.

BBC. 2017. "The Uncertain Future of Democracy." British Broadcasting Corporation. www.bbc.com/future/story/20170330-the-uncertain-future-of-democracy.

BBC. 2019. "Hong Kong elections: Pro-democracy groups make big gains." British Broadcasting Corporation. www.bbc.com/news/world-asia-china-50531408.

Bell, Daniel A. 2015. The China Model: Political Meritocracy and the Limits of Democracy. Princeton: Princeton University Press.

Berridge, G. R. 2015. Diplomacy: Theory and Practice. 5. UK: Palgrave Macmillan.

Bhagwati, Jagdish N. 2004. In Defense of Globalization. Oxford: Oxford University Press.

Brambor, Thomas, William Roberts Clark, and Matt Golder. winter 2006. "Understanding Interaction Models: Improving Empirical Analyses." Political Analysis 14: 63-82.

Brown, Stephen. 2005. "Foreign Aid and Democracy Promotion: Lessons from Africa." European Journal of Development Research 17: 179-198.

Brown, Stephen. 2013. "Routledge Handbook of African Politics." Chap. Democracy Promotion in Africa, edited by Nic Cheeseman, David M. Anderson and Andrea Scheibler, 404-413. Routledge.

Burnside, C., and D. Dollar. 1997. "Policy Research Working Paper." Chap. Aid, Policies, and Growth. Washington, DC: World Bank.

Burnside, C., and D. Dollar. 2000. "Aid, Policies, and Growth." American Economic Review 90: 847-868.

Burnside, C., and D. Dollar. 2004. "World Bank Policy Research Paper.” Chap. Aid, Policies and Growth: Revisiting the Evidence. Washington, DC: World Bank.

Carothers, Thomas. 2009. "Democracy Assistance: Political vs. Developmental?" Journal of Democracy 20(1): 5-19. 
Chang, Ha-Joon, 2006. The East Asian Development Experience: The Miracle, the Crisis and the Future. London and New York: Zed Books.

Chanlett-Avery, Emma. 2009. "Political Turmoil in Thailand and U.S. Interests." Congressional Research Service Report. http://fas.org/sgp/crs/row/R40605.pdf.

The_Chronicle_of_Higher_Education. 2014. "AAUP Rebukes Colleges for Chinese Institutes and Censures Northeastern Il." AAUP Rebukes Colleges for Chinese Institutes and Censures Northeastern Il. 6. www.chronicle.com/article/ AAUP-Rebukes-Colleges-for/147153/.

Collier, P. 2007. The Bottom Billion: Why the Poorest Countries Are Failing and What Can Be Done About It. Oxford: Oxford University Press.

Crawford, Gordon. 1997. "Foreign Aid and Political Conditionality: Issue of Effectiveness and Consistency." Democratization 4: 69-108.

Diamond, Larry. 2015. "Facing Up to Democratic Recession." Journal of Democracy 26: 141-155.

Dietrich, Simone, and J. Wright. 2015. "Foreign Aid Allocation Tactics and Democratic Change in Africa." The Journal of Politics 77: 216-234.

Dollar, David, and Lant Pritchett. 1998. Assessing Aid - What Works, What Doesn't, and Why. Washington, DC: The World Bank. http://documents.worldbank.org/curated/ en/612481468764422935/Assessing-aid-what-works-what-doesnt-and-why.

Dunning, Thad. 2004. "Conditioning the Effects of Aid: Cold War Politics, Donor Credibility, and Democracy in Africa." International Organization 58: 409-423.

Easterly, William. 2014. The Tyranny of Experts: Economists, Dictators, and the Forgotten Rights of the Poor. New York: Basic Books.

Edwards, Sebastian. 2014. "Economic Development and the Effectiveness of Foreign Aid: A Historical Perspective." Centre for Economic Policy Research.

Emmanuel, Nikolas G. 2013. "Democratization in Malawi: Responding to International and Domestic Pressures." African and Asian Studies 12: 415-434.

Fukuyama, Francis. 2012. "The Patterns of History." Journal of Democracy 23: 14-26.

Fukuyama, Francis. 2015. "Why Is Democracy Performing So Poorly." Journal of Democracy $26: 11-20$.

Haynes, Jeff. 2001. Democracy in the Developing World: Africa, Asia, Latin America, and the Middle East. Cambridge, Malden, MA: Polity Press and Blackwell.

Hempel, Carl. 1966. Philosophy of Natural Science. Englewood Cliffs: Prentice-Hall.

Huntington, Samuel. 1991. The Third Wave: Democratization in the Late Twentieth Century. Norman, London: University of Oklahoma Press.

James, William E., Seiji Naya, and Gerald M. Meier. 1989. Asian Development: Economic Success and Policy Lessons. Madison, WI: University of Wisconsin Press.

Kurlantzick, Joshua. 2014. "Southeast Asia's Regression From Democracy and Its Implications." Working Paper. www.cfr.org/sites/default/files/pdf/2014/05/Democratic Regression_Paper.pdf.

Marshall, Monty G., and Keith Jaggers. 2014. "Polity IV Project: Political Regime Characteristics and Transitions, 1800-2013." Polity IV Project: Political Regime Characteristics and Transitions, 1800-2013. www.systemicpeace.org/inscrdata.html.

McCawley, Peter M. 1998. "Development Assistance in Asia in the 1990s." Asian-Pacific Economic Literature 12: 41-50.

Moyo, D. 2010. Dead Aid: Why Aid Makes Things Worse and How There Is Another Way for Africa. London: Penguin Books.

Nathan, Andrew. 2015. "China's Challenge." Journal of Democracy 26: 156-170.

OECD. 2016a. "Development Aid at a Glance: 1. Developing Countries." OECD. 


\section{The regional picture}

OECD. 2016c. "Development Aid at a Glance: 2. Africa." OECD.

OECD. 2016b. "Development aid at a glance: 4. Asia." OECD.

Przeworski, Adam, Michael E. Alvarez, Jose Antonio Cheibub, and Fernando Limongi. 2000. Democracy and Development: Political Institutions and Well-Being in the World, 1950-1990. New York: Cambridge University Press.

Sachs, J. 2005. The End of Poverty: Economic Possibilities for Our Time. New York: Penguin Press.

Soesastro, Hadi. 2004. "Sustaining East Asia's Economic Dynamism: How Aid Worked." CSIS Working Paper. www.csis.or.id/papers/wpe084.

Steinberg, David I. 1990. "Japanese Economic Assistance to Burma: Aid in the 'Tarenagashi' Manner?” Crossroads: An Interdisciplinary Journal of Southeast Asian Studies 5: $51-107$.

Stiglitz, J. 2002. Globalization and Its Discontents. New York: W. M. Norton.

Tan, Bann Seng. 2016. "Aid and Democracy Promotion in Asia." Asian Journal of Comparative Politics 1: 152-170.

Teehankee, Julio. 2007. "The Political Aftermath of the 1997 Crisis: From Asian Values to Asian Governance?" Ten Years After the Asian Crisis: Assessing the Economic and Political Landscape in Southeast Asia, Siem, Reap.

Tierney, M. J., D. L. Nielson, D. G. Hawkins, J. T. Roberts, M. G. Findley, R. M. Powers, B. Parks, S. E. Wilson, and R. L. Hicks. 2011. "More Dollars than Sense: Refining Our Knowledge of Development Finance Using Aid data." World Development 39: 1891-1906.

UN. 2006. "UN Millennium Project." UN Millennium Project. www.unmillenniumproject. org/press/07.htm.

Woo-Cumings, Meredith. 1998. "The Role of Government in East Asian Economic Development: Comparative Institutional Analysis." Chap. The Political Economy of Growth in East Asia: A Perspective on the State, Market, and Ideology, edited by Masahiko Aoki, Hyung-Ki Kim and Masahiro Okuno-Fujiwara, 323-340. Oxford: Clarendon Press.

WorldBank. 1993. The East Asian Miracle: Economic Growth and Public Policy. Oxford: Oxford University Press. 


\section{Myanmar and donor switching}

\section{Introduction}

To understand why donor pressure for democracy promotion fails in some cases but succeeds in others, I argue that we should examine why donors value some recipients more than others. In prior chapters, I test this argument with statistics. By their nature, cross-national datasets tend to go for breadth instead of depth. Case studies allow us to explore nuances in aid relationships that Large-N studies necessarily gloss over. In this case study, I examine the implications that follow when a recipient switches between two donors.

This chapter will focus on Burma, also known as Myanmar, ${ }^{1}$ as a recipient with moderate salience. It represents a case where the recipient has enough salience to attract some attention from donors but not so much leverage as to dictate the terms of aid relationship (that would obviate the need to liberalize in the first place). The fact that Burma provides some value to China allows Burma to seek aid from China instead of the US. At first glance, this suggests Burma has considerable leverage during aid negotiations with donors. Yet, as I will subsequently demonstrate, Burma's room for maneuver is circumscribed by both donors.

Burma has had a long history of military rule (Holiday 2012). When the military junta announced, yet again, new plans for a transition to democracy in 2003 (Sun 2012b: 54), skepticism was understandably widespread. Yet, the country has experienced political liberalization that caught many external observers by surprise (Aspinall and Farrelly 2014). Even Burmese citizens, such as the youth of Yangon (the old capital), were disoriented at the rapid pace of change (BBC 2017a).

This surprising turn allows us to explore the influence of external actors (especially the United States and China) on this process of liberalization. Given our interest in democracy promotion, we want to understand the specific measures Western donors applied to Burma with a view to their effectiveness. It also helps us to recognize that political transition is a non-teleological process and contingent on the incentives of key domestic actors.

The Burmese case highlights the potential for liberalization even in the scenario when one alternative donor, China, has leverage and is opposed to the resultant regime change. To understand the nuance of this claim, I draw upon 
an example from the sanctions literature. Consider the impact of the economic sanctions on Iran.

When a new sanctions regime on Iran was announced by the international community in 2007 over its alleged nuclear weapons program, it could be argued that such actions are merely symbolic. After all, Iran has been under sanctions from the United States since 1979 (over the Iran Hostage Crisis). Further sanctions on the already limited trade between Iran and the United States are arguably redundant. Furthermore, Iran could sell its oil on the non-Western markets, notably to China and India. ${ }^{2}$ However, we will be underestimating the impact of sanctions if we only consider the value of trade between Iran and the West. We should also consider the impact of sanctions on the terms of trade between Iran and non-Western markets. Iran, of course, sought to sell its oil at a price it would have gotten on the Western markets had Iran not been under Western sanctions. That was not the offer it got from non-Western buyers. For example, its oil trade with India paid in Indian rupees instead of the more desirable US dollar. Furthermore, that payment was used instead to fund Iranian purchases of Indian goods specifically in food, drugs, auto parts, and consumer products (WSJ 2016). ${ }^{3}$ That is to say, Iran is getting a lower value for its oil than it could have had in the Western market. Why did Iran accept this deal on such poor terms of trade? Precisely because Iran was banned from the Western market due to sanctions, its leverage with its non-Western buyer was weak. The non-Western buyers of Iranian oil understand this and exploit the circumstances to extract more concessions from Iran. Here, we have a case of an alternative buyer, India, utilizing its leverage to get more value out of a trade with Iran. The Western sanctions have had an indirect impact on the leverage of Iran visà-vis India. That Iran can find an alternative non-Western buyer for its oil does not automatically translate into an advantage for Iran. Bargaining can cut both ways.

I will now apply the example drawn from the sanctions literature to the aid bargaining dynamic. Imagine a hypothetical scenario between two donors, A and $\mathrm{B}$, and a recipient $\mathrm{X}$. Donor $\mathrm{A}$ is a democratic regime with a mild preference for democracy promotion. By mild preference, I mean that donor A will prefer strategic and commercial concessions over democracy promotion. By contrast, donor B is an authoritarian regime with no intrinsic preference for democracy promotion. There is a good reason to suppose this preference. Intervention for democratization in a client state opens the authoritarian regime up to similar demands from within. It also creates opportunities for external intervention into donor B from without. Recipient $\mathrm{X}$ has an authoritarian regime and the country itself has some value to the donors. Donor A applies donor pressure on the recipient $\mathrm{X}$ to enact political reforms. The authoritarian regime from recipient $\mathrm{X}$ does not want to pay the political costs and starts to look for alternative donors. I call this process of shopping around for alternative donors "donor switching”. Recipient X turns to donor B for aid without the political conditionality. Donor B could have offered the aid to recipient $\mathrm{X}$ on the same terms that donor $\mathrm{A}$ was offering (without the democratization conditionality). Alternatively, donor B could exploit the situation to its advantage. Donor B could change the terms to extract more concessions from recipient $\mathrm{X}$ to account for the fact that recipient $\mathrm{X}$ has turned down an offer 
from donor $\mathrm{A}$. In this scenario, the fact that recipient $\mathrm{X}$ has alternative donors need not mean it has necessarily more leverage. Taking the agency of donor B seriously yields the theoretical implication that donor switching need not always be to the recipient's advantage.

Our recipient $\mathrm{X}$ is not without means to protect its interests though. If the demands of the donor $\mathrm{B}$ should prove excessive, recipient $\mathrm{X}$ does not have to accept the terms on offer. It has agency too. It could choose to walk away from a deal. It might decide to switch back to donor A. Since donor A has a preference for liberalization, recipient X may even accept limited political liberalization as the lesser of two evils. This outcome of liberalization occurs despite the best efforts of recipient X. The prospects of exploitation by donor B make the offer from donor A more palatable by comparison. This outcome emerges from the pursuit of rational self-interests by all three actors; two of whom, donor B and recipient $\mathrm{X}$, are simply adapting to the circumstances. This leads to another theoretical implication, that donor switching may have the unintended effect of creating a space for political liberalization!

Burma has aid relationships with multiple interactional actors, including Japan, India, the European Union (EU), and the Association of Southeast Asian Nations. The key relationships are between Burma, the United States, and China though. Applying the theoretical framework to the case study, the United States could be donor A and China donor B, and the recipient X, Burma. The attempt by Burma to donor switch between the US and China could give leverage to China depending on the extent to which Burma has burnt its bridges with the West. This yields the following Hypothesis 8:

H8a: China extracts more concessions from Burma/Myanmar when the latter is unable to receive aid from the West.

H8b: China extracts less concessions from Burma/Myanmar when the latter is able to receive aid from the West.

Since the Burmese junta is rational, they can be expected to donor switch if the Chinese terms are too demanding. This is our Hypothesis 9:

H9: When the Chinese demands become excessive, Burma/Myanmar will switch back to the West and implement some political reforms.

Donor switching is example of the nuances that case studies, rather than Large-N studies, are more suitable for highlighting.

The rest of the chapter is structured as follows. I start with a brief discussion of identity politics in Burma. That is followed by an analysis of the salience of Burma to the donors. I conduct an overview of Burmese domestic politics with an eye to its foreign policy predilections. This in turn sets the context for understanding the political reforms that Burma undertook. As required by the theory, we will focus on the role of external actors in those reforms. In addition, I also explore the Chinese reaction to those reforms. I add in the caveats that the reforms do not equate to democratization. The conclusion discusses the implications of the case study. 


\section{What is in a name?}

The polity in question has been known as Burma and its people as a collective whole, the Burmese people, for much of its modern history. Since 1962, Burma has been under military rule. Repeated economic mismanagement provoked a democratic uprising in 1988. That uprising was crushed by the new military government, known as the State Law and Order Restoration Council, or SLORC. It was SLORC that decreed in 1989 a name change for the country with the Law No. 15/89 (Holiday 2012: 5). Burma was renamed as Myanmar and its people as the Bamar people.

One could treat the name change as a mere update of names given during British colonial times. For example, the Chinese capital, Beijing, is the updated version of its old colonial name Peking (Holiday 2012: 5-6). That is not the situation here. The name change was controversial on several levels. A technical reason against the change is that there were only two linguists in the commission tasked with the name change. As a result, transliterations that are more faithful to the local language such as "Myanma" or "Myanmah" were not chosen (Holiday 2012: 6).

The main controversies are political and moral. The political objection to the name change is due to the transitional nature of SLORC. It came into being as a reaction to the events of 1988 , justified its rule on a temporary basis, and tasked itself with a transition to democracy. Given its status at best, as a caretaker government, it lacks the political authority to make changes to the country on a permanent basis.

The subsequent moral status of SLORC did not help either. It promised a transition and held an election in 1990. The opposition party, the National League for Democracy or NLD, led by Aung San Suu Kyi (the de facto president of the current government in Myanmar), won a landslide victory in that election. SLORC refused to acknowledge the results of the elections, transfer power, and step down. The NLD argued that without the endorsement of an elected parliament, the name change was illegitimate (Holiday 2012: 8).

The ethnic minorities in the country also opposed the name change. They resented the fact that the chosen name was transliterated from the dominant language of the dominant ethnic group, the Bamar people (Holiday 2012: 8). They preferred the original name despite its colonial origins. Given the importance of the ethnic cleavage and the history of ethnic conflict in Burma (to be explained later), opposition by the ethnic minorities has to be taken into account too if a stable country is the goal.

The name change was polarizing in the field of Burma studies. From the viewpoint of those who support the democratic opposition, it was seen as the capricious act of an illegitimate body that lacks the political authority to do so and thus rejected. Western donors, most important of all the United States, tend to take this position. The United States did not recognize the change for many years (Holiday 2012: 8). Those who argue that the function of a name is to denote a place, and nothing else, accommodated the name change. They use 
the current name, Myanmar, and retrospectively apply it to refer to the polity before 1989.

I make a theoretical argument for democracy promotion emphasizing the agency of foreign aid donors, one of whom, the United States, explicitly rejected the name change for a time. Insisting on the use of Burma seems too anachronistic since that name is no longer widely used in 2020; yet insisting on the use of Myanmar violates the spirit of the book.

A solution is to use the name appropriate to the political context of that time. Before 1989, it is Burma, and after 1989, it is Myanmar. Since ethnic cleavage is an issue, we want to differentiate between the people of the country as a collective and also to identify the dominant ethnic group. I use "the Burmese people" to refer to the collective people in an ethnicity-blind manner and I use "Bamar" to refer specifically to the dominant ethnic group. For all other situations, I use the adjective Burmese (instead of Myanmarese). This is the approach adopted by the scholars of that region (Holiday 2012) and is a reasonable compromise without getting into distracting semantics. This convention will be implemented henceforth.

\section{Salience of Myanmar}

The theory argues that the value or salience of the recipient plays an influential role in the ability of the recipient to resist donor pressure to liberalize politically. In the real world, we have to deal with recipients who give more value to some donors but not others. Myanmar is one such case. Generally, it is more valuable for China than it is for the United States.

From the Chinese point of view, Myanmar as a client state yields several strategic and commercial benefits. Within the Chinese political context, the Chinese Communist Party seeks performance legitimacy as part of its strategy for longterm political survival. The two key aspects of this strategy are the delivery of near continuous economic growth and vigorous defense of China's territorial integrity (Yang and Zhao 2015). To its credit, the Chinese economy, compared to the developed world, has enjoyed remarkable growth rates since the reforms of Deng Xiaoping. Currently, the Chinese economy is considered either the largest or the second largest (behind the United States) economy in the world. One consequence of a growing economy is a voracious appetite for energy, especially oil and gas. Over $75 \%$ of China's oil imports pass through the Malacca Straits. Since that strait lies outside the reach of the Chinese Navy but is well within the reach of the US Navy, it represents a strategic vulnerability for China.

Myanmar offers one solution to China's "Malacca Dilemma" (Chan 2017: 4; Fiori and Passeri 2015: 681). By laying oil and gas pipelines through Myanmar, China can import energy from the Middle East and bypass the Straits. This was the reason for China's interest and heavy investment in the Sittwe-Yunnan pipeline (Fiori and Passeri 2015: 681, 690). The pipeline connects the Chinese city of Kunming in Yunnan with the Burmese deepwater port of Kyaukphyu. Such is the importance of this pipeline that China accelerated its construction after 2011. The 
reason for haste is because China sought to forestall more unwelcomed policy change from Myanmar in the aftermath of the cancellation of the joint Myitsone Dam project (Sun 2012b: 59).

Besides being a transit shortcut for energy supplies, China had more ambitious aspirations for Myanmar. Formulated in a time when China assumed, erroneously as it turns out, that the new civilian government would be plaint to Chinese wishes, its strategic plan for Myanmar was laid out in its "comprehensive strategic cooperative partnership" (Sun 2012a, 2012b). Under the plan, Myanmar would be China's "bridgehead" into the Indian Ocean (Sun 2012a: 83-84). Chinese interest in access to the Indian Ocean is part of its "Two Oceans" strategy. The two oceans in question being the Pacific and the Indian Ocean. For the eastern side of China, the Pacific Ocean is the natural strategic priority. For the western side of China, the Indian Ocean is the more convenient outlet (Sun 2012a: 84). Essentially, China is worried about the security of its maritime shipping and sees the two oceans as the key regions where its navy should operate and eventually secure. In the more militant interpretation of this Two Oceans strategy, Burmese ports will be part of a "String of Pearls", a network of ports that can neutralize a potential encirclement of China by both India and the United States (Fiori and Passeri 2015: 691). In the less militant interpretation, access to Burmese ports is the "least threatening" option for the Chinese navy to project power into the Indian Ocean (Sun 2012a: 84).

The 2,816 km long border between China and Myanmar is also a security concern for China. The issue is a potential refugee spillover for China as a result of the ethnic conflict in Burma. In 2009, for example, fighting in Kokang caused 37,000 refugees to flee into Yunnan, much to the displeasure of the Chinese authorities (Sun 2012a: 75). Myanmar has had a history of multiple, long-running, and concurrent ethnic conflicts (Farrelly 2014). Two of those in particular - involving the Kachin Independence Army (KIA), the United Wa State Army (UWSA) and the Burmese military - affect Chinese interests. The former matters because the KIA exercises some influence in the Kachin State where the controversial Myitsone Dam project is located. Chinese infrastructure projects in that state were vulnerable to KIA attacks (Sun 2012a: 76). The latter matters because the UWSA is the successor to the remnants of the Burmese Communist Party, the BCP (Holiday 2012: 68). The BCP used to enjoy military support from China.

Myanmar can also provide some diplomatic cover for China. Chinese claims in the South China Sea overlap and clash with rival claims by several maritime member states of the Association of Southeast Asia or ASEAN. ASEAN has a proclivity to hold many international meetings every year. Some of those multilateral meetings have the potential to embarrass China. China wants to prevent a united front among ASEAN members as that would give legitimacy to American intervention on the behalf of ASEAN. To forestall such an outcome, China expects Myanmar to support its position on the South China Sea dispute in such multilateral forums (Sun 2012a: 74, 2012b: 82).

Myanmar provides commercial benefits to China as well. Since both Yunnan and Sichuan provinces are landlocked, Myanmar is the natural outlet for their 
products (Asia Times Online 2011). China sees Myanmar "as a resource-rich and largely underdeveloped neighboring country which could help China in alleviating her voracious appetite for resources" (Fiori and Passeri 2015: 681). Much of Chinese foreign direct investment in Myanmar is concentrated in natural resources extraction. That natural resource trade has both a legal and illicit counterpart. ${ }^{4}$ In either form, the Chinese market is the final destination for those exports (The Diplomat 2015).

Myanmar's potential in hydropower and as an energy transit route appeals to the "energy-starved" southwestern provinces in China (Sun 2012b: 69). The Sittwe-Yunnan pipeline, when complete, would send 22 million tons of crude oil and 12 billion cubic meters of natural gas annually to China (Sun 2012b: 69). The Myitsone Dam project, had it not been suspended, would have generated 6000 megawatts of electricity; $90 \%$ of which would have been sold to China (Chan 2017: 6).

The United States, by contrast, has less at stake in Myanmar. Its policy towards Myanmar - until recently - is part of its overall attitude towards Southeast Asia. This attitude is characterized as one of "benign neglect, with episodic attention to perceived security threats" (Mauzy and Job 2007: 622). The United States has been relatively disengaged since 1975 when it pulled out of Vietnam. With the end of the Cold War, even the imperative of containing communism in Southeast Asia disappeared. ${ }^{5}$

Amidst benign neglect, Myanmar, compared to the other challenges facing the US, is considered negligible. Few US policymakers specialized in that country. It is fashionable, however, among those who advocate for human rights. No wonder, Myanmar is described by some as a "boutique issue" (Fiori and Passeri 2015: 692) and as a "forgotten crises" (Holiday 2012: 120).

This state of affairs has a positive side effect. It allowed, under the Clinton administration, the imperative of democracy promotion to be temporarily prioritized (Kurlantzick 2014). The Clinton administration reacted to the Burmese junta's crushing of the 1988 democratic uprising with sanctions. In a telling statement, Bertil Lintner, an expert on Burmese politics, reported the following observation by a senior US diplomat in Yangon made in 1989:

Since there are no US bases and very little strategic interest, Burma [Myanmar] is one place where the United States has the luxury of living up to its principles.

(Asia Times Online 2011)

The logic behind this statement strongly collaborates with the claim that donors push for democracy only in the cases of marginal importance.

Under the Bush administration, the focus shifted to counterterrorism after the September 2001 attacks. Democracy promotion in the region was downplayed compared with the Clinton years (Kurlantzick 2014: 19-20). The US was willing to tolerate authoritarian allies in exchange for aid in counterterrorism. Unlike Thailand (Tan 2016), ${ }^{6}$ Myanmar has no contribution to American counter-terrorism 


\section{0}

operations. It is reported that First Lady Barbara Bush was personally affected by the human rights abuses in Myanmar and became an advocate for political pressure (Kurlantzick 2014: 20). Condoleezza Rice, in her Senate confirmation hearing in 2005, ranked Burma as the second worst "outpost of tyranny" (Fiori and Passeri 2015: 692). Accordingly, there was little incentive to lift sanctions.

The next significant change occurred under the Obama administration, whose signature foreign policy initiative was the "Pivot to Asia". The Obama administration felt that the United States had overcommitted to Europe and the Middle East, with its forces entangled in the quagmire of Afghanistan and Iraq. Meanwhile, the rising power with a successful economy, China is gaining influence in the AsiaPacific. The pivot represents the American re-engagement with the region and is meant to reassure American allies (Clinton 2011). An unspoken premise of this strategy is the geostrategic competition with China.

In rivalry with China, Myanmar becomes more significant for the US. Consider, for example, the rationale offered by key US policymakers. Jim Webb, a US senator from the Democratic Party and the first senior US official to meet with the reclusive Burmese leader Than Shwe, in 2009 made following observation:

Sanctions by Western governments have not been matched by other countries, particularly Russia and China. Indeed, they have allowed China to dramatically increase its economic and political influence in Myanmar, furthering a dangerous strategic imbalance in the region.

(New York Times 2009)

The reorientation to Asia provides an opportunity for the US to rethink its policy on Myanmar. Instead of using sanctions as a symbol of international condemnation of the regime, the lifting of sanctions might be used to persuade the regime to reform.

Domestic US politics also played a role. At the beginning of his presidency, Obama was eager to distinguish himself from his predecessor. Countries which were under sanctions during the Bush years received a reassessment under the Obama administration (Fiori and Passeri 2015: 693). Near the end of his presidency, he faced a foreign policy track record that is criticized as weak overall (Walt 2017). The Obama administration needed a "win" in Asia. The strategic value of getting Myanmar onto the Western side and its "enormous untapped market [made] it a potential prize" (Kurlantzick 2014: 21) for the Obama administration. It should be emphasized that such a policy shift on Myanmar is not trivial domestically. The Obama administration expended "significant political capital restarting relations with the country and convincing Congress to go along" (Kurlantzick 2014: 21). The subsequent reforms in Myanmar, as it turns out, provided the symbolic victory the Obama presidency sought. This helps to explain why the US was willing to engage with the regime despite the ongoing ethnic conflict and human rights abuses. The American objective is still to promote democratization in the long run. Under Obama, Myanmar gained strategic value as the US sought to wean Myanmar off Chinese patronage. 


\section{Burmese praetorian politics and its concomitant foreign policy}

After independence in 1948, Burma had a brief period of civilian rule under U $\mathrm{Nu}$. This ended with the coup of 1962 led by General Ne Win. From 1962 to 2012, Burma has over 50 years of near-continuous military rule. ${ }^{7}$ Given this history, the Burmese military, known as the Tatmadaw, has overwhelming influence over Burmese politics. We want to understand the worldview underpinning that influence.

A starting point is Huntington's classic work on praetorian politics (Huntington 1957). In it, professionalism in the developed countries is understood to entail the subordination of the military to civilian leadership. A professional military has as its primary mission the defense of the country against an external threat. Intervention into domestic politics is anathema to the professional military of a developed country. This framework, Myoe (2014) argues, does not apply for the developing world. Many states in the developing world face a legitimacy crisis at birth. The state itself is contested by various social groups such as ethnic groups, sectarian groups, separatists, and communist parties. "Threats of armed separatism, communal violence, and communist armed struggle are among the common security problems in post-colonial developing countries" (Myoe 2014: 235). Such circumstances direct the threat perception inward instead of outward.

For developing countries, the path to independence entails armed struggle against the colonial masters. Those armed militias that led the struggle tend to form the nucleus of a new national army. In Burma, anti-colonial politicians form their own private militias, known locally as the Tats (Myoe 2014: 241). In fact, Burma's independence leader and war hero Aung San also founded a Tat. Aung San is of course, the father of Aung San Suu Kyi, the current elected leader of Myanmar. In those early years of independence, some politicians joined the national army, the Tatmadaw, while some soldiers took the role of politicians. "Both politician-turned-soldier and soldier-turned-politician have employed the Tatmadaw to advance their careers" (Myoe 2014: 241). Such intermingling created a national army that was born political.

By virtue of being the most organized of the state groups, the military in a developing country tends to arrogate for itself the leadership role in combating internal security threats. On top of that, they respond to the legitimacy crisis by adopting a nation-building enterprise. Armies in such circumstances tend to have an expanded political role. This is the case for the Tatmadaw. Its praetorian ideology is articulated in its 1958 National Ideology and the Role of Defense Services. Under this ideology, the Tatmadaw defined internal security, counter insurgency, and economic development as its duties. In so doing, it acquired a guardianship role that ensured it would remain the dominant political force (Myoe 2014: 242-243).

The first major challenge in Burmese nation-building lies in its deep-rooted ethnic conflict. A persistent cleavage is the conflict between the center governed by Bamar ethnic majority and the hill tribes (non-Bamar ethnic groups) in the 
periphery. To paraphrase from a senior Burmese government official and cited by Farrelly (2014: 252):

[T] he problem is that 60 percent of our people live on 40 percent of the land, and 60 percent of the land is home to only 40 percent of the people.

The original status quo enshrined in the Panglong Agreement between the original civilian government led by Aung San and the major ethnic groups that led to the Union of Burma envisioned a unified republic, albeit with autonomy for many of the ethnic groups. For various reasons, the spirit of the Panglong Agreement was not upheld and armed insurgencies involving multiple ethnic groups broke out. Some of these groups wanted more autonomy within the Union, others sought secession (Myoe 2016: 4). After Ne Win's military coup of 1962, this became the Tatmadaw's problem. The Tatmadaw adopted three principles, known later as the Three National Causes, it sees as its duty to defend: the non-disintegration of the Union, the non-disintegration of national solidarity, and the perpetuation of national sovereignty (Myoe 2014: 243). In defense of these principles, the Tatmadaw engaged in what is in effect decades of a low-intensity civil war against its ethnic minorities. This context of civil war helps account for the preoccupation of the Tatmadaw with internal security.

The other major challenge is economic development. The Tatmadaw was heavily influenced by leftist ideology. From 1962 to 1988, it tried to build a socialist economy using Marxist principles under its "Burmese way to socialism" slogan (Myoe 2014: 243). The junta nationalized key industries, pursued aggressive autarky with import substitution industrialization, cut off foreign investments, and crippled its important rice export industry within a few years of power (Holiday 2012: 49-52). The outcome was dysfunctional state capitalism characterized by widespread shortages of basic goods as well as a thriving black market (Holiday 2012: 51). It was an economical disaster. The currency was demonetized in 1987. That change caught many by surprise and wiped the savings of its people (Holiday 2012: 54). Burma went from a country that was well-endowed with mineral and organic wealth to one of the poorest countries in Southeast Asia by the 1980s. "The Burma Road to Poverty", to borrow Mya Maung's evocative phrase, is complete (Maung 1991).

As a small state, the foreign objectives of Burma under civilian rule, pre-1962, are understandably modest. Its perennial objectives are to remain independent and to maintain full sovereignty (Barany 2016). Its traditional diplomatic means were to stay neutral and avoid entanglement with the alliance structures of major powers. As an example, Burma refused to participate in the British Commonwealth and sought membership in the United Nations instead (Myoe 2016: 4). It did this because it wanted to break from its colonial past and to avoid alignment with major powers (in this case, the United Kingdom). Unlike its neighbor Thailand, Burma did not seek a de facto military alliance with the United States. Burma is also one of the leading states in the Bandung conference of 1955, an attempt by the countries of the Global South to avoid choosing sides between the superpowers. 
This predisposition towards neutrality and non-alignment is partly due to its challenging neighborhood. Burma is a small state wedged between two regional hegemons, India and China, with by now, over 2.6 billion in population between them (Barany 2016). Burmese threat perception is focused on China for three historical reasons. First, the nationalists lost the Chinese Civil War and elements of the Kuomintang (KMT) fled into Burma. Second, the Burmese Communist Party (BCP) started a communist insurgency which lasted from 1948 to 1989 . China had provided substantial military support for the BCP (Myoe 2016: 9). Third, the border between China and Burma was not demarcated and China had, from 1953 to 1956 , maintained its troops inside Burmese territory.

To manage Chinese relations, the Burmese civilian government came up with the concept of "Pauk-Phaw" which translates into fraternity between the Burmese and the Chinese peoples (Myoe 2016). In practice, it means Burma sought to maintain as friendly relations as possible with China. Burma avoided any explicit action that would have given China a pretext with which to intervene into Burmese domestic politics (Myoe 2016: 7). Thus, Burma did not join any anti-communist alliances.

The military junta that took over in 1962 faced the same external constraints. However, the country was weakened by domestic insecurity and economic malaise. Chinese business interests were nationalized in Burma as part of the junta economic autarky program and anti-Chinese riots broke out in 1967. Relations took a further turn for the worse when China underwent its Maoist phase and sought to export revolutions in Asia. Maoist China stepped up its military support of the Burmese Communist Party (Myoe 2016: 9). Lintner reports that China gave more military aid to the BCP than to any other communist movement outside of Indochina (Asia Times Online 2011). The Tatmadaw is well aware of Chinese aid to the BCP. ${ }^{8}$ Yet Ne Win, in a revealing speech (the 1969 Party Seminar), insisted that Burma has no choice but to seek cordial ties with China (Myoe 2016: 9). Consequently, the junta maintained the traditions of nonalignment and friendship with China.

The friendly ties received a boost near due to the international repercussions from two domestic events, the Tiananmen massacre in 1989 and the 8/8/88 incident in 1988. Both were situations where an authoritarian regime crushed pro-democracy protests. China and Myanmar were condemned and became international pariah states. While China was too important to remain internationally isolated, Myanmar was not. It retained that pariah status until around 2011. During the period, Myanmar was afforded diplomatic protection by China. Significantly, it used its UN veto to shield Myanmar from the United Nations sanctions in 2007 (Sun 2012a: 91). China provides support because it adheres to the principle of non-intervention in the domestic affairs of others. Like many other authoritarian regimes, it opposes foreign efforts at regime change since that justifies foreign intervention into its own affairs.

The other rationale for Chinese patronage for Myanmar is economic. Since Myanmar was under Western sanctions, it became heavily dependent on Chinese trade and investment to fund its economic development (Sun 2012a: 87; Chan 
2017: 2). From 1990 to 2012, China has invested a total of US\$ 14.14 billion in Myanmar. The size of that investment dwarfs all other foreign investors in Myanmar by 2012 (Sun 2012b: 57).

Myanmar's diplomatic preference for neutrality is not usual. Many countries in the Global South prefer not to take sides between the superpowers during the Cold War. As a small state, its room for maneuver is limited in most situations. The challenging neighborhood meant Myanmar had to avoid alienating stronger neighbors, especially China. Both the civilian and military governments followed these foreign policy predilections. The diplomatic isolation and economic sanctions imposed after 1988 pushed Myanmar towards Chinese orbit. This was the diplomatic context that set up the transition years.

\section{A series of political change}

When the junta announced in 2003 a seven-step roadmap to a "disciplined democracy" as part of its transition plan, most observers had low expectations (Aspinall and Farrelly 2014). The track record of the junta since 1988 in governance was ad hoc, and motivated mainly by the goal of political survival (Holiday 2012: 12). Given the way it brushed aside the results of the 1990 election that the opposition NLD won, crushed the protest by Buddhist monks in 2007, and blocked humanitarian aid in the aftermath of Cyclone Nargis (Selth 2008), there is little to suggest the regime is serious about political liberalization. Even the country with the closest ties to Myanmar, China, expected a symbolic transition and the pro-China policy to be maintained (Sun 2012a).

Against expectations, a series of remarkable political changes occurred. First, there were significant leadership turnover. Khin Nyunt was the former head of intelligence and generally considered the third most powerful member of the military junta leadership. He was initially dominant but was subsequently purged in 2004. The next dominant leader was Than Swe. Than Swe, a hardliner, in turn chose Thein Sein to be his successor (NYT 2012). Thein Sein was the junta leader credited for maintaining the country on the path of reforms, even if he was not personally the most powerful actor within the junta leadership.

Second, the steps of the roadmap were actually implemented! The National Convention created to draft a new Constitution for Myanmar (to replace the 1974 Charter) started in 1993 finally completed its work in 2007 (Holiday 2012: 12). The new constitution was subjected to a referendum in 2008 and approved. ${ }^{9}$ A general election was held in 2010. It was won by the junta's preferred party, the Union Solidarity and Development Party (USDP). The USDP formed a civilian government that took over power from the military junta. The civilian government held two elections since then, the 2012 by-election and the 2015 general election.

Third, the military junta changed its approach to ethnic conflict in the country. Instead of a purely militaristic approach, it offered political conciliation with ethnic minorities. The junta sought peace settlements with over ten armed ethnic groups and entered negotiations for ceasefires with others (Myoe 2014: 236). By 
2016, the regime had ceasefires with over 17 ethnic armed groups (Barany 2016). Some of the ethnic armed militias were integrated into the Tatmadaw as Border Guard Forces (Myoe 2014: 246). The junta offered the ethnic groups representation in both the upper and lower house of the new parliament, the Pyidaungsu Hluttaw (Farrelly 2014). Ethnic parties were formed and had their first chance to contest in the 2010 elections. Although the electoral system is still new, Farrelly (2014: 259) suggests that both the NLD and the junta-backed USDP will need some form of accommodation with ethnic parties to claim nation-wide representation. In that respect, the formation of united front parties, such as the Federal Union Party, representing 13 smaller ethnic parties is encouraging (Farrelly 2014: 261). These efforts are significant. After all, one of the key raison d'être for the Tatmadaw is the defense of the nation against the threat of secession. Compared to Western armies, the Tatmadaw is ideological and committed to its praetorian logic (Myoe 2014). For it to return to barracks, it has to demonstrate substantial progress in resolving the ethnic cleavages in the country.

Fourth, the constitutional changes were supplemented by socioeconomic reforms. In the main, this is the natural extension of a commitment to political liberalization. For new political institutions to be credible, the mindset of the people, who lived under military rule for over 50 years, must change too. The junta and its civilian replacement started talks with the opposition and its leader Aung San Suu Kyi in 2009 (BBC 2017b). A key demand of the opposition is the release of political prisoners. The government started to release more political prisoners. This included releasing from house arrest the vice chairman of the NLD, Tin Oo and more significantly, the release of Aung San Suu Kyi herself in 2010 (BBC $2017 \mathrm{~b}$ ). The NLD contested and won by a landslide for both the 2012 by-elections and the 2015 general elections.

In authoritarian systems where the public expressions of dissent are punished, much of the criticisms of the government are oblique. The social/cultural sphere is an outlet for such indirect expressions of dissent. This is why the social reforms and cultural change in Myanmar have political significance. Previously the censorship board would ban dissent outright, now the Burmese people are officially free to dissent. Laws were passed allowing for the formation of trade unions in 2011 (BBC 2017b) and press censorship was relaxed (Fiori and Passeri 2015: 682; BBC 2017b). Menager (2014) identified three social groups in Burmese youth culture - the children of business elites, the children of the military elites, and the cultural elites - and examined how they reacted to the liberalization of the public sphere. The BBC (2017b) reports that in Yangon, the people are bewildered by the rapid social change and are unsure of the boundaries of safe political expression. This is because the current government can still evoke the notorious 66D defamation clause to punish critics (BBC 2017a).

Fifth, one of the more important expressions of dissent was the public protest over the Myitsone Dam project (Chan 2017). The Myitsone Dam was a joint hydropower project between the Chinese and Burmese governments. Both governments used their respective state-owned enterprises. The Myitsone Dam itself is part of a planned seven dam cascade located at the confluence of the 
Ayeyarwady river basin. This massive project was described as China's overseas Three Gorges Dam, to the displeasure of the Burmese populace (Chan 2017: 6-7). The completed dam project would have generated several negative externalities. The reservoir it would create would displace at least 18,000 people in the politically sensitive (due to ethnic conflict) Kachin State. The downstream effects of the dam were considerable too since the Ayeyarwady river is an important commercial waterway (Chan 2017: 7). Furthermore, the Burmese economy is dominated by Chinese businesses. This contributes to a groundswell of resentment against Chinese goods and business (Holiday 2012: 12). The fact that $90 \%$ of the generated electricity is sold to China instead of Myanmar added to that resentment (Chan 2017: 6-7).

A "Save the Ayeyarwady" campaign started and it grew into a movement of problematic proportions by 2010-2011 (Chan 2017). The USDP government could have crushed the protest with the aid of the army but that would have meant the collapse of the political reform project initiated since 2003. With the collapse of reforms, Western sanctions would have resumed, and Thein Sein, the leader who invested much of his political capital into the reforms would have been hard-pressed to stay in power. The treatment of the movement became a test of the will of the junta to stay on the path of reforms (Sun 2012b: 58-59). The regime chose to suspend the project in 2011. Thein Sein announced, "We have to respect the will of the people as our government is elected by the people" (BBC 2011).

The significance of this U-turn is the way it shattered Chinese complacency about relations with Myanmar (Sun 2012a, 2012b). It was followed by rapidly warming ties between Myanmar and the US (Fiori and Passeri 2015). This is the first signal that the severe tensions within the junta over the extent of Chinese influence within Myanmar can no longer be contained (Asia Times Online 2011).

\section{The impact of external actors}

What prompted these political reforms? We know, in the main, democratization is an internally driven process. There is a view that the military leadership was simply exhausted with governance, humiliated by the economic backwardness of the nation and was facing a growing desire by its own people for change (Sun 2012b: 54). Slater (2014) argued that the Tatmadaw enacted reforms at a time when it has already crushed all opposition and is at the height of its power. Slater's view is that the junta enacts reforms because it is able to dictate terms of the transition.

For these reasons, the military junta enacted reforms while ensuring its imperatives were protected. The 2008 constitution guaranteed the army autonomy and protected it from civilian interference (Myoe 2014). Our theoretical focus however is on the role of external actors, China and the US in particular, have in prompting that change.

Since 1988, China was dealt with a good set of cards. The junta needed, as required by its own praetorian ideology, to provide economic development to enhance its legitimacy. Myanmar's diplomatic and economic isolation meant 
China was the only realistic source of foreign investment (Sun 2012a: 87). The result in bilateral trade was dramatic. In 1988, the value of bilateral trade was US\$ 270 million. By 2010, that amount was US\$ 4,442 million with US\$ 2,509 million trade surpluses in China's favor (Myoe 2016: 11). A second current trend was the increasing use of Chinese state-owned enterprises and an investment emphasis on large-scale resource extraction projects (Sun 2012a: 79). The economy of northern Myanmar itself was heavily integrated into Yunnan's economy (Fiori and Passeri 2015: 689).

Chinese economic penetration created resentment among the Burmese public. The public impression of Chinese goods was generally negative (Myoe 2016: 11). The Chinese brand name among the Burmese populace was bad. Sun (2012b: 59) observes that "Chinese project (sic) has become a synonym for corruption, pollution, local condemnations and oppositions, sometimes without much evidence or reason". Ethnic Chinese inside Burma were distrusted by the locals and trade relations were seen as asymmetric (Ganesan 2011).

The Chinese government also extracted political concessions from Myanmar too. Myanmar had to adopt pro-China positions in regional forums such as ASEAN instead of its preferred stance of neutrality (Sun 2012b: 57). Myanmar had to accept China interference in its ethnic issues on the border (Myoe 2016). This includes Chinese participation as a third party negotiating between Myanmar and the ethnic groups, China's military support for specific armed ethnic groups, especially the UWSA, and demands that other third-party state observers to peace deals be excluded (Myoe 2016: 13-14). Chinese interference into Myanmar affairs was unwelcomed. Bertil Lintner reports that Aung Lynn Htut's observation that the "country's military leaders have not forgotten that they once fought against the China-backed CPB [Burmese Communist Party] and that many of their comrades were killed by Chinese arms" (Asia Time Online 2011). ${ }^{10}$

China expected the Burmese authorities to ignore the public discontent over the Myitsone Dam as well as the protest over the other Chinese investments such as the Letpadaung Copper Mine (Chan 2017). China wanted Myanmar to carry on with business as usual. The confidence of the Chinese government is reflected in Sun's following observation:

This extreme confidence was based on the fundamental belief that an isolated and sanctioned Myanmar would not risk angering its largest political and economic patron over a dam project. Despite the repeated appeals by Naypyidaw for China to reconsider the project and reassess its environmental impact, China brushed off such messages, believing the government was effectively "silenced".

(Sun 2012a: 85)

We should parse the logic underlying Chinese expectations more deeply. Our theory tells us to focus on the bargaining leverage the actors have. ${ }^{11}$ Applied to this case, a Myanmar that was under sanctions has no choice but to depend on China, giving China strong leverage against Myanmar. It is this leverage that enables 
exploitation by China. Sun provided more evidence of this line of reasoning when she considered the implications of Myanmar's overreliance on China: ${ }^{12}$

The downside of such overdependence is apparent: It gives China an asymmetrical leverage over Myanmar, putting it at a highly disadvantaged position. Indeed, Chinese investment and support came at a price. Economically, China's exploitation of Myanmar's rich natural resources has created serious problems: Neither the hydropower dams nor the oil and gas pipelines would help alleviate Myanmar's extreme power shortage; most investments from China focus on extractive industry with little regard for sustainable development, job creation or technology transfers; many of them bring irreversible detrimental environmental and social impacts. Politically, the unbalanced relationship forced Myanmar to reluctantly accept China's de facto interference on the border ethnic groups issue and agree to adjust its diplomatic positions for China on regional forums such as ASEAN

(Sun 2012b: 57)

For a regime as paranoid (Selth 2008), as suspicious of foreign influence (Sun 2012b: 57-58), as jealous of its sovereignty (Myoe 2014) as this junta is, this state of affairs is not tolerable. It goes against the traditional preference of the country for neutrality. This is the reason why Myanmar underwent a foreign policy realignment and started to act against Chinese interests (Sun 2012a, 2012b; Asia Times Online 2011). This state of affairs supports H8a, that the leverage of China allows it to extract more over time. It extracted so much that the junta started to look (donor switching) for alternatives to its predicament.

Even if the Burmese junta wanted to end overdependence on China, it needed a viable alternative as an exit option. Otherwise, it would have been stuck with the worst of both worlds: be under Western sanctions and be without Chinese patronage! Our first task is to consider, briefly, the impact of Western sanctions. It helps us understand why Myanmar seeks closer ties with the United States and liberalizes politically at the same time.

The scholarship gives the US the lion's share of the credit for bringing about reform in Myanmar (Fiori and Passeri 2015). ${ }^{13}$ We will focus on American measures since it plays the leading role. The current sanctions regime, in its broad sense, started in 1988 during the last years of the Reagan presidency. It is maintained by every administration since till the presidency of Obama. The initial policy concerns were the Burmese human rights violations, democratic malpractices, and illicit opium trade (the notorious Golden Triangle overlaps Myanmar. The measures adopted in the Reagan and H.W. Bush administrations include the suspension of US military and economic aid, sanctions, and bans on bilateral trade (Fiori and Passeri 2015: 692).

The American measures were also responsive. Major transgressions by the junta against democracy and human rights were met with stronger punishments and sanctions. For example, the US banned future investments in Myanmar over the regime treatment of Aung San Suu Kyi and the arrests of delegates from the 
NLD in 2003. The jade and ruby mining industry in Myanmar contributes economic rent to the military regime. Recognizing this, the US banned the imports of these gems in 2003 (HRW 2008). After the Saffron revolution was crushed in 2007, the US targeted directly the financial assets of specific leaders within the junta, their business associates, and banned their families from visiting the United States (Reuters 2011).

The impact of these measures is significant. After several publicity campaigns by human rights organizations in the West, most major Western multinational companies left Burma (Holiday 2012: 118). By around 2007, there was almost no bilateral trade between the US and Myanmar (Fiori and Passeri 2015: 692).

The sanctions did bite. Myanmar had a garment industry exporting textiles to the US before the sanctions. The 2003 sanctions devastated that industry. According to estimates from the US State Department, the 2003 export ban caused over 100 garment factories to close with the loss of between 50,000 to 60,000 jobs (Holiday 2012: 109)

An assessment of the economic costs to Myanmar should also account for the aid that would had been allocated to Myanmar, were it not for the sanctions. Holiday (2012) notes that Myanmar in 2006 was among the world's 50 poorest countries. The average per capita assistance for countries in that group is US\$ 58 while the score for Myanmar is only US\$2.88. The discrepancy between the two values allows Holiday to estimate that Myanmar effectively lost US\$ 3 billion in assistance due to the Western sanctions (Holiday 2014: 117).

Western sanctions on Myanmar reduced Myanmar's leverage vis-a-vis China. For this state of affairs to change, Myanmar needs another source of development assistance and foreign investment. Western donors are the only viable alternative. Since the lifting of sanctions is conditioned on democratization, the junta had to enact political liberalization in order to widen the country's diplomatic room for maneuver. Put another way, the junta sought to acquire defensive leverage against China. Political liberalization is the means to that end.

Under the Obama administration's Pivot to Asia, Myanmar became more strategically valuable. Senator Jim Webb who visited Myanmar in 2009, telegraphed the Obama administration view when he is reported to have said:

We (the US) are in a situation where if we do not push some kind of constructive engagement, Myanmar is going to basically become a province of China ... how does the US develop a relationship that could increase stability in the region and not allow China to have dominance in a country that has strategic importance in the region?

(Asia Times Online 2011)

Even with the geostrategic rivalry as a background, the US was deliberate in coupling the easing of the considerable pressure with specific domestic reforms. For example, Secretary of State Clinton, after her visit to Myanmar in 2009, linked the lifting of some sanctions to the release from house arrest of Aung San Suu Kyi (Guardian 2009). In 2011, when the military regime enacted a series of 
substantive domestic reforms including a transition to civilian rule, the US rewarded Myanmar with a historic visit by President Obama in 2012, the first by any US President. During that visit, President Obama relaxed more sanctions and offered US aid worth over US\$ 170 million. He offered more financial support and aid conditional on further democratization. Even with the lifting of the sanctions and the ban on US foreign investment in Myanmar, the US did not let go of its leverage. Clinton warned that the laws underpinning US sanctions "would remain as Washington seeks to maintain leverage while pushing the reclusive country's government further on democratic reforms" (Reuters 2012). The US is aware of the possibility of backsliding. The language used by the US State Department is explicitly conditional:

The extent to which the [Burmese] government follows through on its [reform] commitments ... as well as the success of the next government in continuing broad reforms - will determine the level and type of engagement and support Burma will receive from the United States in the future.

(U.S. Department of State 2015)

It is important to understand there is a quid pro quo here. Both sides get some of what they seek. As Fiori and Passeri (2015: 695) observe:

Burmese officials knew that a process of growth could be brought about only through the lifting of American sanctions; on the other side, the USA was able to persuade Thein Sein that sanctions could be revoked only after having ignited a mature process of democratic reforms and national reconciliation with the political opposition. . . . This 'offer' may probably be considered highly advantageous for both actors: Myanmar can thus find a way out of the backwardness and break the chain of dependency from Beijing; the USA is playing this game to bring Myanmar again on the proscenium of the international community, grabbing it from the hands of China.

The US is essentially buying reforms on the cheap here. Myanmar is using reforms to preserve its independence of action internationally.

The evidence shows one push and one pull factor for reforms. On the SinoBurmese side, the dependency on China provides a motive for the junta to seek an alternative. On the American-Burmese side, the aid conditionality provides a motive for the junta to reform. Collectively, this supports H9. Over-reliance on one donor prompts the rational recipient to seek and pay the price of political liberalization for that outside option.

\section{The reactions of external actors to Burmese reforms}

In this section, we want to understand the extent to which our theory can account for the Chinese reaction to Burmese political reforms. We care about China because it is the actor that has the motive and potential to act against the reforms in Myanmar. The initial Chinese response was stunned disbelief, such was the 
extent of its "strategic misjudgment" (Sun 2012a). Once it became apparent that the Myitsone Dam suspension was serious, China made both economic and political adaptations to the new status quo.

In terms of trade, China started to reduce its foreign investments in Myanmar drastically. Since 2011, no new projects were announced, and the emphasis is on finishing existing contracts (Sun 2012b: 64-65). China started taking the Burmese public sentiment seriously. It incorporated public outreach and initiated publicity campaigns to shape Burmese public opinion of China (Sun 2012b: 67-68; Chan 2017). Chan (2017: 12) argues this reflects Chinese recognition that Myanmar faced a credible domestic audience cost.

In terms of politics, the Chinese government cooled its political ambitions for Myanmar. Gone is the emphasis on the "comprehensive strategic cooperative partnership" and the rhetoric of Myanmar as the "Yunan Bridgehead" (Sun 2012b: 65-66). In a sharp break with its traditions, the Chinese government reached out to the NLD and invited Aung San Suu Kyi to China for talks (Sun 2012b: 66-67). A remaining area where China does have some leverage is over the ethnic minority armed groups along the Sino-Burmese border. These include the Kachin Independence Army (KIA), the United Wa State Army (UWSA), the Myanmar National Democratic Alliance Army (MNDAA), and the National Democratic Alliance Army (NDAA) (Myoe 2016). Of these four, the UWSA issue is more acute because the Chinese government is allegedly transferring arms to the UWSA to use as a leverage against Myanmar (Myoe 2016: 13).

The Chinese response, on the whole, has been remarkably moderate. It is worth asking why this is the case. China could have pressed the Burmese government to compensate its losses over the Myitsone Dam suspension as it is legally entitled. The amount of compensation is reported to vary between US\$ 400 million to US\$ 5 billion (Chan 2017: 15), and would, in any case, be an "astronomical" amount that is "well beyond the solvency of the Myanmar government" (Sun 2012a: 86). China did not pursue that route. Instead, it adopted a public relations strategy to systemically engage with the Burmese public (Chan 2017). Sun observed that the Chinese "policy community seems to have accepted the new reality that China will no longer be the sole dominant power and are preparing for new competition in the country" (Sun 2012a: 92).

The muted Chinese response and the tempering down of pre-2011 expectations are telling. Together, they support hypothesis H8b. China had to settle for less after Myanmar gained an exit option.

\section{Alternative accounts of the Burmese reforms}

I characterized the Burmese reforms as controlled, elite-led, and top-down. An alternative account is that those reforms were society led. Lall (2016) argued that the key drivers of the reforms were indigenous civil society organizations (CSOs) who articulated, educated, and represented the growing middle class in Myanmar. ${ }^{14}$ Even in her bottom-up account, she acknowledged that the path of the reforms reflected the legacies of several decisions by elites. These include i) the path dependence imposed by the 'Seven Step Road Plan to Democracy' 


\section{Myanmar and donor switching}

announced in 2003; ii) the purge of Khin Myunt and his powerbase, which weakened the state surveillance of civil society; iii) the aftermath of Cyclone Nargis, which allowed collaboration between local CSOs and international groups; and iii) the retirement of the old guard (Than Shwe), and the personal commitment of the new leadership (President Thein Sein) to see the reform through.

Were her claims to stop here, her book constitutes a richly detailed insiders' perspective. It makes good use of her connections to regime elites, to activists, and to the CSOs, and in particular, the group known as the Myanmar Egress. To that extent, her work helps to address a gap in Burmese studies which tend to be dominated by judgements from the outside (ibid: 5-6). However, she made two claims, on democratization and on international sanctions, that are contested and given emphasis here.

\section{On democratization}

The most egregious claim in Lall's book is that the reforms in Myanmar should not be judged by Western standards. Specifically, she claimed that "what is happening in Myanmar cannot be measured by Western standards, but rather judged by local and Southeast Asian views" (ibid: 4). There are two aspects to that claim.

First, rejecting Western standards of assessment has a theoretical price. Lall's work does not engage with the literature on electoral authoritarianism (Schedler 2013) and on bottom-up democracy promotion (Bush 2015). It means she is not differentiating between reforms that lead to democratic consolidation from those designed to entrench authoritarian rule. This skews her framework for assessing the reforms. At various points in her book, her refusal to use Western standards means that she uses assessment standards that she presents as indigenous but in effect, represents the junta's (rather than the people's) best interests. For instance, she criticized opposition and exile groups for not supporting the junta's efforts to lift international sanctions (Lall 2016: 144-146). ${ }^{15}$ The audacity of the opposition to oppose the preferences of an authoritarian regime!

Second, the local standards she wants to use are those preferred by the activists and politicians who are aligned with neither the junta nor with the NLD-led opposition. This group is described as the "third force" in Burmese politics (ibid: $8,52)$. This eclectic group includes activists who led CSOs and politicians from ethnic minority parties. Unlike the NLD (before 2012) and activists in exile who rejected collaboration with the junta, this group worked from within the regime. According to her, they sought to avoid the "path of confrontation, protest and revolution" and instead "push internal boundaries" to achieve "gradual nonrevolutionary transformation" (ibid: 6).

The authenticity of this third force is questionable. The civil society groups that Lall gave prominence to, especially the Myanmar Egress, has extraordinary ties with the regime. The modus operandi of such CSOs is "to form alliances and personal relationships with officials within the regime in order to function" (ibid: 9). Even Ashley South, a colleague of Lall and whose quotes figure prominently in the book, questioned whether such groups can "really be described as a part of civil society, given their cozy business and government connections" (South 2016). 
This reflects the tight control the junta had over Burmese civil society. The junta ensured that none of the CSOs can function without the consent of the regime (ibid: 38 ).

The origin of the ethnic minority parties is also problematic. The main opposition, the NLD, boycotted the 2010 elections. To legitimize the 2010 elections, the regime had to create its own opposition (Lall 2016: 47). Anticipating this problem, Myanmar Egress help found nine ethnic parties that were supposed to be independent of the regime. However, in order to fund those parties, the Myanmar Egress had to seek financial help from fifteen cronies of the same regime (ibid: 48)! Lall portrays the ethnic political parties representing the will of the Burmese middle class. Yet in the 2015 elections that the NLD did participate in, most ethnic parties, along with the junta party, the USDP, lost to the NLD by a landslide. Such electoral results suggest it is the NLD who has the greater claim to represent the Burmese middle class.

This is why Lall's claim that CSOs are an effective force pushing reforms in Myanmar is surprising. It is revisionist history. ${ }^{16}$

\section{On sanctions}

The conventional view is that international sanctions were effective in prompting the Burmese junta to embark on reforms (Kipgen 2016: 94-95). This viewpoint has been increasingly challenged by area studies scholarship (Jones 2014; Lall 2016; Selth 2018). I address some aspects of the debate on the effectiveness of sanctions in this section. I highlight works, giving emphasis to Lall (2016) as her claims are forceful. I do this review even though the effectiveness of sanctions is not my main research question. My primary concern, rather, lies with the determinants of leverage in state-to-state bargaining in the context of democracy promotion. Thus, I am only tangentially interested in sanctions as a tool of statecraft for the purposes of determining leverage in donor-recipient relationships.

There is a policy consensus in the West that economic sanctions are "powerful tools" of foreign policy even if the academic view is more circumspect (Peksen 2019). The US under the Trump administration, for instance, treats sanctions as a tool of first resort. We want to differentiate between different types of sanctions. General sanctions do not increase the democracy levels in authoritarian states. What should be assessed are sanctions where the explicit purpose is democracy promotion in the targeted states or "democratic sanctions". In a new dataset of sanctions that differentiates between democratic sanctions and general sanctions covering the years, 1990-2010, Soest and Wahman (2015) found a significant correlation between democratic sanctions and increased democracy in targeted authoritarian countries. This bares emphasis, the larger nomothetic pattern is that such democratic sanctions can work!

Moving from mainstream Political Science to the area-studies literature, Selth dismisses the conventional view that sanctions worked in the following manner:

While some of these measures may have had a modest impact, the regime had successfully sidestepped sanctions by cultivating relations with the 
Association of Southeast Asian Nations (ASEAN) and major powers like China, India and Russia.

(Selth 2018: 3)

Selth's account is purely dyadic. Myanmar reacts to pressure from the West by donor switching. Here, I go two steps further. I focus on China's imperative given Myanmar's dependence on it. I posit how increased pressure from China might in turn prompt Myanmar to switch back to the West. My account is triadic (US-Myanmar-China).

Lall also rejects the view that international sanctions prompted Myanmar's transition (Lall 2016: 9). While acknowledging the existence of a discourse that the sanctions were successful, she nevertheless forcefully asserts "(n)othing can be further from the truth" (Ibid: 9). She further claims this rejection of sanctions as a factor is the third key theoretical contribution of her book.

There is not enough substantive analysis on sanctions in her book to warrant her theoretical stance on their effectiveness. At the risk of being pedantic, only 15 pages of her 346 paged book mentioned sanctions. Of those, eight pages were descriptive rather than analytical. ${ }^{17}$ The remaining seven pages can be grouped into two batches. The first batch was about how sanctions were a point of contention between Thein Sein's government and the NLD led opposition (ibid: 40, 59-60, 69). The government wanted the opposition to support the lifting of sanctions; the opposition naturally refused.

The second batch of three pages exists in a section subtitled "The issue of sanctions" (ibid: 144-146). In it, she complains that some opposition groups still refused to support the lifting of sanctions and digressed into a report by Conflict Risk Network. In the middle of that section, she insists:

Part of the problem with the debate on sanctions is that activists have refused to acknowledge that sanctions never actually stopped the military leadership from ruling and only harmed the general population. More recently discussions have emerged that sanctions in fact were successful, since they apparently 'forced' the government to reform. As the first chapters of this book has shown, this is blatantly incorrect and the reforms were started for quite different reasons.

(ibid: 145)

There was no further analysis of the effectiveness of sanctions in the book after that quote in that section. As Lall makes clear in the aforementioned quote, she claims to have made her case by that point in her book. I do not see how Lall came to that conclusion on sanctions if, going by her own account, i) Thein Sein government wanted sanctions lifted (ibid: 9); ii) the opposition wanted the West to keep sanctions as a way to pressure the government (ibid: 40, 59-60, 69, 144145); and iii) the regime sought the support of the opposition in their campaign of sanction relief (ibid: 40, 59-60, 69). Lall is simply far more invested in proving 
her claim that reforms started for domestic reasons than in supporting the claim about the ineffectiveness of sanctions.

\section{The price of political change}

Myanmar is undergoing three simultaneous changes, from a civil war to peace with ethnic minorities, from a command economy to a market-based economy, and from military rule to civilian rule. Even in the best of times, this is challenging. I do not claim here that the transition is complete or that the end result will be a consolidated democracy. Previously, I discussed how the junta maintains a tight grip on civil society groups (Bush 2015; Lall 2016) and how the transition is managed by the Tatmadaw from a position of strength (Slater 2014). Regime control over the transition process and over the civil society groups has a predictable outcome. One view is the opposition was coopted by the regime (Jones 2014). There is disappointment in the West that Aung San Suu Kyi prefers to support the post-2015 status quo instead of pushing for further democratization. My objective with this section is to explore three issues that hinder democratic consolidation without proposing a resolution of them. After all, the research focus of this book is not on the ultimate fate of the democratic transition but on the influence of donors over an otherwise domestically driven political process.

The first issue is the "golden parachutes" given to the elites from the previous regime. "Golden parachutes" refer to economic bribes and political guarantees granted to the leadership of autocracy in order to persuade them to give up power. This appeared to be the case for Myanmar's transition. Key figures of the previous regime are immune from prosecution for the crimes conducted during their reign. General Than Shwe, the junta leader who is widely reviled for his suppression of the opposition during his rule, is allowed to retire gracefully with his illicit gains. The elite within Tatmadaw also looted the country during the economic transition from a command economy (the "Burmese way to socialism") to a free market system (NYT 2012). The privatization of state-owned industries in 2009-2010 is meant reduce the state dominance of the private sector. It became a means of enriching the elite. Even the peace deals the Tatmadaw sought with the ethnic groups, by opening up mineral-rich border regions and their prized trade routes, has the effect of facilitating rent-seeking by the Tatmadaw (Barany 2016). This is particularly salient for the four key extractive industries: jade, rubies, teak, and opium (The Diplomat 2015). Myanmar's economy post transition typifies crony capitalism. It is dominated 12 to 15 individuals, known locally the 'Biz15', with links to the junta. This set of cronies collectively own "the biggest conglomerates across all sectors, including banking, infrastructure, transport, tourism, and real estate" (Lall 2016: 135-136).

The crony capitalism that results is part of a deal whereby the old guard in the Tatmadaw retires in exchange for economic benefits. The political reality in Myanmar is that such implicit pacts are necessary. We must remember that Thein Sein, the leader who eventually led the democratic reforms, was chosen by Than 
Shwe. A reason for his choice is the fact that Thein Sein lacks an independent power base of his own (NYT 2012). ${ }^{18}$ This meant Thein Sein cannot go against the core interests of Than Shwe and his support base. Transitional justice (Holiday 2014) in the format of holding key junta figures to account in a formal trial may not be politically possible.

The second issue is the autonomy of the Tatmadaw. The 2008 Constitution enshrined the Tatmadaw as the guardian of the country. The army controls three ministerial portfolios: Defense, Home Affairs, and Border Area Affairs (Myoe 2014: 238). The police reports to the Commander in Chief, not the President! The selection of the position of the Commander in Chief position is controlled by the army with no say from the civilian leadership. The military maintains its own financial allocation and procurement. These have the effect of keeping the operational command of the military outside the purview of the civilian government (Myoe 2014: 240). This is unlikely to change. The army is guaranteed $25 \%$ of the seats in the national parliament and one-third of the seats in state and regional assemblies. Since $75 \%$ of the representatives have to agree to change the constitution, the military has an automatic veto on any constitutional change (Myoe 2014: 238). Since we know that the willingness of the military to respect civilian rule is a key condition for democratic consolidation (Barany 2012), this state of affairs is a concern.

The third issue concerns the remaining ethnic conflict. Not all ethnic groups joined the peace process with the government. Some groups adopted a wary wait-and-see attitude to the reforms. Some groups retained their armed militias and refused to integrate into the Burmese army. Others resumed their armed struggle. They are not equally significant. The ethnic groups - Wa, Kachin, and Kayin, in particular - are negotiating from a position of significant armed strength (Farrelly 2014: 264).

Post-2011, the Kachin state (Northern Myanmar), and the Rakhine state (Western Myanmar) remain prone to violence. In the Kachin state, the violence is between the Kachin Independence Army (KIA) and the Tatmadaw (Farrelly 2014: 263). It is a conflict between the state and the periphery. In the Rakhine state, the conflict is between the Buddhist Rakhine majority and Muslim Rohingya minority. Here the conflict is intercommunal, with the Tatmadaw taking the side of the majority. The violence generated the repeated outflows of Rohingya refugees into neighboring countries. This has gathered international attention that has become increasingly critical of the leadership of Aung San Suu Kyi herself (The Diplomat 2017; BBC 2017c). The international critique runs as follows. Aung San Suu Kyi as the leader of the country should not be covering up the persecution of Rohingya Muslims by the Tatmadaw. If she is refusing to step in, it must mean she is not committed to human rights and democracy.

I argue that it is politically risky for her to intervene on behalf of the Rohingya Muslims. There is a precarious balance of power between the NLD and the Tatmadaw. The 2008 constitution specifically prevents Aung San Suu Kyi from being the President of Myanmar. As a workaround, she invented the position of State Counsellor while her confidante Htin Kyaw is officially the President. It is 
understood that Aung San Suu Kyi is the President in all but name. Yet, the Commander in Chief does not report to the President when it comes to issues of national security. This is because the 2008 constitution guarantees the military full autonomy over issues of national security and the Tatmadaw is interpreting the conflict in Rakhine as a counterterrorism operation, that is, as a national security issue. An intervention by Suu Kyi threatens the army's prerogative and invites a backlash from the military. Such an intervention will also alienate the Buddhist majority and cost her party votes. These explain her reluctance to speak out on this issue. Just as Thein Sein cannot go after his predecessor, Than Shwe, Suu Kyi cannot intervene on the side of the Rohingya Muslims. Significantly, when she was forced to take a stance in the UN International Court of Justice recently, she chose to reject the charge of genocide against the Rohingya (BBC 2019).

There we have it; the Myanmar of today is a work in progress. The corruption and impunity of the elites, the autonomy of the military, and the ongoing ethnic conflict are intractable in the short run. They represent real obstacles to further democratic consolidation. Yet, it is worth recalling the progress that has been made. In the aftermath of the 2015 general elections, NLD won and took over power from the army-backed government led by the USDP. While the Tatmadaw clearly prefers the USDP to win (Slater 2014), it - significantly - did not intervene to annul the election results it does not like. This is a break with the past. It is a signal of the commitment of the elites to political reforms so long as their imperatives are not thereby threatened. To the extent that external actors have the means, we should build upon that (Barany 2016).

\section{Conclusion}

Some recipients happen to fit clear-cut categories. Many don't. The aid dynamic for Myanmar, with a focus on its relations with China and the belongs to the latter. The case study illustrates how complex such aid bargaining can be. The recipient who desires more leverage may switch between donors. Likewise, donors can play the same game and extract more concessions from the recipient when they are able. This can set limits to donor switching. Autocratic Myanmar was forced by Western sanctions to rely on Chinese patronage. The increased demands of China proved chafing for a country with a traditional predilection towards neutrality. In order to get out of a bad situation, the military junta needs an alternative supply of aid. With a rapid series of reforms, the military junta demonstrated their willingness to pay the political price in exchange for Western aid.

To be sure, the transition is not complete and backsliding is possible. The West is getting what it is willing to pay for, a hybrid regime caught in an uneasy threeway truce between the civilians (led by the NLD), the ethnic minorities, and the Tatmadaw.

This case highlights the limits of donor switching. It suggests that the impact of Chinese aid on the Western aid architecture may be smaller than popularly assumed. It illustrates how political liberalization might still emerge when we attribute rationality to all three actors, Burma, the US, and China. 
This case study dealt with a recipient in the intermediate zone of salience. In the following chapter, we will deal with two recipients, Egypt and Fiji, that are at different ends of the salience. We want to examine the extent to which the recipient with leverage, Egypt, is able to fend off US demands for political liberalization. Conversely, for the recipient who lacks leverage, Fiji, we want to see how it tries to ward off donor pressure, with less effectiveness.

\section{Notes}

1 For this introduction, I use Burma to denote the country. I will explain more on the identity politics involved with the that name in a followup section.

2 When the Obama administration negotiated a comprehensive deal with Iran, sanctions were lifted. Under the Trump administration, it is as yet unclear if sanctions will be re-imposed.

3 This is why news reports argued that the ending of the sanctions against Iran would end up hurting those same sectors of the Indian economy (WSJ 2016).

4 For instance, Myanmar was also the world's 2nd largest producer of illicit opium in 2008 (CIA 2008).

5 The US wants to maintain sanctions on North Korea and seeks to end the military ties between Myanmar's military and North Korea.

6 Thailand provides an airbase operated by its Navy that is a major logistical hub for US forces operating in Afghanistan.

7 I characterize it as near continuous due to exceptional periods such as the 1988 democratic uprising, known as the 8/8/88 event when the country experienced riots and a military internal coup and the 1990 elections where the military government SLORC was preparing a power transfer (which was subsequently aborted).

8 The Burmese intelligence made specific allegations on the extent of Chinese support for the BCP (Myoe 2016: 9, 16).

9 The referendum result of around $92-93 \%$ of the voters in favor was controversial. The junta was accused of vote rigging. Cyclone Nargis $(2 / 5 / 08)$ occurred just before the referendum date $(10 / 5 / 08)$. The regime concentrated on the referendum instead of disaster relief (Tan and Davis 2016).

10 Aung Lynn Htut is a former intelligence officer from Myanmar who sought political asylum in the US.

11 Analogously, this is similar to the logic underlying the extreme exploitation of refugees and illegal migrants. They are targeted for ill treatment precisely because they have few other options and cannot easily walk away from a bad deal.

12 The emphasis is added to highlight the theory. Footnotes were also removed from the original quote for clarity.

13 Among the Western donors, the only other major donor that has a significant investment in Myanmar was Japan and it generally followed the American lead (Ganesan 2011; Reilly 2013).

14 I thank Chanintira Na Thalang and Yong Soo Eun for early feedback leading to this alternative account. I also thank Chhani Bungsut and Payoja Ahluwalia for their research assistance.

15 I elaborate more on the context in the subsequent section on sanctions.

16 McCarthy (2017) also described Lall's book as "[p]art memoir, part revisionist history"; albeit, his characterization is more favorable.

17 The descriptive pages are in three groups. The first group of three pages is substantively about other issues where sanctions were mentioned in passing (Lall 2016: 22, 67, 152). The second group consists of two pages about the economic losses due to sanctions (ibid: $134,153)$ and two pages about the lifting of sanctions after substantial reforms by the 
West (ibid: 150, 76). The second group supports the view the sanctions hurt and were lifted after the regime liberalized. Therefore, it suggests that sanctions were effective.

18 Khin Nyunt had the support of the military intelligence while Than Shwe had the support of the hardliners.

\section{Bibliography}

Asia Times Online. 2011. “China Behind Myanmar's Course Shift.” Asia Times Online, 19 October 2011, www.atimes.com/atimes/Southeast_Asia/MJ19Ae03.html (last accessed $1 / 1 / 2016)$.

Aspinall, Edward, and Nicholas Farrelly. 2014. "Special Issue: Myanmar's Democratization: Comparative and South East Asian Perspectives Introduction." South East Asia Research (IP Publishing Ltd) 22: 163-169. www.ingentaconnect.com/contentone/ip/ sear/2014/00000022/00000002/art00001.

Aung San Suu Kyi. 1997. "Please use your liberty to promote ours." International Herald Tribune.

Barany, Zoltan. 2012. The Soldier and the Changing State: Building Democratic Armies in Africa, Asia, Europe, and the Americas. Edited by Zoltan Barany. Princeton, NJ: Princeton University Press.

Barany, Zoltan. 2016. "Armed Forces and Democratization in Myanmar: Why the U.S. Military Should Engage the Tatmadaw." www.csis.org/analysis/armed-forces-anddemocratization-myanmar-why-us-military-should-engage-tatmadaw.

BBC. 2011. "Burma Dam: Work Halted On Divisive Myitsone Project." British Broadcasting Corporation. www.bbc.co.uk/news/world-asia-pacific-15121801.

BBC. 2017a. "Yangon Renaissance: Punks, Poets and Painters." British Broadcasting Corporation. www.bbc.co.uk/programmes/b08wp54l.

BBC. 2017b. "Myanmar Profile - Timeline.” British Broadcasting Corporation. www.bbc. com/news/world-asia-pacific-12992883.

BBC. 2017c. "Who Will Help Myanmar's Rohingya?” British Broadcasting Corporation. www.bbc.com/news/world-asia-38168917.

BBC. 2019. "Myanmar Rohingya: Suu Kyi Rejects Genocide Claims at UN Court.” British Broadcasting Corporation. http://bbc.com/news/world-asia-50741094.

Bush, Sara. 2015. The Taming of Democracy Assistance: Why Democracy Promotion Does Not Confront Dictators. Cambridge: Cambridge University Press.

Chan, Debby Sze Wan. 2017. "Asymmetric bargaining between Myanmar and China in the Myitsone Dam Controversy: Social Opposition Akin to David's Stone Against Goliath." The Pacific Review, 1-18. doi:10.1080/09512748.2017.1293714.

CIA. 2008. "CIA World Factbook 2008." Central Intelligence Agency, USA. www.cia.gov/ library/publications/download/download-2008/index.html.

Clinton, Hillary. 2011. “America's Pacific Century.” Foreign Policy. http://foreignpolicy. com/2011/10/11/americas-pacific-century/.

Department of State. 2015. "US Relations with Burma." Bureau of East Asian and Pacific Affairs. www.state.gov/r/pa/ei/bgn/35910.htm.

The Diplomat. 2015. "Blood Teak: How Myanmar's Natural Resources Fuel Ethnic Conflicts." The Diplomat. http://thediplomat.com/2015/04/blood-teak-how-myanmarsnatural-resources-fuel-ethnic-conflicts/.

The Diplomat. 2017. "The Cowardice of Aung San Suu Kyi: Is The Lady Still a Champion of Rights and Democracy?" The Diplomat. https:/thediplomat.com/2017/03/ the-cowardice-of-aung-san-suu-kyi/. 


\section{0}

Myanmar and donor switching

Farrelly, Nicholas. 2014. "Cooperation, Contestation, Conflict: Ethnic Political Interests in Myanmar Today." South East Asia Research 22: 251-266. doi:10.5367/sear.2014.0209.

Fiori, Antonio, and Andrea Passeri. 2015. "Hedging in Search of a New Age of NonAlignment: Myanmar Between China and the USA." The Pacific Review 28: 679-702. doi:10.1080/09512748.2015.1012543.

Ganesan, N. 2011. "Myanmar - China Relations: Interlocking Interests but Independent Output." Japanese Journal of Political Science (Cambridge University Press) 12: 95-111. doi:10.1017/S1468109910000216.

The Guardian. 2009. "Senator Jim Webb's Burma Visit Raises Speculation of New US Policy." The Guardian. www.theguardian.com/world/2009/aug/14/us-senator-jimwebb-burma.

Holiday, Ian. 2012. Burma Redux: Global Justice and the Quest for Political Reform in Myanmar. New York: Columbia University Press.

Holiday, Ian. 2014. "Thinking About Transitional Justice in Myanmar." South East Asia Research (IP Publishing Ltd) 22: 183-200. www.ingentaconnect.com/contentone/ip/ sear/2014/00000022/00000002/art00003.

HRW. 2008. Human Rights Watch. www.hrw.org/news/2008/07/29/us-burma-gem-banstrengthened.

Huntington, Samuel. 1957. The Soldier and the State. Cambridge, MA: Harvard University Press.

Kipgen, Nehginpao. 2016. Myanmar: A Political History. Oxford: Oxford University Press.

Kurlantzick, Joshua. 2014. "Southeast Asia's Regression From Democracy and Its Implications." Working Paper. www.cfr.org/sites/default/files/pdf/2014/05/Democratic_ Regression_Paper.pdf.

Lall, Marie. 2016. Understanding Reform in Myanmar: People and Society in the Wake of Military Rule. London: Hurst and Co (Publishers) Ltd.

Lee, Jones. 2014. "Explaining Myanmar's Regime Transition: The Periphery Is Central." Democratization 21: 780-802.

Maung, Mya. 1991. The Burma Road to Poverty. New York: Praeger.

Mauzy, Diane K., and Brian L. Job. 2007. "U.S. Policy in Southeast Asia: Limited ReEngagement After Years of Benign Neglect." Asian Survey 47: 622-641.

McCarthy, Gerard. 2017. "Legacies Matter in 2017 Myanmar." New Mandala, 9 February 2017, www.newmandala.org/legacies-matter-2017-myanmar/.

Menager, Jacqueline. 2014. "Law Fuckers, Cultural Forgers and the Business of Youth Entitlement in Yangon, Myanmar." South East Asia Research 22: 201-212. doi:10.5367/ sear.2014.0207.

Myoe, Maung Aung. 2014. "The Soldier and the State: The Tatmadaw and Political Liberalization in Myanmar since 2011.” South East Asia Research 22: 233-249. doi:10.5367/ sear.2014.0205.

Myoe, Maung Aung. 2016. "The Logic of Myanmar's China Policy." Asian Journal of Comparative Politics 1: 283-298. doi:10.1177/2057891116637476.

NYT. 2009. "We Can't Afford to Ignore Myanmar." New York Times. www.nytimes. com/2009/08/26/opinion/26webb.html.

NYT. 2012. “A Most Unlikely Liberator in Myanmar.” New York Times. www.nytimes. com/2012/03/15/world/asia/a-most-unlikely-liberator-in-myanmar.html.

Peksen, Dursun. 2019. "When Do Imposed Economic Sanctions Work? A Critical Review of the Sanctions Effectiveness Literature." Defence and Peace Economics 30: 635-647.

Reilly, James. 2013. "China and Japan in Myanmar: Aid, Natural Resources and Influence.” Asian Studies Review 37: 141-157. doi:10.1080/10357823.2013.767310. 
Reuters. 2011. "Special Report: How the U.S. Coaxed Myanmar in from the Cold." Reuters. www.reuters.com/article/us-myanmar-engagement-idUSTRE7BL0IT20111222.

Reuters. 2012. "U.S. Suspends Sanctions on Investment in Myanmar." Reuters. www. reuters.com/article/us-usa-myanmar-sanctions-idUSBRE84G0XQ20120517.

Schedler, Andreas. 2013. The Politics of Uncertainty: Sustaining and Subverting Electoral Authoritarianism. Oxford: Oxford University Press.

Selth, Andrew. 2008. "Even Paranoids Have Enemies; Cyclone Nargis and Myanmar's Fear of Invasion." Contemporary Southeast Asia 30: 379-402.

Selth, Andrew. 2018. "All Going According to Plan? The Armed Forces and Government in Myanmar." Contemporary Southeast Asia 40: 1-26.

Slater, Dan. 2014. "The Elements of Surprise: Assessing Burma's Double-Edged Détente." South East Asia Research (IP Publishing Ltd) 22: 171-182. www.ingentaconnect.com/ contentone/ip/sear/2014/00000022/00000002/art00002.

South,Ashley.2016. "Book Review-'Understanding Reform in Myanmar'." The Irrawaddy, 20 August 2016, www.irrawaddy.com/culture/books/book-review-understandingreform-myanmar.html.

Sun, Yun. 2012a. "China's Strategic Misjudgement on Myanmar." Journal of Current Southeast Asian Affairs 31: 73-96.

Sun, Yun. 2012b. "China and the Changing Myanmar." Journal of Current Southeast Asian Affairs 31: 51-77. https://journals.sub.uni-hamburg.de/giga/jsaa/article/view/582.

Sutter, Robert. 2010. “Assessing China's Rise and US Leadership in Asia - Growing Maturity and Balance.” Journal of Contemporary China 19: 591-604. doi:10.1080/ 10670561003666186.

Tan, Bann Seng. 2016. “Aid and Democracy Promotion in Asia." Asian Journal of Comparative Politics 1: 152-170.

Tan, Bann Seng, and Nicholas Davis. 2016. "The Logic of Authoritarian Reaction to Foreign Relief." American Political Science Association Conference.

US Department of State. 2015. "US Relations with Burma." US Relations with Burma 12. www.state.gov/r/pa/ei/bgn/35910.htm.

Von Soest, Christian, and Michael Wahman. 2015. "Are democratic sanctions really counterproductive?" Democratization 22: 957-980.

Walt, Stephen M. 2017. "Barack Obama Was a Foreign-Policy Failure." Foreign Policy. http://foreignpolicy.com/2017/01/18/barack-obama-was-a-foreign-policy-failure/.

WSJ.2016."WhatLifting SanctionsonIranMeans forIndia.”WallStreetJournal.https://blogs. wsj.com/indiarealtime/2016/01/18/what-lifting-sanctions-on-iran-means-for-india/.

Yang, Hongxing, and Dingxin Zhao. 2015. "Performance Legitimacy, State Autonomy and China's Economic Miracle.” Journal of Contemporary China 24: 64-82. doi:10.1080/1 0670564.2014.918403. 


\section{$6 \quad$ Egypt and Fiji}

\section{Introduction}

In 1961, the US Congress enacted a law known as the "Foreign Assistance Act". Section 508 of that act required the automatic suspension of all aid from the United States - including military aid but excluding democracy aid - to any recipient that suffered from a military coup. ${ }^{1}$ Under it, aid is suspended until the restoration of democracy in the aid recipient. By law, there is no presidential waiver, no fudging on what constitutes a coup (NYT 2013). In practice the executive, that is the White House, has considerable discretion over the implementation of the law.

The White House had no issues implementing the policy in the aftermath of the 2006 military coup in Fiji. Yet when reacting to the military coup in Egypt in 2013, the White House studiously avoided all reference to a coup (Foreign Policy 2013). This led to a Kafkaesque discussion by the New York Times (2013) on the semantics of coups. When is a coup not a coup? The immediate rationale for the evasive behavior by the White House is legal. If there was a coup, the US was by law obligated to suspend around US\$ 1.5 billion in annual aid to Egypt (NYT 2013). ${ }^{2}$ Since the Obama administration does not want to do that, it is not surprising that there is no reference to this legal requirement on the official website of the US embassy in Cairo unlike the case for Fiji. ${ }^{3}$

This pair of motivating examples highlights the core query of this book. I seek to understand the conditions under which donors become willing to pressure aid recipients. The US reactions in our examples reveal a strategic consistency that at times stands in contrast to its public rhetoric. This is not an attempt to castigate the foreign policy of the United States. Rather, I argue that the logic underpinning that strategic consistency should be studied and mined to advance democracy promotion.

Broadly speaking, our approach in the Large-N studies is to correlate instances of aid commitment with reports of political reform or its absence. Here, the use of case studies allows us to consider additional nuances. We will consider the donors' assessment of democracy promotion as a goal relative to the other priorities they have. We also consider multilateral issues outside of a strict donorrecipient context. From the Egyptian case, we will learn how Israeli security considerations factor into the US-Egyptian aid relationships. From the Fijian case, 
we will understand how the regional dynamics of the South Pacific modifies the influence of the Western donors.

We know Egypt is a country of considerable strategic importance to the United States, yet the research shows Egypt is a "heavily leveraged country" (Brownlee 2012:173). One would assume a country that is vulnerable to donor pressure - which Mubarak's Egypt qualifies - is especially likely to liberalize. Yet Egypt was able to consistently get away with a lack of democratization, precisely because that outcome is compatible with American strategic interests (Brownlee 2012).

We know Fiji is in a marginal part of the world, the South Pacific. And yet, postcoup Fiji has exhibited considerable agency in its foreign policy by seeking Chinese patronage and starting its own international organization, the Pacific Islands Development Forum or the PIDF (Kelly 2015). The Fijian case illustrates how Western donors who would otherwise wield considerable leverage might choose to hold back to avoid the charge of neo-colonialism (Lawson 2017). Furthermore, the Fijian case study illustrates the role of Western donors other than the United States, specifically Australia and New Zealand. In a time where American leadership is absent, this is significant.

Both countries experienced turbulent politics. Fiji experienced four coups by 2006. Egypt, after the long 30-year reign of Mubarak, experienced rapid political liberalization followed by another military coup, all within a short period (from 2011 to 2013). Our objective here is not to give a blow-by-blow account of the history of political upheavals. Neither is it to explain the prospect for the eventual democratization in both countries. Rather, we want to focus on the roles important donors play in promoting or hindering political liberalization.

For that purpose, we want to understand the nature of the US-Egypt aid relationship, and the conditions under which the US is successful, and also when it is not successful, in exerting pressure on Egypt. In the case of Fiji, we explore the ethnic cleavage of Fijian politics to situate its coups. We want to see how Western donors react to the 2006 coup and how Fiji and China have responded in turn. Before we proceed to the analysis of the cases, we want to set our theoretical expectations and identify the salience of each recipient.

\section{Theoretical expectations}

The theory advanced in the book exerts that donors privilege their strategic and commercial interests over the imperative of democracy promotion. Applied to the Egyptian case study, it means that the United States is interested in democracy in Egypt only as far as it does not see a conflict with its strategic interests. When such interests are threatened due to an unwelcomed leadership succession (Gamal Mubarak versus Omar Suleiman), the election of an anti-Western Party (the Muslim Brotherhood), or an unanticipated revolution from below (the Arab Spring), 
we expect the US to pull back on democracy promotion. To guide subsequent research, this argument is captured in Hypothesis 10:

H10: The United States will exert its influence on Egypt to promote democracy up until the point it starts to hurt its national interests and then it will pull back on such pressure.

Since Egypt is reliant on American aid, the US does have leverage. How America chooses to apply that leverage is theoretically relevant. We want to consider cases where the US could have pushed harder for democracy but chose not to (example, Bush's Freedom Agenda) and the cases where the US did apply pressure successfully but for non-democracy related concessions (example, closing the Egypt-Gaza border). This selective application of pressure reveals the true priorities of the US; namely, democracy for Egypt is less important than the guarantee of Israel's security. H11 captures this intuition.

H11: When national interests are at stake, the US will be especially forceful with its pressure on Egypt.

The combination of a mild pressure for democracy (from H10) and a stronger pressure for national security interests (from H11) leads to a familiar outcome. So long as Mubarak's regime can provide the security concessions that the US wants, it is able to get away with authoritarian rule and receives American aid.

The theory also considers the cases where recipients have little of value to bargain with. After the 2006 coup, the military government led by Commodore Josaia Voreqe (Frank) Bainimarama quickly found itself under pressure from Western donors. To compensate, Bainimarama's Fiji actively sought Chinese patronage to counterbalance the West. Despite some expression of interest from the Chinese leadership, the region is a low priority for China (Yang 2009). As a result, Fiji despite its best efforts from 2006 to 2014, struggled to find alternative donors.

H12: Regional actors applied donor pressure on the post-2006 Fiji to enact political reforms.

H13: The post-2006 Fiji was not able to offer enough concessions to attract the levels of Chinese aid it desires.

The South Pacific region in general and Fiji in particular, is not a priority for most donors. The lack of interest allowed the West the luxury of supporting democracy in Fiji (from H12). The same rationale helps account for the indifference of China towards Fiji (from H13). The outcome of the pressure from the West and indifference from China is also theoretically anticipated. Fiji held multiparty elections in 2014.

\section{Salience of the recipients}

The theory links the bargaining leverage of the recipients to the concessions they could offer in exchange for the desired aid. Here, we have a recipient, Egypt, that 
fits the ideal type of a primary recipient, and another recipient, Fiji, that is located on the less valuable end of salience. ${ }^{4}$ I start with the valuable end.

The value of Egypt is primarily strategic, although the commercial side is significant as well. Egypt was one of the key contested states between the superpowers during the Cold War. Due to American support for Israel, many Arab states leaned towards the Soviet Union in the initial years of the Cold War. For instance, Egypt under Nasser aligned towards the Soviets. When Sadat took over, Egyptian allegiance was maintained until the 1973 War. After the 1973 War, Sadat signed a separate peace with Israel in 1979 (the Camp David Accords) and famously switched allegiance to the Americans. He was assassinated for his policies in 1981. His replacement, Hosni Mubarak, maintained that alliance with the US until his downfall in 2011. Even after his fall, the Egyptian military under Tantawi and later under Al-Sisi maintained a pro-US alignment.

The alliance posture of Mubarak's Egypt was consistently pro-American for all three decades. This simplifies the assessment of recipient salience. It allows us to focus on the American assessment of Egypt's salience.

Egypt and its strategic Suez Canal help the US project power into the Persian Gulf, where much of the world's crucial oil shipments must flow. Egypt was in a position to grant the US access, basing, and overflight (also known as ABO rights). At times, such as during Operations Desert Shield and Desert Storm, and the US War on Terror in Afghanistan and in Iraq, such transit privileges were significant. A 2002 Department of State report asserts that the "importance of Egypt's cooperation for Suez Canal access and security, as well as overflight clearances, cannot be overstated". 5

During the Camp David peace accords, the US brokered and secured a peace between Egypt and Israel. This secures Israel's southern flank in the Sinai. It allows Israel to concentrate its forces on more threatening fronts. Using Egypt to protect Israel's security became another foundational part of the strategic value that Egypt provides the US.

For domestic reasons, the US is committed to safeguard Israel's security. With the Second Intifada in 2000 and the post-2006 election victory by Hamas, the Egyptian role in Israeli security and hence its value to the US changed yet again. Initially, Egypt was responsible for the security on the southern border of Gaza (Brownlee 2012: 92). When the US imposed sanctions on Hamas, it sought to use the Egyptian army to enforce a blockade of Gaza. In particular, the US wanted Egypt to cut smuggling routes through the Gaza-Egypt border at the border town of Rafah (Brownlee 2012: 115).

In terms of commercial value, Egypt is an important market for the American defense and agricultural industries. Under the Camp David Accords, the US committed to modernize Egyptian weaponry. This benefitted both sides. The Egyptian army relied on older Soviet equipment and wanted to update them. The US, after the loss of its Iranian client, needed a new market for its arms (Brownlee 2012: 6-7). ${ }^{6}$ The majority of US aid to Egypt is military aid. The value of the military aid is around US\$ 1.3 billion annually. That aid helped Mubarak's regime pay for Egypt's defense. It covers between one third to one half of Egypt's annual defense expenses, as well as up to $80 \%$ of procurement costs for military hardware (Berger 


\section{6}

2012: 611-612). Thanks to this aid, Egypt from 1999 to 2008, is the second most important consumer of US military hardware (Berger 2012: 612).

Egypt is also important to US agriculture. Berger reports that Egypt has "consistently ranked among the Top 10 export markets for U.S. agricultural products" (Berger 2012: 611). Brownlee (2012: 17) observed that Egypt was once the "world's largest per capita consumer of American food aid".

There is a domestic lobbying angle as well. The US has a history of using its aid as a subsidy for its domestic industries, especially in defense and in agriculture (Berger 2012: 607, 611). Such was the value of the Egyptian market - subsidized by US taxpayers in the form of aid - that the oil, agriculture, and defense lobbies developed in order to defend that aid to Egypt (Berger 2012). Berger argued that such lobbies made campaign contributions to US representatives in Congress in return for political support to shield Mubarak's regime from aid conditionality. He tested and found evidence for his argument on four significant Congressional roll calls votes from 2004 to 2007 (Berger 2012).

In the post-Cold War era, the strategic priorities of the US shifted to counterterrorism. The seminal event in the popular account is of course, the September 11 attacks in 2001. Yet, when it comes to Egypt's role in counterterrorism, the 1993 World Trade Center bombing in the US is more significant. When an Egyptian cleric was linked to the bombing, the US became invested in Mubarak's domestic campaign against terrorism (targeting among other groups, the Muslim Brotherhood). The United States started a clandestine campaign of extraordinary renditions. Terrorist suspects were secretly captured by American forces and sent to countries like Egypt where it is understood they would be interrogated and tortured (Brownlee 2012: 44). The contribution of Egypt in intelligence is a key reason why the US preferred Omar Suleiman, the Egyptian intelligence (the GIS) chief, to succeed Mubarak. In sum, the utility of Egypt in logistics and military deterrence declined over time while its value in intelligence and counterterrorism increased.

Fiji, by contrast, has less to offer. Fiji is an archipelago of over 800 islands (522 islets and 322 volcanic islands). Its main islands are Vanua Levu and Viti Levu, where the capital, Suva, is located (BBC 2015). The Fijian land size collectively is just over 18,000 square kilometers or as the CIA Factbook phrases it, "slightly smaller than New Jersey" (CIA Factbook 2017). Fiji is not the largest landmass in the South Pacific - that distinction belongs to Papua New Guinea. If we were to consider the broader Oceania, the largest landmass would be Australia (Lanteigne 2016: 47-48).

The Fijian economy relies on agriculture with an emphasis on sugar, fishing, and timber. Tourism and remittances are also important for its economy (Lanteigne 2016: 48). In 2014, Fiji had a population of around 886,500 with a GDP of US\$7.857 billion. In purchasing power parity, that GDP figure places Fiji in the 161st place; Egypt's position, by contrast, is 23 (CIA Factbook 2017). ${ }^{7}$ In addition to its low economic base, Fiji has persistent trade and budget deficits (BBC 2015). Crucially, Fiji is also one of the world's largest per capita recipients 
of aid (BBC 2015). It needs the aid. These characteristics do not translate into a recipient with economic leverage.

Countries that are predominately island-based have the potential to make large maritime claims. Fiji has an exclusive economic zone (EEZ) of 1.29 million square kilometers. To put into perspective, this is less than $1 \%$ of the Pacific Ocean, which covers 165 million square kilometers. It is possible that the EEZ contains valuable fishing and mineral deposits. In a frank assessment of the Chinese valuation of the natural resources of the South Pacific as a whole, Yang notes that:

China's economic interests in the South Pacific are still limited. The trade volume of US\$1.2 billion in 2006 was a tiny fraction of China's total trade of US $\$ 1,760$ billion in the year. The region does have valuable natural resources. But on the whole, it is not resource rich. Pacific ocean-floor resources will be difficult to extract for the foreseeable future.

(Yang 2009: 144)

We established that the case for the economic value of Fiji is weak; the case for its strategic value is slightly stronger. To understand this, it is helpful to understand the regional dynamics of the South Pacific (Lawson 2017). The South Pacific consists of three sub-regions: Micronesia, Polynesia, and Melanesia (where Fiji is located). Each sub-region has a dominant power. The United States is dominant in Micronesia, New Zealand is more dominant in Polynesia, and Australia is dominant in Melanesia (Yang 2009: 150-151; Lawson 2017: 215).

Of the three powers, Australia and New Zealand, being the closest, have been the most invested in the region. Their interest in the region has held true since their time as British colonies (Lawson 2017: 216). The primary security concern for Australia and New Zealand is the exclusion of outside colonial powers, especially Germany and France (ibid: 217 ).

A means to such ends is the regionalization of the Pacific islands. Both Australia and New Zealand led the initial efforts to form regional bodies for the Pacific islands. These include early intergovernmental organizations such as the South Pacific Commission or SPC (1947) and the later and more dominant organization that came to be known as the Pacific Islands Forum or PIF (founded in 1971, renamed in 1999). Given the economic disparity between two regional powers and the Pacific Islands, Australia and New Zealand "effectively bankrolled" such organizations and acquired leadership roles (Lawson 2017: 231). As such, both powers are invested in the success of these regional organizations where they have real influence. Both seek to prevent the development of the Pacific Islands Development Forum (PIDF, founded in 2013) into a viable rival organization.

Anti-colonialism is a core concern of the Pacific Islands, even back in the days of the SPC (Lawson 2017). Amongst the Pacific Islands, Australia has been criticized for its "neo-colonial tendencies" (Lawson 2017: 215). For example, the statement by Australia's Prime Minister John Howard that Australia was to serve as America's “deputy sheriff” for the Pacific (Yang 2009: 153) did not go down 


\section{8}

well. New Zealand, which hosts significant numbers of Pacific Islanders in its territory, is generally considered by the Pacific Islands to be the more acceptable partner of the two (Yang 2009: 151) even though both countries share a "common ambition" (Lawson 2017: 217). Thus, both Australia and New Zealand have tangible leverage over the Pacific Islands but they also want the PIF to be effective. Given the regional sensitivities, both did not want to be perceived as domineering in their respective spheres of influence (Lawson 2017).

Australia, unlike New Zealand, has an additional imperative. The South Pacific is one region where Australia could claim major power status. As such, Australia was "determined to demonstrate to the United States that it was holding up its share of the responsibility for maintaining peace in the Asia-Pacific". (Kelly 2015: 5). For the sake of maintaining its reputation, Australia has a vested interest in the affairs of Fiji.

The US interest in the South Pacific is also limited. It is already dominant in Micronesia and its allies are influential in Polynesia and Melanesia. This status quo favors the US. While it is true that Fiji offers US warships the use of its bases without a fear of a nuclear ban (Kelly 2015: 5), ${ }^{8}$ the US already has access to its own bases on Guam and Northern Mariana Islands located in Micronesia (Yang 2009: 145).

The US became more interested in the region after 2011, under President Obama's signature "Pivot to Asia". The policy was itself a reaction to the economic rise of China. There is a perception that China is spreading its influence in the Asia Pacific (Economist 2017). Chinese soft power and its foreign aid seemed to have grown in the South Pacific (Yang 2009). The Pivot can be viewed as the US decision to double down on its stake in the Asia Pacific (for the policy articulation, see Clinton 2011). For example, the US Secretary of State Hillary Clinton attended the 2012 Pacific Island Forum (PIF) summit (Lawson 2017: 215). However, unlike the Middle East - which attracts American attention due to its oil resource - the South Pacific is not intrinsically important. The US interest in the South Pacific is part of its attempt to neutralize Chinese influence. Therefore, the South Pacific is valued by the US only as part of a geostrategic competition with a rising China (Yang 2009; Lanteigne 2016).

The strategic value of the South Pacific to China is low (Yang 2009). The People's Liberation Army (PLA), that is the Chinese armed forces, articulated different versions of its long-term strategic plans for the Asia Pacific. According to one prominent version, associated with PLA Navy Admiral Liu Huaqing, China seeks eventually to control three "island chains" (Yang 2009:145). The first island chain stretches from the south of Japan to Taiwan to the Philippines. The second island chain stretches from west of the Aleutians to the Marianas to the eastern end of Papua New Guinea. The third island chain stretches from the Aleutians in the north to Antarctica in the south. Fiji lies within the second island chain. The target timeline for Chinese control of the second island chain is projected to be the year 2025 or five years from the present! This is an ambitious goal since the Chinese navy was considered a coastal-bound navy rather than a true blue water navy. To be sure, China has been modernizing its navy, developing anti-shipping 
missile technology and building its own aircraft carrier. While the technological gap between the PLA navy and the US Pacific Fleet is narrowing, most consider the US to have the upper hand for the immediate future.

Geographically, the South Pacific is simply too remote for China. WesleySmith (2007) observes that:

None of the island states lie close to the strategic sea lanes that service the bulk of China's trade in energy and raw materials or, for that matter, to other important trans-Pacific commercial or military sea routes Wesley-Smith.

(Wesley-Smith 2007: 14)

According to Wesley-Smith (2007), the South Pacific is a low priority from the Chinese point of view. In summary, Egypt facilitates access to the Persian Gulf, provides logistical and intelligence support to the US and, crucially for the US secures the southern flank for Israel. It is a recipient with leverage. Fiji is in a weaker situation; it has limited economic value and some strategic salience. What is striking for Fiji is the tertiary justification of that value. It is not Fiji per se that is significant, it is the South Pacific region that is important. Even then, that importance is indirect. It revolves around the need to deny the opposing side (Western versus Chinese camp). Now that the respective value of recipients is established, I will consider the aid dynamic for each recipient.

\section{Case study of Egypt's aid relations}

\section{The nature of the US-Egypt relations during Mubarak's reign}

The Egyptian-American alliance is over 30 years old and it outlasted Mubarak's reign (1981 to 2011). Despite its longevity, it may surprise some to note that Egypt was not the United States' first choice for an American gendarme or a regional policeman in the Middle East. That role was initially reserved for Iran under the Shah (Brownlee 2012: 6). When the Shah's regime collapsed in the aftermath of the Iranian Revolution, the US started to look for a new linchpin to anchor its Middle East interests (Brownlee 2012: 35). An immediate concern back then was access to the Persian Gulf. Egypt, with its Suez Canal, met that need (Brownlee 2012: 7).

When the 1973 War and the Arab oil boycott jolted the American security establishment, the US recognized a need to resolve the Israeli-Arab rivalry. With an initial ambitious goal of a true Middle East peace, the US, after the Camp David Accords, settled for a lesser goal of peace between Israel and Egypt. Even that lesser goal took effort. It took the American promise of foreign aid and military aid to get both sides to an agreement.

Israel and Egypt were initially promised around US\$ 2.2 billion and US\$ 1.5 billion in American military financing respectively (Brownlee 2012: 36). A norm was established that the ratio of aid and military financing would be $3: 2$ in 


\section{0}

Israel's favor. Both sides were promised an upgrade of their military with American hardware. The US will maintain the Israeli military edge over their neighbors and Egypt gets to modernize their army from its older Soviet stocks.

The Iranian Revolution and the 1977 Price Riots in Egypt (Brownlee 2012: 25) made the US sensitive to the domestic impact of an American alignment (Brownlee 2012: 41). The US realized that it needed to support the Egyptian regime, in order to maintain Egyptian alignment with the US security interests (Brownlee 2012: 17, 41-42). The American foreign aid spigot started to flow. To use an expression that would seem quaint now, the United States Agency for International Development, USAID, in Egypt “couldn't spend the money as fast as Congress appropriated it". (Brownlee 2012: 52). That aid includes funding for food aid, known as the Public Law 480 or "Food for Peace" Program. The food aid was significant; what the Egyptian foreign reserves spent on wheat imports could have been used elsewhere. After all, the key reason for the 1977 Price Riots was the decision by the then Egyptian government to end governmental subsidies of basic staples. The understood that its food aid allowed the Egyptian government to keep bread prices low, thus that aid "backstopped the regime" (Brownlee 2012: 25).

Another aspect of the US financial assistance is over debt restructuring. Egypt had sizeable foreign debt, including its military debt owed to the US. By 1987, Egypt was struggling to service its military debt. This put Egypt at risk of aid suspension as required under the "Brooke Amendment" (Brownlee 2012: 55). ${ }^{9}$ The US used it influence with the International Monetary Fund (IMF) and the Paris Club to secure new sources of funding for Egypt. Later, as a reward for Egyptian help in the First Gulf War, the US forgave US\$ 6.7 billion of Egyptian debt (Brownlee 2012: 57). As Brownlee characterized this payoff: "Not since 1979 had an Egyptian president so effectively cashed in on security cooperation with the United States". (Brownlee 2012: 58). Just like the case for food aid, US financial assistance and debt forgiveness are means to buttress Mubarak's regime.

Since 1979, Egypt received nearly US\$ 2 billion every year (Snider and Faris 2011). Over the 30 years of Mubarak's reign, the total value of this flow amounts to US\$ 60 billion (Brownlee 2012: 2). No doubt, the majority of this aid is in military aid. However, a significant proportion of that aid is non-military and was meant, in practice if not in rhetoric, for regime support. Why did the US committed commit this much in the financial support to ensure the survival of Mubarak's Egypt? ${ }^{10}$

Brownlee (2012) articulates a provocative but well-researched answer to this question. We know the values Egypt, inter alia, for Israeli security and access to the Persian Gulf. Brownlee argues these concessions are best met by an authoritarian regime in Egypt. A more democratic Egypt could lead to two outcomes that are both unpalatable to the In the first outcome, we assume Mubarak was not voted out but was forced to take positions that were more popular with the masses - those same masses that hold anti-American views in public opinion polls over many years (Brownlee 2012: 3, 14). In the second outcome, we assume Mubarak was voted out. If so, the replacement is likely to be the Muslim Brotherhood, a party that espouses an anti-American foreign policy. What the US failed 
to plan for, was a popular revolution which that overthrew Mubarak by force (and not by elections), allowing for democratically elected parties such as the Muslim Brotherhood led by Mohamed Morsi.

To be clear, the US strategic interests lie in a regime that meets Washington's interest, if necessary, at the expense of the Egyptian people. The US supported Mubarak because he was willing to meet that need. In the words of Brownlee:

What has mattered for the U.S.-Egyptian alliance more than the dollars, the artillery, and the latest generation of vehicles is the political superstructure through which the support flows: U.S. and Egyptian officials worked to block coups and revolts; they colluded to protect the Egyptian government's international alignment; and they accepted U.S. primacy within a mutually advantageous accord.

(Brownlee 2012: 172)

Brownlee goes further. He attributes this material investment into authoritarian allies as a type of "transnational authoritarianism" (Brownlee 2012: 173). This is the conceptual opposite of the relationship between international linkages and the pressure to democratize that is posited by Levitsky and Way (2010). International linkages, instead of constituting a means to political reforms, are the reason why Egypt failed to democratize. This occurred because US strategic needs are best met by an authoritarian rather than by a democratic regime. In terms of my theory, it is because democracy promotion is a secondary concern, behind national interests.

The lesser prioritization of democracy promotion, I stress, is not unique to Egypt. Ely Ratner (2009) in a careful empirical study argued this is consistent with the general US pattern of intervention. The US prioritizes regimes that are willing to align with its interests regardless of regime type. It turns out states that are willing to protect US security interests are also the states that tend to be authoritarian. When such authoritarian states collapse and democratize, Ratner argues the pattern of US prior intervention helps to determine their subsequent foreign policy alignment. He found that when the US did not support the prior regime and did not intervene in the transition, the post-transition regime tends to align with the US. Conversely, when the US did support the prior regime and did intervene in favor of the incumbent during transition, the post-transition regime typically aligns against the United States. In the evocative phrase of Ratner, this is a case of "reaping what you sow".

\section{The donor pressure that failed}

The prior section establishes the baseline concerns that drive the US Egypt aid relationship in the time of Mubarak. This section addresses specific attempts at donor pressure. Interestingly, despite the lesser priority of democracy promotion, there were moments when the US did exert some pressure on Egypt to liberalize. We want to investigate them to understand the effectiveness of that effort. 


\section{Egypt and Fiji}

US democracy aid to Egypt is strongly associated with the presidency of George W. Bush. Yet the history of that aid is traceable back to the 1990s when the USAID started to include democracy aid systemically into its traditional aid programs (Snider and Faris 2011).

The proportion of democracy aid allocated was minuscule relative to the overall level of aid. Of the US\$ 2 billion Egypt gets on average every year, around US\$ 20 million per year was democracy aid (Snider and Faris 2011). The programmatic focus of that democracy aid was in the rule of law and civil society in the early 1990s. In the latter half of the 1990s, it was in the domain of good governance and the media.

The problem does not lie in the absolute value amount of the democracy aid. Rather, it lies in the lack of political will. Those involved in democracy promotion (USAID staff) in Egypt faced resistance by the Egyptian authorities and the unwillingness of the US State Department to stand up for them. In the words of a former USAID officer ${ }^{11}$ :

The [USAID] Mission had to deal with their reality, which was an Embassy which didn't want to have Egyptian ministries complaining about AID all the time, and an Egyptian bureaucracy which had a very, very fundamentally different view of how this money should be used. Their attitude seemed to be "a deal is a deal. Give us the money. What is all this bureaucratic nonsense? Why should we talk to you about policy?"

(Snider and Faris 2011)

We know from Chapter 1 that authoritarian regimes do not want to give up power if they can help it. The Egyptian regime already traded a security concession and did not feel a need to add political liberalization to the bargain. The imperative of the White House lies with national interests and not democracy promotion. The State Department, whose job is to maintain friendly ties with the Mubarak regime, understood that imperative. Of course they accepted the position of the Egyptians! The outcomes of such constraints are predictable. Bush (2015) argues that there will be a systemic pressure to aim for lesser objectives and "tame" democracy promotion itself. For example, democracy aid projects in Egypt were couched in neoliberal terms, as ways to improve the extractive efficiency of the Egyptian state (Snider and Faris 2011).

The effectiveness of democracy aid in the 1990s was negligible. Mubarak's regime achieved all its goals. The 1990s saw Egypt hold multiple elections at different levels of government, in 1990, 1993, 1995, and 1999 (Brownlee 2012). Superficially, elections are signs of political liberalization. In practice, elections were orchestrated contests and meant to entrench the regime. The regime secured an extension of the presidential term for Mubarak. It ensured Mubarak's party, the National Democratic Party (NDP), controlled the major levels of power including the trade unions. It marginalized the liberal opposition, such as the Kefaya movement (Kefaya is translated as "Enough!" in English). It left the Muslim Brotherhood as the only viable opposition to the regime. This was deliberate. Mubarak's 
regime was forcing Washington to choose between the regime (NDP) and the Muslim Brotherhood. It knew full well which will be the American preference when the push comes to shove (Brownlee 2012: 90-91). The regime even managed to start the process of preparing for the political succession of the dictator's son Gamal Mubarak.

The September 11 attacks on the US galvanized the Bush administration to emphasize democracy in the Arab world as a way to counter extremism (Brownlee 2012: 69-70). At first glance, the prognosis was promising. The Bush administration launched the Middle East Partnership Initiative (MEPI) and dramatically expanded funding for democracy aid. The value of democracy aid increased from US\$ 500 million in 2000 and was worth more than US\$ 2 billion by 2005 (Snider and Faris 2011).

In practice, the first term of the Bush presidency saw the US rely on Egyptian cooperation in a series of Middle East conflicts. The US needed the Egyptian logistical support for the US invasion of Iraq in the 2nd Gulf War (Brownlee 2012: 78-79). This was especially important since Turkey refused the US permission to launch attacks from its territory and thereby narrowed US strategic options (Brownlee 2012: 79). Turkey at that time was a democracy and had to respond to Turkish public opinion that was anti-American even though it is a NATO ally. The US needed Egypt to provide diplomatic cover and security for the IsraeliPalestinian Peace Process. In one version of the "Road Map to Peace", Israel pulls out of the Gaza Strip and transfers the responsibility of securing the Gaza border to Egypt (Brownlee 2012: 83). The problem was that the democratization of Egypt will hurt US strategic priorities.

In Bush's second term, he renewed his emphasis on democracy promotion in Egypt (Brownlee 2012: 89). The core issue is the political succession in Mubarak's regime. At the start of his fourth presidential term in 1999, Mubarak was already 71 years old and showing his age. Rumors of his ill health were one of the contributing factors to his downfall in 2011. The US preferred Omar Suleiman, the head of the Egyptian General Intelligence Services (GIS) because Suleiman was useful to the US in counterterrorism (Brownlee 2012: 69).

Mubarak had other plans. Article 76 of the Egyptian Constitution allowed for a single candidate plebiscite. Mubarak's regime proposed an amendment to the constitution to allow for multiple candidates for the presidency. In theory, that amendment will allow for multiparty contestation for the position of the chief executive. What the US did not count on is that Mubarak would rig the selection process and its outcome. Ayman Nour, the candidate preferred by the liberal reformers was put on trial on politically motivated charges (Berger 2012: 625). The regime introduced a clause to the amendment requiring all nominees to come from official parties that have $5 \%$ of the parliamentary seats to qualify to run as a presidential candidate (Brownlee 2012: 93). Since no party, except the regime's party, the NDP, met this criterion, it all but guaranteed the succession of the dictator's son, Gamal Mubarak.

We have the benefit of hindsight. We know that hybrid authoritarian regimes are skilled in manipulating elections to engineer the result they want. Ayman 


\section{Egypt and Fiji}

Nour, the moderate opposition's candidate, was allowed to contest the presidential election of 2005. In reality, he had no chance of winning that election. The subsequent parliamentary elections that same year reinforced this trend. Mubarak's regime resorted to its "well-rehearsed violent intimidation tactics" to suppress the votes for the opposition (Berger 2012: 604). By using vote suppression, the regime marginalized the non-Islamist opposition parties. The regime's party, the NDP won a supermajority in parliament. What was equally significant, the regime allowed the Muslim Brotherhood to win enough seats to become the main actor among the opposition. This setup is a replay of the "Mubarak-Muslim Brotherhood dichotomy" (Brownlee 2012: 94) card that the regime played in the 1990s. The aid dynamic that relegated democracy to a lesser priority asserted itself again to produce the same outcome.

The US Congress also played a role in the politics of aid to Egypt. Historically, aid to Egypt was considered politically "untouchable" (Berger 2012: 608). Yet, from 2004 to 2007, there were four Congressional roll call votes on US foreign aid to Egypt. Berger (2012) conducted a fascinating study on the determinants of those votes. The first three are pertinent to this section while the fourth amendment deals with Israel's security and is discussed in the following section. The 2004 amendment attempt by Representative Tom Lantos sought to shift US\$ 325 million from the military aid budget to its economic aid counterpart (Berger 2012: 608). It reflected the sense in Congress that Mubarak was overemphasizing Egypt's military upgrades at the expense of its domestic economic needs. The 2005 amendment attempt by Representative Joe Pitts sought to reallocate half (US\$ 750 million) of the military aid to Egypt to fight malaria in Africa (Berger 2012: 609). That attempt reflected Congress's displeasure with Egypt's human rights record. It coincided with the Bush administration's effort to persuade Mubarak's regime to hold its first presidential election (the one that was rigged by Mubarak). The 2006 amendment attempt by Representative David Obey sought to transfer US\$100 million from the economic aid to Egypt to other development needs in Africa (Berger 2012: 610). All three amendment attempts were voted down. Berger's focus is on the role of campaign contributions by the lobby groups to the Congressmen in those roll call votes.

What is pertinent for our purpose is the fact that "overwhelming majorities of both parties were still willing to follow the Bush administration's call not to upset the bilateral relationship" (Berger 2012: 609). Even though some members in Congress wanted to signal their displeasure at Mubarak's regime for obstructing political reforms by cutting, diverting, or transferring aid, the coalition that backed the continual flow of aid was stronger. So long as Mubarak's Egypt provides valuable concessions (and in this specific situation, generates the campaign contributions to Congressmen) that the US needs, that state of affairs would continue.

The US prefers a post-Mubarak Egypt led by Omar Suleiman; it accepted as the alternative a pliant Egypt led by Gamal Mubarak. What it would not accept ${ }^{12}$ was an anti-American but democratic government led by the Muslim Brotherhood. This set of preferences reveals that regime continuity, not democracy, is the 
US goal. The disagreement between the US and Egypt over the succession was not about fundamental regime change, rather it was over the best way to preserve American strategic interests (Brownlee 2012: 77). The US decision to accept the 2005 election results which all but guaranteed Gamal Mubarak's rise strongly supports H10. The US is inclined to push for democracy, but not to the point of sacrificing its national interests (Gulf access and Israeli security).

\section{The aid conditionality that worked}

The preceding section dealt with an attempt where the donor was not invested in the outcome. This section deals with an attempt where the donor is highly motivated. It demonstrates the ability of the donor to assert pressure when it wants to.

Like the case with Egypt, the US also pressured the Palestinian leadership to hold elections. The US expected the elections to strengthen Fatah, which has relatively moderate views on America/Israel. Instead the 2006 elections gave a mandate to Hamas, which has radical views on America/Israel. This forced the US to choose between the results of a democratic process, a democratically elected government that is anti-American, or a backtrack on the democratic process itself.

In response, the US dropped the emphasis on elections and sought what it termed "effective democracy" (Brownlee 2012: 100). As articulated in a post2006 National Security Strategy document, "effective democracy" translates into a set of demands on the Hamas government that the latter must meet in order to be accepted by the West. The content of the demands is immaterial to their antidemocratic nature. These are demands imposed by the West on the Palestinians. They are not the demands that the Palestinians would have freely chosen. Brownlee, comparing the Egyptian and Palestinian cases made the following observation:

International legitimacy stemmed from alignment with U.S. security needs, not accountability to the local populace. So long as parties who threatened U.S. interests could prevail at the ballot box, fullblown democratic elections would be deemed precipitous, whether that judgment was made beforehand, as with Egypt, or after the fact, as with the Palestinian Authority. "The people" were sovereign only insofar as they chose leaders who did not contest U.S. power.

(Brownlee 2012: 101)

The US, as I have previously emphasized, was consistent in prioritizing security needs over democracy promotion. The theoretical concern is to understand how the US used its leverage over Egypt to enforce its wishes. In 2006, open warfare between Hamas and Israel and a separate fight between Hezbollah and Israel forced Washington's hand. There was a rethinking of the Freedom Agenda. Washington needed Mubarak's help over Hamas and over the Hezbollah conflict. Given the strong anti-American and anti-Israeli mood in Egypt at that time (Brownlee 2012: 104-106), a more democratic Egypt under a weaker leader could have played up anti-Americanism, hurting US strategic interests. 


\section{6}

Egypt and Fiji

The compromise was to let up on the demands for political reforms. Washington did not complain when Mubarak's regime went after the opposition (the Kefaya movement, the Muslim Brotherhood) and the judiciary. It signaled, privately, its acceptance of Gamal Mubarak as the heir designate (Brownlee 2012: 107-109). An issue of contention was over the control of the aid programs. Under the terms of the Camp David Accords, both the US and Egyptian governments have to agree on the aid to specific programs (Snider and Faris 2011). The US preferred to give directly to the civil society organizations (this is the bottom-up approach described in Chapter 1). Mubarak's Egypt sought to control that outlet by passing Law 84 in 2002 that sought to impose state supervision on foreign funding to local non-governmental groups (Brownlee 2012: 109). The discussion within the US over this issue demonstrated how Washington was acutely aware of its strategic need for Egypt. Predictably, Egypt got its way (Brownlee 2012: 111-112).

By 2007, Israel was engaged in multiple conflicts. On security issues that matter to the US, namely Israeli security, Washington became more assertive. Congressional Representative David Obey inserted a clause into the Consolidated Appropriations Act of 2008 that required the cutting of US\$ 200 million in military aid to Egypt:

[U]nless the Secretary of State certifies and reports to the Committees on Appropriations that the Government of Egypt has taken concrete and measurable steps to (a) adopt and implement judicial reforms that protect the independence of the judiciary, (b) review criminal procedures and train police leadership in modern policing to curb police abuses, and (c) detect and destroy the smuggling network and tunnels that lead from Egypt to Gaza.

(CR 2007: H6913)

Congressional Representative Charles Boustany introduced an amendment to remove this clause. Although this amendment attempt failed, it prompted the inclusion of language to allow the Bush administration to use a "national security waiver" (Berger 2012: 610). The roll call vote was symbolic because it is understood that the White House would bypass the proposed aid cut. Yet, this was the first time Congress, after multiple previous abortive attempts (see Berger 2012), voted to impose an unprecedented conditionality on military aid to Egypt (Brownlee 2012: 115, 117; Berger 2012: 611). Although Congress expressed frustration with the lack of democratic reforms, the primary concern was arms and material smuggling through the border town of Rafah into Gaza. The US sought to impose an international blockade on Hamas and wanted Egypt to do more. As the blockade of Gaza tightened, smuggling, which became more profitable, increased. Egypt argued that the proposed aid cut made it harder to maintain its side of the blockade to limited avail. Washington did eventually invoke its executive privilege to waive the Congress-imposed aid conditionality. However, the threat of aid conditionality had its intended impact. Under pressure, Egypt had to agree to let 
a US Engineer corps survey the border and build a subterranean steel wall to curb smuggling (Brownlee 2012: 120, 138).

The US also changed its view on the utility of the Egyptian alliance. As the US prioritized counterterrorism, it wanted the Egyptian military to focus on intelligence operations. The Egyptian army resisted as it wanted to keep its focus on conventional warfare. The US gradually reduced its military aid to Egypt, breaking the 3:2 aid ratio that was established since Camp David (Brownlee 2012: 121).

Collectively, the outcome from the congressional vote and the cut in military aid supports $\mathrm{H} 11$ or the claim that donors can apply pressure effectively on issues that do matter to them.

\section{Case study of Fiji's aid relations}

\section{The nature of Fijian politics}

Internal instability in Fiji posed a persistent security challenge for the South Pacific. Fiji has had four coups since 1987 and its coup-prone politics is a constant concern for the regional powers. Since its dependence in 1970, the central cleavage in Fiji is ethnic, between the indigenous Fijians and the Indo-Fijians. The indigenous Fijians are Melanesians and refer to themselves after 2010 as the iTaukei or Taukei (Lanteigne 2016: 48). The Indo-Fijian are the descendants of indentured servants brought mainly from India (and some from Southeast Asia) during Fiji's past as a British colony. The cultural separation between the two ethnic communities is deep with informal segregation at almost every level of society (BBC 2015). Until recently, both groups account for approximately half the population (with small Chinese and Rotuman minorities) each. As a result of the coups, the communal agitations, and the political instability, the Indo-Fijians started to leave. This migration started to change the Fijian population distribution. By one estimate (Lanteigne 2016: 48), the population is now 55\% indigenous and $38 \%$ Indo-Fijian. Those Indo-Fijians who left also tend to be more highly skilled. Their absence damages the long-term economic prospects of the country (Kelly 2015: 5).

The first military coup in 1987 saw Lieutenant Colonel Sitiveni Rabuka and the Royal Fiji Military Force (RFMF) overthrow the coalitional government between the National Federation Party (NFP) and the Fiji Labor Party (FLP) led by the Prime Minister Timoci Bavadra of the FLP. Bavadra's leadership was perceived, unfairly according to Lawson (2015: 211), to be a political victory for the IndoFijians. The military coup was on behalf of the indigenous Fijians. There was a second coup, in the same year, led again by Rabuka. The political situation after the coup, especially after the 1990 constitution, favored the indigenous Fijians at the expense of the Indo-Fijians (Lawson 2015: 211). It also started a long-term exodus of Indo-Fijians. Internationally, the coup was condemned by the Commonwealth and the Pacific Island Forum, PIF (Lawson 2015; Kelly 2015). Australia and New Zealand as Fiji's most important metropolitan partners were harsh 


\section{8}

Egypt and Fiji

critics of the coup. They imposed aid cuts and mild economic sanctions (Lawson 2015: 211). Their motivation was consistent "with a broad western ideology of support for democratic rule and robust civil and political rights regimes both at home and abroad, although this is mediated by a pragmatism that usually places interests before principles" (Lawson 2015: 212).

As the economic situation in Fiji deteriorated, a new constitution was agreed between the major political parties in 1997. The election held under the 1997 constitution was won in a landslide by the multi-ethnic coalitional government led by Mahendra Chaudhry. Chaudhry was the first Indo-Fijian to ever hold office in Fiji (Kelly 2015: 5-6). This intensified racial tensions and the indigenous Fijians mobilized against the government again (Lawson 2015: 212). A failed businessman, George Speight, led a group of Fijian extremists to hold the government hostage. The attempt failed but gave a pretext for yet another military takeover in 2000 .

As before, Australia, under the Prime Minister John Howard, condemned the coup. So did regional groups such as the Commonwealth and the PIF. The Commonwealth suspended Fiji's membership again. The PIF, alarmed by the instability in the South Pacific due to the turmoil in Fiji and also in the Solomon Islands, articulated the Biketawa Declaration in 2008, which commits the region to democracy and good governance (Lawson 2015: 213). Signatories of the declaration, which have the support of regional powers, included Fiji. The Declaration was important as it justified subsequent interference into the internal affairs of the PIF member states.

The region was relieved when Fiji returned to civilian rule under the prime ministership of Laisenia Qarase. Fiji's suspension from international bodies was revoked and its relations with neighbors were normalized (Lawson 2015: 213). The problem was that Qarase and his conservative party relied on the same racist and nationalist politics that motivated Speight and the Fijian nationalists. The commander of Fijian military, Commodore Bainimarama, was personally opposed to that brand of politics. As tensions between the elected government and the Fijian military worsened, Bainimarama campaigned openly against the Qarase government in the elections of 2006. When Qarase won the 2006 election, Bainimarama launched his “coup to end all coups" and overthrew Qarase's government (Lawson 2015: 213).

\section{The international reaction to the 2006 coup}

We know from Shannon et al. (2015) that there is a trend towards a stronger condemnation of coups after the Cold War. The international reaction was therefore predictable. Immediately after the 2006 coup, Fiji faced international condemnation from the UN Security Council, the EU president, the Commonwealth, Norway, Japan, Singapore, Australia, New Zealand, Papua New Guinea, and Vanuatu (Lawson 2015: 214). The Commonwealth also suspended Fiji's membership. The PIF started a Forum-Fiji working group with the task of guiding Fiji back to democracy. 
Bainimarama, however, wanted to eradicate Fiji's racial politics and develop its economy (Lawson 2015: 214). This would be a long-term project. It meant that Bainimarama will not return power to elected parties that resorted to racial politics before. For example, Bainimarama announced the work on a new constitution would not begin until 2012. A general election that was supposed to be held in 2009 was delayed to 2014 (Kelly 2015: 11). From 2006 to 2009, the PIF working group met 35 times without any progress towards democracy (Lawson 2015: 214). By 2009, the delaying tactics of Fiji were apparent to the international community.

In an unprecedented move, the PIF invoked its 2008 Biketawa Declaration and suspended Fiji's membership. The PIF is an organization of the Pacific Islands made up of small states that are sensitive to the intervention from outside powers, especially Australia and New Zealand, into the domestic affairs of member states (Lawson 2017). This makes the decision to suspend all the more remarkable. The Fijian regime alleged the decision was the result of manipulation by Australia and New Zealand working behind the scenes in the PIF. Lawson disputes this. She points out that the decision to suspend has unanimous support. The Pacific Islands are sensitive about neo-colonialism and would not have followed the Australia and New Zealand lead unless they themselves agreed with the stance. She argues the membership suspension reflects both the frustration of the region with the continued instability in Fiji and the commitment of the organization to democracy (Lawson 2017: 225-226).

Sub-regional and intra-organizational politics also play a role. Recall there are three sub-regions in the South Pacific. Fiji is physically located in the Melanesia sub-region, but is considered a linchpin at the crossroads of two sub-regions, Polynesia and Melanesia (Lanteigne 2016: 46). After the suspension, Fiji used the Melanesian Spearhead Group (MSG) to provide diplomatic cover. The MSG was originally an informal lobby group within the PIF whose goal was to represent the interests of the Melanesia states. Fiji used the MSG to argue that its regime type is an internal matter and not subject to outside (read PIF) interference (Lawson 2015: 215; Lawson 2017: 219). One consequence of that maneuver was to prompt another sub-regional group, Polynesian Leaders' Group (PLG) to develop its own sub-regional identity. The PLG is formalized in 2011 to represent the interests of the Polynesian states (Lawson 2017: 226). Additionally, key Polynesians states, Tonga, Western Samoa, and Niue all have bad relations with Fiji. Tonga gave shelter to a high-ranking member of the Fiji military accused of plotting the overthrow of the government in 2011 (Lawson 2015: 215). The tensions between the island states demonstrate that the South Pacific is not reducible to Great Power and small state dynamics only.

The reactions of the major Western powers were in favor of democracy. The EU, Australia, New Zealand, United Kingdom, and the US all imposed a variety of diplomatic and economic sanctions on Fiji (Lawson 2015: 214). The US invoked its Foreign Assistance Act to immediately cut its aid to Fiji (AFP 2006; Lanteigne 2016: 51). The online site of the US embassy in Suva used to feature its principled stance to reject military rule and to demand the return of democracy 
before the resumption of aid. ${ }^{13}$ The US had a consistent stance and resumed aid only after the 2014 Fijian elections. That said, the US is a minor aid donor in the South Pacific. From 2006 to 2014, the total value of US aid was around US\$ 15.09 million. This places the US behind all the significant Western donors of aid to Fiji (Brant 2015).

The pertinent reactions are from the South Pacific powers, Australia and New Zealand. Both imposed limited sanctions, an arms embargo, and a travel ban on key personnel of the Fijian military and Fijian government. The travel ban also targets Bainimarama personally and the family members of key figures (Lanteigne 2016: 48-49). New Zealand reduced the scope of the seasonal work programs for Fijian workers. There was also a rugby sport ban (Lanteigne 2016: 49). The Foreign Minister of Australia in 2006 under John Howard's government was Alexander Downer. He asserted: "I think the ordinary people of Fiji and the institutions of government in Fiji should show passive resistance to this imposition of dictatorship on their country" (Kelly 2015: 7). Urging the civil resistance of the people to its illegitimate government is extraordinary under normal circumstances. Given the regional sensitivity to outside interference, this was an unusually forceful stance by Australia. It reflected the strength of the opposition from Australia to the coup in Fiji. Australia underwent a period of leadership change, which led to a rapid series of Australian Foreign Ministers, from Downer to Smith to Rudd to Carr to Bishop. ${ }^{14}$ In all of them, the rejection of the military regime in Fiji remained a consistent policy stance (Kelly 2015). The Foreign Minister Bob Carr emphasized that the Fijian return to democracy was an issue of principle for Australia. He said:

In the end dictatorships only become lazy, corrupt and brutal. Think of Zimbabwe. You've got to remember that the Commonwealth is a community of democracies. The Pacific Island nations are a community of democracies. There's just no respectable future for a country where military officers rule by decree.

(Carr 2014; cited in Kelly 2015: 9)

Interestingly, Carr met with the Secretary of State Hillary Clinton and had US support for Australia's stance towards Fiji (Kelly 2015: 9). This is a case of Western donors expressing a clear preference for democracy. Australia can afford to be tough on Fiji because it has considerable leverage. Australia is the guarantor of the South Pacific and is "its largest source of aid, trade, and investment" (Guardian 2013). What is more, Philippa Brant observes that this regional dependence on Australia "will remain so for decades to come" (Guardian 2013). The extent of this regional dependence needs emphasis. The Lowy Institute estimates that from 2009 to 2011, the US provided 51\% of the total bilateral Official Development Assistance (ODA) in the Middle East. By contrast, Australia accounts for $62 \%$ of the total bilateral ODA in the South Pacific. The Australian influence dominant role in aid to the South Pacific is greater than the US equivalent role for the Middle East (Guardian 2013). 
Lane (2012) argues Fiji is too heavily integrated into the first world trading system to sustain a dictatorship. Fiji relies on trade with Australia and New Zealand. In 2013 for example, Australia is Fiji's top export destination and the second most important source of imports (Kelly 2015: 9). Australian aid to Fiji is the largest of the Western donors. It has a value of US\$ 303.14 million from 2006 to 2014 and is just behind the value of Chinese aid to Fiji (Brant 2015).

Slightly over a third of the Fijian economy is based on tourism (Lanteigne 2016: 49). Australia is an important source of those tourists. Around half of all tourists to Fiji from 2003 to 2012 were from Australia (Kelly 2015: 8). New Zealand and Australia could have used a tourism ban as leverage against Fiji. They may have declined to do so to avoid the appearance of bullying Fiji. The region, as Lawson (2017: 221) notes, is sensitive to the appearance of neocolonialism. The regional power may be worried about the possibility of provoking a nationalistic backlash in Fiji (Lanteigne 2016: 49). We know, with the benefit of hindsight, that a tourism ban was not necessary since Fiji did hold an election in 2014.

That donor pressure was exerted on a Fijian economy that is already not doing well. It was in a slow long-term decline pre-2006 due to politically driven migration. It was further weakened by the 2008 global recession and by the slowdowns in the Chinese and Australian economies (Lanteigne 2016: 50).

We know the donor pressure exerted on Fiji is considerable. Authoritarian regimes do not naturally cede power if they can help it. The fact remains that Fiji gave in and held a multiparty election in 2014. Furthermore, the election is witnessed by international elections observers from the Multinational Observer Group (MOG). The international presence was at the behest of Australia and New Zealand (Lanteigne 2016: 49). After the election was held and accepted by the MOG, the donors eased pressure on Fiji. The US and Australia ended their sanctions and resumed aid to Fiji (Lanteigne 2016: 49; BBC 2014). New Zealand normalized relations with Fiji in early 2014.

The collective responses from Western-aligned aid donors and from the PIF support the claim that donor pressure for democracy, when used consistently on Secondary recipient such as Fiji, can bring about political change. This supports H12.

\section{The Fijian response and Chinese Aid}

Although Fiji did eventually return to civilian rule, it demonstrated considerable agency from 2006 to 2014. Its activist foreign policy sought to break the international condemnation by i) creating its own forum and by ii) seeking alternative donors.

Fiji felt compelled to make a forceful response. It expelled the High Commissioner from New Zealand in 2007, in 2008, and again in 2009 along with the Australia High Commissioner (Lawson 2015: 215). It also proactively started the Melanesian Spearhead Group (the MSG), that has already been discussed previously.

In a direct response to the suspension of Fiji by the PIF (Lawson 2017: 226), Fiji started the Pacific Islands Development Forum, the PIDF, in 2013. The declared goal of the PIDF was to allow the Pacific Islands state a platform to address purely 


\section{2}

Egypt and Fiji

developmental issues. It is meant for South-to-South dialogue. In their jargon, it is a forum for the Pacific Islands Small Developing States (PSIDS) only (Lawson 2017: 226-227). The organization asserts it is not meant to duplicate or bypass the more established PIF. In reality, the PIDF is a way for Fiji to mitigate Australia and New Zealand influence in the PIF. For example, both Australia and New Zealand were not given core member status in the PIDF.

The long-term fate of the PIDF is in doubt after 2014. The PIDF relies on voluntary contributions from members. By contrast, the PIF has secured funding from Australia and New Zealand. The PIDF needs a source of staff and funding. Both were provided by Fiji initially. Russia, Kuwait, and China offered funding for a secretariat (Lawson 2017: 228). Whether that is enough remains to be seen. Fiji does not need it as an alternative platform after ties with the West were restored following the 2014 elections.

Fiji is a country that is reliant on aid (BBC 2015). Faced with sanctions from Western donors, the Bainimarama regime has strong incentives to look for alternative sources of aid. The regime revived its "Look North" foreign policy - a policy that predates the military regime - to search for non-traditional, non-DAC donors such as Russia, and the Gulf states. The real prize of the policy was China. The Chinese policy is to separate governance issues (where a lot of the aid conditionality lies) from economic/developmental issues (Lanteigne 2016:52). Unlike aid from traditional DAC donors, Chinese aid appeals because it is perceived to lack conditionality. When the coup occurred in 2006, several Chinese aid projects were disrupted (Brant 2015). Beyond that minor hiccup, the Chinese demonstrated a willingness to do business with and commit aid to any regime that is in power regardless of circumstances (Yang 2011: 76).

The Chinese response has been mixed. China has intrinsic concerns that are arguably separate from the value of Fiji. Since 1949, both China (or the PRC) and Taiwan (or the ROC) competed for diplomatic recognition. Initially the ROC had the upper hand as communist PRC was diplomatically isolated and poor. Over time, most countries switched recognition over to the PRC. To compete in a decreasing pool for state recognition, the ROC resorted to a form of "dollar diplomacy" or using foreign aid as an inducement to buy recognition; occasionally, the PRC will retaliate in kind (Atkinson 2014; Tan 2016).

The South Pacific is one such arena for diplomatic recognition. As a case in point, six of the 23 countries in the South Pacific still recognized Taiwan in 2009 (Yang 2009: 143). There may have been an effort to court the region. The Chinese Premier Wen Jiabao participated in the 2006 China-Pacific Islands Countries Economic Development and Cooperation Forum summit where China announced 3 billion yuan or US\$ 375 million in loans and aid (Lanteigne 2016: 52). China offered to underwrite the construction of the MSG secretariat building in 2007 (ibid) and to fund the PIDF (Lawson 2017: 228).

The Taiwan connection may be one reason why Fiji is of interest to China. Fiji maintains a Taiwanese representative office in Suva and receives Taiwanese developmental aid despite a diplomatic relationship with China (Lanteigne 2016: 52). This may account for the immediate US\$ 5 million in aid China gave to Fiji 
in 2006. China may be seeking to discourage Fiji from recognizing Taiwan (Fifita and Hanson 2011: 4).

Yet, the claim that the Chinese aid is driven primarily by the Taiwan-China diplomatic struggle is not persuasive. The Kuomintang party (KMT) won power in Taiwan in 2008. The Chinese government welcomed this since the KMT shared similar policy stances with China especially over the viability of Taiwanese independence. Under the government of President Ma Ying-Jeou, the relationship between Taiwan and China improved markedly. There was a tacit gentlemen's agreement between PRC and ROC not to resort to dollar diplomacy (Atkinson 2014). According to Fifita and Hanson (2011), no country switched diplomatic recognition between the two since Costa Rica recognized China in 2007. The diplomatic truce between the two Chinas lessened the need for China to use aid to buy recognition from Fiji.

Despite the lack of concessions from Fiji, the aid by China to Fiji increased over time. The Lowy Institute estimates that the value of China's aid to Fiji from approximately 2006 to 2014 was around US\$ 359.80 million (Brant 2015). This puts China as the top donor to Fiji and ahead of Australia. This increase should be set in perspective. Over the same time period in the South Pacific, China gave the most aid to the resource-rich Papua New Guinea (Brant 2015). The statistics for Chinese aid are estimates. China does not follow the accounting and transparency standards of DAC donors. The Bainimarama government sought to highlight its ties with China. This in turn prompted the Fijian media to report the same project as if they were new sources of aid (Guardian 2013). Furthermore, the 2006 to 2014 period saw the major Western donors, especially Australia and New Zealand, cut aid with Fiji. Thus, Chinese aid seems high during a period that discounted the impact of Western donors.

The picture is also mixed when we look at the broader China-Fiji relations. Chinese-Fijian trade has been increasing. In 2014, the value of trade was US\$ 472 million (Lanteigne 2016: 53). This was an object of praise when Chinese president Xi Jinping visited Fiji in November 2014. There are also discussions of a feasibility study over a free trade agreement between the two countries. Yet, when the Chinese navy made a goodwill tour of the South Pacific in 2010, Fiji was conspicuously not a port of call despite its central location (Lanteigne 2016: 54). Furthermore, in an earlier 2010 visit by the then Vice President Xi Jinping to Suva, China received assurances from the Bainimarama regime that it was committed to a return to democracy (Lanteigne 2016: 54)! What could account for the mixed signals by Beijing? A view is that China did not want to be the "regional spoiler" (Lanteigne 2016: 54). The Chinese government may be reluctant to associate with a pariah state, one that does not offer much by way of concessions. As Fifita and Hanson argue:

China seems to have felt pressure not to be seen to be lavishing aid on a pariah government (most likely because it is uncertain of the return for seemingly frustrating the United States, Australia and New Zealand). 
Overall, Fijian attempts to break its diplomatic isolation did yield some success. It founded its own international platform and attracted some aid from non-traditional aid donors. Yet the long-term future of the PIDF is uncertain. Chinese aid seems to be part of its general commitment to the South Pacific and driven in part by the China-Taiwan diplomatic rivalry. Collectively, these outcomes provide only partial support for H13. Fijian attempts to seek aid were somewhat successful although the concessions it can offer to China in return were not apparent.

The case of Fiji illustrates how the prospects for political liberalization can be higher for secondary recipients. Yet, the extent of political change can be limited. There were concerns about due process in the 2014 election even though it was recognized by international observers (Fraenkel 2015). Bainimarama's regime passed a Public Order (Amendment) Decree that placed more restrictions, compared to the previous regime, on the media (NYT 2012). Under the harsher law, Fijian journalists resorted to self-censorship. Two prominent politicians who could have formed a viable opposition to Bainimarama, Mahendra Chaudry and Laisenia Qarase, were prohibited from participating in the election (NYT 2012). The political party created and led by Bainimarama, Fiji First, won that election by a comfortable margin. Bainimarama became Fiji's Prime Minister. Therefore, the man who led the 2006 coup, Bainimarama, is still in charge.

Another problem is the ethnic cleavage in Fijian politics. The Indo-Fijian community voted for the Fiji First party in part "because it offered the best guarantee against a re-run of the Qarase years" (Madraiwiwi 2015: 58). Despite the rhetoric of equal citizenship, the fact remains that the Fijian military and public service are disproportionately dominated by the Taukei (Madraiwiwi 2015: 58).

Finally, the foreign policy of Fiji retains its activist posture post-2014. Although Fiji resumes membership of the PIF after the election, tensions remain. Prime Minister Bainimarama is still critical of Australia and New Zealand. He sought to expel countries from the PIF or alternatively, add countries such as China as new members in order to dilute Australia and New Zealand's influence. When this proved unsuccessful, the Prime Minister refused to attend PIF meetings to protest against the current structure of the PIF (Lanteigne 2016: 55). Political liberalization in Fiji, therefore, is limited and should not be mistaken for democratic consolidation.

\section{Conclusion}

This chapter explores two cases at opposing ends of recipient salience. At one end, the recipient with salience should have an easier time getting aid without the concomitant democratization.

At the other end, the recipient without salience should have to commit to political reforms in order to receive aid. On the whole, the evidence from the case studies supports these expectations. Yet they also reveal nuances that are idiosyncratic to both recipients. Due to its economic condition, Egypt as Brownlee (2012) reminds us, is a heavily leveraged aid recipient. The US could get its way on issues it deemed vital for its national interests. It was able to force the Egypt military to 
devote more resource to enforce the international blockade of post-2006 Hamas than the Egyptian military chief Tantawi would have liked. Such American pressure is conspicuously absent when it comes to political reforms. For all the rhetoric of Bush's Freedom Agenda, the US prefers the Mubarak regime as a pliant ally over a democratic but hostile government led by the Muslim Brotherhood. The choice of the US to exert pressure in one situation and to be complicit in other situation, I argue, highlights the political reality democracy promotion must deal with.

Fiji is a small state with significant ethnic cleavages. It has limited value to the West, outside of a context of geostrategic competition with China. Western donors have no issues putting sanctions on Fiji in the aftermath of its coups. The pressure by donors on a weakening economy that is dependent on foreign aid persuaded the Bainimarama regime to hold elections in 2014. In the past, when China was competing with Taiwan for diplomatic recognition, Fijian attempts to seek Chinese aid might have been more successful. China did commit aid to Fiji but in lesser amounts compared to Papua New Guinea who can offer more mineral resources. China appears to be otherwise reluctant to antagonize regional powers, Australia and New Zealand, over Fiji.

These two cases inform us on the conditions under which donors are likely to push for democracy promotion. When the recipient lacks salience, as in the case of Fiji, donors will indulge in democracy promotion. Even the agency that Fiji displayed in its activist foreign policy could not save it from donor pressure or attract substantial Chinese interest. When the recipient is valuable as in the case of Egypt, strategic considerations override democracy promotion. Astute authoritarian regimes understand this and play up the anti-Western public opinion that political reforms could engender.

We have by now the opportunity to examine both the results of the statistical analysis and the case studies of specific recipients. What are the policy, political, and normative implications that can be inferred from this research? How does the theory hold up in the current era, characterized by some as the age of populism? How might we build upon this research? The concluding chapter addresses these issues.

\section{Notes}

1 Section 508 of the Foreign Assistance Act can be found online at this site: www. gpo.gov/fdsys/pkg/PLAW-109publ102/html/PLAW-109publ102.htm (last accessed 15/9/17). To the best of my knowledge, it is also known as the "Foreign Operations, Export Financing, and Related Programs Appropriations Act 2006", Public Law 109102, 14 November 2005, United States Government Printing Office.

2 This is the Section 7008 of the FY2012 Consolidated Appropriations Act, available online at this site www.gpo.gov/fdsys/pkg/PLAW-109publ102/html/PLAW-109 publ102.htm (last accessed 21/07/13).

3 The official websites of the US embassies are professionally standardized and follow a similar format. That is why in 2013, it was not difficult to spot an omission.

4 By definition, secondary recipients do not have much to offer to donors. The problem with using them for a case study is that the aid literature on them are likely to be 
sparse. In Fiji, there is an existing literature that deals with the activist foreign policy of Bainimarama's regime. This lends itself to a more interesting contrast with Egypt. Thus, I choose Fiji for the sake of narrative convenience, even though it is not strictly speaking, a secondary recipient.

5 "Foreign Military Training and DoD Engagement Activities of Interest: Joint Report to Congress," Department of State, March 2002, www.state.gov/t/pm/rls/rpt/ fmtrpt/2002/10723.htm (last accessed 18/5/2010). Cited in Brownlee (2012: 71).

6 When the USSR invaded Afghanistan, Egypt helped the Central Intelligence Agency (CIA) funnel its stockpile of old Soviet weapons to Afghan anti-Soviet groups (Brownlee 2012: 38).

7 It is available at this site www.cia.gov/library/publications/the-world-factbook/ rankorder/2001rank.html\#fj from the CIA World Factbook (2017) (last accessed 22/9/17).

8 Keep in mind that the region is sensitive about nuclear weapons due to the past nuclear tests and misdeeds by major powers in the region (such as the sabotage of the Greenpeace ship the Rainbow Warrior).

9 The statute suspends aid if a country fails to repay its military debt to the US by more than one year (Brownlee 2012: 55).

10 I discuss democracy aid in the next section.

11 Bradshaw Langmaid, head of development planning for the Near East Bureau, 197680, Georgetown University Library, July 14, 1998, 51, cited in Snider and Faris 2011.

12 That was true until the US had no choice but to work with Muslim Brotherhood in post-2011 Egypt.

13 The policy statement by the US embassy to Fiji was available here: http://suva.usem bassy.gov/section_7008.html (last accessed 21/07/13).

14 Australian domestic politics is notorious for its dramatic leadership struggles, within the framework of a parliamentary democracy.

\section{Bibliography}

AFP. 2006. "US Cuts Aid to Fiji." Agence France-Presse. www.abc.net.au/news/200612-20/us-cuts-aid-to-fiji/2158366.

Atkinson, J. 2014. “Aid in Taiwan's Foreign Policy: Putting Ma Ying-jeou's Aid Reforms in Historical Perspective." The Pacific Review 27: 409-431.

BBC. 2014. "Australia Ends Sanctions on Fiji After Democratic Elections." British Broadcasting Corporation. www.bbc.com/news/world-australia-29844291.

BBC. 2015. "Fiji Profile - Full Overview." British Broadcasting Corporation. British Broadcasting Corporation.

Berger, Lars. 2012. "Guns, Butter, and Human Rights - The Congressional Politics of U.S. Aid to Egypt." American Politics Research 40: 603-635.

Brant, Philippa. 2013. "Chinese Aid in the South Pacific: Linked to Resources?" Asian Studies Review 37: 158-177.

Brant, Philippa. 2015. "The Geopolitics of Chinese Aid: Mapping Beijing's Funding in the Pacific." ForeignAffairs. www.foreignaffairs.com/articles/china/2015-03-04/geopoliticschinese-aid.

Brownlee, Jason. 2012. Democracy Prevention: The Politics of the U.S.-Egyptian Alliance. Cambridge: Cambridge University Press.

Bush, Sara. 2015. The Taming of Democracy Assistance: Why Democracy Promotion Does Not Confront Dictators. Cambridge: Cambridge University Press.

Carr, B. 2014. Diary of a foreign minister. Sydney: University of New South Wales Press. CIA. 2017. "CIA world factbook." Central Intelligence Agency. 
Congressional Record. 2007. "Consideration of Foreign Operations and Related Programs Appropriations Act 2008." Consideration of Foreign Operations and Related Programs Appropriations Act 2008. US, 621.

Djerejian, Edward P. 1992. "The US and the Middle East in a Changing World." U.S. Department of State Dispatch.

Economist. 2013. “Coup-lio."Economist.www.economist.com/blogs/democracyinamerica/ 2013/07/americas-response-coups.

Economist. 2017. "China's Battle for Influence in Its Region.” Economist. www.economist. $\mathrm{com} /$ news/special-report/21720718-countrys-status-among-its-neighbours-notkeeping-up-its-growing-powers-chinas.

Fifita, Mary, and Fergus Hanson. 2011. "China in the Pacific: The New Banker in Town." Issues and Insights. Pacific Forum CSIS 11: 1-26. http://csis.org/files/publication/ issuesinsights_v11n05.pdf.

Foreign Policy. 2013. "WH Refuse to Call It a Coup." Foreign Policy. http://foreignpolicy. com/2013/07/08/obama-administration-wont-call-egypts-coup-a-coup/.

Fraenkel, Jon. 2015. "The Remorseless Power of Incumbency in Fiji's September 2014 Election." The Round Table 104: 151-164.

Guardian. 2013. "Australian Anxiety Over China's South Pacific Aid Efforts Is Misplaced." Guardian. www.theguardian.com/global-development/2013/aug/28/australia-chinasouth-pacific-aid.

Hillary, Clinton. 2011. "America's Pacific Century.” Foreign Policy.

Kelly, Andrew. 2015. "Restoring Democracy: Australian Responses to Military Coups in Fiji." Journal of International Studies 11: 1-13.

Lane, J. 2012. "Fiji: What Kind of Militocracy?" Japanese Journal of Political Science 13: 401-417.

Lanteigne, Marc. 2016. “Choppy Waters: The 'Return' of Fiji to Pacific Affairs After the 2014 Vote." Third World Thematics: A TWQ Journal 1: 46-62. doi:10.1080/23802014. 2016.1188673 .

Lawson, Stephanie. 2015a. "Fiji's Foreign Relations: Retrospect and Prospect." The Round Table 104: 209-220. doi:10.1080/00358533.2015.1017257.

Lawson, Stephanie. 2015b. "The State of Democracy in Fiji." E-International Relations. www.e-ir.info/2015/12/02/the-state-of-democracy-in-fiji/.

Lawson, Stephanie. 2016. "Regionalism, Sub-Regionalism and the Politics of Identity in Oceania.” The Pacific Review 29: 387-409. doi:10.1080/09512748.2015.1022585.

Lawson, Stephanie. 2017. "Australia, New Zealand and the Pacific Islands Forum: A Critical Review." Commonwealth \& Comparative Politics 55: 214-235. doi:10.1080/14662 043.2017.1280205.

Levitsy, Steven, and Lucan A. Way. 2010. Competitive Authoritarianism: Hybrid Regimes After the Cold War. New York: Cambridge University Press.

Madraiwiwi, Joni. 2015. “The Fijian Elections of 2014: Returning to Democracy. . .?" The Journal of Pacific History 50(1): 54-60.

Megan, Shannon, Clayton Thyne, Sara Hayden, and Amanda Dugan. 2015. "The International Community's Reaction to Coups." Foreign Policy Analysis 11: 363-376.

NYT. 2012. "In Fiji, a Detour on the Road to Democracy." New York Times. www. nytimes.com/2012/07/03/world/asia/in-fiji-a-detour-on-the-road-to-democracy. html?pagewanted=all.

NYT. 2013. "A Coup? Or Something Else? 1.5 Billion in U.S. Aid Is on the Lin.” New York Times. www.nytimes.com/2013/07/05/world/middleeast/egypts-arrests-of-islamistspose-test-to-us-over-military-aid.html. 


\section{Egypt and Fiji}

Ratner, Ely. 2009. "Reaping What You Sow." Journal of Conflict Resolution 53: 390-418. doi:10.1177/0022002709332206.

Snider, Erin A., and David M. Faris. 2011. "The Arab Spring: U.S. Democracy Promotion in Egypt." Middle East Policy Council XVIII (Fall). www.mepc.org/ arab-spring-us-democracy-promotion-egypt.

South China Morning Post. 2014. "US and Australia Drop Sanctions Against Fiji Following Democratic Elections." South China Morning Post. www.scmp.com/news/asia/ article/1629100/us-and-australia-drop-sanctions-against-fiji-following-democratic.

States Government Printing Office, United. 2005. "Foreign Operations, Export Financing, and Related Programs Appropriations Act, 2006." United States Government Printing Office Public Law 109-102.

Tan, Bann Seng. 2016. "Aid and Democracy Promotion in Asia." Asian Journal of Comparative Politics 1: 152-170.

The Washington Post. 2013. "Law Says the U.S. Is Required to Cut Aid After Coups. Will It?” The Washington Post. www.washingtonpost.com/news/worldviews/wp/2013/07/03/ law-says-the-u-s-is-required-to-cut-aid-after-coups-will-it/?utm_term=.805a331f8cc9.

Wesley-Smith, T. 2007. "China in Oceania: New Forces in Pacific Politics." Honolulu: East - West Center.

Yang, Jian. 2009. "China in the South Pacific: Hegemon on the Horizon?" The Pacific Review 22: 139-158.

Yang, Jian. 2011a. "China in Fiji: Displacing Traditional Players?" Australian Journal of International Affairs 65: 305-321. doi:10.1080/10357718.2011.563778.

Yang, Jian. 2011b. The Pacific Islands in China's Grand Strategy: Small States, Big Games. New York: Palgrave Macmillan. 


\section{$7 \quad$ No golden age, no silver bullet}

\section{Introduction}

This book is motivated by a sense that democracy promotion has not just lost momentum but gone awry. When I explored the reasons for this state of affairs in Chapter 1, I concentrated mainly on democracy aid. Here I use the leeway afforded by the conclusion to explore larger themes that my argument could speak to. I address whether the strategy of liberalization at the margins still applies in the current international context and the price of democracy promotion.

The larger themes addressed can be grouped into three. They are the policy prescriptions that follow from this research, the extension of this work to other research domains, and the political and normative implications of this strategy of aid allocation. The chapter will accordingly be divided into three parts.

In the first part, I summarize the findings of the book and consider the policy implications for policymakers, both in democratic donors (primary focus) and in authoritarian recipients (secondary focus). Given the normative goal of democracy promotion, my primary concern is policymaking in democratic donors. My focus for the former is primarily with the mid-level bureaucrat with some aid allocation authority. I arm them with a list of given recipients that is generated by my data. Anticipating strategic behavior by authoritarian recipients, I also consider how a chief executive of an authoritarian regime might react given their knowledge of this argument.

In the second part, I extend my research to new policy domains and suggest future avenues of research. I suggest a way to fine tune my aggregate data and the pitfalls of doing so. I highlight the potential of my framework to inform on loan and environmental conditionality, associated with the International Monetary Fund (IMF) and the World Bank respectively. I discuss the democracy diffusion potential of secondary recipients and anticipate the reaction of autocrats to such diffusion.

In the third part, I engage with the international context my theory is embedded in. What is the case for my approach given the absence of leadership by key liberal democracies, especially from the US? I refute the notion of a golden age of democracy promotion. Precisely because there was no golden age, the current era, bad as it is, does not represent a fundamental break with the past. The 
transactional nature of current liberal democracies does not obviate the tradeoffs that come with democracy promotion. In discussing the tradeoffs, I clarify how avoiding conflict with autocracies is not feasible. The discussion will also make it clear that there are no silver bullets that will render democracy promotion politically safe for democracies.

\section{What is to be done?}

\section{What we now know}

Observing a world where the global momentum towards democracy is stalling, I ask what donors can do to nudge aid recipients towards democracy. Unlike other approaches to democracy promotion, I do not assume donors value democracy promotion as much as they say they do. Neither for that matter do I assume that authoritarian regimes will give up power voluntarily. Given this state of affairs, I carve out a path that works around both the disinterest by democratic donors and the resistance by authoritarian recipients.

I focus on state-to-state aid deals because the hybrid regimes of today are apt at neutralizing state to civil society aid. Law 84 passed by the Mubarak regime, for example, was designed to ensure state control over foreign funding to nongovernmental organizations. I focus on the strategic opportunities and concessions that recipients offer because donors, despite their rhetoric, seek value for the money spent on their aid. The US, for example, will push Mubarak for reforms until it appears the Muslim Brotherhood that has anti-American preferences might win a free election.

Given these limitations, a more effective way to use the limited aid resources is to focus on recipients that lack attributes to offer the concessions that donors seek. Since they cannot offer much by way of alternative, they are less likely to get other sources of aid and thus have less leverage overall. Such recipients, conditional on them accepting the aid, are more likely to liberalize as a result of aid. This is a smarter way to spend the limited political capital for democracy. Conversely, democracy aid spent on primary recipients that do have a lot of value to donors, has leverage. Nudging these types of recipients is less likely to be effective.

I assessed the implications of the argument with both cross-sectional statistics and case studies. For my statistical tests, I built an original dataset containing information on the aid the recipient receives, the regime characteristics of the recipient, and the salience of the recipients to donors, as well as pertinent control variables. In Chapter 2, I tested the hypotheses from the theory against separate pools filtered by their salience, as well as in a combined pool. I found that there are systemic differences between the two types of recipients. Secondary recipients are systemically more likely to liberalize compared to their primary counterparts. These differences hold up when reverse causality is accounted for. The Cold War proved too challenging for Western donors since enterprising recipients can switch allegiance to the Soviet camp. 
The next set of analysis in Chapter 3 disaggregates the different subcomponents and composite indices that could go into the concept of salience. The geographic proximity of recipient and aggregation rule emphasizing economic attributes tend to perform relatively better. On the whole, I found the default measure, which requires a recipient to have both strategic and economic value, to provide a better account of the difference during and after the Cold War.

Moving down from the global level of analysis, I consider regional dynamics in Chapter 4. I compare Africa, a region that is relatively underdeveloped, to Asia, a more prosperous region. The proposed aid dynamic applies more to Africa than to Asia. Given the more challenging environment of Asia, I also compare across different criterions of salience for Asian recipients and found partial support for the theory.

I explored the aid dynamic of Myanmar in Chapter 5. This is a case where the recipient has some salience but not so much that the Western donors will not consider imposing sanctions on Myanmar. Myanmar sought alternative donors. The dependence of the Burmese regime on Chinese patronage increased the Chinese demands on Myanmar. This prompted Myanmar to switch back to the West in an attempt to restore their leverage. Political liberalization was the price they paid for Western aid. This demonstrates the limits of donor switching. The recipient does not always get its way even when it has alternatives.

I also compare the aid dynamics of Egypt and Fiji in Chapter 6. By conventional intuition, one is an important state, the other is not. Egypt provides logistical support and intelligence to the US and security for Israel. The US was selective in the application of its leverage. The US was successful when it comes to isolating Hamas and unsuccessful when it comes to political reforms. The outcome is a result of the American preference hierarchy. Democracy promotion is not a priority for the US. By contrast, Fiji is a small state in the South Pacific that is historically dominated by Australia and New Zealand. Western donors and the Pacific Islands Forum had little qualms punishing Fiji. Fiji sought and, surprisingly, got some support from China. Nevertheless, it did hold multiparty elections in 2014 after which its ties with Western donors were partially restored.

\section{For the modal policymaker}

The practical implications that flow from this research will interest two distinct groups of policymakers. They are the policymakers interested in democracy promotion from democratic donors and the chief executives of authoritarian regimes that are potential aid recipients. I start with the first group and then consider the autocrats' response.

The modal policymaker I have in mind is a mid-level bureaucrat with some authority in aid allocation. This hypothetical policymaker is working in a national aid agency. They are in charge of a department, a foreign policy desk, or an informal sub-unit that has its institutional mandate of democracy promotion. They have the authority or discretion to choose between recipient countries within an assigned geographic region but not necessarily to allocate funds across regions 
(say from Asia to Africa). ${ }^{1}$ Our modal policymaker has to deal with bureaucratic politics in the Allisonian sense. Allison (1969) in his study of decision-making in the Cuban Missile Crisis notes that most bureaucracies seek to survive, to procure more resources for their own use, and where possible, to thrive. When different bureaucratic agencies clash, the resultant policy is usually a compromise reflecting the bargaining strengths of the respective stakeholders. For example, one could understand US occupational policies for Iraq after the second Gulf War as a compromise between the priorities of the State and the Defense departments.

Applied here, our policymaker should recognize that democracy promotion is not a priority for all other agencies from the donor's state. After all, their institutional mandate is not democracy promotion. When we make the case for democracy promotion, we must anticipate both the pushback from the recipient and how that, in turn, feeds back to other agencies in the donor's state. For example, we learned from Chapter 6, the staff at the USAID, whose mandate is to promote democracy aid, sought to give aid to civil society groups in Egypt. The Mubarak regime pushed back by seeking state control over those same aid projects. The State Department, whose job is to advance US national interests by securing friendly ties with Egypt, faces an inevitable tension between conflicting policy goals (democracy promotion against national interests). This means our policymaker would be wise to rank prospective recipients according to concessions they could counteroffer. The evidence suggests most state agencies rank the salience of recipients in the following manner:

Primary recipients $>$ Economically valuable recipients $>$ Strategically valuable recipients $>$ Secondary recipients.

Our policymaker should then allocate the agency's limited political capital accordingly. Three rules of thumb can be useful here. First, given a choice among heterogeneous recipients that do not belong to clear categories, prioritize recipients with strategic value over recipients with economic value. We know from Chapter 3 that recipients with economic value are more likely to be valued by donors after the Cold War. We should expect the state agencies within the donor whose institutional mandate is not democracy promotion will react likewise. A savvy policymaker should compensate for that by targeting the recipient with strategic value for democracy promotion instead. Second, given a choice between primary and secondary recipients, the latter group should be the priority. The other state agencies are less likely to be invested in recipients that lack strategic and economic value and hence more likely to collaborate with the aid agency with democracy promotion.

Finally, primary recipients should be avoided where possible. The other state agencies will value the strategic and commercial attributes of the primary recipient and are more likely to side with the authoritarian but valuable recipient. The policymaker should anticipate strong interagency resistance in this situation.

To help the policymaker anticipate the political pushback, it will be helpful to have a list of recipients sorted by leverage. Primary recipients, those with leverage, 
Table 7.1 List of Primary and Secondary Recipients

\begin{tabular}{ll}
\hline Recipients & Countries \\
\hline Primary & Dominican Republic, Jamaica, Trinidad \& Tobago, Mexico, \\
& Guatemala, Panama, Colombia, Venezuela, Ecuador, Brazil, \\
& Argentina, Croatia, Nigeria, South Africa, Iran, Turkey, Iraq, \\
& Egypt, Israel, Saudi Arabia, Yemen, Kuwait, Uzbekistan, China, \\
& South Korea, India, Pakistan, Bangladesh, Thailand, Philippines, \\
& Indonesia \\
Secondary & Georgia, Azerbaijan, Cape Verde, Guinea-Bissau, Equatorial \\
& Guinea, Gambia, Benin, Guinea, Burkina Faso, Liberia, Sierra \\
& Leone, Togo, Cameroon, Gabon, Central African Republic, Chad, \\
& Republic of the Congo, Uganda, Tanzania, Burundi, Rwanda, \\
& Djibouti, Angola, Mozambique, Zimbabwe, Malawi, Lesotho, \\
& Swaziland, Madagascar, Comoros, Jordan, Bahrain, Qatar, Oman, \\
& Turkmenistan, Tajikistan, Kyrgyz Republic, Mongolia, Taiwan, \\
& Bhutan, Nepal, Cambodia, Laos. \\
\hline
\end{tabular}

represent cases with a lower likelihood of success. Secondary recipients, those without leverage, represent cases with a higher likelihood of success. I extract from the current dataset, a list of Primary and Secondary recipients in Table 7.1. ${ }^{2}$

This list is tentative. It should be treated as a representative take on donorrecipient relationships because the unit of analysis is the recipient-year. This means a given country can acquire or lose the secondary recipient status over time, depending on their relationship with donors. To emphasize the contingent nature of this assessment, I generate another table, Table 7.2, that reports the pool of Secondary recipients in a recipient-year format. These are the cases where our policymaker is more likely to get a return on their aid investment.

Collectively, Tables 7.1 and 7.2 render the opportunity costs of democracy promotion clear. The effort, in terms of political capital and monetary value of aid spent on a single primary recipient, could have funded several secondary recipients instead. This is the first of the several trade-offs policymakers make.

\section{The autocrats' response}

Given the goal of democracy promotion, my natural target audience are the policymakers who are invested in democracy promoters or "democrats". Although this is meant to help democrats make better policies, the nature of information is such that it cuts both ways. How might those who seek the survival of authoritarian regimes or autocrats react to this information?

We can draw an analogy from another period when the US also had other priorities other than democracy promotion. During the Cold War, it was more important for the US that its aid recipients commit to an anti-communist coalition than the democratization of their internal regime. Some countries, for instance, Egypt 
154 No golden age, no silver bullet

Table 7.2 List of Secondary Recipient-Years

\begin{tabular}{|c|c|c|}
\hline No & Country & Years \\
\hline 1 & Suriname & $1982,1992-2006$ \\
\hline 2 & Peru & $1973,1975-1979,1992-1993$ \\
\hline 3 & Bolivia & 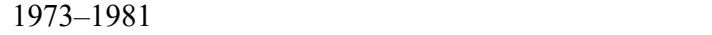 \\
\hline 4 & Paraguay & 1973-1976, 1979, 1981, 1983-1987, 1989-1990 \\
\hline 5 & Chile & 1973-1977, 1979-1985, 1988 \\
\hline 6 & Uruguay & 1973, 1975, 1982-1984 \\
\hline 7 & Albania & 1989, 1991-1994 \\
\hline 8 & Georgia & 1993-2001 \\
\hline 9 & Azerbaijan & 1993-1999 \\
\hline 10 & Cape Verde & $1975-1990$ \\
\hline 11 & Guinea-Bissau & 1974-1993, 1997-1999, 2001-2004 \\
\hline 12 & Equatorial Guinea & 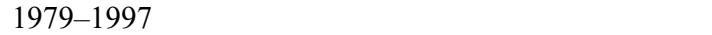 \\
\hline 13 & Gambia & 1994-2006 \\
\hline 14 & Benin & $1973-1990$ \\
\hline 15 & Guinea & 1973-1993, 1995-1997, 1999-2001, 2004 \\
\hline 16 & Burkina Faso & $1973,1979,1983-2006$ \\
\hline 17 & Liberia & $\begin{array}{l}1973,1974,1978-1983,1985,1987-1988,1990-1998, \\
2000-2002,2004\end{array}$ \\
\hline 18 & Sierra Leone & $1973-1993,1995-2006$ \\
\hline 19 & Togo & 1973-1976, 1979-2006 \\
\hline 20 & Cameroon & 1973-1976, 1979-1983, 1985, 1987 \\
\hline 21 & Gabon & 1973-1974, 1976-1977, 1979-2006 \\
\hline 22 & Central African Republic & $1973-2006$ \\
\hline 23 & Chad & $1973-2006$ \\
\hline 24 & Republic of the Congo & 1973-2006 \\
\hline 25 & Uganda & 1973, 1976-1978, 1980-2006 \\
\hline 26 & Tanzania & $1973,1974,1980,1987-2006$ \\
\hline 27 & Burundi & $1973-2004$ \\
\hline 28 & Rwanda & 1973-2006 \\
\hline 29 & Djibouti & $1977-2006$ \\
\hline 30 & Angola & $\begin{array}{l}1975-1976,1980-1981,1983,1987-1988,1991,1993, \\
1995,1999,2001-2006\end{array}$ \\
\hline 31 & Mozambique & 1975-1991, 1993, 1995-1997, 1999, 2001-2005 \\
\hline 32 & Zimbabwe & 1974-1976, 1978-1979, 1981-2006 \\
\hline 33 & Malawi & 1973, 1975-1977, 1979-1993, 2001-2003 \\
\hline 34 & Lesotho & $1973-1992,1998-2000$ \\
\hline 35 & Swaziland & 1973-1976, 1978-2006 \\
\hline 36 & Madagascar & $1973-1991$ \\
\hline 37 & Comoros & 1975-2003 \\
\hline 38 & Jordan & 1973-1975, 1986-1987, 1989-1990, 1992, 1995-2003 \\
\hline 39 & Bahrain & $1974,1986,1994$ \\
\hline 40 & Qatar & 1994 \\
\hline 41 & Oman & 1977, 1981-1992, 1994-1997, 1999-2006 \\
\hline 42 & Turkmenistan & $1993-2006$ \\
\hline 43 & Tajikistan & $1992,1993,1995,1999-2002,2005$ \\
\hline 44 & Kyrgyz Republic & $1993-2005$ \\
\hline 45 & Mongolia & 1988,1991 \\
\hline 46 & Taiwan & 1981-1986 \\
\hline 47 & Bhutan & 1989-2006 \\
\hline 48 & Nepal & $1973-2005$ \\
\hline 49 & Cambodia & $1973,1988-2006$ \\
\hline 50 & Laos & $1973-2006$ \\
\hline
\end{tabular}


with its strategic Suez Canal, naturally that have lots to offer to an anti-communist coalition. Others, with less strategic value, might play up the threat of internal communist subversion to get US aid. There are grounds to think such attempts might work. Forsythe (1992) did a study of US covert actions in the Third World during the Cold War. In some cases, the US intervened when the targets in question turned communist. In others, the US intervened when the targets were not communist, but rather the US feared the "remote possibilities" that they might become communist (Forsythe 1992: 392). This allowed him to suggest that the US motivation for intervention is based, in part, on perceived, rather than the actual threat of communism.

The lesson from the Cold War is that some states might be able to manipulate their value in the eyes of donors. ${ }^{3}$ Applied to aid bargaining, I can think of two contexts where authoritarian recipients might find it easier to manipulate salience while taking the American perspective as the key donor. They are i) when the US has an overriding policy priority and ii) when the US fears losing influence to a rival. I will address both in order.

During the Cold War, anti-communism was a top priority in the same way the War on Terror requires anti-terrorism to be the current priority. If an aid recipient has little to offer to the US but is otherwise a hotbed of radicalism, savvy autocrats might be able to parlay the threat of regime collapse to garner US support. American receptivity to this type of manipulation depends on how much it desires the country from becoming a base for terrorist groups that the US seeks to destroy. From the viewpoint of the US, one policy option is to help the regime in question stay in power, an alternative option is to directly attack terrorist bases in the same country without helping the authoritarian regime (for example, Obama's policy in the Syria war). Since the US has the most capable military in the world, it might not always choose to support authoritarian regimes, especially if they have no other value to offer. While this type of manipulation is worrisome for those who seek democracy promotion, key donors like the US have alternative means to deal with such threats and it need not play out in the way autocrats expect.

In the second context, an authoritarian recipient could threaten to defect from one camp to another. For that threat to be credible, losing out to the opposite side must be an actual concern for donors. The Cold War encouraged a mindset where every gain to the communist side is seen as a loss to the capitalist camp. That mindset made such threats credible (Dunning 2004). In this period of potential rivalry between the US and China, the authoritarian recipient could threaten to defect to the Chinese camp if the US aid was not forthcoming. This attempt by the recipient to play one donor against another is essentially donor switching. The would-be defector must justify its value to the opposite camp too. Secondary recipients with little to offer to the US might also have little to offer to China too! Furthermore, the logic of rational self-interest dictates that the Chinese side would use its leverage to extract more concessions from the would-be defector. This was the situation that Myanmar faced as discussed in Chapter 5. Thus, donor switching has its limits. From the perspective of the would-be defector that seeks to preserve its autonomy, donor switching may not translate into more leverage for the recipient. Rather, the savvy autocrat might threaten to align with one camp 
but not too closely so to avoid exploitation by its preferred side. In that way, the autocrat maximizes his room for maneuver and enjoys the benefits of patronage from both sides.

For the democrats (the policymakers who seek democracy promotion), both international contexts could make democracy promotion harder. If we parse this notion of salience manipulation into the categories of my theory, the picture that emerges is more nuanced. The primary recipient already possesses the commercial and strategic attributes that donors desire. They already have the leverage vis-à-vis donors to deflect pressure to democratize. While they will have an easier time manipulating their salience, they do not need to.

It is the group of secondary recipients who do not have enough to offer that needs to manipulate their salience. However, they are the ones that are least equipped, in terms of attributes that donors want, to do so. In that sense, the exogenous manipulation of salience is a lesser problem than it would appear to be. Therefore, my theory suggests there may be inbuilt checks to how far recipients can manipulate their salience. Secondary recipients have more incentives to manipulate salience but they also have less capabilities to do so.

\section{Research overlaps and future research}

In this section I consider the research overlaps between my theory and thematically related domains. I consider refinements of the aggregate data, the extension of the framework to other types of conditionality, the implications for democracy diffusion and the securitization of democracy promotion.

The quantitative research that underpins this argument relies on data that are publicly available. They are designed to capture general information about donorrecipient relationships. By its nature, it is not suited for capturing circumstances that are idiosyncratic to specific donor-recipient relations. Yet, the notion of salience manipulation suggests the existence of some advantages that are more situational in nature. One future avenue of research, therefore, is to use my framework to determine salience for individual donors (or a small group of donors).

In order to do that, we have to recalibrate, where appropriate, the six components of salience not from the general perspective of all donors but from the perspective of the specific donor. For instance, the significance of a recipient to a given donor as a source of import and as a destination of exports is captured by the variables, Importshare and Exportshare, respectively (discussed in Chapter 2). Since I am looking at the global level of analysis, it makes sense to use a publicly available dataset such as the International Trade dataset (Barbieri and Keshk 2012). A policymaker with access to governmental resources, for example, data from the Trade Ministry, can substitute my general estimates with data specific to their government. It is more likely to be accurate, nuanced, and with fewer missing values than publicly available, especially if the donor in question is a democracy (Rosenberg et al. 2018). Better quality data, in turn, should produce more precise estimates of recipient salience. 
I have in mind three donors for which this exercise might be helpful, the US, the European Union (as a donor group), and China. As an important donor with extensive security and trade ties, the US, compared to other donors with lower international profiles, is subject to greater tensions between its competing policy objectives. The European Union through its European Neighbourhood Policy (ENP) can encourage domestic reforms in aid recipients. Yet the EU also emphasizes its own interests at the expense of its ENP partners (Pinos 2014). Democrats working within the bureaucracy of the US or the EU can use that information to make the necessary interagency bargains and trade-offs. Democrats should also conduct the same exercise using China as the reference donor too. Here, the political considerations work in reverse. Recipients that are important to China are less likely to succumb to Western donor pressure. Democrats should adjust accordingly.

A key disadvantage of this donor-specific approach is that the data required may be sensitive or proprietary. As such, such data is less likely to be available in the public domain. Since it is donor-specific as opposed to a global pool of donors, another disadvantage of this approach is that the number of cases available for statistical analysis is by definition reduced.

While on this issue of donor-specific approaches, the estimation of foreign aid from China presents a methodological challenge. Under OECD's Development Assistance Committee or DAC conventions loans to recipients on a non-concessionary basis are not considered as foreign aid. China does not subscribe to the DAC conventions. In some cases, China includes loans on a nonconcessionary basis as foreign aid. This inflates claims about the overall size of Chinese foreign aid. Compounding this is the fact that the Chinese bureaucracy, like many authoritarian regimes, is opaque about its aid commitments (Rosenberg et al. 2018). As a result, conventional claims about Chinese foreign aid are met with considerable skepticism. This is also why the attempts to quantify Chinese aid have had to resort to creative methodologies and workarounds (Strange et al. 2017). This is one reason why my data does not include Chinese foreign aid. The data on Chinese aid is generally poor and needs considerable data-cleaning to be equal to the DAC standards.

\section{Other types of conditionalities}

The framework in this book posits a scenario of unequal bargaining between two parties. One of them has a valued resource (Side A) that the other side wants (Side B). Side A can impose conditions on Side B as the price for getting the resource. My theory recognizes that such conditions are costly for Side B. It seeks to understand how Side B might respond in such a way as to get the resource without the attendant conditionality. I create a filter to separate those on Side B who can bargain successfully (primary recipients) from those who cannot (secondary recipients). Couched in this way, there are two policy domains that my framework can speak to: IMF conditionality and World Bank environmental conditionality. 
When countries experience financial crises, they may turn to the IMF as the lender of last resort. The IMF typically attaches conditions to its loans to debtor countries. For instance, the structural adjustments frequently include cuts to governmental subsides of key goods such as petrol that are unpopular within the debtor countries. This gives debtor countries an incentive to push back. Stone (2002) found that whether the US has foreign policy interests in the debtor countries is a key determinant of the credibility of IMF conditionality. Where the US has an interest in the debtor country (example, Russia), they are able to resist IMF conditionality. Countries that are more tangential to the US interests are, correspondingly, less able to resist IMF conditionality. Presumably, a similar logic pertains in the politics of environmental aid (Keohane and Levy 1996). Developed countries tend to prioritize environmental protection more than developing countries. The environmental covenants and conditionalities required by the World Bank impose costs on the recipients. Recipients may be able to play upon their ties with developed countries to secure favorable terms.

The issue with aid from multilateral organizations such as the IMF and World Bank is the additional complexity that stems from intra-organization politics. Donors do pool resources to fund larger aid efforts they could not have conducted individually. Challenging recipients (think Iraq or Afghanistan) that are less conducive for a positive developmental outcome and which are beyond the means of individual donors may be selected for funding by a multilateral organization. This may imply a selection effect is active.

\section{Democracy diffusion, leverage and linkages}

Democracy diffusion is the study of how democracy spread over space and time. Its emphasis is more on the organic spread of democratic regimes. A key idea is that democracy tends to spread to nearby states. By contrast, the argument in this book relies on deliberate pressure from donors. My argument is substantively different since it emphasizes the volitional, as opposed to the natural spread of democracy.

One implication of that literature lies in the diffusion potential of secondary recipients. ${ }^{4}$ A strategy of liberalization at the margins should result in more secondary recipients that are democracies. Democracy diffusion implies these secondary recipients may spread democracy to nearby primary recipients over time. There are some grounds to presume such diffusion is possible. Petrova (2014) found that the new democracies in Eastern Europe seek to promote democracies in other countries.

Unfortunately, I fear this optimistic interpretation may not happen. Under my theory, primary recipients, unlike secondary recipients, have more resources from which to draw upon to secure regime survival. If they are strong enough to resist donor pressure, they may be also resilient to pressure from small secondary recipients that happen to be democratic. After all, the secondary recipients are not donors and thus have one less lever to work with. It might even be the 
other way around. The presence of an authoritarian primary recipient serves as a bulwark for secondary recipients to remain authoritarian. Consider or instance, China's neighborhood of Southeast Asia. It is hard to envision China democratizing (peacefully) even if Southeast Asia was a neighborhood of small democracies (such as during the 1990s). It is easier to see how an authoritarian China helps authoritarian states in Southeast Asia stay authoritarian (such as in the modern context). Thus, while democracy diffusion is certainly possible in the long run, I do not see it as a likely route to spread democracy from secondary recipients to primary recipients for the foreseeable future.

A promising research trend in democracy diffusion is to restore the emphasis on volitional elements. One prominent work in this vein is the leverage and linkages argument advanced by Levitsky and Way (2005). According to them, external democracy promotion is more likely to succeed when the target state is vulnerable to external pressure (leverage) and is highly dependent on ties with the external actor (linkages). While this approach is closer to the issue at hand, it does not account for the likely reactions of autocrats. Autocrats facing threats to their regime are likely to gatekeep (Tolstrup 2013) with the goal of actively resisting democracy diffusion (Vanderhill 2017). This is where my theory contributes by zeroing in on the incentive structure of autocrats. My theory seeks to understand how they may leverage what internal resource they possess in order to strike a grand bargain with external donors.

\section{Securitization of external democracy promotion}

The widespread misuse of concepts like national security and national interest is a phenomenon that is the focus of securitization studies (Buzan et al. 1998). It seeks to understand how issues, for instance, immigration, that are otherwise routine, get politicized and elevated into a security issue. It studies how the securitization of such issues is used to justify extraordinary means, responses, and resources in the name of security. "Securitization" is thus the process where some claims are elevated over others and are in turn used to justify specific policy response. The issues areas that Securitization studies focus on typically overlap with the International Security subfield. For example, ordinary acts of dissent can be elevated into acts of "terrorism". The point is that securitization is a flexible tool for the elites to castigate their opponents. I see no reason why foreign aid and development should be exempt from this dynamic.

Authoritarian regimes in aid-receiving countries can deliberately misconstrue foreign aid to civil society groups as "foreign interference" and the nongovernmental groups who receive such aid as "foreign agents". The nature of securitization is that allegations do not even have to be true to do harm to their targets. Consider the global wave of protests that has characterized the year 2019 as reported by the Economist Intelligence Unit (a research unit of the Economist, EIU 2020). Many of the affected authoritarian regimes deliberately mischaracterized the protests as the result of machinations of foreign powers whose goal is to undermine the regime. China infamously insisted, without evidence, the Hong 
Kong protests were instigated by the US (CNN 2019). ${ }^{5}$ By elevating indigenous protests into a threat to national sovereignty, a harsh response by the state is in turn justified.

If democrats pursue a strategy of liberalization at the margins, I submit that one plausible response by autocrats is the deliberate securitization of foreign aid. Both subfields, democracy promotion and securitization studies, should study the rhetorical speech acts and the subsequent policy response of autocrats as a future research avenue. Ironically, as securitization is based on perceptions, I suspect the securitization of foreign aid will operate even if the Western donors refrain from external democracy promotion altogether.

\section{The tradeoffs we make}

\section{Feckless liberal democracies}

This is a book on the politics of democracy promotion. For better or for worse, the effectiveness of democracy promotion is linked to the appeal of liberal democracy. When liberal democracy is vibrant, democracy promotion fares better. When liberal democracy is seen as anemic, democracy promotion is that much harder to achieve. For those who value liberal democracy, cherish its institutions, and respect basic human rights, these are turbulent times.

The trends from 2016 onwards have been bad for liberal democracy. 2016 gave us the Brexit (June 2016) and the election of Trump (November 2016). It took away the certainty that key features of the pre-2016 international liberal order, namely US leadership and Europe as a community of democracies in a union, will endure. The next four years doubled down on the uncertainties. Under Trump, the US pulled out of multiple international treaties and commitments (including the Iranian nuclear agreement). It questioned the value of longstanding alliances and trade commitments. At times, the US under Trump seems to align more with authoritarian regimes than with its liberal allies both within NATO allies and without.

Meanwhile, key states in the European Union failed to provide decisive leadership. The Brexit crisis polarized and upturned British politics. The limited economic reforms of the government of President Macron face resistance from the Yellow Vests popular movement. In Germany, Chancellor Merkel's decision to admit Syrian refugees proved controversial. It contributed to the loss of electoral ground for the centrist parties (CSU and CDU) to the far right. Seen as the last defender of the liberal order (NYT 2016), it is worrisome she has no clear successor. The sense of being adrift was prominent in the last Munich security conference, where the theme was "Westlessness", denoting uncertainty and unease about the purpose of the West (Politico 2020).

In the rest of the world, democratic backsliding has become a recognized phenomenon. The Economist Intelligence Unit, an outfit that is sensitive to recent trends in democracy, catalogued a fall in the average global score for its democracy index every year from 2016 to 2019 (EIU 2020). In fact, it reports the lowest 
global average Democracy Index score for the year 2019 since the index was first used in 2006.

Thematically, what we are witnessing internationally is i) the absence of US leadership and ii) a triumphalist attitude in authoritarian regimes including Russia, China, Iran, Turkey, Egypt, Venezuela, Philippines, Cambodia, and many others (Aeon 2017); within the domestic politics of liberal democracies, we also saw iii) the erosion of public trust in the pillars of liberal democracy such as the media and the electoral process and iv) the rise of anti-establishment movements and populist parties in mature democracies (EIU 2020). Since this book is not about democracy per se, the trends of declining trust and rise of populism are issues that lie outside the scope of my inquiry. Instead, I will focus on the international implications of moribund democracies and aggressive authoritarianism for democracy promotion.

\section{Resurgent authoritarianism}

Feckless liberal democracies and resurgent authoritarianism are a toxic combination for democracy promotion. But they are not equally damaging or equally significant. Resurgent authoritarianism itself is not new. After all, scholars have noted a democratic recession as early as 2006 (Diamond 2015). Furthermore, with the possible exception of China and Singapore (Fukuyama 2012), authoritarianism is generally not seen as a viable, sustainable alternative to liberal democracy (Fukuyama 1992). Authoritarian regimes that are based on oil rents (Russia, Iran, Venezuela), on foreign rents (Egypt, Cambodia), and on Political Islam (Turkey) require pretty specific configurations of geopolitics and geography that do not transfer well to other parts of the world. In principle, liberal democracy does not face such constraints (Fukuyama 1992).

Authoritarian countries who earned an international reputation for high economic performance are rare (Fukuyama 2015: 14). Singapore and China are the exemplars for authoritarian success (Fukuyama 2012: 17). The challenge of Singapore is easier to discount by virtue of its size and unique geography. Larry Diamond, a prominent scholar of democracy, observed that:

I don't see any stable authoritarian states out there. . . . The only wellfunctioning authoritarian regime in the world is Singapore and I'm not sure even that is going to last. . . . In any case, you can't build a theory on a city state of just a few million people.

(BBC 2017a)

The challenge posed by China is more serious. According to Bell (2015), the Chinese model of governance is a type of political meritocracy. By meritocracy, Bell has in mind the selection of leaders by a combination of examinations and performance evaluations at lower levels of government. This stands in sharp contrast to the democratic model where the leadership is legitimated by an electoral mandate. For instance, the Chinese Communist Party after Mao managed 
to institute leadership transitions that are regular, institutionalized, orderly, and crucially independent of democracy. In fact, Bell sees the Chinese model as the alternative to liberal democracy.

Bell's argument did not age well. The empirical cracks in the Chinese model started to show. First and foremost, the claim of political meritocracy was shattered by the way President Xi Jinping has consolidated power onto himself in 2018. In what is essentially a power grab, he rewrote the Chinese constitution to remove presidential term limits, enabling him to rule for life (NYT 2018).

Without the checks and balances found in liberal democracies, the norms and institutions of the Chinese Communist Party proved unable to contain the slide from a concentration of executive power into one-man rule. So much for the ideal of political meritocracy.

Second, internal dissatisfaction with the Chinese model is growing. The ongoing protests in Hong Kong started as an anti-extradition bill protest but evolved into a call for democracy (BBC 2019b). The recent local election in Hong Kong that followed is widely seen as a de facto referendum on the protests. In that election, pro-democracy candidates won by a landslide (BBC 2019a). The fate of Hong Kong was not lost upon Taiwan. In its own election, pro-China candidates lost to President Tsai by a landslide. The Chinese vision of unification under the one country, two systems framework was rejected by the people it was meant to apply to. As one commenter observed:

Beijing's rigid, authoritarian vision of a Greater China, united on its terms, has been wholeheartedly rejected in the one place actually given the opportunity to vote on the concept.

(BBC 2020)

The Chinese state response over the coronavirus included authoritarian repression of whistleblowers. The death of Li Wenliang, a doctor who tried to warn the public and was punished by the state for it, triggered a rare show of public anger by Chinese populace (NYT 2020a). The public started to demand freedom of information before the state censors could react. Collectively, these outbreaks of dissent from within (Hong Kong protest and outrage over the coronavirus response) and from without (Taiwan election) expose the lie that Asians do not want democracy.

Internal dissent notwithstanding, it is authoritarian mimicry that is important for the purpose of democracy promotion. The Chinese model appeals to many regimes as it seems to combine the best of both worlds, economic prosperity with authoritarianism. None of the would-be aspirants have the economic success and the seeming stability that China demonstrated for the last 40 odd years (since Deng Xiaoping open up the Chinese economy). Try as they might, they are simply not China. Therefore, without underestimating the considerable appeal of authoritarianism, I tend towards Fukuyama's view, once articulated in his famous End of History, that authoritarianism, unlike liberal democracy, is not capable of universalization. 


\section{No golden age}

The new confidence, the new assertiveness of authoritarianism is not because such regimes are better at meeting the demands of modernity; rather it is because standard-bearers of Western liberal democracies have not been up to their job. As Joan Hoey, from the Economist Intelligence Unit (EIU) said:

A lot of focus gets put on places like Russia, the Middle East or China.... But the problem is here, in the heart of the most mature democracies in the West".

(BBC 2017a)

Our focus is not on the state of democracy per se, but on the political turmoil in liberal democracies and their implications for democracy promotion. I focus more on the Trump administration as it reflects the leadership role ascribed to the US as the linchpin of the liberal world order. Trump started the presidency with no prior expertise in international relations. In the first year of his administration, there was confusion over the nature of his foreign policy. There is a view that Trump has no foreign policy philosophy beyond the rejection of Obama's policies (Business Insider 2017). Thus, the US withdrew from the Paris climate deal, the Trans-Pacific Free Trade agreement, and the Iran nuclear deal simply because the Obama administration supported them. An alternative view is that Trump is not being opportunistic and there is a positive content to his worldview (Wright 2016; Shirkey 2017). Wright (2016) argues Trump harkens to an older Jacksonian tradition while Shirkey (2017) argues it is more Randian. By the fourth year of the Trump administration, defining features of its foreign policy can be identified.

Trump's foreign policy does not follow traditional Republican principles which include the promotion of free-market capitalism, democracy, and the liberal world order. Trump's "America First" foreign policy is an eclectic mix of realism, protectionism, and personal expediency. Under this approach, any deal is judged acceptable so long as the US or Trump personally benefits more than the other negotiating party. This imperative does not consider the secondary consequences for the international order or the impact on the US credibility as an ally. As a populist, he wants clearly designated enemies and friends from which he can portray his image of strength and in deal-making.

Trump seems to be motivated by personal expediency too. The line between his personal interests and the US interests is repeatedly crossed. This was prominently illustrated in two situations, the refusal to recognize Russian interference on his behalf into US elections and the withholding of aid to pressure Ukraine into investigating Trump's domestic political opponents. The latter infamously led to an impeachment trial.

Trump's approach is indifferent to the identity of his negotiating partner. Liberal democracies are treated no different from authoritarian regimes. Long standing NATO allies (such as Germany, France) and trade partners (Canada, Mexico) 
have to pay their share or they risk US tariffs. Trump demonstrated a personal affinity for populist leaders (including Brazil's Bolsonaro, India's Modi, and Hungary’s Orbán) and found common course with authoritarian leaders (notably Russia's Putin, and North Korea's Kim). Authoritarian regimes, such as Saudi Arabia and Turkey, that provide tangible benefits to the US (or to him personally) were given a free pass in human rights abuse and democratic backsliding.

Underlying Trump's approach is a distrust of career civil servants and the expertise they represent. Convinced of a deep state working against his wishes, he prefers his own interlocutors who bypass official channels. Prominent examples of these include Kushner in Saudi Arabia and Giuliani in Ukraine. Using interlocutors undermined the official channels. It does not help that Trump tends to issue decisions on the fly on social media (Twitter) and frequently contradicts his own official appointees. This is compounded by the constant turnover in his Cabinet (and staff appointments), the highest of any presidency thus far (NYT 2019). All these contributed to a turbulent relationship with key foreign policy institutions, including the State Department, the National Security Council, the Pentagon as well as Congress.

One verdict is that the Trumpian approach has damaged US international standing (BBC 2017b). William Burns, a former Foreign Service Officer, and the President of the Carnegie Endowment for International Peace, made the following memorable observation:

For dictators, Trump is the gift that keeps on giving, a non-stop advertisement for Western self-dealing.

(Foreign Affairs 2019)

What does this imply for external democracy promotion? While the budget for foreign aid is likely to be reduced, I argue the overall impact may be smaller than it would appear. The key is to recognize Trump's foreign policy as transactional. Under Trump, every relationship of the US, regardless of a history of amity (with democracies) or of enmity (with autocracies), has to offer value to the US in monetizable terms. This means that primary recipients, who tend to have a lot to offer to the US, would remain unsuitable targets for democracy promotion. Secondary recipients, who have little to offer to the US, are likely to fall beneath the attention of the White House. This is a good thing as it gives opportunities for aid agencies such as USAID to work behind the scenes and quietly push for liberalization. ${ }^{6}$ As such, secondary recipients remain the more suitable prospects for democracy promotion.

A transactional US does not fundamentally alter a strategy of liberalization at the margins. This hold true even if Trump wins a second presidential term. This is because I assume the US, despite its rhetoric, is not that invested in democracy promotion if doing so entails the sacrifice of other strategic or commercial interests. Had I, as a counterfactual, argued that there was a time when the US valued democracy promotion above all, then the current Trump administration 
would present a severe challenge since they prioritize interests that are immediately monetizable.

Although I focus on the US, the trends I observe are not unique to Trump nor the US. They are generic and experienced by many contemporary liberal democracies (for example, see EIU 2020). Put another way, Trump is not the cause but a symptom of our times.

Since I did not premise my argument upon a golden age of democracy promotion, the fact that contemporary liberal democracies do not value democracy promotion, while clearly negative, is not as traumatic as it would seem. The negative trends against democracy promotion may have been extenuated in this difficult time but the tradeoffs we make remain the same.

\section{No silver bullet}

What are the tradeoffs we make? To answer that it helps to have a common referent. Previously I focused on the modal policymaker, a mid-level bureaucrat. Here I switch track and assume a policymaker with executive level powers. The difference is that the executive has the authority to allocate funds across regions. I use this as the referent because the political nature of the tradeoffs requires a considerable level of authority.

The first tradeoff is the opportunity cost of the resources used to nudge authoritarian recipients.

The resources used for primary recipients are not only likely to fail, they could have been used to fund efforts to persuade several secondary recipients to reform. Our policymaker must decide if the payoff from converting several secondary recipients is worth the costs of a potential primary recipient.

The second tradeoff is over the proper regional emphasis. The results from the regional analysis (in Chapter 4 ) suggest that Africa has more secondary recipients and less primary recipients than Asia. If democracy promotion were the only imperative, one obvious policy implication is to allocate more democracy aid to Africa than to Asia. However, we also know that economic attributes are significant determinants of recipient salience (in Chapter 3) and the current batch of democratic leadership is more transactional. Since Asia is economically dynamic and is also the home region of China, the payoffs of democracy promotion in Africa should be considered against the value of a democratic foothold in Asia. The latter is more difficult to achieve but may be important for the viability of democracy in the long run.

The tradeoffs become even more complicated when we include geopolitics. Secondary recipients that are authoritarian but are also friendly to the West have some, albeit small, utility for donors. After democratization, they are more likely to be aligned against the West (Ratner 2009). Our policymaker must decide if the promotion of democracy in such recipients is worth the loss of potential friendship.

There is no silver bullet. The leadership of liberal democracies must decide if the tradeoffs that come with democracy promotion are worth it. 
In bringing up geopolitics, I do not consider upsetting autocracies to be a tradeoff of democracy promotion. To understand the context for this stance, I will address a normative concern with external democracy promotion. If democrats adopt the strategy of liberalization at the margins, how will that affect relations between democracies and autocracies? Will the adoption of this strategy aggravate tensions between democracies and autocracies even more? It may help to think of democrats as navigating three sets of decisions. They could choose to abandon democracy promotion altogether. Conditional on them opting for democracy promotion, they could choose an assertive policy that actively confronts authoritarianism or a milder version that avoids direct confrontation with authoritarianism. Conditional on them opting for the milder option, they could choose an aid allocation strategy that emphasizes secondary recipients or not (presumably, that means emphasizing primary recipients).

I make four interrelated claims in response to this normative issue. First, democracy promotion is by its nature provocative. Second, opting out of democracy promotion merely defers the costs to the future. Third, restraint by democrats is unlikely to be reciprocated with similar moves by autocracies. Fourth, focusing on secondary recipients is less provocative than an alternative strategy that targets the primary recipients.

To understand my first and second claims, I found the analysis of Nodia (2014) helpful. Nodia sought to explain both the impact of EU democracy promotion into ex-communist countries of Eastern Europe and the visceral reaction by Russia towards it. It is his later explanation of the Russian reaction that is relevant here. Nodia (2014: 147-148) argues that the EU, comprised of liberal democracies who have transcended power politics into a Kantian zone of peace, understood democracy promotion as technical, nonideological, and non-confrontational. If NATO's offer of membership into a military alliance to aspirant states such as the Baltic states is too aggressive, the West can offer EU membership instead. If EU membership is too provocative, the EU can offer associate status through its Eastern Partnership (EaP) instead (Nodia 2014: 145-146). The notion is to bury democracy promotion in technicalities such as visa regimes or trade liberalization that are meant to be non-threatening to authoritarian regimes. Democracy promotion as it is conceived in the West, in Nodia's expression, is not geopolitics (Nodia 2014: 147).

The problem with this notion is that Russia (and by extension, all authoritarian regimes) does not accept it. The claims that the West is altruistically providing international cooperation/developmental for its own sake comes across as hypocritical to autocrats (Nodia 2014: 142). Even if the democracy promotion effort is not directed at their specific regime, it will change the distribution of power at the international level against them, whatever the intention of the democrats. Thus, autocrats see democracy promotion as geopolitical competition for influence using other means. Nodia (2014: 148) emphasized that "[a]dvancing the democratic cause is an enterprise that is hostile and threatening to autocrats, and they will fight back". In other words, autocrats see democracy promotion for it is, a threat, and react accordingly. 
One could dismiss the authoritarian reaction as just misperception that can be dissipated by goodwill from democracies. After all, democracies managed to forge a Kantian peace (Kant 1983) among themselves. The problem with this view is that we still live in a world where democracies have to interact with autocracies. Nodia warns that "promoting democracy is never politically safe" (2014: 142). We must recognize the incentive of autocracies to push back once we choose democracy promotion.

What about the option to abandon democracy promotion altogether? Nodia (2014: 141) is empathic that opting out resolves little:

There is no way to escape the dilemma of national interests versus democratic moral imperatives. The West will be damned whatever it does. If Western countries follow their national interests, they will be criticized for propping up tyrants. Once people living under an autocracy hit the streets to protest their repressive and corrupt rulers, domestic and international public opinion will force democratic governments to drop their pragmatic alliances with the autocracy in question, as happened several times during the Arab Spring. If Western governments arrange their foreign policies around support for democracy and opposition to tyrants just for being tyrants, there will be cries that these governments are naive and driven by ideology. More than likely, they will also be accused of applying double standards, since no democracy can take on all tyrants at the same time.

If the West abandons democracy promotion and favors their authoritarian allies, they are merely deferring the cost until the time when those allies eventually collapse due to social revolutions (such as the Arab Spring). This leaves the West in the situation of facing new regimes that are justifiably hostile to them (Ratner 2009). Opting for democracy promotion provokes an authoritarian backlash. Opting out of democracy promotion provokes a democratic backlash. The West is damned if they do, damned if they don't. ${ }^{7}$

Even if democracies opt out of democracy promotion altogether, the tensions with authoritarian regimes will remain. Authoritarian regimes need to deflect responsibility for their own failures in governance onto others. Since they do not have a model that is capable of universalization (Fukuyama 2012, 2015; Nodia 2014), it is in their interests to highlight the flaws in democracies. In so doing, they hope to appear to be better off by comparison. Given this need, the truth is optional. For instance, China, through its Chinese Ministry spokesperson, Zhao Lijian, is now alleging that the US brought COVID-19 to China (NYT 2020b)! The securitization literature (discussed in a previous section) suggests that authoritarian regimes can simply invent conspiracy theories and blame democracies for any domestic unrest that occurs regardless of the facts. Consider the ways in which Iran blamed the US and Israel for its domestic protests (BBC 2018) and how China blamed the US for the protests in Hong Kong (CNN 2019).

At this point I am not sure if the authoritarian pushback will stop even if democracies refrain from more assertive forms of democracy promotion altogether. 
I offer three examples to support this claim. First, there is the visceral reaction of Russia to democracy promotion by the EU. Nodia notes that the West had assumed that NATO's membership was too geopolitical but EU soft expansion using association status was not. After refraining from further expansion of NATO, the West was caught by surprise when a technical association agreement with Ukraine provoked the "most open showdown between Russia and Europe since the Cold War" (Nodia 2014: 148). Here, a tactical retreat by the West was met with an authoritarian escalation.

Second, Russian election interference into democracies in the West, especially the US. The US under Trump did not engage, as far as I am aware, in democracy promotion in Russia. Yet that did not stop Russia from interfering in US elections in 2016 and again in 2020. This is despite a US foreign policy, given Trump's predilections, that is more disorganized and less hostile towards Russia. Here, non-interference by the West was met with pointed interference into the foundations of American democracy.

Third, a rising China seeks an international order that is "regime-type neutral" or one that is less favorable to democracies (Nathan 2015: 157). Yet this defensive objective requires the systemic subversion of international institutions that were originally designed to promote democratic governance in such a way as to serve authoritarian ends. Consider for instance, the way the UN Human Rights Council that was originally meant to protect human rights, is captured by authoritarian regimes and used to protect the state abusers of human rights (Ginsburg 2019: 35). Such a reconstituted international order would practice what Ginsburg (2019) terms "authoritarian international law", a distinctive set of international legal behavior that is designed to protect and entrench authoritarian rule. Here, the Chinese reaction to a liberal international order is to seek long-term damage to the standing of democracy worldwide.

The underlying theme of all three examples is an authoritarian resurgence amidst a backdrop of moribund democracies. It seems unlikely that autocracies would refrain themselves just because democracies in their moment of weakness decided to do so.

In the era of feckless democracies, there is little appetite for showdowns with authoritarian regimes. This rules out aggressive democracy promotion. We are left with the next best option, which is democracy promotion that avoids direct conflict with authoritarianism. Even with this milder form of democracy promotion, there remains the issue of tactics. Democrats can focus on the group of countries whose liberalization will upset the international order or on the group that will not. In the terms of my theory, primary recipients tend to fit the former group and secondary recipients tend to fit the latter. Secondary recipients, being less important, are also less likely to provoke an authoritarian backlash. Thus, liberalization at the margins is also the safer choice given risk-adverse democracies.

An aid allocation strategy that emphasizes secondary recipients may disappoint some in the democracy promotion community in two specific ways. First, the political reforms that can be bought with democracy aid in the secondary recipients are likely to be shallow. To put it in another way, we are dealing with political 
liberalization, and not democratic consolidation, here. Second, the strategy recognizes that not all recipients are suitable candidates for democracy promotion from without. These are serious limitations. Yet, I argue we should recognize the political limits we have to work with. Western liberal democracies simply do not consider democracy-for-others to be a high priority. The elected representatives of those liberal democracies are just responding to the wishes of their electorate. Until and unless the electorates in those liberal democracies change their preferences, there will be an upper limit to what is politically feasible. In that sense, we the people get what we are willing to pay for.

I started this book with a realistic look at the state of democracy promotion. I take the priorities of the Western donors as they are and not as I would like them to be. I take authoritarianism seriously and observe how authoritarian recipients respond under donor pressure. I argue policymakers should aim to nudge secondary recipients and not those with the capacity to make attractive counteroffers. We have a choice. We can hope for the nadir of liberal democracy to pass. We can bunker down and wait for the tide of resurgent authoritarianism to recede. We can wait for better opportunities for democracy promotion that, frankly, may never arrive. Or we can seek liberalization at the margins. We will be judged by the choices we make. If liberal democracies refuse to defend liberal values and seek the liberty of others, we should not be surprised at the long-term consequences of that choice.

Liberal democracies get no special pass from history simply because they are not authoritarian regimes. Authoritarian regimes have demonstrated resourcefulness in seeking political survival. They have proven that they will not "go gentle into that good night". Liberal democracies, if they are to survive, must do no less.

\section{Notes}

1 Later, I relax this assumption and consider the perspective of a policymaker with executive level authority.

2 The list of Secondary recipient excludes four countries, Slovenia, Armenia, Botswana, and Mauritius, who have little value to donors but are in democratic status (they have a Polity score above 6) and hence rarely under donor pressure to liberalize.

3 I thank an anonymous reviewer suggesting the notion of salience manipulation.

4 I thank another anonymous reviewer for highlighting the implications of democratic diffusion for my theory.

5 The Chinese allegations in 2019 are before the US passed a bill on Hong Kong in 2020.

6 I am not suggesting that branches of the government act against the wishes of the executive. My point is that where the recipient has little else to offer, pushing for liberalization is a rational objective the US can opt for.

7 If this is so, why not do the right thing, especially when the price, due to the nature of Secondary recipients, is small?

\section{Bibliography}

Aeon. 2017. "The New Authoritarians." Aeon Magazine. https://aeon.co/essays/the-newdictators-speak-for-the-complainer-not-the-idealist.

Allison, Graham. 1969. "Conceptual models and the Cuban Missile Crisis." American Political Science Review 63: 689-718. 
Barbieri, Katherine, and Omar Keshk. 2012. "Correlates of War Project Trade Data Set Codebook, Version 3.0." Correlates of War Project Trade Data Set Codebook, Version 3.0. http://correlatesofwar.org.

BBC. 2017a. "The Uncertain Future of Democracy." British Broadcasting Corporation. www.bbc.com/future/story/20170330-the-uncertain-future-of-democracy.

BBC. 2017b. "Trump Causes 'Major' Shift in Global View of US: Pew." British Broadcasting Corporation. www.bbc.com/news/world-us-canada-40409888.

BBC. 2018. "Iran protests: US accused of 'grotesque' interference." British Broadcasting Corporation. www.bbc.com/news/world-middle-east-42563528. Accessed 4 January 2018.

BBC. 2019a. "Hong Kong elections: Pro-democracy groups make big gains." British Broadcasting Corporation. www.bbc.com/news/world-asia-china-50531408.

BBC. 2019b. "Why are there protests in Hong Kong? All the context you need." British Broadcasting Corporation. www.bbc.com/news/world-asia-china-48607723.

BBC. 2020. "Taiwan election: Tsai Ing-wen wins second presidential term." British Broadcasting Corporation. www.bbc.com/news/world-asia-51077553.

Bell, Daniel A. 2015. The China Model: Political Meritocracy and the Limits of Democracy. Princeton: Princeton University Press.

Business Insider. 2017. "European diplomats reportedly consider Trump a 'laughing stock' who is 'obsessed with Obama'." Business Insider. http://uk.businessinsider.com/ european-diplomats-trump-laughing-stock-obsessed-with-obama-2017-8?r=US\&IR=T.

Buzan, Barry, Ole Weaver, and Jaap de Wilde. 1998. Security: A New Framework for Analysis. Bouder: Lynne Rienner Publishers.

CNN. 2019. "China Is Blaming the US for the Hong Kong protests. Can That Really Be True?" Cable News Network. https://edition.cnn.com/2019/07/31/asia/us-china-hongkong-interference-intl-hnk/index.html.

Diamond, Larry. 2015. "Facing Up to Democratic Recession." Journal of Democracy 26: 141-155.

Dunning, Thad. 2004. "Conditioning the Effects of Aid: Cold War Politics, Donor Credibility, and Democracy in Africa." International Organization 58(2): 409-423.

Economist Intelligence Unit. 2020. "Democracy Index 2019: A Year of Democratic Setbacks and Popular Protest."

Foreign_Affairs. 2019. "The Demolition of U.S. Diplomacy." Foreign Affairs. www. foreignaffairs.com/articles/2019-10-14/demolition-us-diplomacy.

Forsythe, David P. 1992. "Democracy, War and Covert Action." Journal of Peace Research 29(4): 385-395.

Fukuyama, Francis. 1992. The End of History and the Last Man. New York: The Free Press.

Fukuyama, Francis. 2012. "The Patterns of History." Journal of Democracy 23: 14-26.

Fukuyama, Francis. 2015. "Why Is Democracy Performing So Poorly?" Journal of Democracy 26: 11-20.

Ginsburg, Tom. 2019. “Authoritarian International Law.” Working Paper.

Kant, Immanuel. 1983. Perpetual Peace, and Other Essays on Politics, History, and Morals. Edited by T. Humphrey. Indianapolis: Hackett Pubication Co.

Keohane, Robert O., and Marc A. Levy. 1996. Institutions for Environmental Aid: Pitfalls and Promise. Cambridge, MA: MIT Press.

Levitsky, Steven, and Lucian Way. 2005. "International Linkage and Democratization." Journal of Democracy 16(3): 20-34.

Nathan, Andrew. 2015. "China's Challenge." Journal of Democracy 26(1): 156-170. 
New Yorker. 2017a. "Hillary Clinton Looks Back in Anger.” New Yorker. www.newyorker. com/magazine/2017/09/25/hillary-clinton-looks-back-in-anger.

New Yorker. 2017b. "Rex Tillerson at the Breaking Point." New_Yorker. www.newyorker. com/magazine/2017/10/16/rex-tillerson-at-the-breaking-point.

Nodia, Ghia. 2014. "The Revenge of Geopolitics." Journal of Democracy 25(4): 139-150.

NYT. 2016. "Donald Trump's Election Leaves Angela Merkel as the Liberal West's Last Defender." New York Times. http://nyti.ms/2ertczZ.

NYT. 2018. "How Xi Jingping Made His Power Grab: With Stealth, Speed and Guile." New York Times. www.nytimes.com/2018/03/07/world/asia/china-xi-jinping-partyterm-limit.html.

NYT. 2019. "The Turnover at the Trump Administration.” New York Times. www.nytimes. com/interactive/2018/03/16/us/politics/all-the-major-firings-and-resignations-in-trumpadministration.html.

NYT. 2020a. "Widespread Outcry of China Over Death of Coronavirus Doctor." New York Times. www.nytimes.com/2020/02/07/business/china-coronavirus-doctor-death.html.

NYT. 2020b. "China Spins Tale That the U.S. Army Started the Coronovirus Epidemic." New York Times. www.nytimes.com/2020/03/13/world/asia/coronavirus-chinaconspiracy-theory.html?action=click\&module=Top Stories\&pgtype=Homepage .

Petrova, Tsetva, 2014. From Solidarity to Geopolitics: Support for Democracy among Postcommunist States. Cambridge: Cambridge University Press.

Pinos, Jaume Castan. 2014. "The Conflicting Aims of the European Neighborhood Policy and Its Secondary Effects." Journal of Borderlands Studies 29: 133-146. 10.1080/08865655.2014.915703.

Politico. 2020. "Trump Camp Find No Appeasement at Munich.” Politico. www.politico. com/news/2020/02/16/trump-munich-security-conference-115645.

Ratner, Ely. 2009. "Reaping What You Sow: Democratic Transitions and Foreign Policy Realignment." Journal of Conflict Resolution 53(3): 390-418.

Rosenberg, Peter, James R. Hollyer, and James R. Vreeland. 2018. Information, Democracy and Autocracy: Economic Transparency and Poltical (In)Stability. Cambridge: Cambridge University Press.

Shirkey, Zachary. 2017. “Trump's Randian Foreign Policy.” Duck of Minerva. http://duck ofminerva.com/2017/02/trumps-randian-foreign-policy.html.

Strange, Austin M., Axel Dreher, Andreas Fuchs, Bradley Parks, and Michael J. Tierney. 2017. "Tracking Underreported Financial Flows: China's Development Finance and the Aid-Conflict Nexus Revisited.” Journal of Conflict Resolution 61(5): 935-963.

Stone, Randwall W. 2002. Lending Credibility. Princeton, NJ: Princeton University Press.

Tolstrup, Jakob. 2013. "When Can External Actors Influence Democratization? Leverage, Linkages and Gatekeeper Elites." Democratization 20(4): 716-742.

Vanderhill, Rachel. 2017. "Active Resistance to Democratic Diffusion." Communist and Post-Communist Studies 50(1): 41-51.

Wright, Thomas. 2016. “Trump's 19th Century Foreign Policy.” Politico. www.politico. com/magazine/story/2016/01/donald-trump-foreign-policy-213546. 


\section{Index}

aid allocation see liberalization at the margins; tradeoffs

affinity $30-32,52-53,58,61-63,164$

Affinity of Nations see affinity

aid conditionality $15,19,43,54,71-74$,

$78,94,110,126,135-136,142,149$,

156-158; environmental conditionality

157-158; loan conditionality $157-158$;

political conditionality $1,7-9,15$,

$19,43,54,71-74,78,94,110,126$, $135-136,142$

aid fungibility $12-14$

aid modality $2,10-11,28,132,136,150$;

donor-to-civil society $2,10-11,28,136$,

150, 152, 159; donor-to-government 11 ,

$110-111,113,150$

authoritarianism see autocracy

autocracy 2-3, 5-6, 11-13, 16-19, 26, $29,35,50,52,54,77,79,94,103,105$,

$115,132-133,141,145,149-153$,

$155,157,159,161-162,166-169$;

authoritarian learning $11,79,162$;

economic performance $3,75,78-79$,

97, 161; leadership tenure 12-14,

73-74, 78, 104, 115, 123, 161-162;

manipulate salience $153,155-156$ (see

also salience); reaction to democracy

promotion 11, 17-18, 26, 110-111,

$114,134,149,153-156,159,166-168$;

resurgent authoritarianism $11,161-162$, 168,169

Australia 123, 126, 127, 128, 137-145,

151; Alexander Downer 140; Bob Carr

140; John Howard 127, 138; ODA to

South Pacific 140; pressure on Fiji 128, 137-143

bargaining: bribery analogy 5-6; see also leverage
Brazil 153, 164

Burma see Myanmar

Canada 78, 163

China 2-4, 9, 21, 70, 77-82, 87-88, 93-95, 97-100, 103-111, 114, 117, $123-124,127-129,141-145,151,153$, $155,157,159,161-163,165-168$; aid to Cambodia 77, 79, 161; aid to Burma 104, 107, 111; aid to Fiji 141-145; aid to Nepal 79; aid to North Korea 79; aid to Pakistan 79; aid to Papua New Guinea 143, 145; aid to South Pacific 128, 142; as Bulwark/patron 2, 21, 76, 80, 101, 103-104, 108, 117, 123, 124, 151, 159; Chinese model 75, 76, 77-79, 88-89, 142, 161-162; Chinese Communist Party 97 161-162; Confucius Institutes 78; Kazakhstan 79; Kyrgyzstan 79; Hong Kong 75, 79, 162, 167; Macau 79; Malacca Dilemma 97; People's Liberation Army (PLA) 128-129; Political Meritocracy 89, 161-162; Public diplomacy 78, 111; "Regime type neutral" 78, 168; Shanghai Cooperation Organization 79; String of Pearls 98; Tajikistan 79; Tiananmen Massacre 103; Two Oceans 98; Uzbekistan 79; Xi Jinping 143, 162; Yunnan 97-99; Wen Jiabao 142

Cold War 1-2, 9, 11-12, 15, 20, 26, $30-31,37,43-46,50-51,54-55,57$, $60,65-66,72-74,76,83-84,86,99$, $104,125-126,138,150-153,155,168$; anticommunism $9,15,55,76,99,153$, 155; control variable $37,38,40-45$, $51,57,59,60-62,65-66,83-87$; credibility of threat to defect $9,15,54$, 72,155 ; as leverage (see leverage); 
post-Cold War 9, 37, 46, 65-66, 126; US covert actions 126, 129, 137, 151, 155 commercial value $29,33-35,52,54-56$, 82,125 ; economically valuable recipients 54-61, 63-66; exports $33-35,52-53,57,59,61-63,99,102$, 126, 141, 156; GDP 33-35, 37, 38, $40-42,45,51-53,57,59-63,70,83$, $85-87,126$; imports $33-35,49,52-53$, $57,59,61-63,97,109,130,141,156$ critical tests $58-61,64-65$

democracy: backsliding $1,8,11,74$, $110,117,160,164$; challenge to democracy $2-3,20,78-80,89$, 161-162; democracy diffusion 2,7 , 158-159; democratic recession 1, 79, 161; feckless liberal democracy 149 , 160-161, 168; liberal democracy 2, 4, $20,79,80,149-150,160,161-163$, 165-166, 169; polity IV 18, 27-29, 38, 43-44, 51, 61-65, 68-69, 81, 84-88; populism $2,80,145,161,163-164$; regional trends $68-69$

democracy promotion $1-5,7-12$, 14-18, 20-21, 26, 28, 35-36, 39, 41, $43,49-50,54,63,65,67-68,72-74$, 76-77, 80, 84, 88-89, 93-94, 97, 99, $112-113,122-124,131-133,135$, 145, 149-153, 155-156, 159-169; commitment to $2,5,16,17,63,77$, $131,134,151-152,155=156,169$; direct or indirect means of 7-8; external vs internal drivers $7-8,131$; golden age 149, 163-165; inducing or following democratization (see methods, statistical, reverse causality); mild or aggressive 166-168; potential to provoke (see reaction to democracy promotion); the state of $1-3,149-150$; taming of $2,11,112$, 115,132

democratization see liberalization donor pressure 1, 6, 7, 14, 18-20, 26, $29,34-45,49-50,52-54,56-57$, $58,61-62,65-67,72,74,80,82-89$, 93-94, 97, 118, 123-124, 131, 141, 145, 157-158, 169; nature of democracy aid 19; operationalization $34-36,52,82$

donors $1-21,26-45,49-58,61-68$, $70-78,80-89,93-97,99,108-110$, $113-115,117-118,122-124,131,135$, $137,140-145,149-153,155-160$,
165, 169; Development Assistance Committee (DAC) 9, 68, 74, 78, 81, 142-143, 157; donors' calculus (see liberalization at the margins); Millennium Challenge Corporation 8, 19; non-traditional donors 9, 17, 93-95, 108, 124, 142, 144; Paris Club 130; The West 2-3, 7, 9, 18, 55, 70, 79-80, $89,94-95,109,113-115,124,135$, $142,145,151,160,163-169$; Western donors $2-5,7,9-10,14-15,17,55,70$, 72-73, 76-78, 93, 96, 109, 123-124, $140-143,145,150,151,160,169$

donor switching, Logic of 94-95; limits of 151,155 ; threat to $155-156$

Egypt 1, 3, 4, 6, 21, 36, 54, 81, 118, $122-126,129-137,144-145$, 151-153, 161; 1973 War 125, 129; Abdel Fattah al-Sisi 6, 125; Ayman Nour 133-134; Camp David Accords 125, 129, 136-137; commercial value to US 125-126, 134; coup 20131 , 122-123; debt restructuring 130; democracy aid amount 132-133; First Gulf War 130; Food for Peace Program 130; Gamal Mubarak 123, 133-134, 136; Gaza-Egypt border 124-125, 133, 136; General Intelligence Services (GIS) 126, 133; Hosni Mubarak 3, 6, 123, 125, 126, 130-134, 145, 150, 152; Kefaya movement 132, 136; Mohamed Hussein Tantawi 125-145; Muslim Brotherhood 123, 126, 130-132, 134, 136, 145, 150;

Mohamed Morsi 1, 3, 131; National Democratic Party (NDP) 132-134; Omar Suleiman 124, 126, 133, 134; parliamentary elections 2005 133-134; political succession 123, 133-136; presidential election 2005 134; Price Riots 1977 130; salience to US 124-126, 137; Second Gulf War 133, 152; strategic value to US 124-126, 129-131, 133, 137; Suez Canal 54, 125 , $129,144,155$

European Union 2, 8, 15, 30, 95, 138-139, 157, 160, 166, 168; EU president 138; European Neighborhood Policy 8, 157; see also future research avenues

Fiji 4, 21, 36, 118, 122-129, 137-145, 151; elections 1997 138; elections 2006 138; elections 2014 124, 140-142, 144-145, 151; Constitution 1990 137; 


\section{Index}

Constitution 1997 138; coups 1987, first and second coup 137; coup 2000138 ; coup 2006 1, 122, 123, 124, 138, 140, 142, 144; diplomatic expulsions and membership suspension 138-139, 141; ethnic cleavage 123, 137, 144-145; Fiji First party 144; George Speight 138; Indigenous Fijians 137-138, 144; Indo-Fijians 137, 138, 141, 144; Josaia Voreqe (Frank) Bainimarama 124, 138-140, 142-145; Laisenia Qarase 1, 138, 144; limited reforms 144; "Look North" policy 142; Mahendra Chaudhry 138; Multinational Observer Group (MOG) 141; salience to US 126-8; salience to Australia/New Zealand 127-128; salience to China 127-129, 142-143; Sitiveni Rabuka 137; Timoci Bavadra 137; trade with Australia/New Zealand 127, 140-141; trade with China $127,141,143$

foreign aid $1,5,6,7,8,10,12-13,15-16$, $27,34-37,41,45,53,58,69-70,72$, $75-76,78,87-88,97,128-130,134$, 142, 145, 157, 159-160, 164; AidData 27, 28, 35, 51, 81; automatic aid suspension (see United States, Foreign Assistance Act); Chinese Aid 157; commitments versus disbursements 28 ; democracy aid, concept of 1, 4, 8-11, 19; democracy aid, operationalization 28, 35-36, 52; developmental aid 19, 28, 52; Official Development Assistance (ODA) 68, 70, 74, 140

France 27, 72, 127, 163

future research avenues 157-160

Geodist see proximity

Germany 31, 127, 160, 163

golden age 149, 163-165

gravity model of trade see Gross Domestic Product (GDP)

Gross Domestic Product (GDP) 33-34; GDP per capita $8,37,38,40-42,45,51$, 59-62, 80, 83, 85-87, 109, 126

Hempelian bridge principle 80,89 Hungary 164

hypotheses, formal $17-18,74,81,95,124$

India 94, 95, 98, 103, 114

International Trade dataset see commercial value, exports; commercial value, imports
Iran $2,94,125,129,130,153,160-161$, 163,167

Israel 122, 124-125, 129-130, 133-136, 151, 153, 167; War with Hamas 2006 135-136, 145, 151; War with Hezbollah 2006135

Japan 75-76, 79, 95, 128, 138; Japanese ODA 30

Kennan, George 54-55

Kuwait 142, 153

leverage $1,4,7,17-18,20,21,34,39,41$, 45-46, 49-50, 54, 56, 63-64, 66, 69, 73, 76, 79-80, 93-95, 107-111, 113, $117,123-124,127-129,135,140-141$, $150-153,155-156,158-159$; attribute sets $21,49-50,54,58-61,64-66$; Cold War versus post-Cold War 59-61, 65-66; economic versus strategic determinants 58-61, 63-66; four aggregation rules $34,50,54-58,61,64$; six components of salience $30-34,46$, $50-53,58-59,63,156$

liberal international order 160, 68 liberalization, definition of 6,26 ; bottom-up versus top-down transition 2, 111-112, 136; democratic consolidation $10,11,15,18,20,73-74$, 112, 115-116, 169; democratization by force 17,131 ; difference from democratization 2-5, 15-16, 168-169; electoral authoritarianism 112; internal vs external drivers $7,8,16$, $18,20,115$; income threshold 8,37 ; inducements vs punishment $8-9$; lesser priority $4,16-17,63,95,131-132$, 134; linkages 7, 131, 159; multiparty elections $1,4,11,16,21,35,124,133$, 141, 151; multipartyism 4, 72-74; operationalization $29,51,82$; theory of democratization 18; transnational authoritarianism 131

liberalization at the margins $20,68,149$, 158, 160, 164, 166, 168, 169; limitations of 18-20, 168-169; work around constraints 4,169

methods, statistical: control variables 36-38, 43-44, 51, 57, 62, 66, 83-84; country fixed effects $38-39,40,41,42$, $45,59-62,85-87$; interaction terms 36 , $40-43,45,53-54,56-57,82,85-87$; 
marginal effects $13,39-45,58-60$, $62-66,83-84,86-89$; qualitative $93-95,122-123$; reverse causality 19-20, 26, 37-38, 42-46, 66, 86, 89, 150 ; robustness check $29-30,32-34$, 52,86 ; second-order effects $80-81,84$, 87,89 ; smoking analogy 39 ; unit of analysis $26,28,51,153$

Mexico 54, 153

modernization theory $7-8$

multilateral organizations 71, 157-158; Asian Infrastructure Investment Bank (AIIB) 2, 78; Association of Southeast Asian Nations (ASEAN) 98, 107, 108, 114; Commonwealth 102, 137-138, 140; International Monetary Fund (IMF) 71, 130, 149, 157-158; World Bank 35, $71,76,80,149,158$

Myanmar 21, 77, 93, 95-101, 103-118, 151, 155; 1988 uprising 96, 99, 103; Aung San 101-102; Aung San Suu Kyi 96, 101, 105, 108-109, 111, 115-116; Aung Lynn Htut 107; Ayeyarwady river 106; Bamar people 96-97, 101; border tensions (with China) 98, 103, 107-108, 111; Burmese Communist Party, (BCP) 98, 103 (see also UWSA); Burmese way to Socialism 102, 115; by-election 2012 104; censorship 105; Chinese foreign direct investment and trade 98-99, 103-104, 107, 111; Chinese reaction to reforms $110-111$; Civil Society Organizations (CSOs) 111-113; Constitution 104, 106, 116-117; Country's name 96-97; crony capitalism and "Biz15" 115; Cyclone Nargis 104, 112; ethnic conflict 96, 98, 100-102, 104-108, 111, 115-117; energy 97-99; ethic parties 105, 113; general election 1990 96, 104; general election 2010 104; general election 2015 104, 117; golden parachutes 115; Kachin Independence Army (KIA) 98, 111, 116; Kachin State 98, 106, 116; Khin Nyunt 104; Kyaukphyu, port 97; Letapadaung Copper Mine 107; military rule 93, 96, 101, 102-106, 109, 114-115, 117 (see also Tatmadaw); Myitsone Dam 98-99, 105, 107, 111-112; Myanmar Egress 112-113; Myanmar National Democratic Alliance Army (MNDAA) 111; National Democratic Alliance Army (NDAA) 111; National League for Democracy (NLD) 96, 104-105,
109, 111-113, 116-117; Ne Win 101, 103; non-alignment 103; opposition cooption 112-113, 115; Panglong Agreement 102; Pauk-Phaw 103; praetorian politics 101-102; Pyidaungsu Hluttaw 105, 116; Public opinion of Chinese influence 105-107, 111; Rakhine state 116-117; referendum 2008 104; Resource extraction 109, 115; Rohingya 116-117; Saffron revolution 2007 104, 109; salience to US 99-100; salience to China 97-99, 105-108; Sittwe-Yunan pipeline 97, 99; State Law and Order Restoration Council (SLORC) 96; Tatmadaw 101-103, 105-106, 115-117; Than Swe 104; Thein Sein 104, 106, 110, 112-114, 116-117; Third force 112; Tin Oo 105; Union Solidarity and Development Party (USDP) 104-106, 113, 117; United Wa State Army (UWSA) 98, 107,111 ; US foreign direct investment and trade $108-110$

New Zealand 123, 127-128, 137-145, 151; Pressure on Fiji 128, 137-141, 143 North Korea 79, 118, 164

Norway 138

Organization for Economic Co-operation and Development (OECD) 9, 28, 35, 68-69, 74, 76; Credit Reporting System 28, 35, 157

Penn World Tables see commercial value, GDP; population

Philippines 2, 76, 77, 89, 128, 153, 161

policymakers $49,63,151-153,156,165$; autocrats 2,16-20,149, 151, 153, 155-156, 159-160, 166-168; chief executive (recipient) (see autocrats); democrats $20,153,156,157,160,166$, 168; executive-level (donor) 165-169; mid-level (donor) 149, 151-153, 165 population $27,30-32,52-53,62,68-69$, $114,126,137$

primary recipients, definition 17 ; list of 153; operationalization $34-35,54-57$, $82-83$

proprietary data 157

recipient $2,6,7,9-10,12-21,26-45$, $49-66,68,70,73-74,77-78,80-89$, $93-95,97,110,113,117-118$, $122-125,127,129,141,144-145$, 
150-156, 159, 165; Default Composite Index 29-23, 54 (see also leverage, four aggregation rules); recipient's calculus 16-20, 94-95; recipient status 29-30, $34-35,54-57,82-83$

region, Africa 11, 21, 35, 68-74, 79, $81,83-86,88-89,134,151-152$, 165; developmental experience 70-74; economic malaise 72-73; good governance 9, 70-72, 76, 132, 138; Malawi 4, 73, 153-154; operationalization 81 ; sub-Saharan Africa $10-11,70,73,81,88$; threat to defect 71-72; Washington Consensus 71, 75; Zaire/Republic of Congo 72, $153-154$

region, Asia 21, 30, 68-69, 74-84, 86-89, 100, 103, 109, 128, 151-152, 165; Asian Economic Miracle 76; Asian Tigers 75; average wealth 80; Asian Financial Crises (1997-1998) 76; Asian Values 75-76; Cambodia 77, 77, 79, 153-154, 161; developmental experience 74-81; export-oriented industrialization 75; Lee Kuan Yew 75; Mahathir Mohammed 75, 77; North Korea 79, 164; operationalization 81-82; Philippines, Ferdinand Marcos 76; South Korea 75-76, 79, 153; Suharto 75-76; Thailand 77, 79, 99, 102, 153; Thai 2006 coup 77, 99; Vietnam 77, 99

region, Middle East 11, 97, 100, 128-129, 133, 140, 163; Middle East Peace Process 133; Palestine Elections 2006 125, 135; Persian Gulf 125, 129-130; US ODA 140 region, South Pacific 123-124, 126-129, 137-140, 142-144, 151; Biketawa Declaration 2008 138-139; colonial sensitivities 123, 127-128, 139; dominant patrons 127; Guam 128; Melanesia 127-128, 139; Melanesian Spearhead Group (MSG) 139, 141-142; Micronesia 127-128; Pacific Islands Development Forum (PIDF) 123, 127, 141-142, 144; Pacific Islands Forum (PIF) 127-128, 137-139, 141-142, 144; Pacific Island Forum (PIF) summit 2012 128, 142; Papua New Guinea 126, 128, 138, 143, 145; Polynesia 127-128, 139; Polynesian Leaders' Group (PLG) 139; Niue 27, 139; Northern Mariana
Islands 128; South Pacific Commission (SPC) 127; Tonga 139; Vanuatu 139;

Western Samoa 139

regime change see liberalization

Resource Curse 12

Russia, (includes USSR) 2, 4, 9, 15, 31, $37,54-55,72,79,100,114,125,130$, $142,150,158,161,163-164,166$, 168 ; interference in US elections 168 ; reaction to EU democracy promotion 166-168

salience see commercial value; strategic value

sanctions $8,73,77,94,99-100,103-104$, $106-110,112-115,117,125,138-142$, 145, 151; democratic sanctions 113; driver of liberalization in Myanmar 113-115; on Iran 94; on Myanmar 99-100, 103-104, 106-110, 112-115, 117, 151; opportunity cost in aid 109

Saudi Arabia 2, 153, 164 secondary recipients, definition 17 ; list of 153-154; operationalization 34-35, $54-57,82-83$

securitization 159-160

selectorate theory $3,5-7,9,12-13$, 15-17, 28, 29, 31, 36, 42; altruism 20; political survival $5,11,12-14,16$, 71-72, 75, 97, 104, 130, 153, 158, 169; selectorate 5; self-interest 95, 110, 155; winning coalition 5-6, 13-14, 36

Singapore $3,75,77-79,138,161$

strategic value $29-33,35,52-56,82$; affinity $30-33,35,52-53,57-59$, 61-63, 66; population 30-33, 35, $52-53,57,59,62,63,66$; proximity 30 , $32-33,35,52-53,57,59,62-63,66$, 151; reward or bribe $31-32,53,57-59$, $61-63$; strategically valuable recipients 54-61, 63-66

Taiwan (ROC) 75-76, 79, 128, 142-145, 153-154, 162; Costa Rica, nonrecognition 143; dollar diplomacy 142-145; Kuomintang (KMT) 103, 143; Ma Ying-Jeou 143

tradeoffs 150, 160-168; normative 166-168; policy $152-153$

Turkey 1, 133, 153, 161, 164

United States (US) $1-3,6,8-9,15$, $19,21,27,31,33,54-55,76-80$, 
93-100, 102, 106, 108-110, 113-114, $117-118,122-137,139-145,149-153$, $155,157-158,160-161,163-165$, 167-168; in Afghanistan 2, 77, 100, 125; aid to Asia 76-77; aid to Egypt 122, 125-126, 129-130, 132-134, 136-137; aid to Fiji 139-140; aid to Israel 129-130, 137; aid to Mexico 54; aid to Pakistan 6, 54; aid to South Pacific 140; attitude towards Fatah 135; attitude towards Hamas 125, 135-136, 145, 151; Barbara Bush 100; Benign Neglect of Myanmar 99-100; Bush Administration (1989-1993) 100, 108; Bush Administration (2001-2009) 2, 77, 99-100, 132-134, 136; Bush's Freedom Agenda (2001-2009) 124, 135, 145; Charles Boustany 136; Clinton administration 2, 77, 99; Condoleezza Rice 100; Congress 77, 100, 122 , 126, 130, 134, 136, 164; Consolidated Appropriations Act of 2008 136; Defense Department 152; David Obey 134, 136; donor pressure on Egypt 131-137; Foreign Assistance Act 122, 139; favor autocracy 3-4, 6, 131, 169;
Hillary Clinton, Secretary of State 100 , 109, 110, 128, 140; Joe Pitts 134; Jim Webb 100, 109; Middle East Partnership Initiative (MEPI) 133; Obama Administration 77, 100, 108-110, 122, 163; protecting Israel 125, 129, 133 , 135-137, 151; Reagan Administration 108; State Department 109, 110 , 125, 132, 152, 164; Tom Lantos 134; Transactional foreign policy 150 , 164-165; Trump Administration 80, 113, 160, 163-165, 168; United States Agency for International Development, (USAID) 130, 132, 152, 164; War on Terror 2, 4, 54, 77, 99, 125-126, 133, 137,155

United Kingdom 2, 102, 139, 160

United Nations (UN) 31, 53, 102-103; General Assembly (see affinity); Security Council 138; UN Human Rights Council (UNHRC) 78; veto power use 103, 116

Ukraine 163-164, 168

Vietnam 77, 99

Venezuela 2, 9, 153, 161 


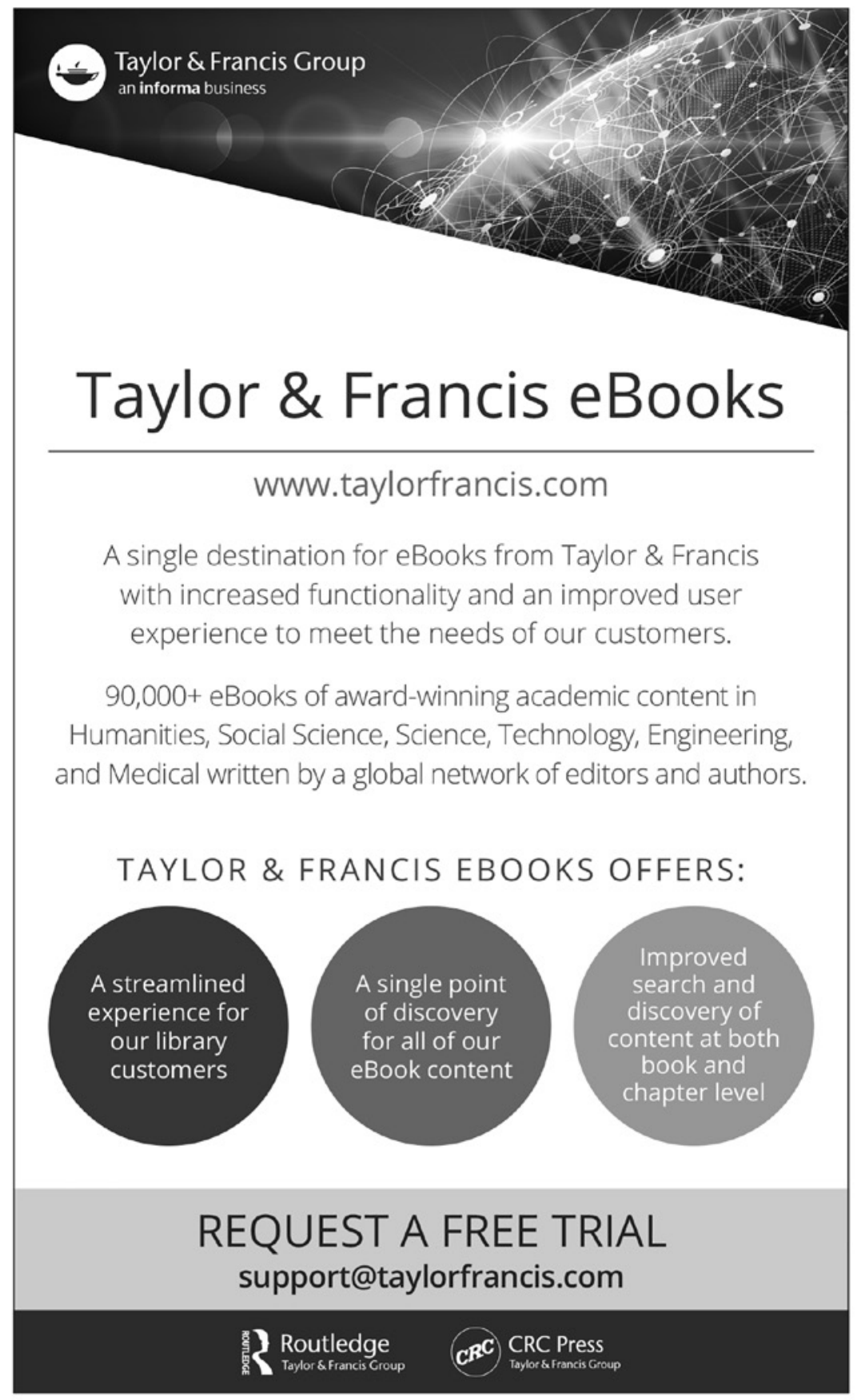

